\title{
4 Origenes
}

\subsection{Einleitung}

Der dritte zu untersuchende Kirchenschriftsteller ist der Alexandriner Origenes. Dieser gehört im Vergleich zu Tertullian und Clemens der nächsten Generation christlicher Denker $a^{1}$ und schreibt in einer Zeit, in der das Christentum zunehmend gesellschaftlich sichtbar wurde. ${ }^{2}$ Mit deren Zunahme dürfte außerdem auch die Anzahl der Christen im Heer gewachsen sein. Allein aus diesem Grund steht zu erwarten, dass die Frage nach ,Christentum und Soldatenstand“ im Werk des Origenes angesprochen wird. Sein Beitrag dazu wird ähnlich dem Tertullians in der Forschung in der Regel eingehend behandelt. ${ }^{3}$ Dieser Sachverhalt erklärt sich nicht nur durch die Ausführlichkeit seiner Stellungnahme vor allem in Contra Celsum, sondern auch durch seine exponierte inhaltliche Ausrichtung. Für R. Klein ${ }^{4}$ gilt er sogar als der Gegenpol des Clemens in der Soldatenfrage. Zugleich konzentriert sich die Forschung oftmals allein auf die Stellungnahme in Contra Celsum, während andere Texte übergangen werden. Im Folgenden werden, nach einem kurzen Überblick zu Person und Werk, zunächst die einschlägigen Passagen aus Contra Celsum behandelt. Im Anschluss werden dann einige oft übersehene Texte aus seinen exegetischen Schriften untersucht. Am Ende werden wieder eine Zusammenschau der Ergebnisse und die Frage nach einer einheitlichen Position stehen.

1 Geboren wurde er um das Jahr 185/186 n.Chr.; Euseb. hist. eccl. 6,2,2.12; vgl. NAUTIN, Origène, 364, 409 und 413; Williams, Rowan, Origenes/Origenismus. In: TRE 25, (1995), 397-420, hier 397; CRouZEL, Henri, Origen - The Life and Thought of the First Great Theologian, 2. Aufl., Edinburgh 1998, 2. Zur Problemtaik der Berechung des Geburtsjahres vgl. BÄBLER, Balbina, Origenes und Eusebios' Chronik und Kirchengeschichte. In: Bäbler, Balbina, Nesselrath, Heinz-Günther (Hrsg.), Origenes der Christ und Origenes der Platoniker, (SERAPHIM 2), Tübingen 2018, 179-199, hier 194-195.

2 Bezeichnenderweise heißt das Kapitel für die Jahre von 193-235 n. Chr. bei FrEND, Rise, 271-306 „Out of the Shadows“. Dieser schreibt pointiert (ebd., 272): „The emergence of the Severan dynasty [...] ushered in a period of dynamic change and expansion for the Christians. Within a generation Christianity had moved from its self-proclaimed status as third race' [...] to the position of one of the major religions of the Roman world.“ Vgl. auch ULRICH, Jörg, Die Begegnung von Christen und Heiden im zweiten (und dritten) Jahrhundert. In: Rothschild, Claire K., Schröter, Jens (Hrsg.) The Rise and Expansion of Christianity in the First Three Centuries of the Common Era, (WUNT 301), Tübingen 2013, 457-485, hier v. a. 481-485. Zur Verbreitung des Christentums bis zur Zeit Konstantins vgl. das noch immer nützliche Kapitel bei HARNACK, Mission und Ausbreitung (1924), 618-927.

3 Eine Ausnahme ist hier SHEAN, Soldiering, bei dem Origenes in dieser Frage kaum eine Rolle spielt. 4 KLein, Tertullian, 107. Auch bei HunTER, Church, 173, erreicht der „antimilitarist strand“ des christlichen Denkens einen „high point“. 


\subsection{Leben und Werk}

\subsubsection{Leben}

Im Gegensatz zu Tertullian und Clemens Alexandrinus ist das Leben des Origenes ${ }^{5}$ durch einen umfangreicheren Quellenbestand besser ausgeleuchtet. ${ }^{6}$ Hier ist neben biographischen Hinweisen im Werk des Origenes selbst vor allem der ausführliche Bericht in der Kirchengeschichte des Eusebius zu erwähnen. ${ }^{7}$ Außerdem finden sich Angaben bei Hieronymus, Rufinus und Photius. Der Wert des Eusebius wird in der Forschung allerdings aufgrund seiner stark apologetischen und gelegentlich sehr komprimierten Darstellung unterschiedlich beurteilt, vor allem was die Angaben zur Frühzeit des Origenes und zur Chronologie angeht. ${ }^{8}$ Zumindest in den großen Linien

5 Schon Campenhausen, Griechische Kirchenväter, 59, stellte fest: „Die Literatur über Origenes ist kaum mehr übersehbar [...].“ An dieser Stelle soll nur auf ausgewählte Titel hingewiesen werden, auf die sich der folgende Überblick stützt. Als Einführung vgl. WiLLIAMs, s.v. Origenes/Origenismus (TRE), 397-403; MARKschies, Christoph, s.v. Origenes. In: DNP 9, (2000), 27-29; VoGT, Hermann J., s.v. Origenes. In: DöPP/GEERLINGS (Hrsg.), LACL, 528-536, hier v. a. 530. Ausführlicher sind HARNACK, Geschichte, 26-36; Hornschun, Leben; Chadwick, Kirche, 111-127; Campenhausen, Griechische Kirchenväter, 43-60; MARKsCHIEs, Christoph, Origenes. In: Graf (Hrsg.), Klassiker Bd. 1, 43-60. Biographisch umfangreich sind u.a. NAUTin, Origène; TRIGG, Joseph W., Origen - The Bible and Philosophy in the Third Century, London 1985; DERS., Origen, (The Early Church Fathers), London, New York 1998, 3-61; CrouzEL, Origen, hier v. a. 1-58; FüRST, Origenes, 45-236. Einen guten Überblick zur Theologie bieten VoGT, Hermann J., Origenes - Theologie des Wortes Gottes. In: Geerlings (Hrsg.), Theologen, 53-66; Markschies, Origenes, 50 -54; außerdem Williams, s.v. Origenes/Origenismus (TRE), 407-414; VoGt, s.v. Origenes (LACL), 532-535; ausführlich CROUzel, Origen, 61-266; und neuerdings HeINE, Origen. Vor allem auf philosophische Aspekte konzentrieren sich ZAMBON, Marco, Wyrwa, Dietmar, Origenes. In: Riedeweg, Christoph, Horn, Christoph, Wyrwa, Dietmar (Hrsg.), Die Philosophie der Kaiserzeit und der Spätantike, (Grundriss der Geschichte der Philosophie, Die Philosophie der Antike 5/1-3), Basel 2018, 957-997.

$6 \mathrm{Zu}$ den Quellen vgl. kurz Williams, s.v. Origenes/Origenismus (TRE), 397; CrouzeL, Origen, 1.

7 Euseb. hist. eccl. 6,1-39. Dieser kennt a) mündliche Überlieferung, b) die von seinem Lehrer Pamphilius abgefasste Apologie des Origenes, c) zahlreiche, heute fast vollständig verlorene Briefe des Origenes. Wie BäBLER, Origenes und Eusebios, 193-194 mit Anm. 66 (Literatur), festhält, muss man allerdings berücksichtigen, dass es im Rahmen der diokletianischen Christenverfolgungen zu Verlusten im Bestand der kirchlichen Bibliothek Cäsareas gekommen sein kann.

8 Äußerst kritisch ist HoRnschun, Leben, hier z. B. 3: „legendarisch“. Mehr oder weniger skeptisch sind z.B. GRANT, Alexandrian Christianity, v.a. 133-136, „basically incredible“ (ebd., 135); NAUTIN, Origène; J. Trigg (Trigg, Bible and Philosophy, 9; Trigg, Origen, 3); Zambon/Wyrwa, Origenes, 958. Deutlich zuversichtlicher sind dagegen z.B. CRouzeL, Origen, 1-30; FüRST, Origenes, 46. NEYMeYR, Lehrer, 96, möchte Eusebius „,zwar mit Vorsicht, jedoch nicht mit radikaler Skepsis begegnen.“ Diese kritische Zuversicht ist dem Zeugnis des Eusebius gegenüber weitestgehend angemessen. Die chronologischen Angaben des Eusebius zum Leben des Origenes und ihre Probleme diskutiert BäBLER, Origenes und Eusebios, 192-197. Sie hält zusammenfassend fest (ebd., 197-198): „Durch die Verwendung verschiedener Kalender und Chronologien, die synchronisiert werden mussten, entstehen dabei fast unausweichlich Inkonsistenzen von ein bis zwei Jahren. [...] Meines Erachtens sollte man daher in Bezug auf Ereignisse im Leben des Origenes nicht mit einzelnen Jahren argumentieren. [...] Der 
dürfte sein Zeugnis allerdings verlässlich sein. An dieser Stelle genügt es, nur wenige, für die Fragestellung entscheidende Punkte anzusprechen und auf relevante Positionen der Forschung hinzuweisen.

Origenes wurde - anders als Clemens und Tertullian - in einem wohlhabenden ${ }^{9}$ christlichen Elternhaus geboren und kann daher auf christliche Familienüberlieferung zurückgreifen. ${ }^{10}$ Er scheint außerdem eine gründliche Erziehung gemäß dem

unglaublichen Leistung des Eusebios, die hier darzustellen versucht wurde, wird durch diese kleinen Ungenauigkeiten in jedem Fall kein Abbruch getan.“

9 Sein Vater Leonides (Euseb. hist. eccl. 6,1,1; vgl. CRouzel, Origen, 5; FÜrst, Origenes, 49; gegen NaUtin, Origène, 32 und 413-414; TrigG, Bible and Philosophy, 30) scheint sehr wohlhabend, gebildet und außerdem mit ziemlicher Sicherheit ein römischer Bürger gewesen zu sein. Seine Mutter dürfte den Status einer Ägypterin gehabt haben. Origenes hätte dann den Status der Mutter geerbt. Vgl. CRouzEL, Origen, 6; FüRST, Origenes, $48-49$.

10 Zur Herkunft siehe v.a. Euseb. hist. eccl. 6,2,2-13; vgl. NAUTIN, Origène, 31-32; 413-415; CAMPenhausen, Griechische Kirchenväter, 44-45; TrigG, Bible and Philosophy, 10-16; Williams, s.v. Origenes/Origenismus (TRE), 397-398; CRouzel, Origen, 4-6; LE Boulluec, Schule, 601-602; MARKSCHIES, Origenes, 44-45; FÜRST, Origenes, 47-49 und v. a. 50 - 53; ZAMBON/WYRWA, Origenes, 958. Die Behauptung des Porphyrius (adv. Christ. frg. 39 Harnack / frg. 6F Becker = Euseb. hist. eccl.

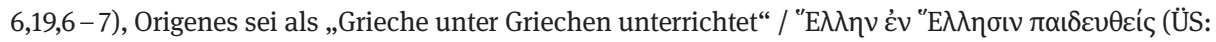
AG) worden und habe sich später zum Christentum bekehrt, ist wahrscheinlich entweder unzutreffend (z. B. TrigG, Bible and Philosophy, 259-260, TANaseanu-DöBler, Ilinca, Die Origineis des Porphyrios. In: Bäbler, Balbina, Nesselrath, Heinz-Günther (Hrsg.), Origenes der Christ und Origenes der Platoniker, (SERAPHIM 2), Tübingen 2018, 152 mit Anm. 116 und 154 mit Anm. 126) oder eine - von Eusebius missverstandene? - polemische Verzeichnung (z.B. FÜRST, Origenes, 59-60; LE BoulluEc, Schule, 604-605; siehe auch Porphyrios, Contra Christianos Neue Sammlung der Fragmente, Testimonien und Dubia mit Einleitung, Übersetzung und Anmerkungen von Matthias BECKER, (Texte und Kommentare 52), Berlin u. a. 2016, 153 und 156-158). Anders Nautin, Origène, 197-202 und 413-414, Anm. 3: er beziehe sich auf die „éducation intellectuelle“ (ebd., 201); so auch EDWARDS, Mark, Ammonius, Teacher of Origen. In: JEH 44/2 (1993), 169-181, hier 172-173; RIEDEwEG, Christoph, Das Origenes-Problem aus der Sicht eines Klassischen Philologen. In: Bäbler/Nesselrath (Hrsg.), Origenes, 13-39, hier 20 mit Anm. 39 (mit weiterer Literatur). Dagegen HoRnschuH, Leben, 15-16 und 25: Origenes stamme aus einem heidnischen Elternaus, Eusebius biete eine Tendenzbehauptung; außerdem NeYmEYr, Lehrer, 97-99: Porphyrius spreche von einem heidnischen Namensvetter. GEMEINHARDT, Peter, Origenes simplex vel duplex? In: Bäbler, Balbina, Nesselrath, Heinz-Günther (Hrsg.), Origenes der Christ und Origenes der Platoniker, (SERAPHIM 2), Tübingen 2018, 41-59, hier 51, meint, die Frage sei „historisch nicht zu entscheiden“. Zur umstrittenen Frage nach den beiden Erwähnungen eines Origenes bei Porphyrius (adv. Christ. frg. 39 Harnack / frg. 6F Becker; vit. Plot. 3,6-21) vgl. zusammenfassend SchroedER, Frederic M., Ammonius Saccas. In: ANRW II 36.1, (1987), 493-526, hier 494-509, mit Forschungsüberblick ebd., 496, Anm. 10 und 11; außerdem jetzt BECKER, Contra Christianos, 153 und 156-158 (mit Literatur); sowie ausführlich die aktuellen Beiträge in BäBLER, Balbina, NESSELRATH, Heinz-Günther (Hrsg.), Origenes der Christ und Origenes der Platoniker, (SERAPHIM 2), Tübingen 2018. Zu den hier genutzten Autoren: 1.) Zwei Origeneis, Porph. adv. Christ. frg. 39 Harnack / frg. 6F Becker, meint den Kirchenschriftsteller: NAUTIN, Origène, 197-202; TRIGG, Bible and Philosophy, 259-260; Schroeder, Ammonius Saccas (ANRW), 494-509; EdwardS, Ammonius, 172-173; LE Boulluec, Schule, 604-605; FÜRST, Origenes, 59-60; BECKER, Contra Christianos, 153; ZAMBon/ WyrWa, Origenes, 959-960; GemeInHARDT, Origenes simplex, 45-48 und 55; TANASEANU-DöBlER, Die Origineis, zusammenfassend 157-159. 2.) Zwei Origeneis, Porph. adv. Christ. frg. 39 Harnack / 
griechischen Bildungskanon wie auch in den Heiligen Schriften des Christentums erhalten zu haben. ${ }^{11}$ Sein Vater starb im Jahr 202/203 n.Chr. in einer lokalen Christenverfolgung, die wohl in unterschiedlicher Intensität fast das ganze erste Jahrzehnt des 3. Jhds. n.Chr. andauerte. ${ }^{12}$ Die Bedeutung dieser frühen Erfahrungen für seine Entwicklung dürfte kaum zu überschätzen sein. Sie lässt sich mit zwei großen Kirchenhistorikern treffend zusammenfassen: Origenes „stand von Anfang an in der rechtgläubigen Kirche“13 und er „schreibt immer als Glied einer Märtyrerkirche“14. Die bewusste Anbindung an die Kirche - trotz mancher Konflikte - ist bei Origenes weit intensiver zu greifen als bei Tertullian und Clemens. Er lehrt, predigt und schreibt in ihrem Dienst. Zugleich ist er sich bewusst, dass der Ort dieser Kirche in der Welt des 3. Jhds. n. Chr., immer ein (mal mehr, mal weniger) angefochtener ist. Beides ist für die Auswertung seiner Stellungnahme zur ,Soldatenfrage، im Blick zu behalten.

Nach dem Tod des Vaters war Origenes in verschiedener Weise als Lehrer tätig, zunächst als grammaticus ${ }^{15}$ und dann als Leiter des christlichen Unterrichts ${ }^{16}$ in

frg. 6F Becker, meint den heidnischen Philosophen: NeymeYR, Lehrer, 97-99. 3.) Nur ein Origenes, der Kirchenschriftsteller: Crouzel, Origen, 10-12; (unsicher) MARKschies, Origenes, 45. RIEDEWEG, Origenes-Problem, 33, hält nach einer ausführlichen Durchsicht der Quellen resümierend fest, man könne „in guten Treuen sowohl für wie auch gegen eine Identität der beiden Origeneis plädieren.

11 Euseb. hist. eccl. 6,2,7-11; vgl. Crouzel, Origen, 5; Le Boulluec, Schule, 601; FÜrsT, Origenes, 50 -53. Die Kritik von NaUtin, Origène, 35, an Eusebius scheint überzogen, auch wenn dieser u.U. zuspitzt.

12 Euseb. hist. eccl. 6,2,2-6.12-13; vgl. NAuTin, Origène, 363-364 und 414-415; WiLliams, s.v. Origenes/Origenismus (TRE), 397-398; CRouZEL, Origen, 5; FÜRST, Origenes, 50-51; ZAMBon/WYrwA, Origenes, 958; RiEdeweg, Origenes-Problem, 28-29. Siehe allgemein ENGBERG, Impulsore Chresto, 271-273; außerdem Molthagen, Staat, 39-41; und BäBleR, Origenes und Eusebios, 195, die diese Verfolgung beide in die Jahre 201/202 n.Chr. datieren.

13 Campenhausen, Griechische Kirchenväter, 45; vgl. auch Trigg, Bible and Philosophy, 11-30; zur Bedeutung seines kirchlichen Aufwachsens; außerdem NEYMEYR, Lehrer, 100 - 102.

14 CHADWick, Kirche, 112.

15 Euseb. hist. eccl. 6,2,15 (Lehrer für klassische Literatur und ihrer Auslegung); vgl. NAUTiN, Origène, 35-39; 415 - 416; TRIGG, Bible and Philosophy, 52-54; WiLLIAMs, s.v. Origenes/Origenismus (TRE), 398; Crouzel, Origen, 6-8; Markschies, Origenes, 45; Wyrwa, Lernen, 283; Heine, Origen, 60-61. Die Bedeutung der literarischen Bildung für das Verständnis des Origenes zeigen TRIGG, Origen, 5-8; und TLOKA, Griechische Christen, 53-64, sehr gut auf.

16 Entsprechend der hier vertretenen Position zur Alexandrinischen Schule (s. oben S. 196ff.) kann man eine später von Demetrius formalisierte Fortführung der Tätigkeit des Clemens und anderer Lehrer annehmen (ander jüngst wieder ZAMBON/WYRWA, Origenes, 959). Inwieweit man Origenes als Schüler des Clemens betrachten kann, hängt davon ab, wie eng man Schülerschaft definiert. Zumindest ein Traditionszusammenhang, wenn nicht sogar die Möglichkeit, dass Origenes den Clemens zumindest gelegentlich lehren gehört hat, ist sehr plausibel. Eine Schülerschaft im engeren Sinn stößt dagegen allein angesichts der Chronologie auf erhebliche Probleme. Im angedeuteten Sinn: vgl. GRANT, Education, 184; TrIGG, Bible and Philosophy, 54 und 65-66; TrIGG, Origen, 9-10; TLOKA, Griechische Christen, 113-116; WYRWA, Lernen, 299-301: „geistige Traditionskontinuität“; ZAMBON/WYRWA, Origenes, 959. Unsicher: CROUZEL, Origen, 7. Sehr skeptisch: BARDY, origines, 84-85; HoRNSCHUH, Leben, 8, sowie ihnen folgende Autoren; vgl. auch vAN DEN BROEK, School, 199; FÜRST, Origenes, 70. 
Alexandria. ${ }^{17}$ Wahrscheinlich noch einmal etwas später besuchte er, wegen des Zustroms auch von heterodoxen Christen und Heiden, selbst noch einmal die Schule. Er nahm philosophischen Unterricht ${ }^{18}$, um besser auf seine philosophisch interessierten

17 Hier bereitet die Chronologie des Eusebius Probleme: Hist. eccl. 6,2,2 setzt die Verfolgung, in der Origenes Vater starb, in das zehnte Jahr des Septimius Severus (202/203 n. Chr. bzw. 201/202 n. Chr. nach ägyptischer Zählung) unter dem Statthalter (Q. Maecius) Laetus. Nach hist. eccl. 6,2,12 ist Origenes zu dieser Zeit 16 Jahre. Laut hist. eccl. 6,3,3 dagegen soll Origenes 17 Jahre gewesen sein, als er die Leitung der Schule übernahm, und Eusebius datiert das in die Statthalterschaft des (Tib. Claudius Subatianus) Aquila. Wie mittlerweile bekannte Papyri zeigen, folgte dem Laetus 203-204/205 n. Chr. erst Claudius Iulianus, Aquila kann also erst 205/206-210/211 n. Chr. praefectus Aegypti gewesen sein (z. B. SB I 4639; P. Giss. 48; SB VI 9393; BGU XI 2024). Somit müsste Origenes zur Zeit des Aquila älter und der zeitliche Zusammenhang zwischen dem Tod des Vaters und der Übernahme der Katechetenschule um einiges gedehnter gewesen sein, als Eusebius meint. Vgl. BARnEs, Pre-Decian Acta, 526-527; BARNEs, Scopiace, 130 -131; und v. a. BARnes, Timothy D., Origen, Aquila, and Eusebius. In: Harvard Studies in Classical Philology 74, (1970), 313-316. Ebenso z.B. Molthagen, Staat, 40; Grant, Alexandrian Christianity, 135; WyrwA, Lernen, 282-284; ENGBERG, Impulsore Chresto, 271. Noch STEIN, Präfekten von Ägypten in der römischen Kaiserzeit, (Dissertationes Bernenses 1), Bern u. a. 1950, 110 -114, lässt allerdings den Aquila unter Verweis auf Eusebius im Jahr 203 n. Chr. praefectus Aegypti sein, als „unmittelbare[r] Nachfolger“ (ebd. 111) des Laetus. Ebenso FREND, Martyrdom, 342, Anm. 149. Ob Eusebius aus Unkenntnis oder aber aus inhaltlichen Überlegungen die Verfolgung auf einen Zeitraum von etwa einem Jahr zusammenpresst, ist unklar. Zur Datierung der erst später erfolgten offiziellen Beauftragung des Origenes vgl. die Positionen bei 1.) Scholten, Katechetenschule, 19 mit Anm. 17; und Crouzel, Origen, 7-8: 203 n.Chr. 2.) NAutin, Origène, 417-418; und NeYmeYr, Lehrer, 99: 211 n. Chr.; ähnlich Williams, s.v. Origenes/Origenismus (TRE), 398; VAN DEN BROEK, School, 202; LE BoulLUEC, Schule, 602-603 und 606; MARKSCHIES, Origenes, 45; WYRWA, Lernen, 284; ZAMBON/WyRWA, Origenes, 958. 3.) HoRnschuH, Leben, 16 - 25 und 203-209: 217 n. Chr. 4.) FÜRst, Origenes, 63; und HeINE, Origen, 61-62, lassen die Frage offen. Die Jahre 210/211 n.Chr. dürften eine plausible Hypothese darstellen.

18 Euseb. hist. eccl. 6,19,12-14, zitiert einen Brief des Origenes, in dem dieser von seinen philosophischen Studien berichtet. Euseb. hist. eccl. 6,19,5-10, lässt den Porphyrius (adv. Christ. frg. 39 Harnack / frg. 6F Becker) sagen, dass der Lehrer des Origenes ein gewisser Ammonius gewesen sei. Aus beiden Stellen ergibt sich die Frage, ob Origenes bei dem berühmten Platoniker Ammonius Sakkas, dem Lehrer Plotins, Unterricht genommen hatte. Die Forschung ist hier uneins. Dass der Kirchenschriftsteller ein Schüler des Ammonius Sakkas (wie eng auch immer) gewesen sei, vertreten in unterschiedlicher Weise z.B. Schroeder, Ammonius Saccas (ANRW), 504-509; CHADWICK, Henry, Origen. In: Armstrong (Hrsg.), Cambridge History, 182-192, hier 182; NAUTIN, Origène, 197-202; TRIGG, Bible and Philosophy, 66-67; Williams, s.v. Origenes/Origenismus (TRE), 399; Scholten, Katechetenschule, 21; TrIgG, Origen, 12-14; Crouzel, Origen, 10 -12; BALtes, Matthias, s.v. Ammonios Sakkas. In: RAC Supplementum 1, (1985), 323-332, hier 324; LE BoulluEC, Schule, 604-605 mit Anm. 212; MARKsChIES, Origenes, 45; WyrWA, Lernen, 285; TLOKA, Griechische Christen, 118-119; FÜRST, Origenes, 56-63; BEcker, Contra Christianos, 153-156; ZAMBon/WyrWA, Origenes, 959; RiEdEWEg, Origenes-Problem, 18-23. Abgelehnt wird eine solche Schülerschaft von z. B. NEYMEYR, Lehrer, 97-99 mit Anm. 469 und 470; außerdem aus der Platonismusforschung z. B. von DöRRIE, Heinrich, Ammonius, der Lehrer Plotins. In: Hermes 83, (1955), 439-477, hier 468-472; DERS., s.v. Ammonios Sakkas. In: TRE 2, (1978), 463 - 471, hier 465 - 468; EDWARDS, Ammonius, 179-181; vgl. außerdem MonTANARI, Franco, s.v. Ammonios [8]. In: DNP 1, (1996), 601, und HADot, Pierre, s.v. Ammonios [9] Sakkas. In: DNP 1, (1996), 601. Am plausibelsten scheint es, mit F. Schroeder anzunehmen, dass der Christ Origenes den Ammonius Sakkas gehört haben wird, ohne Teil seines engeren Schülerkreises gewesen zu sein (Un- 
oder sogar gebildeten Schüler eingehen zu können. ${ }^{19}$ Die hier gewonnene intensive philosophische Bildung sollte seine weitere theologische Arbeit stark prägen. ${ }^{20} \mathrm{Ge}$ rade in der direkten Auseinandersetzung mit dem Platoniker Celsus wird sie immer wieder erkennbar sein und auch die Behandlung der ,Soldatenfrage‘ beeinflussen. ${ }^{21}$

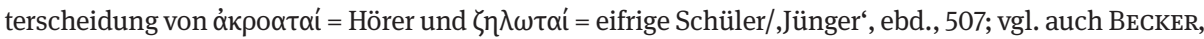
Contra Christianos, 154. Anders versteht ỏkpootís RIEDEwEG, Origenes-Problem, 18: Der Ausdruck sei

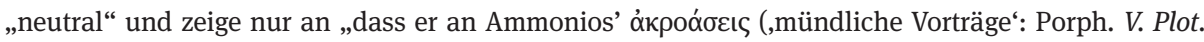
3,26) teilgenommen“ habe.

19 So rechtfertigt Origenes in einem Brief (Euseb. hist. eccl. 6,19,12-14) seine Beschäftigung mit der Philosophie damit, dass er als bekannter christlicher Lehrer immer wieder mit Häretikern und gebildeten Heiden zu tun gehabt habe. Während dieses Philosophieunterrichts habe er den Heraklas kennengelernt, ebenfalls ein Schüler seines Lehrers. Nach hist. eccl. 6,3,2 dagegen hatte Heraklas mit seinem Bruder Plutarch als einer der ersten heidnischen Schüler den Literaturunterricht des Origenes besucht und ihn veranlasst, eine Unterweisung im christlichen Glauben zu beginnen. Daraus ergeben sich Fragen, darunter v. a. die nach dem Beginn seiner philosophischen Studien. Hist. eccl. 6,19 dürfte höheres Gewicht einzuräumen sein, da Eusebius Origenes im Wortlaut zitiert (vgl. HoRNSCHUH, Leben, 8-10; TloKa, Griechische Christen, 118-121; Williams, s.v. Origenes/Origenismus (TRE), 399). Es scheint mit diesen Autoren sehr plausibel, dass Origenes seine Studien erst begann, als er bereits ein anerkannter christlicher Lehrer war (nach 210/211 n. Chr.). Allerdings bleiben Zweifel, v. a. aufgrund des apologetischen Charakters des Briefes. Daher datieren andere diese Studien bereits in seine Zeit als grammaticus (ca. 205 n. Chr.; vgl. z. B. NAUTIN, Origène, 197- 202 und 415; TRIGG, Origen, 12-14). Einen guten Überblick über die Positionen der Forschung bietet RiEDEweg, Origenes-Problem, 19, der zu Ergebnis kommt: „Tatsächlich scheint vor 232/233 fast jedes Datum möglich, auch wenn es, wie wir gleich sehen werden, Gründe zur Annahme gibt, dass dieses Studium kaum ganz am Anfang von Origenes' ,Karriere' erfolgte [...]“.

20 Vgl. Baltes, s.v. Ammonios Sakkas (RAC Suppl.), 324-325; TRIGG, Bible and Philosophy, 66-75, zeigt deutlich, wie Origenes durch den Platonismus seines Lehrers beeinflusst wurde. Zur Rezeption des Platonismus durch Origenes siehe jetzte auch Ковusch, Theo, Produktive Rezeption - Zum Platonismus des ,christlichen Philosophen' Origenes. In: Bäbler, Balbina, Nesselrath, Heinz-Günther (Hrsg.), Origenes der Christ und Origenes der Platoniker, (SERAPHIM 2), Tübingen 2018, 61-89; LöHR, Winrich, Der platonische Ideenkosmos bei Origenes. In: Bäbler, Balbina, Nesselrath, Heinz-Günther (Hrsg.), Origenes der Christ und Origenes der Platoniker, (SERAPHIM 2), Tübingen 2018, 91-108. Sein Verhältnis zur griechischen Philosophie allgemein skizzieren ZAMBon/WYRwA, Origenes, 966-970, die festhalten (ebd., 967): „Man kann Origenes als Vertreter einer grundsätzlich vom Platonismus geprägten christlichen Philosophie bezeichnen, die im Bereich der Ethik und der Logik von der stoischen und peripatetischen Tradition beeinflusst war.“ Dennoch gelte (ebd., 968): „Er verstand sich aber nicht als einen einer bestimmten Schule zugehörigen Philosophen, sondern als Ausleger der Heiligen Schrift auf dem Boden des Glaubens der Kirche.“

$21 \mathrm{Zu}$ Contra Celsum vgl. jetzt v. a. VilLANI, Andrea, Platon und der Platonismus in Origenes` Contra Celsum. In: Bäbler, Balbina, Nesselrath, Heinz-Günther (Hrsg.), Origenes der Christ und Origenes der Platoniker, (SERAPHIM 2), Tübingen 2018, 109-127; außerdem CHADwick, Henry, Contra Celsum, Cambridge 1980, x-xiii; Origenes, Contra Celsum - Gegen Celsus, griech./dt., erster Teilband, eingel. und komm. von Michael FiEDRowicz, übers. von Claudia BARTHOLD, (Fontes Christiani 50,1), Freiburg i. Br. u.a. 2011, 47-51. 
In den Jahren ca. 215-217/218 n.Chr. unternahm Origenes weite Reisen, unter anderem nach Rom ${ }^{22}$, auf Einladung des dortigen Statthalters in die Provinz Arabia ${ }^{23}$ und nach Palästina ${ }^{24}$. Von dort wurde er schließlich durch Bischof Demetrius nach Alexandria zurückgerufen. In den Jahren 231 oder 232 n.Chr. unternahm er eine weitere Reise, dieses Mal durch Palästina nach Griechenland, besonders nach Athen. ${ }^{25}$ In Palästina wurde er von den Bischöfen Alexander (Jerusalem) und Theoctistus (Cäsarea) zum Presbyter geweiht, was den endgültigen Bruch mit Demetrius zur Folge hatte. ${ }^{26}$ Aufgrund dessen musste er Alexandria verlassen und ließ sich in Cäsarea nieder. Dort begann eine zweite, ebenfalls sehr produktive Phase seines Wirkens als Lehrer, Prediger und Schriftsteller und Leiter einer christlichen Philosophieschule. Origenes predigte, wie es seinem neuen Amt als Presbyter entsprach, regelmäßig und fügte, nachdem er die Erlaubnis zur Veröffentlichung von Mitschriften gegeben hat$\mathrm{te}^{27}$, so seinen wissenschaftlichen Bibelkommentaren zahlreiche Auslegungen für das Kirchenvolk hinzu. Auch von Cäsarea aus unternahm er weitere Reisen: Bereits um das Jahr 232 n.Chr. wurde er von der Kaisermutter Julia Mamea an den Hof nach Antiochia eingeladen, um dort Vorträge zu halten. ${ }^{28}$ In den $240 e r$ Jahren reiste er unter

22 Euseb. hist. eccl. 6,14,10; vgl. NAUTIN, Origène, 54-55, 365, 409 und 418-419; TriGG, Bible and Philosophy, 76-80; Trigg, Origen, 15; Crouzel, Origen, 14; Williams, s.v. Origenes/Origenismus (TRE), 399; MARKSCHIES, Origenes, 46; ZAMBON/WYRWA, Origenes, 960.

23 Euseb. hist. eccl. 6,19,15; vgl. NAuTin, Origène, 54-55, 365-366, 40 und 420 - 421, der diese Reise allerdings erst in die späten 220er Jahre n.Chr. ansetzt; TRIGG, Origen, 15; CROuzEL, Origen, 14; WILLIAMs, s.v. Origenes/Origenismus (TRE), 399; MARKschiEs, Origenes, 46; ZAMBON/WYRWA, Origenes, 960.

24 Euseb. hist. eccl. 6,19,16-19; vgl. CROuzEL, Origen, 15-17; WilliAMs, s.v. Origenes/Origenismus (TRE), 399; MARKschies, Origenes, 46; ZAmbon/Wyrwa, Origenes, 960. NAutin, Origène, 54-55, 366-368, 410 und 425-427, dagegen datiert die erste Reise nach Cäsarea in das Jahr 230 n. Chr. Ihm folgt u.a. LE Boulluec, Schule, 617.

25 Euseb. hist. eccl. 6,23,4; vgl. NAUTIN, Origène, 69, 366-368, 410 und 427-429; TrigG, Bible and Philosophy, 137-138; Crouzel, Origen, 18-22; Williams, s.v. Origenes/Origenismus (TRE), 400 - 401; ZAMBON/WYRWA, Origenes, 960.

26 Euseb. hist. eccl. 6,8,4-6; 6,23,4; vgl. NAUTin, Origène, 60-61, 420, 428-431; TrIGG, Bible and Philosophy, 130 -140; Crouzel, Origen, 17-24; Williams, s.v. Origenes/Origenismus (TRE), 400 - 401; LE Boulluec, Schule, 617-619; MARKschies, Origenes, 46-47; ZAMBON/WyrWA, Origenes, 961.

27 So dürfte Euseb. hist. eccl. 6,36,1 zu verstehen sein. Vgl. dazu NAUTIN, Origène, 91-93; TRIGG, Origen, 38-40; Crouzel, Origen, 29-30; MARkschies, Origenes, 49-50; außerdem Origenes, Der Kommentar zum Evangelium nach Matthäus, Bd. 1, eingel. und übers. von Hermann J. VoGT, (BGL 18), Stuttgart 1983, 3-4; Origenes, In Lucam homiliae - Homilien zum Lukasevangelium, lat./griech./dt., übers. und eingel. von Hermann-Josef Sieben, Bd. 1, (Fontes Christiani 4,1), Freiburg i. Br. 1991, 31. 28 Euseb. hist. eccl. 6,21,3-4, der aber den Eindruck vermittelt, der Besuch hätte in der Frühzeit des Alexander Severus (222-235 n.Chr.) stattgefunden. So datiert HARNACK, Geschichte, 30, den Besuch „[z]wischen 218 und 222, wahrscheinlich 218“. Anders NAUTIN, Origène, 68-69; 366-368 und 427-428, der ihn 231/232 n.Chr. vor der Übersiedlung nach Cäsarea ansetzt; ebenso J. Trigg (TRIGG, Bible and Philosophy, 135-137; TRIGG, Origen, 15). Richtig dagegen CrouzEL, Origen, 17; WiLLIAMs, s.v. Origenes/Origenismus (TRE), 401; LE Boulluec, Schule, 617-618. Siehe außerdem Grant, Alexandrian Christianity, 135; BIRLEy, Anthony R., s.v. Severus [2] S. Alexander. In: DNP 11, (2001), 486-487; Stegmann, Helena, s.v. Iulia [9] I. Avita Mamea. In: DNP 6, (1999), 3-4. 
anderem noch zweimal nach Arabia ${ }^{29}$, auf Einladung des Bischofs Firmilian nach Cäsarea in Kappadokien ${ }^{30}$ sowie erneut nach Athen $^{31}$ und nach Ephesus ${ }^{32}$. Diese Reisen ermöglichten es Origenes, einen bedeutenden Teil der christlichen Welt in der Osthälfte des Römischen Reiches bis nach Rom kennenzulernen, ein Gesichtspunkt, der noch von großer Bedeutung für das Verständnis von Cels. 8,73 sein wird.

\subsubsection{Werk}

Das Oeuvre des Origenes ist nach Umfang ${ }^{33}$ wie Inhalt selbst in seinem heutigen, durch Überlieferungslücken reduzierten Bestand beindruckend. ${ }^{34}$ Den größten Teil machen exegetische Schriften aus, dazu kommen theologisch-philosophische und polemische Werke. Vieles davon ist, wenn überhaupt, nur fragmentarisch oder in lateinischen Übersetzungen überliefert. Der Grund dafür ist, dass Origenes im Verlauf der Kirchengeschichte zum Ausgangspunkt leidenschaftlicher Auseinandersetzungen wurde, die schließlich mehrfach zu synodalen Verurteilungen origenistischer Lehren führten. ${ }^{35}$

Eine Folge war, dass seine Schriften gerade im Osten zunehmend weniger kopiert, teilweise vielleicht sogar vernichtet wurden. ${ }^{36}$ Die lateinischen Übersetzungen stammen vor allem von Rufinus und Hieronymus (Wende 4./5. Jhd. n.Chr.). Fragmente

29 Euseb. hist. eccl. 6,33.37; vgl. NAUTIN, Origène, 94-96, 387-389 und 433; CrouzEL, Origen, 31-33; WiLliams, s.v. Origenes/Origenismus (TRE), 401; ZAMBON/WYRWA, Origenes, 961.

30 Euseb. hist. eccl. 6,37; vgl. Crouzel, Origen, 30 - 31.

31 Euseb. hist. eccl. 6,32,2; vgl. NAUTIN, Origène, 411, 435-436; CrouZEL, Origen, 31; ZAMBON/WYRWA, Origenes, 962.

32 Vgl. Nautin, Origène, 436-437; Crouzel, Origen, 22.

$33 \mathrm{Zu}$ den antiken Angaben (Epiph. haer. 64,63 schreibt ihm z. B. 6000 Werke zu) und den damit verbundenen Problemen vgl. Williams, s.v. Origenes/Origenismus (TRE), 403-404; CrouZEL, Origen, 37-41. Einen unvollständigen, aber beeindruckenden Katalog bietet Hieronymus (epist. 33 [Sancti Eusebii Hieronymi Epistulae, Bd. 1: Epistulae I-LXX, ed. Isidor HILBERG, (CSEL 54), Wien, Leipzig 1910, 253-259]); vgl. HARNACK, Geschichte, 37-48; NAUTIN, Origène, 214-215 und 227-241; CRouZEL, Origen, 37-38. Auch Eusebius (hist. eccl. 6,23,1-36,4) nennt einige Titel, verweist aber ansonsten auf einen verlorenen Katalog bei Pamphilius (ebd., 6,32,3; vgl. dazu NAUTıN, Origène, 225-260).

34 Zum Werk des Origenes allgemein vgl. HARNACK, Geschichte, 36-54; Williams, s.v. Origenes/ Origenismus (TRE), 403-406; TRIGG, Origen, 16-35 und 40-61; CROUZEL, Origen, 37-58; VogT, Hermann J., Origenes - Leben und Werke. In: Vogt, Hermann J., Origenes als Exeget, hrsg. von Wilhem Geerlings, Paderborn u.a. 1999, 9-22; VoGT, Origenes, 55-65; VoGT, s.v. Origenes (LACL), 529-532; HeINE, Alexandrians, 122-127; und außerdem aktuell und ausführlich HeINE, Origen, 83-256; ZAMBON/WYRWA, Origenes, 962-966.

35 Vgl. z. B. Williams, s.v. Origenes/Origenismus (TRE), 414-417; СHADWick, Kirche, $214-223$ und 244-246; ZAмвоN/WyRwA, Origenes, 992-995. Höhepunkt war die Verurteilung von Lehrsätzen auf der 5. Synode von Konstantinopel 553 n.Chr. unter Justinian.

36 Zur Überlieferung der Werke des Origenes vor dem Hintergrund der wechselnden Urteile über seine Orthodoxie vgl. den Überblick bei Fürst, Origenes, 209-236. 
finden sich bei späteren Autoren - Verteidigern wie Kritikern des Origenes -, aber auch in Katenen ${ }^{37}$.

Aus diesem Überlieferungsstand ergeben sich ganz eigene Probleme ${ }^{38}$ : Bei den Übersetzungen stellt sich die Frage nach der Zuverlässigkeit ${ }^{39}$, bei Katenen die nach der Korrektheit der Wiedergabe ${ }^{40}$ und der Verfasserzuschreibung. Ähnliche Schwierigkeiten ergeben sich auch bei den Zitaten und Zusammenfassungen, vor allem in Schriften von Gegnern. Darauf wird bei der Diskussion der Texte jeweils am konkreten Ort einzugehen sein.

\subsection{Textinterpretation}

\subsubsection{Contra Celsum}

\subsubsection{Einführung}

Die acht Bücher Contra Celsum ${ }^{41}$ gehören zu den bedeutendsten Werken des Origenes $^{42}$. Verfasst um 248 n. Chr. in Cäsarea ${ }^{43}$ zeigen sie ihn auf dem Höhepunkt seiner

37 Vgl. MÜHLENBERG, Ekkehard, s.v. Katenen. In: TRE 18, (1989), 14-21.

38 Vgl. z. B. CrouzeL, Origen, 42-49.

39 Vgl. treffend CROUZEL, Origen, 42: „On the whole these are not literal translations [...], but have been composed as independent literary works intended for the Latin public: paraphrases rather than translations. However, apart from omissions, they render the ideas closely enough." Siehe ebd., 48-49, zur Frage des Umgangs mit den Übersetzungen bei der Erarbeitungen der inhaltlichen Positionen des Origenes. Vgl. außerdem FÜRST, Origenes, 231-233.

40 Vgl. Crouzel, Origen, 45: „[...] in many cases that the fragments are summaries [...]; the ideas are authentic but not always their expression.“

41 Zum Titel vgl. BARTHOLD/FIEDROWicz Bd. 1, 39.

$42 \mathrm{Zu}$ Contra Celsum vgl. kurz Nautin, Origène, 375-376; Trigg, Bible and Philosophy, 214-239; Williams, s.v. Origenes/Origenismus (TRE), 406; TRIGG, Origen, 52-61; VoGT, s.v. Origenes (LACL), 531. Ausführlicher CHADwick, Contra Celsum, ix-xxxiii; Frede, Michael, Origen's Treatise Against Celsus. In: Edwards, Mark; Goodman, Martin; Price, Simon (Hrsg.), Apologetics in the Roman Empire - Pagans Jews and Christians, Oxford 1999, 131-155; BARTHOLD/FiEdrowicz, Contra Celsum Bd. 1, 38-122. Sehr gut und ausführlich inkl. Forschungsüberblick bis in die 70er Jahre ist PICHLER, Karl, Streit um das Christentum - Der Angriff des Kelsos und die Antwort des Origines, (Regensburger Studien zur Theologie 23), Frankfurt am Main 1980, 193-301. Der Text ist Origène, Contre Celse, 5 Bde., introd., texte critique, trad. et notes par Marcel BoRRET (SJ), (Sources chrétiennes), Paris 1967-1976, entnommen. Ebenfalls regelmäßig konsultiert wurde Origenes, Contra Celsum - Gegen Celsus, griech./dt., 5 Bde., eingel. und komm. von Michael Fiedrowicz, übers. von Claudia BARTHOLD, (Fontes Christiani 50), Freiburg i. Br. u.a. 2011-2012. Verweise auf den Texte des Celsus durch Origenes - bei M. Borret kursiv und bei M. Fiedrowicz/C. Barthold in Anführungszeichen - werden als Zitat im (Quellen-)Zitat in einfachen Anführungszeichen wiedergegeben (, ').

43 Euseb. hist. eccl. 6,36,1-2 ordnet Contra Celsum in sein Alterswerk ein. Werkimmanente Hinweise bestätigen und präzisieren diese Datierung. Vgl. NAUTin, Origène, 375 - 376 und 412; CHADWICK, Contra Celsum, 14-15; Fürst, Origenes, 217 mit Anm. 44; BARTHold/Fiedrowicz, Contra Celsum Bd. 1, 10. Die Datierung ist nicht strittig. MÄNNLEIN-ROBERT, Irmgard, Kelsos (von Alexandrien?). In: Riedeweg, 
intellektuellen und theologischen Schaffenskraft. ${ }^{44}$ Zugleich handelt es sich um „einen unbestrittenen Höhepunkt der apologetischen Literatur der frühen Kirche insgesamt ${ }^{\star 45}$.

Origenes verfasste Contra Celsum auf Drängen seines Gönners Ambrosius ${ }^{46}$ als Antwort auf eine literarische Kritik am Christentum. Diese war durch einen Philoso-

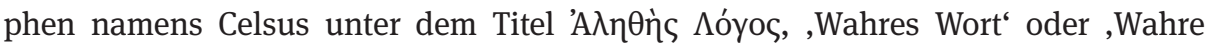
Lehre ${ }^{647}$ abgefasst worden. Um die Antwort des Origenes angemessen zu verstehen, ist es daher notwendig, Person und Werk des Celsus einzuordnen. Die Skizze wird sich auf Aspekte beschränken, die für die Interpretation hier untersuchter Texte zur ,Soldatenfrage، wesentlich sind. Außerdem müssen auch die von Origenes diskutierten Angaben des Celsus selbst angemessen kontextualisiert werden.

\section{Celsus und seine Kritik am Christentum Verfasser}

Bereits Origenes hatte keine sichere Kenntnis mehr über Celsus ${ }^{48}$, abgesehen von dem, was er dessen Schrift selbst entnehmen konnte, und war daher auf Ableitungen und

Christoph, Horn, Christoph, Wyrwa, Dietmar (Hrsg.), Die Philosophie der Kaiserzeit und der Spätantike, (Grundriss der Geschichte der Philosophie, Die Philosophie der Antike 5/1-3), Basel 2018, 665-672, hier 656, datiert mit Euseb. hist. eccl. 6,36,2 breit in die Jahre 244-249 n.Chr. und meint, „eine Fixierung auf 248 n.Chr. entbehrt jeglicher faktischen Grundlage.“ ZAмвоN/Wyrwa, Origenes, 965, datieren auf „nach dem Jahr 246 .

44 Barthold/FiEdrowicz, Contra Celsum Bd. 1, 109. Vgl. Heine, Origen, 219-256, zu seinen letzten Schriften (Contra Celsum, Matthäuskommentar): Werke eines „senior scholar and theologian“ (ebd., 220); sein „most mature thinking about the Christian faith“ (ebd., 222). Er zeigt, dass Origenes in der letzten Schaffensphase bekannte Inhalte teilweise anders akzentuiert, zum Teil neue Schwerpunkte setzt und mindestens an einer Stelle - der Eschatologie - frühere Überzeugungen wahrscheinlich revidiert. Siehe dazu Vogt, Hermann J., Die Exegese des Origenes in Contra Celsum - Das neue Interesse an der Eschatologie. In: Vogt, Origenes als Exeget, 143-159.

45 Barthold/Fiedrowicz, Contra Celsum Bd. 1, 109. Vgl. auch Frede, Against Celsus, 131-132; FÜRST, Origenes, 217. PICHLER, Streit, 182-192, bietet einen Überblick über verschiedene Bewertungen - positive wie negative - des Werks im Lauf der Forschungsgeschichte.

46 Siehe Cels. praef. 1.3-4; 3,1; 4,1; 5,1; 6,1; 7,1; 8,76.

47 Bereits die Übersetzung des Titels ist strittig und hängt mit der jeweiligen inhaltlichen Einordnung zusammen; vgl. PichleR, Streit, 39-42 mit Beispielen. Siehe zuletzt MännLEIn-RoBERT, Kelsos, 668. $48 \mathrm{Zu}$ Celsus und seiner Kritit am Christentum vgl. ausführlich ANDRESEN, Carl, Logos und Nomos Die Polemik des Kelsos wider das Christentum, (Arbeiten zur Kirchengeschichte 30), Berlin 1955; PICHLER, Streit, 4-179, inkl. Forschungsüberblick bis in die 70er Jahre (ebd., 5-101); außerdem Chadwick, Contra Celsum, xvi-xxxii; Trigg, Bible and Philosophy, 215-222; Wilken, Robert L., The Christians As the Romans Saw Them, 2. Aufl., New Haven 2003, 94-125; FredE, Michael, Celsus philosophus Platonicus. In: ANRW II 23,1, (1994), 5183-5213; FrEDE, Michael, Celsus' Attack on the Christians. In: Barnes, Jonathan; Griffin, Miriam (Hrsg.), Philosophia Togata II - Plato and Aristotle at Rome, Oxford 1997, 218 - 240; BALTES, Matthias, s.v. Kelsos. In: DNP 6, (1999), 385 - 387; HARGIS, Jeffrey, Against the Christians - The Rise of Early Anti-Christian Polemic, New York u. a. 2001, 17-61; ENGBERG, Impulsore Chresto, 293-313; zuletzt LonA, Horacio E., Die wahre Lehre des Kelsos, (KfA Erg.-Bd. 1), 
Vermutungen angewiesen..$^{49}$ Alle weiteren antiken Bezugnahmen auf Celsus scheinen sich einer Verwendung des Origenes zu verdanken ${ }^{50}$, so dass es keine von ihm unabhängigen Informationen zu Person und Werk gibt. Auch die moderne Forschung ist über dessen Stand kaum hinausgekommen. Zu Recht wird Celsus heute allerdings nicht mehr - wie teilweise von Origenes - als Epikureer, sondern als Mittelplatoniker betrachtet und interpretiert. ${ }^{51}$

\section{Datierung}

Mit Blick auf die zeitliche Einordnung ist in der Forschung, vor allem aufgrund des Plurals oi vũv $\beta \alpha \sigma \iota \lambda \varepsilon v ́ o v \tau \varepsilon \varsigma \grave{\eta} \mu \tilde{\omega} v$ in Cels. 8,71, die Ansetzung zur Zeit eines Dyarchats sehr weit verbreitet. Diese Dyarchatsthese wird oftmals mit werkimmanenten Hinweisen $^{52}$ verbunden. Daraus folgt dann eine Datierung zwischen 177 und 180 n. Chr. ${ }^{53}$

Freiburg i. Br. 2005, 11-70, mit aktuellem Forschungsüberblick (ebd., 57-69); und - mit einem Fokus auf den philosophischen Positionen - MÄNnLEIN-RoBERT, Kelsos, 665-672 und 704-705 (Bibliographie).

49 Vgl. Chadwick, Contra Celsum, xxiv-xxvi; Frede, Celsus (ANRW), 5186-5187; Frede, Celsus’ Attack, 222-227; ReEmTs, Christiana, Vernunftgemäßer Glaube - Die Begründung des Christentums in der Schrift des Origenes gegen Celsus, (Hereditas 13), Bonn 1998, 101-103; BALTES, s.v. Kelsos (DNP), 386; Wilken, Christians, 94; Lona, Kelsos, 27-28; BARThold/FiedrowiCZ, Contra Celsum Bd. 1, 13; MÄNNLEIN-ROBERT, Kelsos,666..

50 Vgl. Frede, Celsus (ANRW), 5186; Frede, Against Celsus, 132 und 148.

51 Vgl. z.B. Chadwick, Contra Celsum, xxvi-xxii; TRIgG, Bible and Philosophy, 216 und 222-223; Frede, Celsus (ANRW), 5185 und 5193-5213; Frede, Celsus’ Attack, 223-227; Hargis, Christians, 24 passim; Fürst, Origenes, 217-218; BARTHOLd/FiEdrowicz, Contra Celsum Bd.1, 19-22 (Literatur ebd., 20, Anm. 64); LonA, Kelsos, 28-31 und 42-50; BALTES, s.v. Kelsos (DNP), 386. Die Einordnung als Epikureer hatte in der älteren Forschung bedeutende Anhänger, darunter KeIM, Theodor, Celsus' Wahres Wort - Aelteste Streitschrift antiker Weltanschauung gegen das Christentum vom Jahr 178 n.Chr., Zürich 1873, 275-293; HARNACK, Geschichte, 314-315. Vgl. die Forschungsüberblicke bei PICHLER, Streit, 27-38; LonA, Kelsos, 28-30 und 64-67.

52 Darunter v.a. 1.) die Androhung christenfeindlicher Maßnahmen (Cels. 8,69.71), die mit der Christenverfolgung 177 n. Chr. verbunden wird; 2.) die akute äußere Bedrohung durch Barbaren (Cels. 8,68.73), die v. a. mit den Germanenkriegen des Marcus Aurelius verbunden wird.

53 Vgl. z. B. Origène, Contre Celse, Bd. 5, Introduction générale, tables et index par Marcel BoRRET (SJ), (Sources chrétiennes 227), Paris 1976, 122-129; KERESZTES, Government I (ANRW), 297-304; CHADWICK, Contra Celsum, xxvi-xxviii, der zugleich eine einflussreiche Verteidigung der Dyarchatsthese gegen Kritik bietet; Trigg, Bible and Philosophy, 215; Frend, Rise, 163 und 177-178; LonA, Kelsos, 54-55; FÜRst, Origenes, 217; BARThold/Fiedrowicz, Contra Celsum Bd. 1, 34-35. Cook, John G., The Interpretation of the New Testament in Greco-Roman Paganism, Peabody 2002, 23 - 24, verbleibt dabei, dass 177-180 n. Chr. eine mögliche Abfassungszeit darstellt, die Datierung aber ,conjectural and open to skeptical attack“ (ebd., 24) ist. Einen forschungsgeschichtlichen Überblick zur Datierung sowie zu Entstehung und Entwicklung der Dyarchatsthese bieten RosenBAUM, Hans-Udo, Zur Datierung von

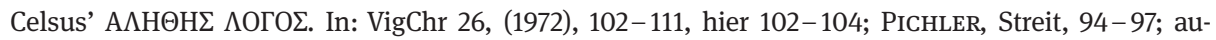
ßerdem LonA, Kelsos, 54-55. Zur älteren Forschung vgl. KeIM, Wahres Wort, 261-273. HARGIS, Christians, 17-24, datiert dagegen später, auf den Beginn des 3. Jhds. Allerdings ist er sich bewusst, 
Allerdings hat H.-U. Rosenbaum durch eine Analyse aller $\beta \alpha \sigma \iota \lambda \varepsilon u ́ \varsigma$-Aussagen des Celsus die Dyarchatsthese massiv in Frage gestellt. ${ }^{54}$ Als Konsequenz spricht er sich, gefolgt von K. Pichler ${ }^{55}$ und M. Frede ${ }^{56}$, dafür aus, den möglichen Abfassungszeitraum weiter zu fassen. So meint K. Pichler, es sei ,angemessener [...], [...] einen weiteren Zeitraum, von der Mitte des 2. Jh.s bis zu Beginn des 3. Jh.s offenzulassen [...]. ${ }^{\circ 57}$

Im Anschluss daran wird im Folgenden das Werk des Celsus gegen die Mehrheit der Forschung eher allgemein in die zweite Hälfte des 2. Jhds. n.Chr. datiert. ${ }^{58}$ Damit geht zwar eine gewisse Schärfe bei der historischen Verortung einzelner Aussagen des Celsus verloren, andererseits werden jedoch falsche Sicherheiten bei der Interpretation vermieden. Auch die Aussagen des Celsus über das Verhältnis der Christen zum Heeresdienst können daher nur ungefähr in die zweite Hälfte des 2. Jhds. n.Chr. eingeordnet werden, ohne dass größere Präzision möglich wäre.

\section{Abfassungsort}

Als Ort der Abfassung werden meist Rom und Alexandria diskutiert, die Mehrheit der Forschung dürfte Alexandria zuneigen. ${ }^{59}$ Dass der Alexandriner Origenes so gar nichts Substantielles über ihn in Erfahrung bringen konnte, könnte allerdings Alexandria zumindest in Frage stellen. Eine endgültige Entscheidung ist nicht möglich. Daher können auch Aussagen zur ,Soldatenfrage‘ nicht mit Sicherheit geographisch verortet werden.

\section{Erhaltungszustand und Gliederung}

Das Werk des Celsus ist nicht erhalten geblieben, sondern es ist einzig durch die ausführlichen Bezugnahmen des Origenes bekannt. Origenes zitiert und paraphrasiert Celsus nicht nur in großer Ausführlichkeit, sondern er folgt auch seiner Stoffanordnung bei seiner Widerlegung von wenigen Ausnahmen abgesehen ${ }^{60}$ bis ins Kleinste. ${ }^{61}$

dass seine Datierung „by no means secure“ (ebd., 23) ist, sondern Fragen offen lässt. Es scheint, dass diese offenen Fragen erheblicheres Gewicht haben, als er erlaubt.

54 Rosenbaum, Datierung, 104-111. Siehe auch unten S. $285 \mathrm{f}$.

55 PICHLER, Streit, 94-97.

56 FrEDE, Celsus (ANRW), 5188-5190.

57 PICHLER, Streit, 97; ähnlich Frede, Celsus (ANRW), 5190.

58 Ähnlich jetzt auch MÄNnLEIN-RoBERT, Kelsos, 666: „[...] nur ungefähr [...] zwischen 160 und 240 n. Chr., wahrscheinlich [...] $160-180$ n.Chr. [...]“.

59 Vgl. z.B. BorRet, Contre Celse 5, 136 -140; CHADwick, Contra Celsum, xxviii-xxix; PiCHLER, Streit, 97-98; Frede, Celsus (ANRW), 5190-5191; sie alle lassen die Frage letztlich offen. LonA, Kelsos, 56-57; BARThold/Fiedrowicz, Contra Celsum Bd. 1, 35; MÄnnlein-Robert, Kelsos, 666-667, dagegen votieren für Alexandria.

60 Vgl. dazu LonA, Kelsos, 19.

61 Für den literarischen Plan des Origenes vgl. Pichler, Streit, 220 - 235; Frede, Against Celsus, 145-152; BARTHOLD/FiedrowiCz, Contra Celsum Bd. 1, 41-44. Origenes widerlegt den Celsus zumeist 
Aus diesem Grund ist es möglich, den ’A $\lambda \eta \theta$ ǹৎ $\Lambda$ óyoৎ zumindest in seinen Grundzügen mit einiger Sicherheit zu rekonstruieren. ${ }^{62}$ Allerdings stellen mehrere Aspekte der Darstellung des Origenes vor Probleme ${ }^{63}$, so dass es im Detail zu teilweise divergierenden Einschätzungen kommt, wie viel vom Originaltext und seiner Disposition rekonstruierbar ist. ${ }^{64}$

Da die folgende Textinterpretation immer wieder auf den Gang der Argumentation des Celsus zurückgreift, soll im Anschluss an H. Lona und M. Fiedrowicz eine Gliederung skizziert werden ${ }^{65}$ :

1. Im ersten Hauptteil $(1,28-2,79)$ lässt Celsus einen fiktiven Juden Kritik an Jesus und dem Christentum aus (celsisch-)jüdischer ${ }^{66}$ Perspektive üben.

2. Im zweiten Hauptteil $(3,1-5,65)$ werden Lehre und Lebensweise von Judentum und Christentum einer Kritik unterworfen, da „beide Gruppen gleichermaßen Produkt eines Aufruhrs sind“67. Beide repräsentierten eine „Welt ohne Logos und Nomos “68.

3. Im dritten Hauptteil $(6,1-8,75)$ zeichnet Celsus dann, unter fortgesetzter Polemik, ein Bild des Logos und des Nomos der griechischen Überlieferung. Im Vordergrund steht jetzt die positive Darstellung seiner Überzeugungen. Verbunden damit ist das Werben, zu einem dem wahren Logos gemäßen Leben zurückzukehren. Besonders interessant ist hier der Abschnitt Cels. 7,53-8,75, wo er „die Gültigkeit

Punkt für Punkt. Zu den Gründen für dieses Vorgehen vgl. v.a. PICHLER, Streit, 228 - 234 und 236; Frede, Against Celsus, 145-147; BARThold/Fiedrowicz, Contra Celsum Bd. 1, 42. U. a. war es ihm so möglich, Argumentationszusammenhänge bei Celsus seinen eigenen Bedürfnissen gemäß aufzubrechen.

62 Vgl. dazu PICHLER, Streit, 8-26, mit einem Überblick über verschiedenste Versuche, den 'A $\lambda \eta \theta \dot{\eta} \varsigma$

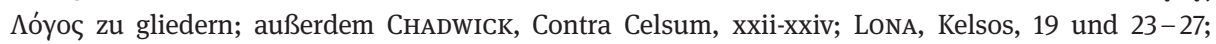
BARthold/Fiedrowicz, Contra Celsum Bd. 1, 22-24 und 29-31. Die folgende Skizze stützt sich auf diese Darstellungen.

63 Er bietet verschiedene Formen der Bezugnahme (direkte und indirekte Zitate, Paraphrasen, freie Wiedergaben), eine klare Abgrenzung der Fragmente ist nicht immer möglich und es ist mit „Verkürzungen, Sinnverschiebungen, parteiische[n] Akzentuierungen“ (BARTHOLd/FIEdRowicz, Contra Celsum Bd. 1, 22) zu rechnen.

64 Vgl. Pichler, Streit, 15-26; LoNA, Kelsos, 23-27; BARTHold/Fiedrowicz, Contra Celsum Bd. 1, $28-31$.

65 LonA, Kelsos, 24-27; BARThold/Fiedrowicz, Contra Celsum Bd. 1, 29-31. Eine weitere Gliederungsmöglichkeit bietet BORRET, Contre Celse 5, 118-121.

66 HARgIs, Christians, 30-40, zeigt deutlich, dass Celsus keineswegs genuin jüdische Einwände gegen das Christentum zu Wort kommen lässt. Diese Zurückhaltung erklärt er überzeugend mit seiner rhetorischen Strategie (ebd., 34 und 36): Celsus ist letztlich auch dem Judentum gegenüber ablehnend eingestellt und ein Teil seiner Christenpolemik besteht darin, Christen mit dem Judentum in Verbindung zu bringen. Die antijüdische Haltung wird im zweiten Hauptteil vollends deutlich. Anders MÄNNLEIN-RoBERT, Kelsos, 668: „Wohl aus der jüdischen anti-christlichen Polemik kommen die gegen christliche Argumente formulierten Einwände die Kelsos vor allem im ersten Hauptteil (1,28-2,79 [...]) fast immer der Figur eines fiktiven Juden in den Mund legt (Ethopoiie).“

67 BARThold/FiEdrowicz, Contra Celsum Bd. 1, 30.

68 LonA, Kelsos, 25. 
des überlieferten Nomos, also der traditionellen Werte, gegenüber den Christen mit aller Konsequenz darstell[t] ${ }^{\text {“69. }}$. Die Christen werden am Ende aufgerufen,

„sich durch Erfüllung ihrer Pflichten gegenüber Kaiser und Staat vorbehaltlos in die gesellschaftliche Ordnung zu integrieren, um durch die Akzeptanz des geltenden Nomos einen angemessenen Platz im Gesellschaftsgefüge einnehmen zu können. “70

Dazu sollen sie die Götter durch den Vollzug entsprechender Kulte verehren und dem Kaiser gegenüber ihre jeweilige Pflicht bedingungslos erfüllen. Es handelt sich also um den Aufruf, Glaubensinhalte und Lebensweise des Christentums zugunsten der alten, wahren Lehre aufzugeben. M. Borret hat die Konsequenz des Appells gut getroffen:

„En sorte qu'il ne laisse au chrétien qu'une alternative : revenir au civisme et à la religion traditionnelle qui le fonde, ou rejoindre son chef dans la fin ignominieuse où l'a justement conduit sa révolte : bref, se convertir au paganisme ou mourir." ${ }^{671}$

\section{Adressaten und Zielsetzung}

Celsus richtet seine Streitschrift an ein wohlhabendes und gebildetes Publikum. ${ }^{72}$ Sein Werk ist außerdem an Leser gerichtet, die gegenüber dem Christentum unterschiedliche Haltungen einnehmen. Unter ihnen mögen sich Gegner, Interessierte und Sympathisanten wie auch Christen aus gebildeten Schichten selbst befinden. ${ }^{73}$ Sein Ziel ist es, die Gegnerschaft der einen zu bestärken, die anderen aber von ihrem Interesse abzubringen oder wieder zur wahren Lehre zu ,bekehren' und in die Gesellschaft $\mathrm{zu}$ reintegrieren. ${ }^{74}$

Dabei geht Celsus gemäß dem philosophischen Denken seiner Zeit ${ }^{75}$ davon aus, dass es eine wahre Lehre, eine Art „common core of believes and values“76 gibt. Dieser gemeinsame Kern stehe hinter den unterschiedlichen Kulturen und Religionen und sei in mehr oder weniger unverfälschter Weise in ihnen allen, am klarsten aber in der

69 Lona, Kelsos, 26.

70 BARThold/Fiedrowicz, Contra Celsum Bd. 1, 31.

71 Borret, Contre Celse 5, 117-118. Siehe dazu auch unten S. 272f.

72 Vgl. dazu v. a. Frede, Celsus' Attack; Lona, Kelsos, 50 - 54; BARTHold/Fiedrowicz, Contra Celsum Bd. 1, 31-34; EMMENEGGER-SiEBER, Gregor, Die heiligen Pflichten müssen wir erfüllen - Origenes und Kelsos. In: Delgado, Mariano, Leppin, Volker, Neuhold, David (Hrsg.), Ringen um die Wahrheit - Gewissenskonflikte in der Christentumsgeschichte, (Studien zur christlichen Religions- und Kulturgeschichte 15), Fribourg, Stuttgart 2011, 73-82, hier 75-77, auf deren Überlegungen die folgende Darstellung aufbaut.

73 Zur Verbreitung des Christentums in der zweiten Hälfte des 2. Jhds. n.Chr. vgl. den Überblick bei Frend, Rise, 178-184; mit Blick auf die Gesellschaft Kruger, Christianity, 11-39.

74 Siehe Cels. 8,76. Vgl. Barthold/Fiedrowicz, Contra Celsum Bd. 1, 29; EMmeneGger-Sieber, Pflichten, 77.

75 Vgl. FredE, Celsus (ANRW), 5193-5194, mit Belegen.

76 FREDE, Celsus' Attack, 220. Vgl. auch FÜRST, Origenes, 217. 
griechisch(-platonischen) Tradition ${ }^{77}$, vorzufinden. ${ }^{78}$ Diese Lehre habe von alters her Bestand $^{79}$, sie sei von weisen Männern aller Völker bewahrt und tradiert worden. ${ }^{80}$ Damit verbunden ist auch der Gedanke, dass die auf dieser wahren Lehre begründete Weltordnung sich in bestimmten, gottgewollten religiösen, gesellschaftlichen und politischen Strukturen konkretisiere. ${ }^{81}$ Jedes Volk folgt dem eigenen Nomos, seiner kultisch-religiösen und sozialen Lebensweise, und betet diesem Nomos entsprechend die eigenen Götter in der ihm eigenen Weise an. ${ }^{82}$ An der Spitze der weltlichen Strukturen steht für ihn der römische Kaiser in einer gewissermaßen providentiellen Rolle als Garant dieser Ordnung. Dieser leite seine Macht aus einer abgestuften Hierarchie ab, beginnend mit dem höchsten Gott ${ }^{83}$, den Göttern und den Dämonen ${ }^{84}$, und sei ein Glied in einer Kette von über die Welt gesetzten göttlichen Statthaltern. ${ }^{85}$

77 Siehe Cels. 1,2. Vgl. dazu Pichler, Streit, 122; Barthold/Fiedrowicz, Contra Celsum Bd. 1, 25. 78 So v. a. Cels. 1,14. Vgl. v. a. CHAdwick, Contra Celsum, xvi-xxii; Frede, Celsus (ANRW), 5193-5203; Frede, Celsus' Attack, 218-221, 229-230 und 236-240; sowie BALTES, s.v. Kelsos (DNP); WiLKEN, Christians, 117-125; HARgis, Christians, 54-59; LonA, Kelsos, 45-50; BARThold/Fiedrowicz, Contra Celsum Bd. 1, 24-28; MÄNnLEIN-RoBERT, Kelsos, 668.

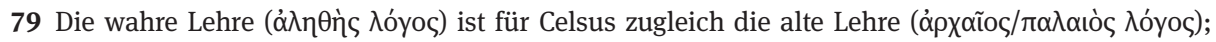
siehe Cels. 1,14; außerdem z. B. Cels. 1,21. Vgl. ANDresen, Logos, 111; Pichler, Streit, 122; BARTHOLD/ FiEdrowicz, Contra Celsum Bd. 1, 24-25.

80 So z. B. Cels.1,14-16. Es ist signifikant, dass Celsus das Judentum mit Mose nicht zu diesen rechnet; vgl. HARgis, Christians, 30-40, v.a. 35-36; Frede, Celsus (ANRW), 5195; siehe auch oben S. 269, Anm. 66. Dadurch unterscheidet sich Celsus von Numenius von Apamea, der dem Judentum einen Anteil an der wahren Lehre zugesteht (Orig. Cels. 1,15); vgl. FredE, Michael, Numenius. In: ANRW II 36.2 (1987), 1034-1075, hier v. a. 1047-1049; FrEDE, Celsus (ANRW), 5202; FrEDE, Celsus' Attack, 232-235; HARgIS, Christians, 57-58; FERrARI, Franco, Numenios von Apamea. In: Riedeweg, Christoph, Horn, Christoph, Wyrwa, Dietmar (Hrsg.), Die Philosophie der Kaiserzeit und der Spätantike, (Grundriss der Geschichte der Philosophie, Die Philosophie der Antike 5/1-3), Basel 2018, 649-664, hier v.a. 651; MÄNNLEIN-RobERT, Kelsos, 668.

81 Vgl. ANDRESEN, Logos, 119.

82 Zentral für das Nomosverständnis des Celsus sind die Texte Cels. 5,34 sowie 5,25.41, die wohl ursprünglich zusammen gehörten und erst von Origenes auseinandergerissen wurden. Vgl. dazu ANDRESEN, Logos, 193-200; LonA, Kelsos, 292-304. AndRESEN, Logos, 195, hält fest: „Jedes Volk hat sein Recht auf den ihm eigenen Volksnomos, wie es auch die Pflicht besitzt, demselben treu zu bleiben.“ Außerdem gilt: „Jedes Land darf eigene Sitten pflegen, die sich von denen in den anderen Ländern unterscheiden. [...] Das politische Gleichgewicht hing mit der Toleranz und dem gegenseitigen Respekt vor diesen Formen zusammen.“ (LonA, Kelsos, 298 und 300).

83 Der Mittelplatonismus weiß durchaus um die Existenz einer höchsten, henotheistischen Gottheit. Vgl. Frede, Michael, Montheism and Pagan Philosophy in Later Antiquity. In: Athanassiadi, Polymnia, Frede, Michael (Hrsg.), Pagan Montheism in Late Antiquity, Oxford 1999, 41-67, hier v. a. 53-56; Chadwick, Contra Celsum, xvii-xx; Frede, Celsus (ANRW), 5206-5208; Frede, Celsus' Attack, 228-229; BALTES, Matthias, s.v. Mittelplatonismus. In: DNP 8, (2000), 294-300, hier 295; BARTHOLD/ FiEdrowicz, Contra Celsum Bd. 1, 91-92.

84 Zur Dämonenlehre des Kelsos siehe jetzt den Überblick bei MäNNLEIN-RoBERT, Kelsos, 670 - 671. 85 Siehe Cels. 8,63.67-68. Vgl. dazu auch unten S. 277 ff. mit Anm. 116. Zu ,Statthaltern' siehe Cels. 5,25; 7,68; 8,2 und v. a. 8,35.57-58; 8,66-67. Vgl. dazu Chadwick, Contra Celsum, xvii-xix; Frede, Celsus 
Indem sich das Christentum durch die Ablehnung der traditionellen Kulte gegen diese wahre Lehre positioniert, ja alle Menschen zur Abkehr davon aufruft, stellt es für Celsus die vorgegebene Ordnung der Welt in Frage. ${ }^{86}$ Es richte seinen eigenen, absoluten Nomos auf und versuche alle anderen Menschen dazu zu ,bekehren ${ }^{6}{ }^{87}$ Damit bedrohe es zugleich die religiösen, moralischen, gesellschaftlichen und politischen Ordnungen dieser Welt. ${ }^{88}$ Für Celsus stellen die Christen also eine zutiefst unsoziale, Ordnung, Zusammenhalt und Sicherheit der Gesellschaft bedrohende Gruppe von Aufrührern dar. ${ }^{89}$ Diese Abwendung der Christen von der wahren Lehre ist der Hauptkritikpunkt des Celsus und schimmert auch in seiner Einzelkritik christlicher Anschauungen immer wieder hindurch. ${ }^{90}$ Aus diesem Grund wendet sich Celsus einerseits so vehement gegen das Christentum und wirbt andererseits so dringlich dafür, der wahren Lehre weiterhin oder wieder $\mathrm{zu}$ folgen. ${ }^{91}$

In der Forschung wurde immer wieder die einflussreiche Ansicht vertreten, es

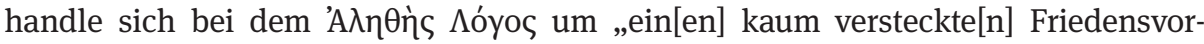
schlag“92 an das Christentum. Gegen diese Interpretation ist nachdrücklich festzu-

(ANRW), 5208-5210; Frede, Montheism, 55-56; Wilken, Christians, 119-120; BARTHold/FiedRowicz, Contra Celsum Bd. 1, 91-92; EMmEnEGger-SieBer, Pflichten, 76.

86 PiCHLER, Streit, 117-179, arbeitet diesen wiederkehrenden Vorwurf heraus; vgl. kurz FrEDE, Celsus (ANRW), 5184; Wilken, Christians, 121; Lona, Kelsos, 51-52; BARTHOLD/FiEdRowicz, Contra Celsum Bd. 1, 25-26.

87 Siehe z.B. Cels. 3,44.50.52.55.59; 8,68-69.72.

88 Zur gesellschaftlichen und politischen Dimension der ,wahren Lehre‘ vgl. CHADwick, Contra Celsum, xxi-xxii; TRIGG, Bible and Philosophy, 221-222; FrEDE, Celsus (ANRW), 5184 und 5201-5203; Frede, Celsus' Attack, 237-239; WilKen, Christians, 118-121; BARTHold/Fiedrowicz, Contra Celsum Bd. 1, 25-26. Pointiert zusammengefasst bei Frede, Celsus (ANRW), 5184: „To abandon this true account handed down by tradition, and to incite others to abandon it, is to threaten the natural order of things; it is to threaten the common bond which unites civilized mankind in the Empire; it undermines the cohesion and the order of the society of the Empire by sowing division concerning the very fundaments on which the order of this society rests."

89 So z.B. Cels. 8,2.63.68-75.

90 Daneben hat er auch noch sehr konkrete Kritik an Lehrinhalten des Christentums vorzubringen (vgl. Frede, Celsus' Attack, 230 -232; Wilken, Christians, 102-107; BARTHOLD/FiEdrowicz, Contra Celsum Bd. 1, 51-109). Aber diese inhaltlichen Grundgedanken stellen die eigentliche Basis seiner Kritik dar. Seine Ablehnung einzelner Aspekte steht im Dienst dieser prinzipiellen Kritik. Was das Christentum so unannehmbar machte, war der exklusive Anspruch, den die Christen - ähnlich dem Judentum - mit ihrer Lehre verbanden. Siehe treffend FredE, Celsus’ Attack, 234 und 235: „[T]hey would not reciprocate [...].“; vgl. CHADwick, Contra Celsum, xxi-xxii; TRIGG, Bible and Philosophy, 221; Barthold/Fiedrowicz, Contra Celsum Bd. 1, 89-92, Lona, Kelsos, 21-22.

91 Vgl. Lona, Kelsos, 22; BARTHOLD/Fiedrowicz, Contra Celsum Bd. 1, 32

92 HARnaCK, Mission und Ausbreitung (1924), 520; ähnlich KeIM, Wahres Wort, V-VI, 192-193 und 202-203; Bigelmair, Beteiligung, 171; BARTHOLD/FIEDRowicz, Contra Celsum Bd. 1, 33-34, erkennen eine „versöhnende Geste“ (ebd., 34). Am weitreichendsten hat KLAuSER, Oberschicht, diese These entfaltet und erkennt darin ein kaiserliches Angebot an Christen aus der Oberschicht, gegen Mitarbeit in Heer und Verwaltung Toleranz zu erhalten. Ihm folgt noch FreUdENBERGER, Frage, 275-276. EcK, Christen, hat die Thesen Th. Klausers überzeugend widerlegt. Ein Wahrheitsmoment ist darin aber 
halten, dass es dem Celsus nicht darum ging, Bedingungen für eine Tolerierung des Christentums zu übermitteln. Seine Schrift ist vielmehr in letzter Konsequenz ein „Versuch, die Christen selber zur Preisgabe ihrer religiösen Identität zu bewegen. “93 Es sei an M. Borret erinnert: Den Christen bleibe nur „se convertir au paganisme ou mourir."94

Im Zusammenhang dieser Erörterungen der wahren Lehre sowie im Zusammenhang mit der Aufforderung zur Abwendung vom Christentum und zur Hinwendung

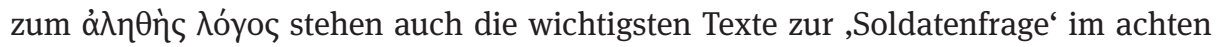
Buch.

\section{Die Antwort des Origenes}

Als Origenes die Bitte des Ambrosius erhielt, eine Antwort auf Celsus zu verfassen, war dessen Werk wahrscheinlich über ein halbes Jahrhundert alt. Aus welchem Grund war nach so langer Zeit eine Erwiderung noch nötig? Oftmals liest man in der Literatur als Erklärung, dass bisher kein christlicher Apologet eine angemessene Antwort auf die einflussreiche und für das Christentum gefährliche Kritik des Celsus habe geben können. Daher sei Origenes gefordert gewesen, eine Widerlegung zu schreiben. ${ }^{95}$

Dagegen spricht, dass Celsus dem Origenes wie später dem Eusebius völlig un-

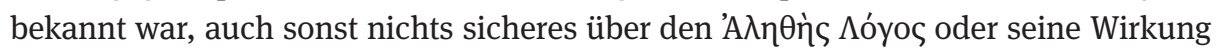
bekannt ist ${ }^{96}$ und Origenes von Ambrosius gedrängt werden musste, eine Replik zu verfassen ${ }^{97}$. Aus diesen Gründen hat M. Frede das Bild von Celsus als einem bedeu-

enthalten: Der Aufruf des Celsus zur Mitarbeit (Cels. 8,73) dürfte sich v.a. an Christen aus der Oberschicht, d.h. den ordines, richten.

93 LonA, Kelsos, 51; vgl. CHADWICK, Contra Celsum, xxi-xxii. M. Fiedrowicz (BARTHold/FiEdRowicz, Contra Celsum Bd. 1, 33-34) stellt dagegen zu Unrecht eine Spannung zwischen dem negativen Urteil über die Christen einerseits und der Einladung an die Christen, „sich von ihrer Lehre abzuwenden und sich in die Gesellschaft zu integrieren“ (ebd., 33) andererseits fest. Einzig die „extreme[] äußere[] Bedrohung dieses Staatswesens zur Zeit der Fertigstellung der Kampfschrift“ (ebd., 34) habe diesen Schritt motiviert. Dabei stützt er sich einerseits zu sehr auf die problematische Datierung in die Jahre 177-180 n.Chr. Andererseits übersieht er, dass es sich gerade nicht um eine „versöhnende Geste“ (ebd., 34) handelt, sondern, wie zuvor richtig festgestellt, um die Aufforderung zur Abkehr vom Christentum. Christen sollen sich einbringen, aber indem sie sich zugleich von ihrem Glauben ab- und der wahren Lehre zuwenden.

94 BorRet, Contre Celse 5, 118; s. oben S. 270.

95 Vgl. z. B. Campenhausen, Kriegsdienst, 258; Trigg, Bible and Philosophy, 215; Barthold/FiedRowicz, Contra Celsum Bd. 1, 12, 35 und 39; Helgeland, Christians (ANRW), 746; ENGBERG, Impulsore Chresto, 284-285; EMmEnEGgER-SIEBER, Pflichten, 74. U.U. versteht auch REEMTs, Vernunftgemäßer Glaube, 38-43, hier v. a. 41, den Sachverhalt in dieser Weise.

96 Zur Frage nach der Bedeutung und Nachwirkung vgl. PICHLER, Streit, 60 - 85; LoNA, Kelsos, 67-69. 97 Der erste Grund für dieses Zögern ist allerdings (Cels. praef. 1-3) das Vorbild Jesu, der sich bei seinem Prozess nicht verteidigte. Genauso würde er sich gegen Kritik auch weiterhin nicht direkt verteidigen, sondern er habe stattdessen „seine Verteidigung im Lebenswandel seiner wahren Jün- 
tenden Philosophen, dessen Kritik am Christentum bisher nicht widerlegt werden konnte, überzeugend in Frage gestellt. Stattdessen hat er ein plausibleres Modell vorgeschlagen, das diesem Kapitel zugrunde liegt. ${ }^{98}$ Ambrosius habe im 'A $\lambda \eta \theta \dot{n}$ s $\Lambda$ óyos lediglich „a fairly complete compendium or repertory of arguments against Christianity“ gesehen, zu dem die Replik des Origenes ein „authoritative manual“ bieten würde, „in which a Christian could count on finding an adequate reply to whatever criticism of Christianity he was likely to encounter."999

Wenn man nach einem Grund sucht, warum gerade um das Jahr 248 n. Chr. die Abfassung einer solchen ,Musterapologie“ notwendig erschien, so ist es sicherlich richtig, auf die restaurativen Tendenzen hinzuweisen, die im zeitlichen Umfeld der Feier des tausendjährigen Bestehens Roms im Jahr 248 n.Chr. an Einfluss gewannen. ${ }^{100}$ Diese Kräfte setzten angesichts zahlreicher Krisen auf eine Erneuerung des ,Römertums‘, die auch den kultischen Bereich einschloss. ${ }^{101}$ In der Gestalt des Decius, seit 249 n.Chr. römischer Kaiser, kam einer ihrer Vertreter an die Macht. Seine Politik der religiösen Erneuerung sollte schnell zur ersten reichsweiten Christenverfolgung führen. ${ }^{102}$

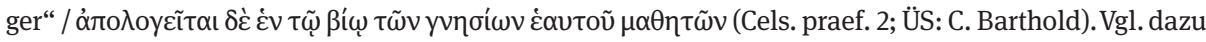
FREDE, Against Celsus, 145.

98 FREDE, Against Celsus, 139-155; v. a. ebd., 147-148: „[...] I doubt very much that Celsus was a wellknown author, that the True Account was a well-known challenge to Christianity, that it had a wide circulation, and that what was urgently needed was somebody with the qualifications of an Origen to respond to it." Ähnlich bereits FrEDE, Celsus (ANRW), 5187. Anders erklärt LoNA, Kelsos, 53-54, die

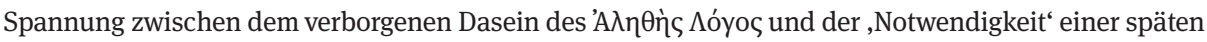
Widerlegung. Der Grund dafür liege im „beschränkten und spezifischen soziologischen Rahmen[]“ (ebd., 54) seiner Entstehung. Für eine spezielle und kleine Zielgruppe geschrieben, habe er diesen Kreis nie verlassen und blieb daher „ohne jedes literarische Echo, und doch so wirksam, dass sich eine Generation später Origenes damit auseinandersetzen musste“ (ebd., 54).

99 FREDE, Against Celsus, 150.

100 Vgl. bereits Bigelmair, Beteiligung, 175; außerdem z. B. TrigG, Origen, 53; Crouzel, Origen, 48; BARThold/Fiedrowicz, Contra Celsum Bd. 1, 11-12; FÜrst, Origenes, 217. Zu diesen Tendenzen vgl. Christ, Kaiserzeit, 657-663; Bellen, Grundzüge Bd. 2, 214-216; Schuol, Monika, Die paganen Religionen. In: Johne (Hrsg.), Soldatenkaiser, 927-935, hier 929-931. Skeptisch dem gegenüber dagegen ist ChADwick, Contra Celsum, xv. Zur Tausendjahrfeier des Jahres 248 n.Chr. vgl. KöRnER, Christian, Philippus Arabs - Ein Soldatenkaiser in der Tradition des antoninisch-severischen Prinzipats, (Untersuchungen zur antiken Literatur und Geschichte 61), Berlin u. a. 2002, 248-259.

101 Für die ,religionspolitische‘ Komponente sind die Gedanken der etwas früher komponierten Maecenasrede bei Cassius Dio (52,36,1-3) ein gutes Beispiel; vgl. Christ, Kaiserzeit, 660; Schuol, Religionen, 929.

102 Zur Verfolgung des Decius vgl. Vogt, Christenverfolgung (RAC), 1184-1187; LAST, Christenverfolgung (RAC), 1226-1227; Molthagen, Staat, 61-84; SELIngER, Reinhardt, Die Religionspolitik des Kaisers Decius - Anatomie einer Christenverfolgung, (Europäische Hochschulschriften, 3/617), Frankfurt a. M. 1994; RIves, James B., The Decree of Decius and the Religion of Empire. In: JRS 89 (1999), 135-154; Christ, Kaiserzeit, 660-661. Außerdem die wichtigen Beiträge in Johne (Hrsg.), Soldatenkaiser: HutTNER, Maximinus, 202-211 (Decius), 204 mit Anm. 390 (Literatur) und 208 (Christenverfolgung); Schuol, Religionen, 930; HeRKLOTZ, Friederike, Der Kaiserkult, 937-948, hier 941 mit Anm. 25 (Literatur); Pietzner, Christen, 994-999. Es dürfte sich primär um den Versuch ge- 
Es ist anzunehmen, dass sich die ersten damit verbundenen Spannungen schon in den Jahren vor 248 n. Chr. bemerkbar gemacht haben werden. ${ }^{103}$ Angesichts dieser Situation bot das Werk des Celsus mit seiner Konzentration auf den Gegensatz zwischen dem Christentum und der alten, wahren Lehre der christlichen Apologetik einen willkommenen Ansatzpunkt zur Auseinandersetzung mit derartigem Gedankengut. Das gilt unabhängig davon, wie weit verbreitet das Werk des Celsus tatsächlich war.

Auch Origenes schrieb für eine Leserschaft ${ }^{104}$, die der des Celsus in etwa entsprach. Es handelte sich um wohlhabende und gebildete Menschen aus den höheren Schichten, die der christlichen Gemeinde zumindest nahe standen oder sich sogar zur Gemeinde zählten, aber noch nicht gefestigt genug in ihrem Glauben waren, um sich nicht von Argumenten wie denen des Celsus erschüttern zu lassen. ${ }^{105}$

\subsubsection{Contra Celsum 8,73-74}

Im Verlauf der Auseinandersetzung mit Celsus kommt Origenes immer wieder in mehr oder weniger ausdrücklicher Weise auf Fragen der Kriegsteilnahme und -führung zu sprechen. Der mit Abstand wichtigste und meistdiskutierte Text steht am Ende der Schrift in Cels. 8,73-74. ${ }^{106}$ Da Origenes seinem Contra Celsum keinen systematischen Aufbau zugrunde legt, sondern der Stoffanordnung des Celsus folgt ${ }^{107}$, kann an dieser Stelle mit Cels. 8,73-74 begonnen werden. Die weiteren Texte aus früheren Büchern ${ }^{108}$ werden dann an gegebener Stelle mit in den Blick genommen.

handelt haben, mit einer reichsweiten supplicatio (vgl. SIEBERT, Anne V., s.v. supplicatio. In: DNP 11, [2001], 1116; RosenBerger, Veit, s.v. Sühnerituale. In: DNP 11, [2001], 1080 -1081; HeRKLOTZ, Kaiserkult, 940 -941) die angesichts vieler Krisen scheinbar verlorene Gunst der Götter zurückzugewinnen, bei der die Christen - wahrscheinlich nicht unbeabsichtigt - unter die Räder kamen. Nach HUTTNER, Maximinus, 208, ging es ihm um die „Erschließung religiöser Ressourcen, mit deren Hilfe die römische Ordnungsmacht wieder zurechtgerückt werden sollte.“ Eine zumindest auch antichristliche Zielsetzung bestreitet SElinger, Religionspolitik. Vgl. dagegen u.a. die Rezension von Bleckmann, Bruno, Rez. zu Selinger, Reinhardt, Die Religionspolitik des Kaisers Decius - Anatomie einer Christenverfolgung, (Europäische Hochschulschriften, 3/617), Frankfurt a. M. 1994. In: ZRG 114/1 (1997), $491-495$. 103 Origenes selbst ist sich bewusst, dass trotz des relativen Friedens jederzeit neue Verfolgungen hereinbrechen können. Siehe z. B. Cels. 3,15; 8,44; 8,70. Vgl. dazu ReEmTs, Vernunftgemäßer Glaube, 45-46; ENGBeRg, Impulsore Chresto, 291-293; BARTHold/Fiedrowicz, Contra Celsum Bd. 1, 10.

104 Vgl. dazu ReEmTs, Vernunftgemäßer Glaube, 38-43; FREDE, Against Celsus, 152-153; BARTHOLD/ FIEDrowicz, Contra Celsum Bd. 1, 39-40.

105 Siehe v. a. Cels. praef. 3-4.6; außerdem Cels. 4,1; 5,1. Vgl. pointiert Frede, Against Celsus, 153. 106 Über die bereits angeführte Literatur zum Thema Christentum und Soldatenstand sowie zu Origenes hinaus ist für die Auseinandersetzung mit Cels. 8,73 der wichtige Beitrag von MAzzUCco, Clementina, Origene e la guerra guista - (Contra Celso VIII 73), in: Civilta Classica e christiana 9 (1988), 67-84, heranzuziehen. Ihr Verständnis der Stelle unterscheidet sich an wesentlichen Punkten vom der hier vorgelegten Interpretation.

107 Siehe oben S. 268, Anm. 61.

108 Hier sind v. a. Cels. 2,30; 4,82-83; 7,26 zu nennen. 


\section{Text}

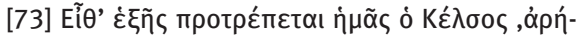

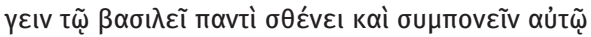

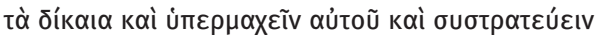

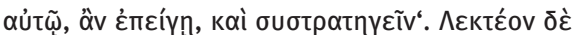

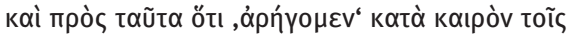

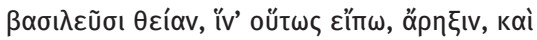

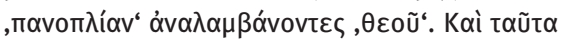

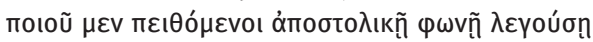

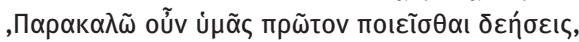

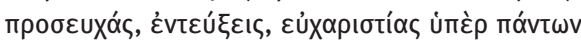

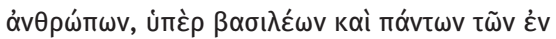

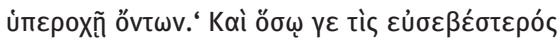

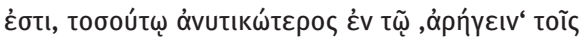

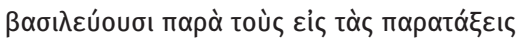

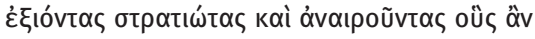

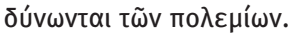

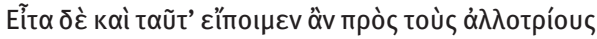

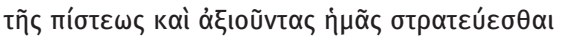

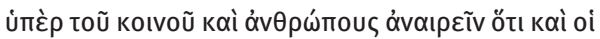

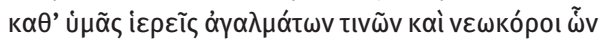

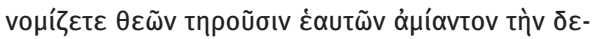

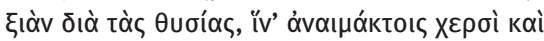

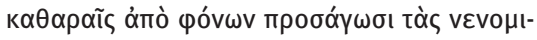

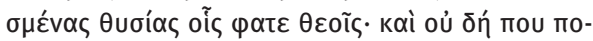

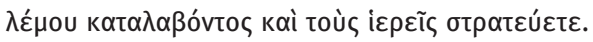

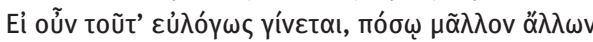

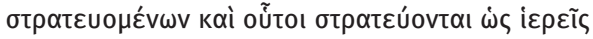

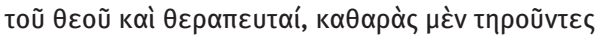

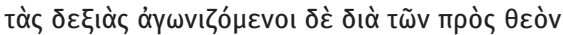

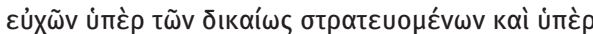

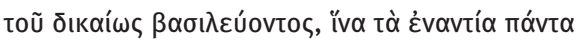

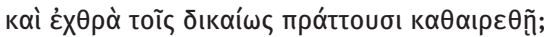

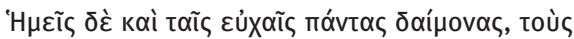

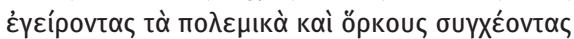

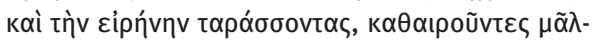

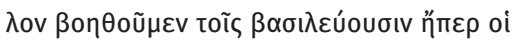

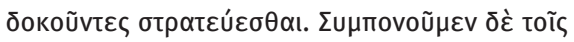

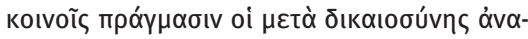

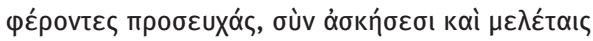

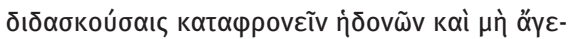

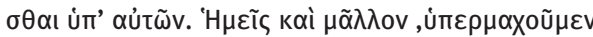

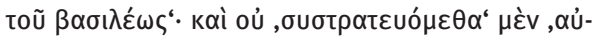

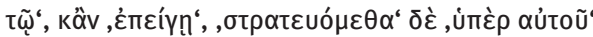

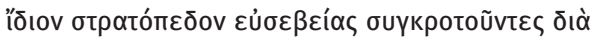

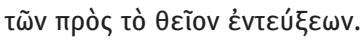

„[73] Anschließend fordert uns Celsus auf, wir ,sollten den Kaiser mit aller Kraft unterstützen, an seinen gerechten Anstrengungen teilnehmen, für inn kämpfen und, wenn er dies fordert [bzw. wenn es erforderlich ist], mit ihm in den Krieg ziehen und mit ihm seine Soldaten kommandieren". Darauf geben wir zur Antwort: Wir ,unterstützen“ die Herrscher zur rechten Zeit, und zwar sozusagen mit göttlicher Hilfe und legen ,die Waffenrüstung Gottes' an, und dies tun wir, weil wir der Stimme des Apostels Folge leisten, die so spricht: ,Ich ermahne euch nun zuallererst: Verrichtet Bitten, Gebete, Fürbitten, Danksagungen für alle Menschen, für Könige und für alle Obrigkeiten`. Und je religiöser jemand ist, umso erfolgreicher ist seine ,Unterstützung für die Herrscher und übertrifft die Soldaten, die zur Schlacht ausziehen und so viele von den Feinden vernichten, wie sie vermögen.

Dann könnten wir denen, die unserem Glauben fernstehen und von uns verlangen, dass wir für das Gemeinwohl als Soldaten kämpfen und Menschen töten sollen, auch diese Antwort geben: Die Männer, die bei euch als Priester für gewisse Götterbilder zuständig sind, und die Tempeldiener derer, die ihr für Götter haltet, bewahren wegen der Opfer ihre Rechte unbefleckt, damit sie mit Händen, die frei von Menschenblut und rein von Mord sind, euren sogenannten Göttern die herkömmlichen Opfer darbringen können; und wenn ein Krieg ausbricht, so lasst ihr doch wohl nicht auch die Priester Soldatendienste leisten. Wenn diese Sitte nun vernünftig ist, wie viel eher entspricht es der Vernunft, wenn die Christen, während die anderen in den Krieg ziehen, auch ihrerseits als Priester und Diener Gottes an der Schlacht teilnehmen, indem sie ihre Hände zwar rein bewahren, aber mit ihren an Gott gerichteten Gebeten für die Verteidiger der gerechten Sache und für den rechtmäßigen Herrscher kämpfen, damit alles bezwungen werde, was sich den Vertretern der gerechten Sache feindlich entgegenstellt. Wir bezwingen mit unseren Gebeten zudem auch alle Dämonen, die die kriegerischen Aktionen anstiften, Eide brechen und den Frieden stören, und helfen dadurch den Herrschern mehr als jene, die dem äußeren Anschein nach kämpfen. Und wir nehmen an den Anstrengungen für die Belange des Gemeinwohls teil, indem wir unsere 


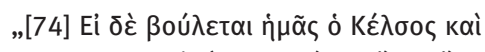

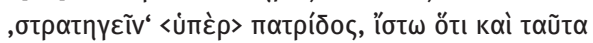

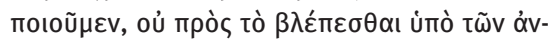

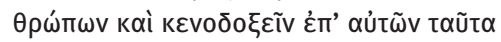

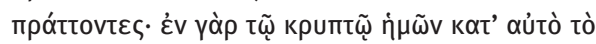

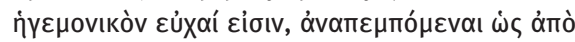

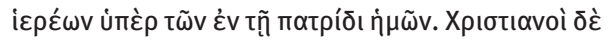

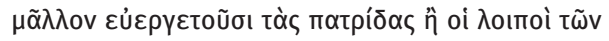

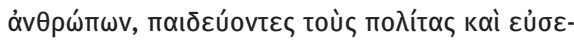

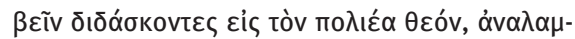

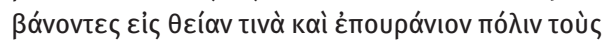

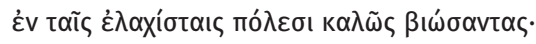

Gebete, die wir in Gerechtigkeit Gott darbringen, mit Übungen und Betrachtungen verbinden, die uns lehren, die sinnenhaften Freuden geringzuachten und uns von ihnen nicht bestimmen zu lassen. ,Wir kämpfen' sogar mehr als andere ,für den Kaiser'; und wenn wir auch nicht ,mit inm in den Krieg ziehen', selbst,wenn er dies fordert' [bzw. ,wenn es erforderlich ist'], so ,kämpfen' wir doch ,für ihn', indem wir ein besonderes Kriegsheer der Gottesverehrung aufstellen, durch unsere Fürbitten, die sich an die Gottheit richten.“

[74] Wenn aber Celsus von uns verlangt, dass wir zur Verteidigung des Heimatlandes auch ,Soldaten kommandieren', so soll er wissen, dass wir auch dies tun, und zwar nicht, um von den Menschen gesehen zu werden und bei innen durch unser Tun nichtigen Ruhm zu erlangen. Denn unsere Gebete finden im Verborgenen, nämlich im Inneren unserer Seele statt und werden von uns wie von Priestern für das Wohl unserer Mitbürger zum Himmel emporgesandt. Die Christen aber erweisen ihrem Heimatland mehr Wohltaten als die übrigen Menschen: Sie unterrichten Bürger und lehren sie die wahre Verehrung gegen Gott, den Herrscher über die Stadt, und heben diejenigen, die in den kleinsten Städten ein gutes Leben geführt haben, zu einer göttlichen und himmlischen Stadt empor. [...].“

(ÜS: AG nach C. Barthold)

\section{Kontext}

Für ein angemessenes Verständnis dieses Abschnitts ist es wichtig, ihn in den weiteren Zusammenhang des letzten Teils des siebten sowie des achten Buches ${ }^{109} \mathrm{zu}$ stellen. ${ }^{110}$ Origenes wendet sich ab Cels. 7,62 ${ }^{111}$ der von Celsus thematisierten „Frage

109 Vgl. v. a. den Überblick bei PICHLER, Streit, 291-297, der die entscheidenden Punkte sehr gut herausgearbeitet hat und dessen Analyse dieser Abschnitt im Wesentlichen folgt.

110 Anders z.B. Mazzucco, Origene, die den Text weitgehend aus der Entwicklung des Gedankengangs im unmittelbare Kontext und im Gespräch mit einigen anderen, eher isoliert genommenen Passagen aus Contra Celsum, interpretiert.

111 Man könnte hier auch schon bei Cels. 7,53 einsetzen, wo der letzte größere Abschnitt des dritten

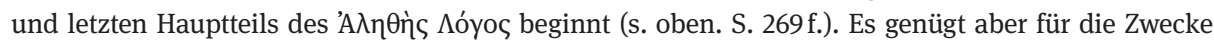
dieser Untersuchung etwas später zu beginnen und Cels. 7,62 bietet hier durch einen inhaltlichen Neueinsatz einen guten Ansatzpunkt: ,Wir wollen nun auch betrachten, was er im Folgenden sagt: ,Gehen wir zu einem anderen Punkt über: Sie ertragen nicht den Anblick von Tempeln, Altären und

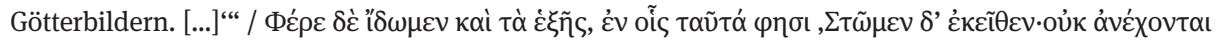

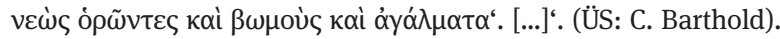


der angemessenen Verehrung Gottes unter den Bedingungen der bestehenden (metaphysischen und irdischen) Ordnung “112 $\mathrm{zu}$. Dabei wird das Problem der Stellung des Christentums zu dieser bestehenden Ordnung beziehungsweise die von Celsus behauptete Gefährdung dieser Ordnung durch die christliche Verweigerungshaltung in mehrfacher Hinsicht thematisiert.

1. Zuerst greift Celsus die Christen an, da sie sich gegen die Verehrung der vielen Götter mit ihren „Tempeln, Altären und Götterbildern“"113 wenden und sich weigern, diesen Gottheiten die ihnen zustehenden Opfer zu bringen. ${ }^{114}$

Demgegenüber versucht Origenes die Richtigkeit des exklusiven Wahrheitsanspruchs und des darauf gegründeten Verhaltens der Christen zu erweisen. Auch das später folgende Argument des Celsus, dass die Verehrung der einzelnen Gottheiten der Völker des Imperiums letztlich nur die Verehrung des einen Gottes vervollkommnen würde, da dieser ja als übergeordnete Größe hinter jenen stehe, lehnt Origenes als irrig ab. ${ }^{115}$

2. Darauf folgt die Behandlung der Verehrung der Dämonen, die unter den genannten Göttern stehen und wie diese ebenfalls dem höchsten Gott dienen ${ }^{116}$, die „mit den Dingen hier unten betraut sind“117 und denen laut Celsus daher ebenfalls kultische Verehrung zusteht. ${ }^{118}$ Er begründet dies unter anderem damit, dass er die Götter und ihre Rolle aus der Vorsehung des höchsten Gottes ableitet, nach dessen Willen alles geordnet ist und der allem einen eigenen vó $\mu$ o૬, ein eigenes Gesetz gegeben hat. Dieses Gesetz drückt sich darin aus, dass „über jedes Ding ein

112 PICHLER, Streit, 291; vgl. auch ebd., 176.

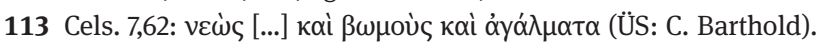

114 Cels. 7,62-66.

115 Cels. 8,2 und 8,66-67; an letzterer Stelle hat Celsus als Beispiel, das Origenes aufgreift, die Verehrung des Helios und der Athene eingeführt.

116 Vgl. Origenes, Contra Celsum - Gegen Celsus, griech./dt., fünfter Teilband, eingel. und komm.von Michael FiEdRowicz, übers. von Claudia BARTHold, (Fontes Christiani 50,5), Freiburg i. Br. u. a. 2012, 1218, Anm. 125: „Im Hintergrund steht die seit dem 1. Jh. n. Chr. verbreitete Vorstellung, dass der höchste Gott ähnlich dem wie der persische Großkönig oder der römische Kaiser zwar die oberste Gewalt innehabe, diese jedoch durch untergeordnete Instanzen ausübe, deren Verehrung letztlich dem Monarchen selber galt.“ Belege ebd., 1388-1389, Anm. 173. Siehe auch oben S. 271, Anm. 85 mit Belegen zu Celsus. Zur Verwurzelung und Bedeutung dieser Sichtweise im Mittelplatonismus vgl. BALtes, Matthias, Johnston, Sarah Iles, s.v. Dämonologie C. Platon und Platonismus. In: DNP 3, (1997), 265-268; FREDE, Celsus (ANRW), 5208-5210, jeweils mit Belegen. BALTES, s.v. Mittelplatonismus (DNP), 296, beschreibt einen wichtigen Aspekt der Dämonenlehre des Mittelplatonismus knapp aber treffend: „Ihre Aufgabe [sc. der Dämonen; AG] ist die Vermittlung zw. den Göttern und den Menschen bei Opfern, Gebeten und Weissagungen.“ Siehe jetzt auch MännLEIN-RoBERT, Kelsos, 670 - 671.

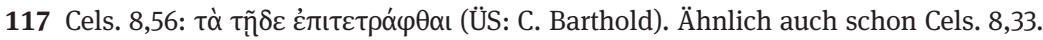

118 Cels. 7,67-8,63. Ab spätestens 8,17 verschwimmen die Grenzen zwischen der Thematik der Dämonenverehrung und derjenigen der Götterverehrung. Zur ihnen zustehenden kultischen Verehrung siehe Cels. 7,68 und v. a. 8,35.57-58. 
Wesen gesetzt wurde, das dieser Machtposition für würdig befunden wurde“119. Die Götter wie auch die Dämonen sind also nach dem Willen des höchsten Gottes über bestimmte Bereiche der Weltordnung - und somit beispielsweise auch über bestimmte Völker - als Statthalter eingesetzt. Mit diesen Göttern haben die Völker auch ihr je eigenes Gesetz, ihre je eigene kultische und soziale Lebensweise erhalten, der sie auch zu folgen haben. Durch die Verehrung der jeweiligen lokalen Götter und Dämonen, so Celsus, „verrichte [man] für das (gesellschaftliche) Leben die pflichtgemäßen Dienste“, haben sie doch „die Verwaltung jener Dinge inne, die zu unserem Bedarf geschaffen sind“120. Außerdem müsse man sich die Dämonen durch Gebete und Opfer wohlwollend stimmen, „um von ihnen menschenfreundliches Verhalten zu erfahren“121. Auch die Christen sollten ihnen also die entsprechende Achtung und Huldigung leisten, so fordert es Celsus ${ }^{122}$, sonst würden sie der gerechtfertigte Zorn und die Rache der Götter und Dämonen treffen $^{123}$. Sie sollen also ihre kultischen und gesellschaftlichen Pflichten tun, die

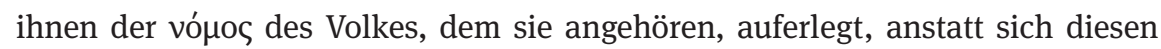
Pflichten unter Verweis auf ihren christlichen Glauben zu entziehen.

Origenes wehrt sich, unter anderem unter wiederholter Bezugnahme auf die Heiligen Schriften des Christentums ${ }^{124}$, vehement dagegen. Denn es gelte vielmehr: „Nach den Gesetzen Gottes jedenfalls hat kein ,Dämon die Dinge auf der Erde zugeteilt erhalten“."125 Stattdessen stellt er der geforderten Verehrung der Götter und Dämonen die Verehrung des einen und einzigen Gottes der Christen in der und durch die Verehrung Christi entgegen, einer Verehrung, die „in einem rechtschaffenen Leben“"126 bestehe. Gerade die Christen als Christen, wenn sie ihrer eigenen Lebensweise - man könnte sagen, ihrem vó $\mu \circ \varsigma^{127}$ - folgen, ehrten

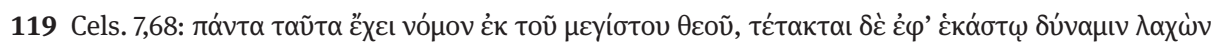

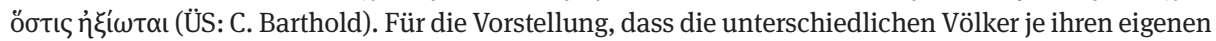
(kultisch-religiösen und sozialen) vó Lehre leben sollen und auch dürfen, siehe den zentralen Text Cels. 5,34 sowie 5,25.41.

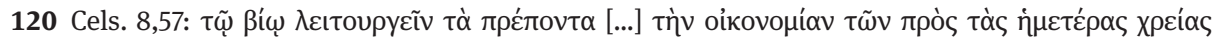

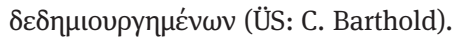

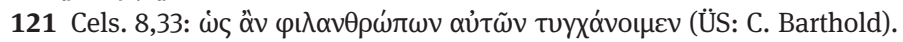

122 Cels. 8,2. Vgl. zur Dämonenverehrung insgesamt PICHLER, Streit, 173: „Kelsos betont nochmals, daß in der Situation, in der die Menschen sich in dieser Welt befinden, es vernünftig ist, den Dämonen als denen, denen Macht über den Bereich des Irdischen und Körperlichen gegeben ist, die ihnen zustehende Ehre zu erweisen [...]; die Christen aber erleiden die Strafen zurecht, denn sie verhalten sich gegenüber dem von den Dämonen verwalteten Bereich wie Räuber (fr VIII 53; 54).“

123 Cels. 8,35-43.

124 Siehe nur Cels. 7,70; 8,3-6.

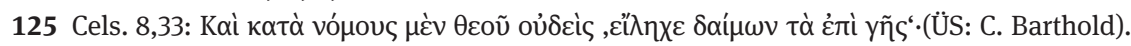

126 PICHLER, Streit, 294.

127 Für Celsus jedoch haben die Christen gerade keinen eigenen vó $\mu$ o̧ im Vollsinn, da sie ja aus den verschiedensten Völkern stammen und jeweils ihre überlieferten Lebensweisen verlassen haben. Aus diesem Grund kann man auch, aus celsischer Sicht, vom Pseudo-vó Christentum selbst ist in seinem Ursprung für ihn ja aus einer Abwendung vom Judentum, aus dem es 
den höchsten Gott in der besten und angemessensten Weise. K. Pichler hat das zusammenfassend auf den Punkt gebracht:

„Origenes knüpft an das (vom Text des Kelsos vorgegebene) Errichten von Altären, Götterbildern und Tempeln als Ausdruck menschlicher Frömmigkeit an; er erweist das christliche Leben als lebendigen Vollzug und damit als Überbietung der in solchen Formen sich manifestierenden Frömmigkeit; vom christlichen Glauben und Leben her erweisen sich dann die Manifestationen der menschlichen Frömmigkeit als Schein-Frömmigkeit, als Ausdrucksformen der Gottlosigkeit, die die Christen mit Recht fliehen; [...]“

3. Am Ende von Cels. 8,63 leitet Origenes dann zu einem dritten und letzten Aspekt der in diesem Zusammenhang besprochenen Frage über ${ }^{128}$ : der Stellung zur politischen Ordnung. Die Überleitung zeigt, dass Origenes die beiden zuerst besprochenen Aspekte und diesen letztgenannten Aspekt zwar unterscheidet, aber dabei dennoch in einem inneren Zusammenhang stehen sieht. Auch die geforderte Verehrung der Herrscher und der geforderte Gehorsam ihnen gegenüber ist, wie es K. Pichler ausdrückt, „dämonologisch begründet[]“129. So heißt es in Cels. 8,63:

„,Wenn sich die Sache so verhält, warum ist es dann schlimm, sich die Herrscher hier auf Erden wohlwollend zu stimmen, sowohl die anderen als auch die Regenten und Könige unter den Menschen, da auch diese ihre irdische Würde nicht ohne dämonische Kraft erhalten haben.' In den früheren Passagen suchte Celsus, soviel an ihm lag, unsere Seele zu den Dämonen herabzuziehen; jetzt aber will er, dass wir uns auch ,die Regenten und Könige unter den Menschen wohlwollend stimmen“ sollen." ${ }^{\text {"130 }}$

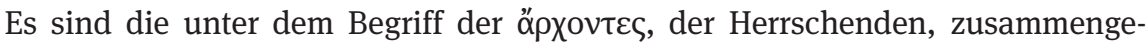
fassten dämonischen und menschlichen Machthaber, deren Wohlwollen es laut Celsus zu erringen gilt. Durch diese Verbindung unter einem gemeinsamen Oberbegriff bezieht er, wie K. Pichler festgehalten hat, „auch die irdischen Herrscher in seine Dämonologie mit ein“131 und begründet ihre Machtstellung explizit mit der Delegation ,dämonischer` Macht.

entstammt, entstanden. Das ist einer der gravierenden Unterschiede, die Celsus zwischen dem Judentum und dem Christentum konstatiert, ist das erstere doch ein echtes Volk und sein Kult daher bei allen Kritikpunkten, die er vorzubringen hat, doch der Ausdruck der Treue zum eigenen vó $\mu$ oc. Zu dieser (allerdings nur vordergründig) positiven Einschätzung des Judentums siehe Cels. 5,25, zu seiner Kritik daran Cels. 5,41. Vgl. ANDRESEN, Logos, 225-238, zum Christentum als einer vó 128 Vgl. PiCHLER, Streit, 295; LONA, Kelsos, 463.

129 PICHLER, Streit, 295; vgl. bereits ebd., 174.

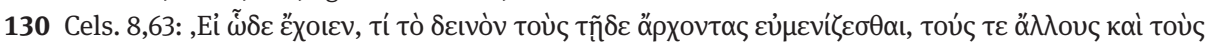

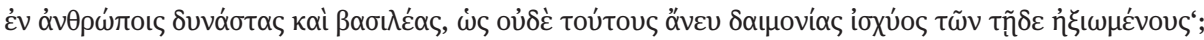

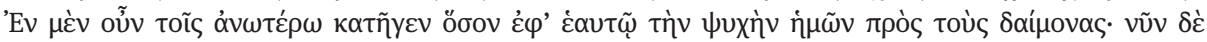

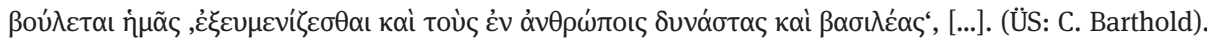
131 PiCHLER, Streit, 174. Vgl. dazu auch LonA, Kelsos, 464. 
Gegen diese Forderung wendet Origenes ein, dass es nur „der über allem waltende Gott“ sei, den die Christen sich „wohlwollend stimmen“ müssten. ${ }^{132}$ Für

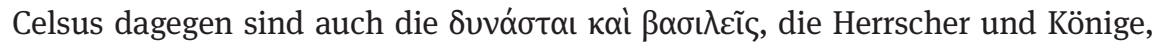
Teil der göttlichen Ordnung und dienen dem höchsten Gott in statthalterlicher Funktion. Kann er doch im Weiteren von ihnen sagen:

\begin{abstract}
„,Wenn man dir auch befiehlt, unter den Menschen beim Kaiser einen Schwur zu leisten, so ist das nicht schlimm. Denn diesem sind die Dinge auf Erden verliehen worden, und alles, was du in diesem Leben empfängst, empfängst du von ihm. ' [...] Anschließend sagt Celsus: ,Man darf einem Mann aus alter Zeit nicht den Glauben verweigern, der schon lange zuvor den Ausspruch getan hat: 'Einer nur sei König, dem es verlieh der Sohn des ränkevollen Kronos.' [Hom. Il. 2,204f. ]“ Und er fügt hinzu: ,Denn wenn du diesen Grundsatz ablehnst, so wird dich natürlich der Kaiser strafen." ${ }^{133}$
\end{abstract}

In enger Parallelität zu den Göttern und Dämonen ist also auch die Stellung der menschlichen Herrscher, hier konkret des römischen Kaisers, durch seine göttliche Einsetzung und Beauftragung bestimmt. ${ }^{134}$ Wie jenen muss auch den menschlichen Herrschern Anerkennung und Verehrung entgegengebracht werden, muss auch ihr Wohlwollen errungen werden, können auch diese ihre Verächter streng bestrafen. Auch hier ruft Celsus die Christen dazu auf, ihre Pflicht diesen Mächten gegenüber zu erfüllen und sich damit in die durch die wahre Lehre gegebene Ordnung der Dinge einzufügen, wie im Folgenden zu sehen sein wird. Denn würden alle anderen Menschen dem Vorbild der Christen folgen, würden sie also den Grundsatz Homers von der göttlichen Einsetzung und Einbindung des Herrschers sowie die daraus folgende, sich im Eid erweisende Loyalität ihm gegenüber ablehnen, wären die Konsequenzen desaströs. Celsus zeigt das auf, indem er unmittelbar an das vorherige Zitat anschließend schreibt:

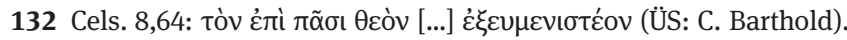

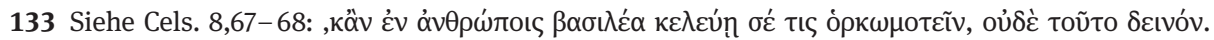

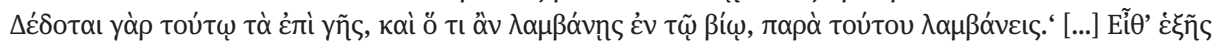

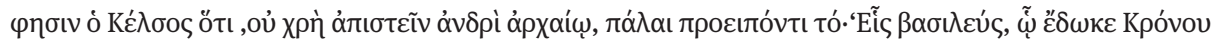

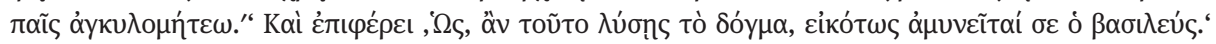
(ÜS: C. Barthold). Vgl. dazu LoNA, Kelsos, 464-469. Zur Bedeutung des Homerzitats für das staatsphilosophische Denken der Zeit vgl. z. B. aus den Reden über das Königtum des Dion Chrysostomos or. 1,11-14; 3,45-47; s. außerdem LonA, Kelsos, 467-468; BARTHOLd/FIEdRowicz, Contra Celsum Bd. 5, 1456, Anm. 239.

134 Vgl. den treffenden Kommentar von LonA, Kelsos, 467 zu Cels. 8,67: „Der Kaiser ist der Geber, der zuerst die Gaben von Gott (passivum divinum) empfangen hat, vor allem die Macht und Würde. Die Hierarchie der Macht - sie geht vom überhimmlischen Gott aus und steigt stufenweise zu den niedrigeren Instanzen herab - findet in ihm den menschlichen Repräsentanten und Verwalter. Sich dem Kaiser zu widersetzen, indem man ihm diese Anerkennung verweigert, würde bedeuteten, aufrührerisch sich der Ordnung der Welt zu widersetzen.“ Siehe auch FüRST, Origenes, 189. 
„,Handelten nämlich alle so wie du, so wird nichts verhindern, dass er allein übrig bleibt, die Güter auf Erden aber in die Hände der Barbaren geraten und dass weder von deiner Religion noch von der wahren Weisheit unter den Menschen etwas zurückbleibt.““135

An dieser Stelle zeigt sich, wie eng für ihn die Achtung der wahren Lehre von der den Kaiser einschließenden - göttlichen Ordnung der Welt und die Aufrechterhaltung der sozialen sowie der politischen Ordnung zusammengehören. Beide sind untrennbar miteinander verbunden! Das eine ist ohne das andere nicht $\mathrm{zu}$ haben. Ehre für die Götter sowie Gehorsam und Loyalität gegenüber dem Kaiser sind für Celsus zwei Seiten ein und derselben Medaille.

Die Antwort des Origenes ist, anders als diejenige gegenüber der geforderten Verehrung der Götter und Dämonen, vorsichtig ausdifferenziert: Er lehnt es ab, das Wohlwollen von Menschen erringen zu müssen, wenn diese Unrecht tun oder sich an dem „Gott des Universums“"136 durch Freveleien vergehen. Wo das aber nicht der Fall sei, würden die Christen selbstverständlich dem Wort der Schrift folgen - hier wird konkret auf das 13. Kapitel des Römerbriefs Bezug genommen und sich der Obrigkeit unterordnen. Nur bei der Tyche des Kaisers dürfe ein Christ nicht schwören. ${ }^{137}$ Im Anschluss schiebt er eine Diskussion der Verehrung anderer Götter am Beispiel des Helios und der Athene ein, die dem einen Gott laut Celsus keine Ehre raube, sondern vielmehr dessen Ehrung vervollkommne. ${ }^{138}$ Hier zeigt sich erneut, wie eng Götterkult und Herrscherverehrung für Celsus zusammengehören. ${ }^{139}$ Daraufhin bestätigt Origenes noch einmal die Ablehnung des Schwurs „bei dem Kaiser“ beziehungsweise seiner Tyche ${ }^{140}$. Auch das Argument des Celsus, dass dieser Schwur gestattet sei, da die Menschen alles, was sie besäßen, vom Kaiser empfangen hätten ${ }^{141}$, wird zurückgewiesen. Denn Christen empfangen das ihre „von Gott und seiner Vorsehung“142. Eine Einsetzung der Herrscher durch die göttliche Vorsehung kann Origenes bejahen, nur ist es nicht Zeus, der Sohn des

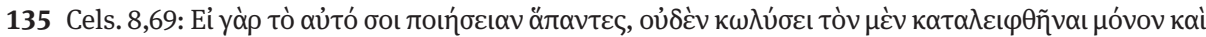

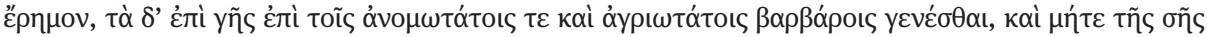

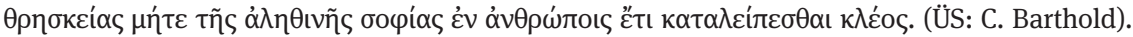

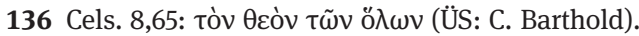

137 Cels. 8,65. Zum Schwur siehe die nahezu identische Position bei Tert. Apol. 32; darauf weist auch BARThold/Fiedrowicz, Contra Celsum Bd. 5, 1452, Anm. 235 hin. Zu diesem Schwur bei der Tyche bzw. dem genius des Kaisers vgl. mit Belegen CHADwick, Contra Celsum, 502, Anm. 2; Origène, Contre Celse, Bd. 4, Livres VII et VIII, introd., texte critique, trad. et notes par Marcel BoRRET (SJ), (Sources chrétiennes 150), Paris 1969, 325, Anm. 4; LonA, Kelsos, 465.

138 Cels. 8,66-67.

139 Vgl. den Kommentar dazu bei LoNA, Kelsos, 465-467, der diesen Gesichtspunkt gut herausarbeitet. Es dürfte sich um ein dreiteiliges Argument des Celsus gehandelt haben mit dem Ziel, die Christen davon zu überzeugen, dass es legitim ist, bei der Tyche des Kaisers zu schwören. In dieses Argument ist der Abschnitt über Helios und Athene als der zweite Schritt eingearbeitet.

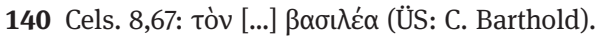

141 Cels. 8,67; siehe oben, S. 281, Anm. 133.

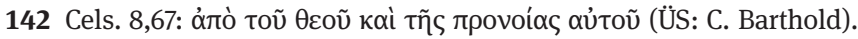


Kronos, sondern der eine Gott, den die Christen verehren, der Herrscher ein- und auch wieder absetzt. ${ }^{143}$ Aus diesem Grund sei das Prinzip Homers abzulehnen, aber der Herrscher sei im Anschluss an die göttliche Lehre über den König dennoch zu ehren. ${ }^{144}$ Unter dieser Voraussetzung läuft auch der zuvor im Anschluss an das Homerzitat geäußerte Vorwurf des Celsus ins Leere, dass nämlich, wenn alle sich - man kann ergänzen, so unsozial - verhielten wie die Christen und das homerische Wort über den König ablehnten, der Kaiser „allein und verlassen übrig bleibt“145, die zivilisierte Welt in die Hände der Barbaren fiele und damit auch das Christentum unterginge ${ }^{146}$. Die Christen stehen ja ihrem eigenen Nomos gemäß in ihrer Weise zum Kaiser und sind ihm gegenüber durchaus loyal. Würden außerdem tatsächlich alle - Celsus meint natürlich nur „alle Römer“ - so handeln wie die Christen, so würden ja auch, wie Origenes mit einem kräftigen Schuss Sophisterei feststellt, die erwähnten Barbaren, jetzt Christen geworden, „ganz gesetzestreu und zivilisiert sein“147.

Dieser vergleichsweise lange Überblick über den weiteren Zusammenhang war nötig, um die ,dämonologische ${ }^{\text {‘148 }}$ Einbettung der Diskussion um das rechte Verhalten dem Kaiser gegenüber in angemessener Weise zur Geltung zu bringen. Wie M. Fiedrowicz für Celsus festhält:

„Wer einen einzigen Gott gegen alle sonstigen Götter ausspielte bzw. eine Beziehung zu jenem höchsten Prinzip exklusiv für sich beanspruchte, störte die Harmonie nicht nur auf der metaphysischen Ebene, sondern bedrohte zugleich die politisch-soziale Ordnung.“"149

Diese Einbettung der Stellung zum Kaiser in die Haltung den Göttern gegenüber wird in dem jetzt zu diskutierenden Abschnitt über den Kriegsdienst im Hintergrund weiter

143 Cels. 8,68.

144 Cels. 8,68; Origenes verwiest hier auf 1. Petr 2,17, wo ermahnt wird den Kaiser zu ehren.

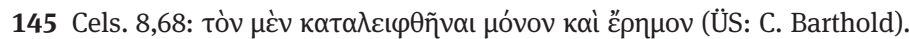

146 Cels. 8,68.

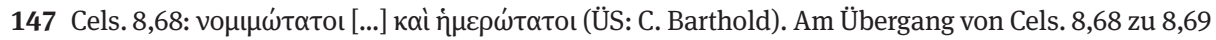
zeigt sich exemplarisch, wie Origenes in gekonnter Weise einzelne Gedankengänge des Celsus auseinandernimmt, einzeln beantwortet und ihm dann durch das Zerreisen argumentativer Zusammenhänge Widersprüche unterstellen kann. Vgl. dazu Pichler, Streit, 228-235. Denn Celsus hat das ,alle“ aus 8,68 sicherlich auf das „die Römer“ aus 8,69 bezogen. Nur indem er diesen unmittelbaren Zusammenhang aufbricht, kann Origenes in das „alle“ auch die Barbaren jenseits der Grenzen des Reiches einschließen und dem Celsus einen Widerspruch vorwerfen. Celsus aber fragt gerade danach, was passieren würde, wenn zwar die Römer schon Christen seien, die Barbaren jenseits der Grenzen aber noch nicht. Origenes missdeutet ihn hier absichtsvoll im Sinne einer gleichzeitigen ,subita conversio‘ der Römer und der auswärtigen Feinde. Vgl. die Kritik daran bei SchöPf, Tötungsrecht, $224-225$. Dagegen glaubt CADoux, Christian Attitude, 146, den Origenes im Recht und meint, Celsus habe versucht, „some sort of bogey“ zu fabrizieren. MAzzucco, Origene, 75-76, sieht Origenes hier eine ernstgemeinte Hoffnung auf die Möglichkeit der Bekehrung der Barbaren zum Ausdruck bringen.

148 Nach PICHLER, Streit, 295.

149 Barthold/Fiedrowicz, Contra Celsum Bd. 1, 93-94. 
mitschwingen und für sein Verständnis eine wichtige Rolle spielen. Denn es ist diese „dämonologische“150 Begründung der Stellung des Herrschers und der daraus folgenden Gehorsamspflicht auch der Christen, die Origenes mit all ihren Implikationen ablehnt.

\section{Interpretation}

Cels. 8,69-72

Ehe Cels. 8,73 interpretiert werden kann, müssen allerdings noch die Kap. 69-72 des achten Buches untersucht werden. In Cels. 8,69 wendet sich Origenes dem eigentlich noch mit dem Vorherigen zusammengehörenden Vorwurf zu, dass, wenn alle Römer Christen würden, der Gott der Christen doch sicher nicht „vom Himmel herabsteigen und für sie kämpfen würde, so dass sie keine andere Schutzmacht mehr bräuchten. “151 Zugleich nutzt er diesen Vorwurf, den er vom vorhergehenden Abschnitt abgetrennt hatte, um neu anzusetzen und sich mit der Frage nach der Sicherheit des Kaisers und des Reiches angesichts der Ausbreitung des Christentums einerseits und der Gefährdung der Grenzen durch die ,Barbaren“ andererseits auseinanderzusetzen. Origenes antwortet an dieser Stelle noch einmal grundsätzlich auf diese Frage. Damit ist der Punkt in Contra Celsum erreicht, wo es möglich ist, sich der Frage nach dem Verhältnis von Christentum und Heeresdienst zuzuwenden.

Origenes antwortet auf diese seiner Meinung nach hypothetisch gestellte Frage ${ }^{152}$ des Celsus folgendermaßen: Würde tatsächlich das ganze Imperium den christlichen Glauben annehmen, dann würden die Gebete der nun wahrhaft gottesfürchtigen Römer gemäß dem neutestamentlichen Grundsatz von Mt 18,19153 dem Logos dargebracht werden, der schon den von den Ägyptern verfolgten Hebräern verheißen hatte, für sie Krieg zu führen. ${ }^{154}$ Dann würden die Römer „weit mehr feindliche Verfolger vernichten können, als das Gebet des zu Gott rufenden Mose und seiner Gefährten vernichtet hat. “155 Die Römer würden also, so folgert er weiter, „durch ihr Gebet über ihre Feinde triumphieren oder überhaupt nicht mehr Krieg führen müssen, da sie

150 Nach PICHLER, Streit, 295.

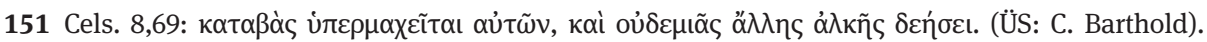

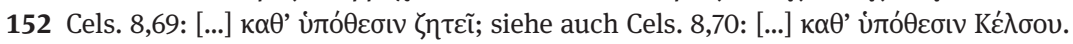

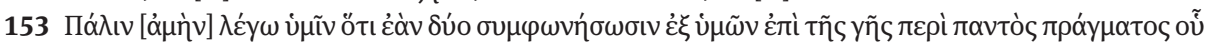

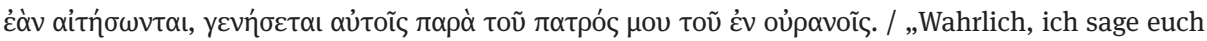
auch: Wenn zwei unter euch eins werden auf Erden, worum sie bitten wollen, so soll es ihnen widerfahren von meinem Vater im Himmel.“ (ÜS: LÜ 1984). Origenes argumentiert a minori ad maiorem,

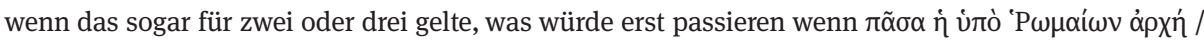
„das ganze römische Imperium“ (ÜS: C. Barthold) im Gebet übereinstimmen würde.

154 Cels. 8,69; Origenes bezieht sich hier auf die alttestamentliche Überlieferung vom Auszug Israels aus Ägypten und die betreffende Verheißung aus Ex 14,14.

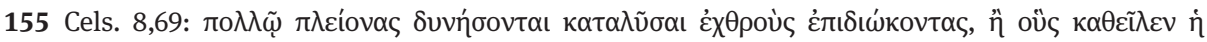

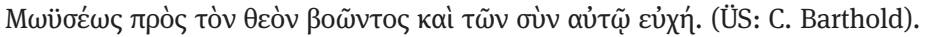


unter dem Schutz jener göttlichen Macht stehen [...].“156 Zugleich geht Origenes auf zwei mögliche Einwände gegen diese Behauptung ein, die er Celsus bereits zu Beginn von Cels. 8,69 hatte vorbringen lassen ${ }^{157}$ : Die militärischen Katastrophen der Juden in ihren Konflikten mit den Römern seien auf deren Schuld gegenüber ihrem Gott, hier vor allem ihre Schuld durch die Zurückweisung Jesu Christi zurückzuführen. ${ }^{158}$ Die Verfolgung der Christen aber und ihre Leiden unter diesen Bedrückungen seien von Gott zeitweilig zugelassen. Beide Gesichtspunkte widersprächen daher nicht der Behauptung, dass der jüdisch-christliche Gott seine Anhänger schütze.

Im Folgenden setzt Origenes sich mit einem Vorwurf des Celsus auseinander, der eine etwas eingehendere Betrachtung verlangt, da das hier vertretene Verständnis von der Mehrheitsmeinung der Forschung abweicht. Celsus legt einem Christen folgende Worte in den Mund:

„[...] dass dann, wenn unsere gegenwärtig Herrschenden sich von dir überzeugen ließen und anschließend in Gefangenschaft gerieten, du die anschließend Herrschenden gewinnen würdest; und wenn auch diese in Gefangenschaft gerieten, so würdest du es mit anderen ebenso machen und dann wieder mit anderen - bis endlich, wenn alle von dir Überzeugten gefangen werden, eine kluge Herrschaft, die das künftige Schicksal voraussieht, euch alle, bevor sie selbst vorher zugrunde geht, bis auf den letzten Mann vernichten wird.“159

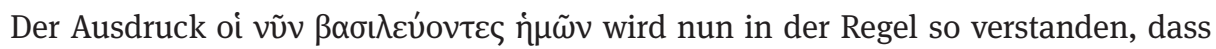
hier eine Anspielung auf die gegenwärtig regierenden Kaiser, sehr wahrscheinlich Kaiser Marcus Aurelius und Commodus, vorliegt. ${ }^{160}$ Diese würden, nachdem sie sich

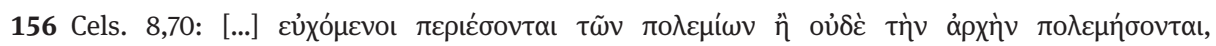

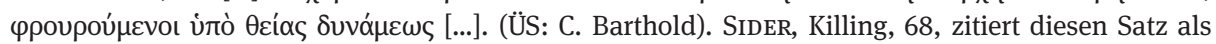
Beleg dafür, dass Origenes sich eine christliche Beteiligung an kriegerischen Auseinandersetzungen überhaupt nicht vorstellen könne. Er übergeht aber die zuvor zitierte Passage aus 8,69 sowie den hochgradig hypothetischen Kontext der ganzen Erörterung. Ebenso in seiner Diskussion ebd., 176.

157 Zum Zusammenhang vgl. LoNA, Kelsos, 469-471. Die Einwände implizieren natürlich, dass es den Römern, sollten sie sich von den Christen verführen lassen, ganz genauso ergehen würde, wie den Juden und den Christen: Sie würden besiegt und verfolgt werden. Vgl. HeLGELAND, Christians (ANRW), 750; MAZzucco, Origene, 77-78: „E il senso era: il cristianesimo non è una religione che serva sul piano pratico, non si presta a diventare un sostegno politico (come la religione pagana).“ Außerdem REEMTS, Vernunftgemäßer Glaube, 196-97.

158 Cels. 8,69; vgl. REEMTs, Vernunftgemäßer Glaube, 197.

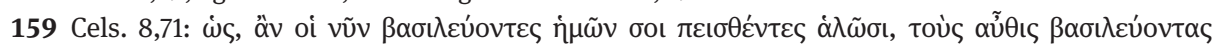

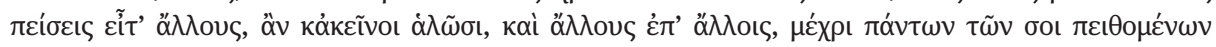

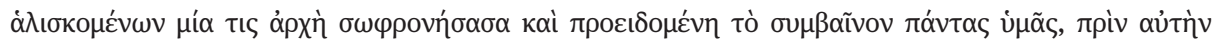

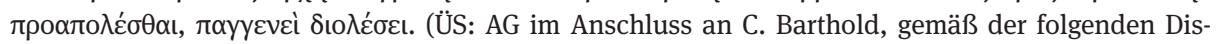
kussion abgeändert). MAzzucco, Origene, 76-77, sieht hierin mit Recht eine Karikatur des Celsus. 160 Vgl. die Übersetzung bei BARTHOLD/FIEDRowicz, Contra Celsum Bd. 5, 1463: „dass dann, wenn unsere gegenwärtigen Herrscher [...]“. Ebenso übersetzen z. B. CHADwick, Contra Celsum, 506; BoRRET, Contre Celse 4, 339, ist etwas behutsamer und übersetzt „,i ceux qui règnent aujourd'hui sur nous“, fügt kurz darauf aber ein les rois in den Text ein („tous les rois, convaincus par toi“), das zeigt, 
vom Christentum hätten überzeugen lassen, in Gefangenschaft geraten. Das würde

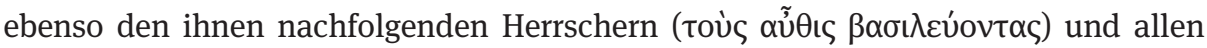

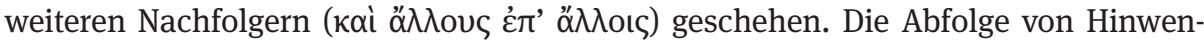
dung zum Christentum sowie anschließender Gefangennahme würde sich so lange

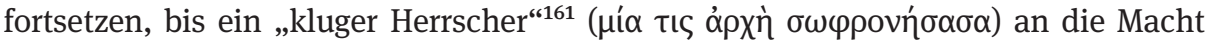
gelange, der erkenne, welche Gefahr ihm droht, und der darum die Christen allesamt

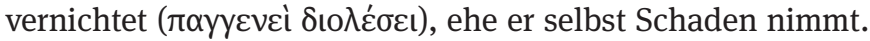

H.-J. Rosenbaum hat dagegen eingewandt, dass sowohl mit Blick auf die anderen $\beta \alpha \sigma \iota \lambda \varepsilon v \dot{s}$-Aussagen des Celsus als auch auf den unmittelbaren Kontext eine andere Interpretation des Ausdrucks oi vũv $\beta \alpha \sigma \iota \lambda \varepsilon v ́ o v \tau \varepsilon \varsigma \grave{\eta} \mu \tilde{\omega} v$ sinnvoller wäre. ${ }^{162}$ Er versteht ihn in Anknüpfung an die Bemerkung über die Juden, die eigentlich als Volk Gottes „Herrn der ganzen Erde“163 sein müssten, als eine Aussage über „das Herrschervolk der Römer“164. Dazu passten dann auch die folgenden zwei Beobachtungen: Der

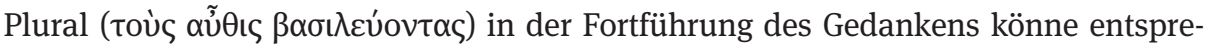

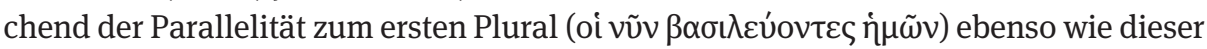
verstanden werden. Auch im Folgenden ist in Cels. 8,72 vom Nebeneinander verschiedener Völker die Rede. Man kann darüber hinausgehend noch darauf hinweisen, dass der Einsatzpunkt der Diskussion in Cels. 8,69-70 die hypothetische Frage des Celsus war, was denn geschehe, wenn sich alle Römer von den Christen überzeugen

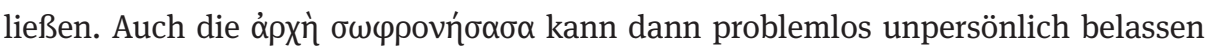
werden, handelt es sich in diesem Fall doch um eine kluge Herrschaft, die eines neuen Volkes nämlich. Diese Überlegungen stärken die Interpretation H.-J. Rosenbaums noch einmal zusätzlich. Celsus prognostiziert also das Ende der Römer als Herren der Oikumene sowie auch aller ihnen in dieser Rolle unter Umständen nachfolgenden Völker, sollte es den Christen gelingen, sie von ihrem Glauben zu überzeugen.

Der Beginn von Cels. 8,72 stellt ein Schlüsselproblem der hier besprochenen Kapitel dar. Origenes lässt Celsus an dieser Stelle einen Wunsch äußern und dann dessen Realisierbarkeit verneinen:

dass er an die Kaiser denkt; und LonA, Kelsos, 469, mit Kommentar ebd., 470 - 471. Für die daraus

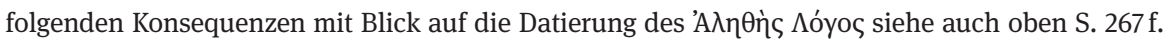

161 So die personalisierende Übersetzung von ópxǹ bei BARTHOLD/FIEDROwICz, Contra Celsum Bd. 5, 1465. Ähnlich Chadwick, Contra Celsum, 506, „a ruler“; Borret, Contre Celse 4, 339, „un chef avisé““. Vorsichtiger ist hier LoNA, Kelsos, 469, mit Kommentar ebd., 471, der übersetzt, „eine kluge [...] Herrschaft“, und dann kommentiert: „Es ist zwar nicht von einem Kaiser oder von einem Mächtigen die

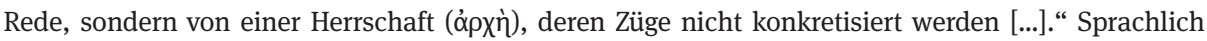
möglich ist eine solche personalisierende Übersetzung allerdings, wie auch LoNA, Kelsos, 471,

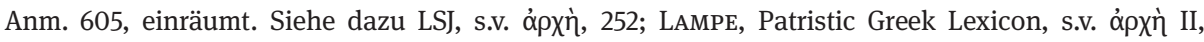
235-236.

162 Rosenbaum, Datierung, 108-109.

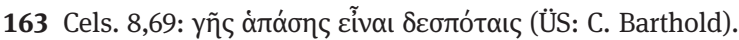

164 Rosenbaum, Datierung, 108. 
„Danach äußert er eine Art Wunsch: ,Wenn es doch möglich wäre, dass Griechen und Nichtgriechen, die Asien, Europa und Libyen bis zu den Grenzen hin bewohnen, in einem einzigen Gesetz übereinkommen!‘ Da er dies aber für unmöglich hält, fügt er hinzu: ,Wer dies glaubt, weiß gar nichts. “ $" 165$

Origenes versteht diesen Wunsch so, dass es ein Wunsch des Celsus selbst ist, den dieser aber als unmöglich ansieht. H. Chadwick hat dieses Verständnis in seiner kommentierten Übersetzung als richtig verteidigt. ${ }^{166}$ Es handelt sich unter dieser Voraussetzung um das - allerdings für unrealisierbar gehaltene - persönliche Ideal ${ }^{167}$ des Celsus von der Einheit aller Menschen unter einem Gesetz (vó $\mu \circ$ ).

Diesem Verständnis stehen allerdings einige Probleme entgegen: So bereitet die grammatikalische Form Schwierigkeiten, da Celsus dann im Optativ hätte formulieren müssen. ${ }^{168}$ Außerdem ist dann die Anknüpfung an den vorhergehenden Gedankengang schwierig und es ist weiterhin zu berücksichtigen, dass sich Celsus zuletzt im Diatribenstil mit von ihm aufgegriffenen Positionen der Christen auseinandersetzte. ${ }^{169}$ Stünde nicht zu erwarten, dass das hier auch der Fall ist? Es könnte sich also statt um einen Wunsch des Celsus selbst um einen christlichen Gedanken handeln, den dieser anführt und dann als unmöglich verwirft. ${ }^{170}$ Die Christen wollten schließlich, dass alle Völker unter einem einzigen vó $\mu$ oৎ, dem christlichen vó $\mu$ oৎ nämlich, zusammenkommen. Es ginge also in diesem Fall, wie C. Barthold es ausdrückt, „um die Weltherrschaft der christlichen Religion“"171. Celsus verteidigt dagegen gerade die Einheit und Gemeinsamkeit in dem alten, wahren hóyos, der es den Völkern erlaubt, unter

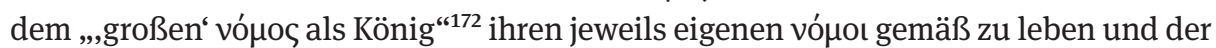
eben nicht verlangt, diese aufzugeben. ${ }^{173}$ Nimmt man an, dass die Erfüllung dieses

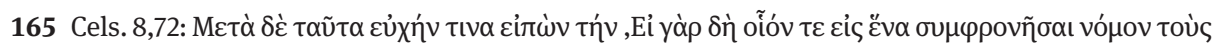

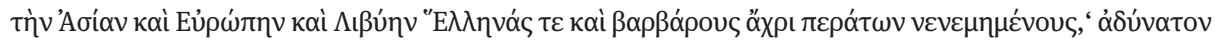

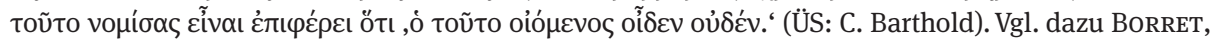
Contre Celse 4, 340 -341, Anm. 1; Lona, Kelsos, 471-472; BARTHold/FiEdrowicz, Contra Celsum Bd. 5, 1464, Anm. 247.

166 Chadwick, Contra Celsum, 507, Anm. 1; zuvor z. B. schon KeIM, Wahres Wort, 139, Anm. 1, 193 und v. a. 212-213; außerdem FÜRST, Origenes, 189. Zur Kritik daran vgl. ANDRESEN, Logos, 263-269; diesem folgend Lona, Kelsos, 472, Anm. 608.

167 Eine Formulierung, die BARTHold/Fiedrowicz, Contra Celsum Bd. 5, 1464, Anm. 247, folgt.

168 So Lona, Kelsos, 472, unter Verweis auf ANDRESEN, Logos, 191.

169 Vgl. Lona, Kelsos, 472.

170 So verstehen den Text ANDRESEn, Logos, 190 - 192; CooK, Interpretation NT, 90 - 91; LoNA, Kelsos, 472; vgl. außerdem Barthold/Fiedrowicz, Contra Celsum Bd. 1, 93 mit Anm. 467.

171 Barthold/Fiedrowicz, Contra Celsum Bd. 5, 1464, Anm. 247, im Rahmen einer Darstellung der unterschiedlichen Verständnismöglichkeiten.

172 LonA, Kelsos, 472, Anm. 611, unter Anspielung auf Cels. 5,34. Wie dieser weiter richtig festhält: „Das hat aber mit dem alle anderen Formen ausschließenden Absolutheitsanspruch der Christen nichts zu tun." Zum Nomosverständnis des Celsus siehe oben S. 271, Anm. 82.

173 Siehe Cels. 1,14; 5,25 und 5,41. Vgl. die wichtigen Anmerkungen bei LoNA, Kelsos, 472 mit Anm. 611, denen dieser Textabschnitt folgt. Liest man wie vorgeschlagen (s. oben S. 269 f.) den Celsustext, der sich in dem ganzen Teil Cels. 7,53-8,75 findet, als „dem antiken Nomos [geltend], dem sich die Christen 
christlichen Wunsches in den Augen des Celsus mit der Hinwendung der Römer zum Christentum verbunden ist, so ergibt sich auch ein plausibler Anschluss an den vorhergehenden Gedanken aus Cels. 8,71. Dann würden sich auch die von diesen beherrschten Griechen und die ,Barbaren', das heißt die nichtgriechischen Völker der im Römischen Reich repräsentierten Oikumene ${ }^{174}$, diesem einen, christlichen vó $\mu$ oৎ unterordnen. ${ }^{175}$ Wie H. Lona festhält: „Die scharfe und eindeutige Ablehnung einer

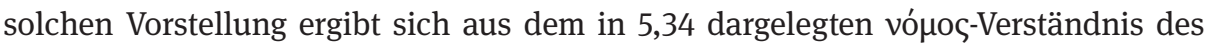
Kelsos, das mit einer religiösen Vereinheitlichung der Völker unvereinbar ist. “176 Demgegenüber entwirft Origenes in eingestandenermaßen ${ }^{177}$ groben Zügen das aus der Heiligen Schrift der Christen geschöpfte Gegenbild der christlichen Hoffnung, „dass irgendwann einmal der Logos die gesamte vernünftige Natur beherrschen und alle Seelen zu seiner Vollkommenheit umgestalten wird. “178 Er schränkt diese Hoffnung aber ein, indem er hinzufügt: „Und vielleicht ist ein solcher Zustand für die Menschen, die noch im Körper leben, wirklich unmöglich; er ist jedoch nicht unmöglich für diejenigen, die von ihm befreit sind. “179 Während einige Autoren hier einen Hinweis darauf finden, dass sich diese Hoffnung wohl nicht mehr zu seinen Lebzeiten, aber vielleicht doch in näherer Zukunft erfüllen könnte ${ }^{180}$, sehen andere darin einen Verweis auf einen eschatologischen Zustand, der innerweltlich nicht

durch die Ablehnung überkommener Werte und religiöser Vollzüge wiedersetzen“ (BARTHOLD/FIEDRowicz, Contra Celsum Bd. 1, 31), und hält man sich vor Augen wie oft Celsus gerade hier das in den wahren $\lambda$ óyoৎ eingebettete Eigenrecht der vielfältigen Lebensweisen der unterschiedlichen Völker in kultischer Hinsicht verteidigt, gewinnt diese Position eine noch größere Plausibilität.

174 Vgl. für dieses Verständnis LoNA, Kelsos, 472, Anm. 610.

175 Man beachte nur, wie Origenes gleich zu Beginn seiner Abhandlung (Cels. 1,1) gegen den Vorwurf

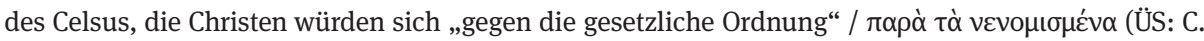
Barthold) bzw. gegen das „gemeinsame Gesetz“ / Tòv koเvòv vó schließen, den Gedanken vorträgt, dass sich die vielfältigen Gesetze der Völker an dem einen, allge-

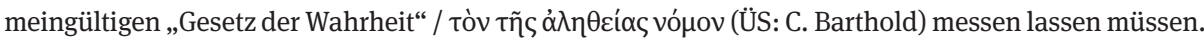
Vgl. dazu Barthold/Fiedrowicz, Contra Celsum Bd. 1, 94-95.

176 LoNA, Kelsos, 472.

177 Cels. 8,72: „Soll ich auch über diesen Punkt sprechen, so kann ich nur wenig darüber sagen, da eine ausführliche Untersuchung und Beweisführung erforderlich ist, um nicht nur die Möglichkeit, sondern auch die Wahrheit der These zu erweisen, dass alle vernünftigen Wesen in einem einzigen

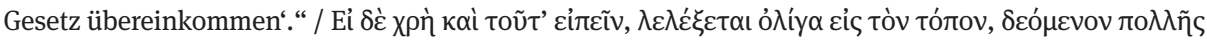

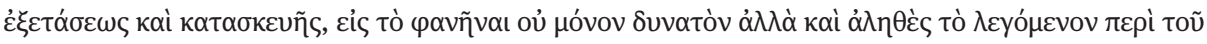

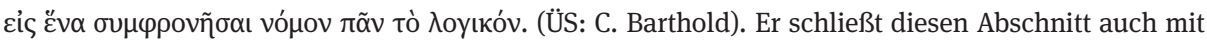
einer ähnlichen Bemerkung am Ende von Cels. 8,72 ab.

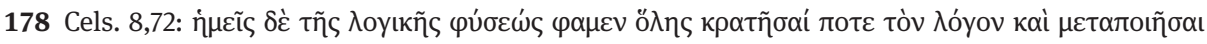

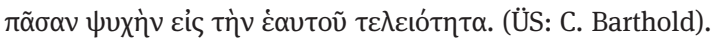

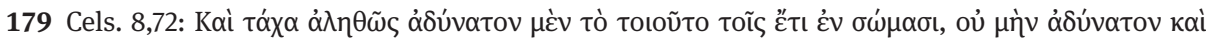
$\dot{\alpha} \pi \circ \lambda v \theta \varepsilon \tilde{\tau} \sigma \nu v \alpha \cup \dot{\tau} \tilde{\omega} v$. (ÜS: C. Barthold).

180 Cadoux, Christian Attitude, 145-146; Swift, War (ANRW), 856 mit Anm. 89. 
realisierbar ist, sondern erst am Ende der Zeiten eintreten wird ${ }^{181}$. Letzteres dürfte zutreffend sein.

Fasst man diese Abschnitte zusammen, so ergibt sich folgendes Bild: Origenes wehrt sich gegen den Vorwurf des Celsus, dass das ihren Glaubensüberzeugungen geschuldete Verhalten der Christen das die Oikumene beherrschende und einende Römische Reich zerstören würde. Denn jene sonderten sich von der Verehrung der Götter und Dämonen sowie von der rechten Würdigung der Kaiser in völlig unangebrachter Weise ab. Die destruktiven Folgen dieses Verhaltens würden umso mehr eintreffen, wenn sich alle anderen Bewohner des Römischen Reiches ihnen anschlössen. Es ist die Abwendung von der alten, wahren Lehre, durch welche die Christen in den Augen des Celsus diese Gefahr heraufbeschwören. Denn sie leben ihrer eigenen, defizitären Lebensweise gemäß und fordern andere dazu auf, ihre althergebrachten vó $\mu$ o zugunsten des christlichen Pseudo-vó $\mu$ oৎ zu verlassen. Celsus stellt außerdem die Drohung in den Raum, dass eine kluge Herrschaft das nicht zulassen, sondern aus reinem Selbstschutz die Christen allesamt auslöschen würde. Damit wäre die Bedrohung durch die christliche Lebensweise ein für alle Mal zu überwinden. Gegen diese Vorhaltungen weist Origenes darauf hin, dass das Reich im Falle einer weitgehenden Konversion seiner Bewohner zum Christentum keineswegs schutzlos den Einfällen der Barbaren und dem folgenden Chaos ausgeliefert wäre. Denn gerade dann würde Gott selbst aufgrund der Gebete der nun zahlreichen

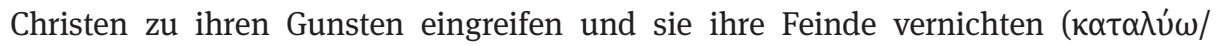
$\kappa \alpha \theta \alpha \iota \rho \varepsilon(\omega)$ lassen. Darüber hinausgehend hält er fest, dass es vielleicht sogar überhaupt keine Kriege mehr geben könnte, da Gott das christlich gewordene Reich vor allem Übel beschützen würde. W. Kinzig hat diesen Gedankengang treffend beschrieben:

\begin{abstract}
„Origenes versteigt sich zu der Behauptung, die rechte Gottesverehrung durch die Römer ließe sich in militärische Erfolge ummünzen. Als wäre er durch die Radikalität seiner Folgerung erschreckt, schränkt er jedoch sogleich ein: Wenn das ganze Reich christlich würde, gäbe es überhaupt keine Kriege mehr. Origenes begründet das seltsamerweise nicht mit dem Gebot der Feindesliebe, sondern von Gen. 18,26 her [...]. In der Interpretation des Alexandriners bedeutet dies: Solange es genügend Christen gibt, so lange wird auch das Reich bestehen." ${ }^{182}$
\end{abstract}

In diesen Kapiteln findet sich keineswegs eine kategorische Ablehnung jedweder Kriegführung. Origenes zeigt vielmehr, dass auch ein christlich gewordenes Reich nicht schutzlos seinen Feinden ausgeliefert wäre, sei es, dass Gott den nun christlichen gewordenen römischen Heeren dann militärische Erfolge schenkte, sei es, dass er selbst zum Schutz des Reiches den Bedrohungen und damit der Notwendigkeit,

181 KinZIG, Novitas Christiana, 473-474, sieht Origenes insgesamt schwanken, „ob der heilsgeschichtliche Fortschritt ein innerweltliches Ziel findet oder darüber hinaus geht.“ (ebd., 474); vgl. außerdem Trigg, Bible and Philosophy, 236; BARTHOLd/FiEdrowicz, Contra Celsum Bd. 1, 94; FürST, Origenes, 190.

182 KInZIG, Novitas Christiana, 472. 
Krieg zu führen, ein Ende bereitet. Origenes erkennt also die Notwendigkeit eines militärischen Schutzes gegen äußere Feinde für das Reich vollauf an und versucht, diesen unter der Voraussetzung eines verchristlichten Reiches $\mathrm{zu}$ begründen. ${ }^{183}$

Ein Problem für die Interpretation mit Blick auf die Haltung des Alexandriners zur Frage von Christentum und Soldatenstand ist die Unklarheit, ob Origenes seine Aussagen hier tatsächlich ernst meint. Entwickelt er hier kurz die Vision eines christlich gewordenen Imperium Romanum, wie es im 4. Jhd. n.Chr. Wirklichkeit werden sollte ${ }^{184}$ Oder beantwortet er einen in seinen Augen hochgradig unrealistischen und daher lediglich hypothetischen Einwand des Celsus - was wäre, wenn das ganze Reich christlich werden würde? - mit einer ebenso hypothetischen und unrealistischen Behauptung? Denn seine Antwort in Cels. 8,73 auf die konkrete Aufforderung des Celsus an die Christen, doch im Heer zu dienen, ist, wie noch zu zeigen sein wird, nur praktikabel, solange das Christentum eine Minderheitenreligion ist. Hier dagegen behandelt er die Frage aus der Perspektive eines (zumindest mehrheitlich) christlichen Reiches. Letztendlich dürfte H. von Campenhausen Recht zu geben sein, der meint:

„Ein christliches Weltreich ist für Origenes immer noch eine ganz utopische Vorstellung; so wagt er eine scheinbar ganz unwirkliche, konstruierte Möglichkeit, die ihm vorgehalten wird, mit einer utopischen Antwort zu erledigen." ${ }^{185}$

Dem entspricht, dass für Origenes gerade die Vereinigung der Völker der Oikumene unter einer Herrschaft, welche damit auch die sonst notwendigen Kriege überflüssig

183 Anders dagegen MAzzucco, Origene, 76 - 81. Sie sieht Origenes seine Argumentation schrittweise aufbauen, als einen Weg vom heidnischen Denken zum alttestamentlich-hebräischen Denken hin zu einem im Vollsinn christlichen Denken (v.a. ebd., 80). Spricht er auf der Ebene des heidnischen und alttestamentlich-jüdischen Denkens noch von der Möglichkeit, dass der christliche Gott seinen Anhängern im Kampf beisteht und den Sieg schenkt, so werde auf der Ebene des genuin christlichen Denkens diese ,Lösung‘ korrigiert und es werde klar, dass Origenes eine Beteiligung an einem Krieg ausschließt. Das Erleiden von Gewalt ohne Gegenwehr und das alleinige Vertrauen auf Gottes Schutz sei die einzig christliche Haltung.

184 Vgl. CAspary, Gerard E., Politics and Exegesis - Origen and the Two Swords, Berkeley 1979, 134: „The proto-Eusebian vision of a Christian Empire in which swords have been beaten into plowshares while the world still persists, has occurred to Origen and he is clearly tempted by that vision; but it would seem that ultimately he has overcome that temptation.“; KINZIG, Novitas Christiana, 471 (Kursiv im Original), zu Cels. 8,68: Es wird „[...] hier erstmals prospektiv aus dem Aufstieg des Christentums auf die zukünftige staatliche Wohlfahrt geschlossen [...]. [...] Der Irrealis eines christlichen Reiches wird nun zum Potentialis.“ Vgl. auch CADoux, Christian Attitude, 143-147; BaINTON, Early Church, 206 (= Kirche und Krieg, 207-208).

185 CAmpenhausen, Kriegsdienst, 260. Vgl. KARPP, Stellung, 508, der zusammenfassend festhält: „Das ist aber nicht mehr eine konkrete Stellungnahme zu einem gegenwärtigen Problem, sondern eine eschatologische Hoffnung.“ Ähnlich GeERLINGs, vorkonstantinische Kirche, 13. Bereits Moffat, War, 666, war der Ansicht, Origenes „propounds a holy experiment, which had no relation tot he moral order or the actual situation of the empire. [...] But the plea of Celsus was as much beside the point as Origen's answer. Neither dealt with the realities.“ 
macht, Teil der providentiellen Rolle des Römischen Reiches war. Erst unter dieser Voraussetzung konnte das Christentum als eine Größe entstehen, die ethnische und politische Grenzen transzendiert und Menschen aus allen Völkern in ihren Reihen versammelt. Die Existenz eines einheitlichen und wehrhaften Reiches erlaubte es, so Origenes, dass die Christen als Volk Gottes der neuen Heilsordnung im Gegensatz zu dem Gottesvolk der alten Heilsordnung, Israel, auf jede Form von Staatlichkeit zur Aufrechterhaltung von Recht, Ordnung und Sicherheit verzichten können. ${ }^{186}$ Damit verbleibt dem Reich als einer nichtchristlichen Macht aber auch genau diese Aufgabe, Schutzmacht für die Ausbreitung des Evangeliums zu sein, bis zum Ende der Zeit. ${ }^{187}$ Anders wäre ein Leben der Kirche in ihrer ,unpolitischen', nichtstaatlichen Gestalt, wie sie nach Origenes kennzeichnend ist, nicht möglich. Alles Weitere ist letztlich eine eschatologische Hoffnung, aber keine Erwartung für das Leben in dieser Welt.

\section{Cels. 8, 73-74}

Origenes beginnt mit der Aufforderung des Celsus, die Christen „,sollten den Kaiser mit aller Kraft unterstützen, an seinen gerechten Anstrengungen teilnehmen, für ihn kämpfen und, wenn er dies fordert [oder: wenn es erforderlich ist; AG], mit ihm in den Krieg ziehen und mit ihm seine Soldaten kommandieren.“188

Hier muss zunächst ein kleineres, aber nicht unwichtiges Problem bei der Übersetzung geklärt werden: Der Ausdruck ôv ع́лcíyn - wie auch etwas später in 8,73 kồv દ̇ंદíyn - kann anstatt wie bei C. Barthold und anderen Interpreten persönlich, „wenn er [sc. der Kaiser; AG] dies fordert" ${ }^{\text {189 }}$, auch wie bei H. Lona unpersönlich im Sinne von „wenn es erforderlich ist“"190 übersetzt werden. In diesem Sinn übertrug bereits P.

186 Cels. 2,30; 7,26; siehe dazu auch unten, S. 300 f. Vgl. CASPARY, Politics, 129-134, hier v. a. 133: „The Pax Romana is thus a special feature of the interim period between the First and the Second Coming, vouchsafed to the world for the sake of the spread of the churches of Christ." Vgl. außerdem BAINTON, Early Church, 206 (= Kirche und Krieg, 207); Helgeland, Christians (ANRW), 747; Mazzucco, Origene, 82-83; und BRENNECKE, An fidelis (2007), 218, der treffend von „einer providentiellen Aufeinanderbezogenheit von Christentum und Imperium Romanum“ bei Origenes spricht; FüRsT, Origenes, 191. 187 Hier scheint Mazzucco, Origene, 83-84, zu weit zu gehen, wenn sie konstatiert, dass Origenes sich über die Rolle des Reiches nach der erreichten Einigung der Oikumene nicht völlig im Klaren sei, aber dennoch in utopischer Weise die völlige Abschaffung des Krieges anzustrebe.

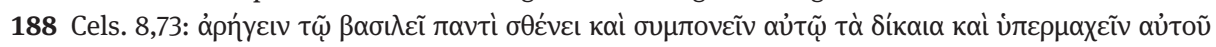

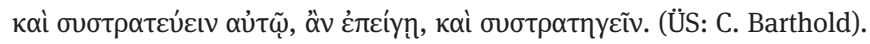

189 BARthold/Fiedrowicz, Contra Celsum Bd. 5, 1469 und 1471; in dieser Weise bereits BigELMAIR, Beteiligung, 171; HARNACK, Militia Christi, 31 und 72; CADoux, Christian Attitude, 135; CAmpenHAUSEN, Kriegsdienst, 259; Bainton, Early Church, 193 (= Kirche und Krieg, 192); Chadwick, Contra Celsum, 509; GeErlings, vorkonstantinische Kirche, 11; Mazzucco, Origene, 70. BoRret, Contre Celse 4, 345 und 349, übersetzt „s'il l'exige“.

190 LoNA, Kelsos, 474. 
Koetschau ${ }^{191}$ den Text und auch B. Schöpf ${ }^{192}$ erwägt dies als plausible Möglichkeit. Letzterer fasst die Bedeutung dieser Übersetzungsvarianten gut zusammen:

„Jedenfalls ist die Wiedergabe 'auch wenn ers verlangt' viel schärfer, als jene andere, die lediglich die Notwendigkeit selbst es verlangen lässt. Im ersten Falle handelt es sich um ausdrückliche Kriegsdienstverweigerung, im anderen nur um ein Abseitsstehen in der Stunde der Not.“"193

Sprachlich sind beide Varianten als gleichwertig zu beurteilen, da sowohl eine transitive als auch eine intransitive Übersetzung von ćrcíy $\omega$ möglich ist. ${ }^{194}$ Daher müssen die kontextuellen Bezüge entscheiden. Absolute Sicherheit ist dabei nicht zu erreichen. Nicht umsonst haben beide Varianten namhafte Vertreter auf ihrer Seite. Dennoch scheint es, dass aufgrund der vorhergehenden Diskussion um die Sicherheit des Reiches angesichts äußerer Bedrohungen sowie die durch diese verursachte Notlage eine intransitive und damit unpersönliche Übersetzung etwas wahrscheinlicher ist. Es ist also wohl nicht der Kaiser, der laut Celsus die Christen explizit aufruft, ins Heer einzutreten, sondern es ist die personifizierte Notlage, in der sich das Reich befindet, welche die Christen zum Militärdienst drängt. ${ }^{195}$

Aus der Aussage des Celsus in Cels. 8,73 wurde wiederholt geschlossen, dass Celsus zu seiner Zeit keine oder zumindest fast keine Christen im Heer kennt. Er sei

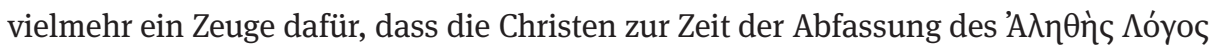
- zumindest weitgehend - dem Heer fernblieben, und das sogar trotz, je nach Übersetzung, dem Aufruf des Kaisers beziehungsweise der drängenden Notlage des Reiches. Exemplarisch sei hier auf eine Bemerkung von R. Bainton hingewiesen:

„Such words are so explicit as to warrant the assumption that Celsus knew of no Christians who would accept military service. [...] Celsus said quite distinctly that there were no Christians who would serve, but as a matter of fact he was mistaken.“196

191 Des Origenes Acht Bücher gegen Celsus, aus dem Griech. übers. von P. KoєtschaU, Buch V-VIII, (BKV 1. Reihe, Bd. 53), München 1927, 391 und 393 „wenn die Not es fordert“ bzw. „sobald die Not es fordert".

192 ScHöPF, Tötungsrecht, 222-223.

193 SснӧPF, Tötungsrecht, 223.

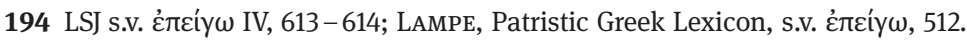

195 Damit verliert auch die Bemerkung von HaRnaCK, Militia Christi, 72, ihr Gewicht „,Wir ziehen nicht ins Feld, auch wenn es der Kaiser verlangt'. So durfte man unter Philippus Arabs sprechen; selbst ein Tertullian hat eine solche Sprache noch nicht gewagt.“

196 Bainton, Early Church, 191-192 (= Kirche und Krieg, 190).Vgl. auch ebd., 193 (= Kirche und Krieg 192): „The section most disinclined to military service appears to have been the Hellenistic East. Such may be inferred in a general way from the testimony of Celsus, whose provenance we do not know but who wrote in Greek.“ Ähnlich urteilte bereits HARNACK, Militia Christi, 54-56, der aber ebenfalls die Spannung notiert, in der die Aussagen des Celsus zu anderen Belegen aus dieser Zeit stehen (ebd., 54, 56-57); so auch KARPP, Stellung, 500 - 501, der sie aber mit einem Hinweis auf zeitliche und regionale Unterschiede in der Haltung zum Heeresdienst erklärt, im hellenistischen Osten lehne die Kirche diesen - so stellt er im Anschluss an R. Bainton fest - ab; außerdem CADoux, Christian Attitude, 139. HoRnus, Politische Entscheidung, 154, hält ebenfalls dezidiert fest: „Demnach hat gegen Ende des 
Interessanterweise erkennt aber gerade auch schon R. Bainton, dass Celsus - wenn man ihn so verstünde - geirrt haben muss. ${ }^{197}$ Denn zu seiner Zeit - R. Bainton datiert

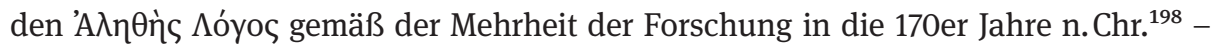
habe es auf jeden Fall schon eine größere Anzahl von Christen im römischen Heer gegeben. Auch wenn man, wie in dieser Arbeit der Fall ${ }^{199}$, die Datierung der Streitschrift des Celsus weniger präzise ansetzt, ist dieser Beobachtung zuzustimmen. In der zweiten Hälfte des 2. Jhds. n. Chr. muss es bereits Christen im römischen Heer gegeben haben. Nicht zuletzt ist es Celsus selbst, der die christlichen Propheten und Missionare mit fragwürdigen Pseudo-Propheten im syrischen Raum vergleicht, die unter anderem „in Städten und Heerlagern“200 herumziehen. Je mehr diese Parodie des Celsus der Realität christlicher Mission angenähert ist, desto wahrscheinlicher ist es, dass er darum wusste, dass auch die Christen selbst die Heerlager aufsuchten, um dort für ihren Glauben zu werben.

Es scheint stattdessen ratsam, eine andere Erklärung für die Aussage des Celsus zu suchen. Hier bietet sich ein zweifacher, sich ergänzender Erklärungsansatz an, der sich vor allem auf Beobachtungen von J. Hargis und H. Brennecke stützt:

Zum einen hat J. Hargis ${ }^{201}$ völlig zu Recht darauf hingewiesen, dass man Celsus keinesfalls als objektiven Beobachter des Christentums lesen darf. Er verfasste eine Polemik, einen „totalizing discourse“202, für den es darauf ankam, die neue Religion in jeglicher Hinsicht vollständig auszugrenzen. Es verhalte sich vielmehr wie folgt:

„[...] Celsus’ characterization of Christians as radically isolated and anti-social sounds one-sided at least. His presentation is mildly anachronistic, perhaps several decades too late to be fully

2. Jahrhunderts ein Heide, der das Christentum einer unerbittlichen Bestandsaufnahme unterzog, nur Christen wahrgenommen, die den Militärdienst ablehnten.“ Ein Bewusstsein, für die Probleme, die sich daraus angesichts des weiteren Befundes ergeben, zeigt er nicht, obwohl er zumindest die Arbeiten von R. Bainton und A.von Harnack an anderer Stelle intensiv verarbeitet. Wie es scheint ist auch Campenhausen, Kriegsdienst, 257-258, dieser Ansicht, meint er doch (ebd., 257), dass es bis ca. 175 n.Chr. keine christlichen Soldaten gegeben habe. SснӧPF, Tötungsrecht, 233, ist dagegen der Meinung, dass zwar die Christen, die dem Celsus bekannt waren, den Heeresdienst abgelehent hätten, dass das aber nicht beweise, „daß alle Jünger Christi in der Frage denselben Standpunkt eingenommen haben“ (ebd., 233). Helgeland, Christians (ANRW), 750, ist lediglich der Ansicht, Celsus müsse mit „some Christians“ Kontakt gehabt haben, die den Heeresdienst verweigerten, ohne das näher zu erläutern. Bereits MofFAT, War, 664, war zu einer ähnlich behutsamen Einschätzung gekommen. Neuerdings hält SIDER, Killing, 67, fest, dass aus anderen Quellen ,at least a few Christian in the Roman army in the last couple of decades of the second century“ bekannt seien. „But Celsus clearly thinks that the normal Christian practice ist to reject military service." Siehe auch ebd. 176, 186 und v.a. 189.

197 Auch z. B. HARnaCK, Militia Christi, 54-56; KARPP, Stellung, 500-501; Sider, Killing, 189, notieren diese Spannung.

198 Bainton, Early Church, 191 (= Kirche und Krieg, 190).

199 Siehe oben S. $267 \mathrm{f}$.

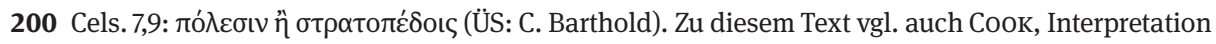
NT, 77-79.

201 Hargis, Christians, 27-30 und 59-61.

202 HARgIS, Christians, 60. 
accurate, yet containing just enough truth to avoid sounding completely implausible. In short, considering the situation of the church at the time, Celsus' objection to Christian social exclusivism has the ring of propaganda to it. [...] His characterization of his opponents as a small isolationist sect was in large part a reaction against the growth of the church and its social integration, and as such was a propagandistic half-truth; not only would such a description be false by the time Origen replied to the critique several decades later, it was not wholly true in Celsus' own day. Since the critic feared the potential for harm that Christianity represented to Roman society, he was concerned to preserve that society from the religion's influence. Seeing the cultural threat, Celsus' task was to put the genie back into the bottle.“203

Was J. Hargis allgemein für den Topos des gesellschaftlichen Isolationismus behauptet, mag im Speziellen auch für die Frage der Übernahme von Posten im Heer und in den Städten gelten. Als ,Propaganda' gelesen dürfte sie eine einseitige, bestenfalls teilweise wahre und hochpolemisch verzerrte Beschreibung der Sachverhalte darstellen, nicht völlig ohne Anhalt in der Wirklichkeit, aber sicherlich auch nicht in toto zutreffend und keinesfalls akkurat.

Hat man zum anderen noch im Blick, dass seine Schrift sich an ein wohlhabendes und gebildetes Publikum richtet, so eröffnet sich im Anschluss an H. Brennecke ${ }^{204}$ folgende Perspektive: Auch die Aufforderung des Celsus an Christen, im Heer des Kaisers zu dienen und - in Cels. 8,75 - Ämter in den Städten ${ }^{205}$ zu übernehmen, richtet sich an seine Leserschaft in den gehobenen Kreisen. Nicht umsonst ruft er nicht nur

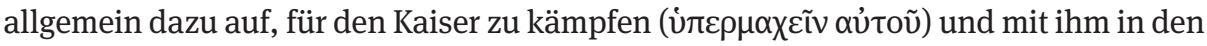

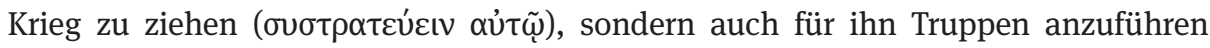

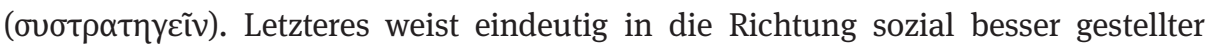
Kreise; zu denken ist in diesem Zusammenhang vor allem an christliche ordo-Angehörige. ${ }^{206}$ Hier kann tatsächlich an zumindest diesen einen Aspekt der Thesen von Th. Klauser angeknüpft werden. ${ }^{207}$ Es mag sein, dass sich diese sozial besser gestellten

203 HARGIS, Christians, 28 und 30.

204 BRENNECKE, An fidelis (2007), 195-197.

205 Im Anschluss an EcK, Christen, 454; und WEISs, Soziale Elite, 181 mit Anm. 31, ist $\pi \alpha \tau$ í́ Stelle besser als „Heimatstadt“ im Sinne von Polis denn als „Heimatland“ im Sinne des Römischen Reiches zu übersetzen. Als „Heimatland“ übersetzen z. B. Borret, Contre Celse 4, 351 („de la patrie“); Chadwick, Contra Celsum, 509; Barthold/Fiedrowicz, Contra Celsum Bd. 5, 1471 und 1471. Für „Heimatstadt“ spricht, dass doch v. a. die Übernahme von Ämtern auf Polisebene im Blick ist. Deutlich

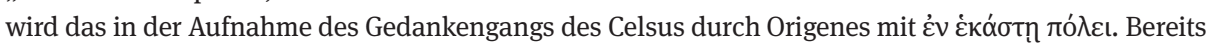
KoEtschau, Celsus V-VIII, (BKV), 393, übersetzte in Cels. 8,75 „Vaterstadt“, in 8,74 (ebd.) dagegen „Vaterland“.

206 Zum Vorhandensein christlicher ordo-Angehöriger im 2. Jhd. n.Chr. vgl. neben den Anmerkungen oben S. 4 ff. und S. 72, Anm. 181 die ausführliche Studie von WEISS, Soziale Elite, hier v. a. 168-216. 207 KLAUSER, Oberschicht. Vgl. dazu die kurzen Ausführungen oben S. 272, Anm. 92 und im Kapitel zu Tertullian S. 72, Anm. 181. Den Anknüpfungspunkt an Th. Klauser hat auch BRENNECKE, An fidelis (2007), 196, richtig gesehen. Auf die im Grundsatz berechtigte Kritik an den insgesamt viel zu weit gehenden Klauser'schen Thesen von Eck, Christen, wurde an den angegebenen Stellen bereits hingewiesen. Für seine Einschätzung von Cels. 8,73 und der damit verbundenen Soldatenfrage verlässt 
Christen tatsächlich öfter als unter ihren Standesgenossen üblich nicht im Heeresdienst oder in den städtischen ${ }^{208}$ Ämtern engagierten. Hat man diese begrenzte Zielsetzung der Argumentation des Celsus sowie ihre polemisch übertreibende Zuspitzung erkannt, dann verflüchtigt sich auch der festgestellte Widerspruch zur weiteren Beleglage aus dieser Zeit und man kann H. Brennecke zustimmen, der schreibt:

„Aus den zur politischen und militärischen Mitarbeit der Christen auffordernden Worten des Kelsos wird man jedenfalls auf keine grundsätzliche und absolute bisherige Verweigerung von Militär- und Staatsdienst durch die Christen schließen und somit keinen fundamentalen Widerspruch zum Zeugnis der übrigen Überlieferung annehmen können.“209

Die Antwort des Origenes auf diese Aufforderung zur Übernahme gesellschaftlicher Pflichten in Heer und Verwaltung gehört zu den meistdiskutierten Texten im Zusammenhang der Frage von Christentum und Soldatenstand. In ihr vertritt der große Alexandriner eine, wie H. Brennecke festhält, „völlig singuläre Position“210 . Origenes betont, dass die Christen den Kaiser in seinen Bemühungen um den Schutz des Reiches tatsächlich „,unterstützen“ [...] zur rechten Zeit“, und zwar mit „göttlicher Hilfe“, indem sie die „Waffenrüstung Gottes“211 anlegen. Als Begründung führt er die Aufforderung zum Gebet für die Obrigkeit aus 1. Tim 2,1-2 an. Bei entsprechender Frömmigkeit, so macht er deutlich, übertreffe diese Unterstützung des Kaisers im Gebet sogar „die Soldaten, die zur Schlacht ausziehen und so viele von den Feinden

sich W. Eck allerdings, wie auch BRENNECKE, An fidelis (2007), 196, Anm. 80, richtig feststellt, zu sehr auf die Studie von J.-M. Hornus.

208 Vgl. WeIss, Soziale Elite, 181-184. Siehe auch die Diskussion der entsprechenden Stellen bei Tertullian oben, S. $72 \mathrm{ff}$., S. $136 \mathrm{ff}$. und S. $149 \mathrm{ff}$. Es wurde gerade eben bereits darauf hingewiesen, dass Celsus bei der Darstellung der sozialen Isolation der Christen ein polemisch verzerrtes Bild bietet. Hier mag er ebenfalls übertreiben, wenn er auch sicherlich nicht völlig haltlose Unterstellungen fabriziert. Wie HARgIs, Christians, 29, zu Recht festhält: „Celsus' rhetoric of Christian separatism was still partially true; after all, half-truths make the best propaganda.“

209 BRENNECKe, An fidelis (2007), 196. Auch SHEAN, Soldiering, 230-231, ist vorsichtig genug, aus den Worten des Celsus keine kategorische Verweigerung aller Christen herauszulesen, wählt aber eine andere Erklärung: „Celsus seemed to assume that withdrawal from public life, and even pacifism, were typical Christian behaviors. This characterization was probably given greater validity by the fact that there were rigorist Christian sects who disdained the pagan world they were forced to live in and repudiated warfare and military service as incompatible with Christian belief." Die Möglichkeit besteht, dass völlig weltabgewandte, rigoristische Gruppen Celsus in seiner Sicht der Dinge bestätigten. Allerdings erklärt das nicht, warum er - laut J. Shean - scheinbar von überhaupt keinen Christen im Heer weiß. Anders jüngst wieder SIDER, Killing, 186 und 189.

210 BRENNECKE, An fidelis (2007), 217.

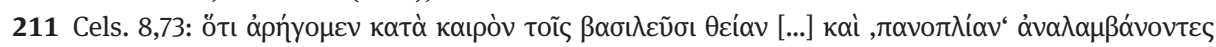

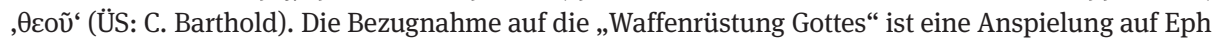
6,11-17, wie sie sich auch bei Tertullian in coron. 1,4 (s. oben S. 112, Anm. 390) und bei Clemens in prot. 11,116,3-4 (s. oben S. 231, Anm. 210 mit dem Wortlaut der Stelle) findet. 
vernichten, wie sie vermögen.“212 In einem zweiten Argumentationsgang setzt er noch einmal neu an, um die Freistellung der Christen vom Kriegsdienst zu begründen.

Dabei wendet er sich dann auch dem Problem des Tötens von Menschen zu. Er macht darauf aufmerksam, dass man gegenüber denjenigen „Gegnern des Glaubens“, die verlangten, dass Christen „für das Gemeinwohl als Soldaten kämpfen und Menschen töten sollen“213, auf das Vorbild bestimmter heidnischer Priester hinweisen könne. Diese würden, um Opfer darbringen zu können, ihre rechte Hand unblutig und rein von Mord bewahren und müssten auch im Krieg nicht als Kämpfer ins Feld ziehen

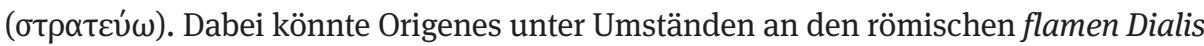
denken, den höchsten Priester des Iuppiter, der von einer Reihe von Tabus umgeben war. So durfte er unter anderem kein Pferd besteigen und ein bewaffnetes Heer nicht einmal ansehen. ${ }^{214}$ Auch der rex sacrorum unterlag gewissen Tabus. So durfte er bis in die Kaiserzeit hinein keine Magistratur ausüben. ${ }^{215}$ Es ist außerdem wahrscheinlich, dass auch anderen Priestern wie den flamines und den pontifices zumindest in früheren Zeiten ähnliche Beschränkungen auferlegt waren, die allerdings nach und nach abgebaut wurden. ${ }^{216}$

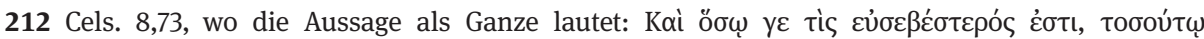

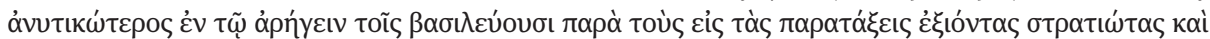

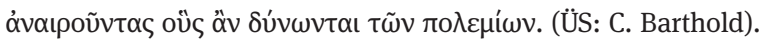

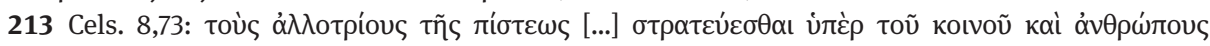

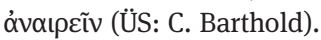

214 Der wichtigste Beleg findet sich bei Gell.10,15,1-25, hier v. a.15,4.Vgl. zum flamen dialis WissowA, Georg, Religion und Kultus der Römer, (HdAW 5.4), München 1902, 410-411, 434-436; PöTsCHER, Walter, Flamen Dialis. In: Mnemosyne 21 (1968), 215-239, hier v. a. 217-226; LATTE, Kurt, Römische Religionsgeschichte, (HdAW 5.4), 2., unveränd. Nachdr. d. 1967 ersch. 2., unveränd. Aufl., München 1992, 202-203 und 402, der meint (ebd., 402), diese Tabus erwiesen den flamen Dialis als „Träger einer magischen Kraft"; VANGAARD, Jens H., The Flamen - A Study in the History and Sociology Roman Religion, Kopenhagen 1988, v.a. 59-69; Prescendi, Francesca, s.v. Flamines. In: DNP 4, (1998), 537-539; Beard, Mary; NoRTh, John; Price, Simon, Religions of Rome, Vol. 1: A History, Cambridge 1998, 28-29 und 106-108; BEARd, Mary; NorTh, John; PricE, Simon, Religions of Rome, Vol. 2: A Sourcebook, Cambridge 1998, 196-197; RÜPKE, Jörg, Die Religion der Römer - Eine Einführung, 2., überarb. Aufl., München 2006, 212-213; LinkE, Bernhard, Antike Religion, (EGRA 13), München 2014, 45-46, 48, 141-142 (Literatur).

215 Siehe Liv. 40,42,8; für die trajanische Zeit ist Cn. Pinarius Severus als Konsul, Augur und Rex sacrorum belegt (CIL XIV 3604).

216 Zum rex sacrorum sowie zur Frage nach ähnlichen Verboten für andere Priester vgl. WissowA, Religion, 410 - 411 und 434-436; LATTE, Religionsgeschichte, 402; VANGAARD, Flamen, v. a. 59-69; BENDLIN, Andreas, s.v. Rex sacrorum. In: DNP 10, (2001), 937-939; und v. a. die Diskussion bei BEARD ET AL., Religions 1 (History), 28-29 und 106-108; LINKE, Bernhard, Antike Religion, (EGRA 13), München 2014, 45-48 und 138-139 und 142-143 (Literatur). CHADwick, Contra Celsum, 509, Anm. 4, verweist auf eine Episode aus der römischen Frühzeit, wie sie bei Plutarch (Camil. 41) erzählt wird. Dort heißt es, im Zusammenhang mit der Plünderung Roms durch die Gallier hätten die Römer ein Gesetz erlassen, welches die Priester vom Kriegsdienst freistellte, mit Ausnahme eines Gallierkrieges (

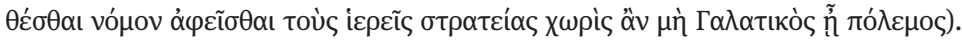


An welche Priester genau Origenes im Einzelnen auch immer denken mag, das Ziel dieser Bezugnahme ist eindeutig: Auch die Christen oder besser gerade die Christen sind „Priester und Diener Gottes“217 und nehmen als solche in einer den heidnischen Priestern vergleichbaren Rolle „an der Schlacht teil“218. Diese Teilnahme geschieht,

„indem sie ihre Hände zwar rein bewahren, aber mit ihren an Gott gerichteten Gebeten für die Verteidiger der gerechten Sache und für den rechtmäßigen Herrscher kämpfen, damit alles vernichtet werde, was sich den Vertretern der gerechten Sache feindlich entgegenstellt.“‘219

Darüber hinaus würden sie durch ihr Eintreten bei Gott auch noch die Dämonen

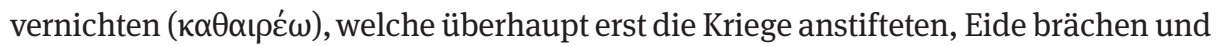
den Frieden störten. Auf diese Weise würden sie „den Herrschern mehr helfen als jene, die dem äußeren Anschein nach kämpfen." ${ }^{220}$ Aus all dem folgert Origenes mit Nachdruck:

„Wir nehmen aber Anteil an den Anstrengungen für das Gemeinwohl, indem wir unsere Gebete in Gerechtigkeit darbringen, zusammen mit Übungen und Betrachtungen, die uns lehren, die sinnlichen Vergnügungen zu verachten und uns von ihnen nicht antreiben zu lassen.“221

Auf dieser Schlussfolgerung liegt, wie noch zu zeigen sein wird, das ganze Gewicht der Ausführungen des Origenes. 1.) Christen nehmen sehr wohl Anteil am Gemeinwohl'22

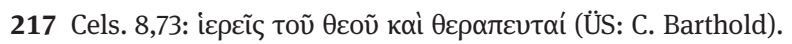

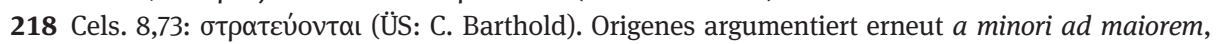
wenn es schon „vernünftig ist“, dass heidnischen Priestern diese Ausnahmestellung gewährt wird,

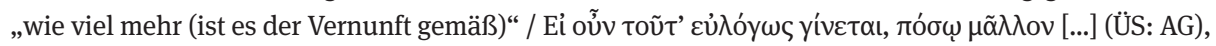
wenn den Christen als Priestern Gottes solches gestattet wird.

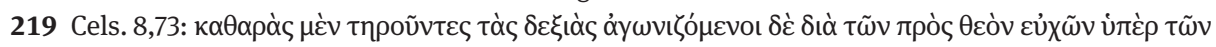

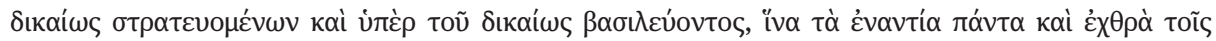

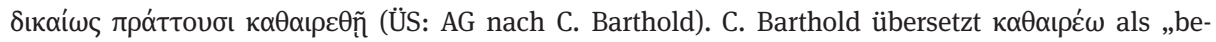
zwingen“ (BARTHOLD/FIEDRowicz, Contra Celsum Bd. 5, 1471), woran sprachlich nichts auszusetzen ist. Angesichts der kontextuellen Bezüge in Cels. 8,73 mit dem mehrmaligen vorkommen von óvaıpé $\omega$, was auch C. Barthold mit „vernichten“ bzw. „töten“ übersetzt (BARTHOLD/FIEDRowicz, Contra Celsum Bd. 5, 1469), und der beim ersteren Vorkommen dazu gehörigen Diskussion um die effektive Ver-

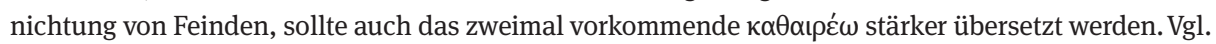

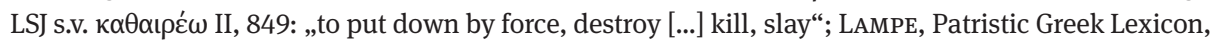

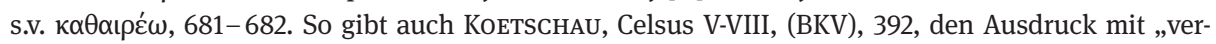
nichten“ wider und CHADwick, Contra Celsum, 509, mit „to destroy“. Siehe auch die Verwendung von ávaıpé $\omega$ in einem ähnlichen Kontext in Cels. 7,26.

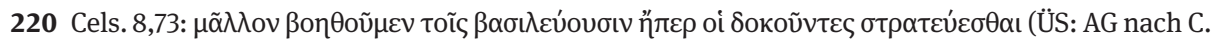
Barthold). Auch hier ist $\kappa \alpha \theta \alpha\llcorner\varepsilon ́ \omega$ wieder im Sinn von „vernichten“ oder „niedermachen“ zu übersetzen.

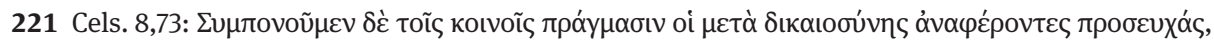

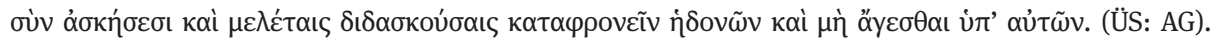
222 Sehr gut arbeitet das GeERLINGS, vorkonstantinische Kirche, 12-13, heraus, wenn auch unter Voraussetzung eines anderen Verständnises des Textes. 
und zwar 2.) gerade dann am effektivsten, wenn sie ihrem eigenen Nomos gemäß leben. Um diesem Gewicht Ausdruck zu verleihen fügt er daher noch zweimal hinzu, dass die Christen tatsächlich für den Kaiser kämpfen und sogar Soldaten kommandieren würden. ${ }^{223}$ Beide Male macht er aber noch einmal explizit deutlich, dass dies auf eine andere Weise geschehe, als von Celsus gefordert, nämlich durch priesterliche „Fürbitten“ und „Gebete“224.

Wie ist nun diese Antwort des Origenes zu verstehen? Zunächst ist festzuhalten, dass Origenes hier, anders als im zuvor behandelten Abschnitt, keine hypothetische Antwort mehr gibt. Was er hier zu sagen hat, ist ernst gemeint und vor dem Hintergrund der konkreten Realitäten des Reiches sowie der ebenso konkreten Aufforderung des Celsus gesprochen. Es geht ihm also darum, eine Antwort zu bieten, die tatsächlich praktikabel ist. Zum anderen kann festgestellt werden, dass er wie auch zuvor die Notwendigkeit der Existenz eines Heeres im Allgemeinen wie auch der Verteidigung des Reiches gegen äußere Feinde im Besonderen anerkennt. Damit ist auch die Legitimität eines gerechten Krieges beziehungsweise eines Verteidigungskrieges grundsätzlich gegeben. Beide Punkte sind in der Forschung weitestgehend unumstritten. ${ }^{225}$ Treffend hat das H. Karpp formuliert, wenn er schreibt, dass Origenes

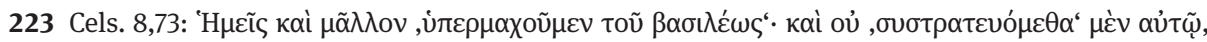

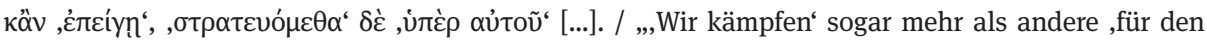
Kaiser'; und wenn wir auch nicht ,mit ihm in den Krieg ziehen', selbst ,wenn er dies fordert' [bzw. ,wenn

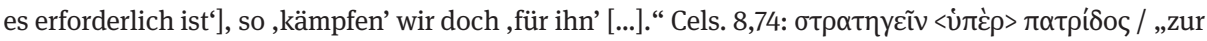
Verteidigung der Heimat auch ,Soldaten kommandieren““ (ÜS: AG nach C. Barthold). Zur Übersetzung

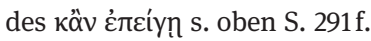

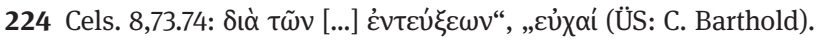

225 Vgl. Harnack, Militia Christi, 70; Cadoux, Christian Attitude, 137-139; CAmpenhausen, Kriegsdienst, 258-259, meint sogar (ebd., 259), dass in Contra Celsum, nämlich in der gleich zu besprechenden Stelle Cels. 4,82, „die ausdrückliche, verantwortliche Anerkennung des Kriegsrechts seitens der Kirche beginnt“; KARPP, Stellung, 507; SchöPF, Tötungsrecht, 222-223; CASPARY, Politics, 128-129; Trigg, Bible and Philosophy, 236; Helgeland, Christians (ANRW), 749; SwIFT, War (ANRW), 854; GEERLINGS, vorkonstantinische Kirche, 12-13; BRENNECKE, An fidelis (2007), 218. Dagegen ausdrücklich MAzzucco, Origene, hier v.a. 69-72: Origenes scheine zwar den priesterlichen Kriegsdienst der Christen auf den ersten Blick mit dem Kriegsdienst der Soldaten auf dieselbe Ebene zu stellen. Bei näherer Betrachtung werde allerdings deutlich, dass der Dienst der Soldaten lediglich ein scheinbarer Kriegsdienst, ein scheinbarer Kampf sei. Nur der priesterliche Dienst der Christen sei ein wirklicher Kriegsdienst und nur auf ihn beziehe sich die Qualifikation als „gerecht“, nicht aber auf den der Soldaten. Anders HunTER, Church, 174-175, der bei Origenes eine nicht aufzulösende Spannung zwischen zwei Positionen entdeckt, die dieser gleichzeitig vertrete: Zum einen die Weigerung, Christen direkt an Kampfhandlungen teilnehmen zu lassen und Blut zu vergießen, zum anderen die Akzeptanz gerechter Kriege, geführt durch gerechte Kaiser, an denen die Christen in geistlicher Weise durch ihre Gebete teilnehmen. Als Folge davon hinterlasse Origenes „an ambiguous legacy. The pacifist tradition is stated with a precision and clarity unmatched in earlier writers. But, at the same time, some of Origen's statements point in the direction of what will later become the Christian just war theory.“ 
„nicht daran denkt, vom Kaiser die Beendigung des Kriegführens zu verlangen, die er von Gott erhofft, sondern daß er eine Ausnahmestellung für die Christen als priesterliche Minderheit beansprucht." ${ }^{\text {"226 }}$

Beide Punkte, die Rechtmäßigkeit der Existenz eines Heeres und die Legitimität eines Krieges, lassen sich außerdem durch weitere Texte aus Contra Celsum untermauern.

\section{Exkurs: Weitere Texte aus Contra Celsum}

1. In der für diesen Zusammenhang wichtigen Stelle Cels. $4,82^{227}$ schreibt Origenes, im Rahmen der Diskussion der „biblischen Anthropozentrik“228 und der Frage der göttlichen Vorsehung ${ }^{229}$, von den Kriegen der Bienen und Ameisen.

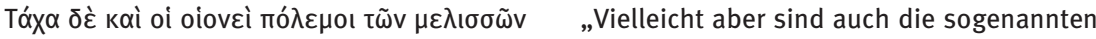

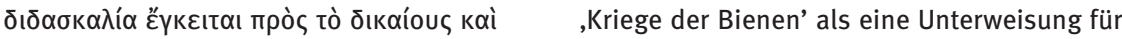

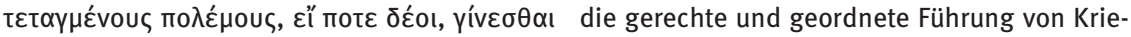

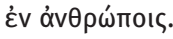
gen bei den Menschen gegeben - wenn solche einmal notwendig sein sollten.“

(ÜS: C. Barthold)

Celsus hatte das bereits klassische Beispiel ${ }^{230}$ der Bienen und Ameisen eingebracht, um die Überlegenheit der menschlichen Kultur über die tierische Schöpfung zu erweisen, da jene Städte bauen, eine Verfassung, Ämter und Regierungen hätten und Kriege führten. ${ }^{231} \mathrm{Im}$ Bemühen, diese Argumentation des Celsus zu widerlegen, führt Origenes unter anderem auch das hier zitierte Beispiel von der Vorbildlichkeit der Kriege der Bienen als Beispiele für „gerechte und geordnete“ Kriege unter Menschen an. B. Schöpf hat die Bedeutung dieses Textes treffend charakterisiert: „Aber, worauf es hier ankommt, ist das: Nach der zitierten Stelle müßte man sagen: Origenes rechnet mit der Möglichkeit gerechter Kriege unter den Menschen.“232

226 KARPP, Stellung, 507.

$227 \mathrm{Zu}$ Cels. 4,82 vgl. HaRnack, Militia Christi, 70, der meint, Origenes habe in diesem Text „einen Ansatz gemacht, notwendige und gerecht geführte Kriege von frivolen und schlimmen zu unterscheiden“; außerdem Cadoux, Christian Attitude, 137 und 207; Campenhausen, Kriegsdienst, 258-259; KaRpP, Stellung, 507; SchöPF, Tötungsrecht, 222; Helgeland, Christians (ANRW), 749; Swift, War (ANRW), 854, Anm. 81; MAZzucco, Origene, 74; BRENnECKe, An fidelis (2007), 218.

228 LonA, Kelsos, 261.

229 Cels. 4,71-5,2; vgl. dazu LonA, Kelsos, 260 -279; BARTHold/Fiedrowicz, Contra Celsum Bd. 1, 68-70. Beide zeigen sehr gut auf, wie sehr Celsus und Origenes sich immer wieder auf die bereits klassische Diskussion zwischen der anthropozentrisch orientierten Stoa und dem auf das Ganze hin ausgerichteten Platonismus über diese Fragen beziehen. Celsus vertritt hier die platonische Position, Origenes die stoische.

230 Vgl. LonA, Kelsos, 268, Anm. 349-357; und Origenes, Contra Celsum - Gegen Celsus, griech./dt., dritter Teilband, eingel. und komm. von Michael FiEdrowicz, übers. von Claudia BARTHOLD, (Fontes Christiani 50,3), Freiburg i. Br. u.a. 2011, 828, Anm. 174, jeweils mit Belegen.

231 Cels. 4,81; vgl. LonA, Kelsos, 268-269.

232 Sснӧрғ, Tötungsrecht, 222. Anders dagegen MAzzucco, Origene, 74, die in 4,82-83 keine Akzeptanz gerechter Kriege erkennt. Vielmehr mache sich Origenes um der Argumentation willen die Sichtweise seines Gegners zu Eigen und schlage diesen mit seinen eigenen Waffen. Er zeige damit auf, dass Celsus beim Versuch die Christen zu widerlegen, Werte, die alle Menschen teilen und die ihm 
2. In Cels. $4,83^{233}$ beklagt er sich dann darüber, dass die Argumentation des Celsus dazu beiträgt, „bei allen Menschen überhaupt die ,Städte, Verfassungen, Ämter, Regierungen` und die für das Heimatland geführten ,Kriege“ abzuwerten“234. Diese Klage über die Abwertung von für die Heimat geführten Kriegen bestätigt das Verständnis seiner Aussage über die gerechten und geordneten Kriege, impliziert sie doch, dass diese Kriege u்mદ̀ zu sehen sind. ${ }^{235}$ Auch wenn diese Bemerkungen in einem eindeutig polemischen Kontext stehen und vor allem dazu dienen, den Argumentationsgang des Celsus zu entkräften, zeigen sie in ihrer Beiläufigkeit doch etwas von der grundlegenden Haltung des Alexandriners zu diesen Fragen. ${ }^{236}$ Origenes war ein viel zu präziser Denker, um an einer solchen Stelle aus Flüchtigkeit eine Position einzunehmen, die ihn im weiteren Verlauf seiner Schrift in schwerwiegende Widersprüche verwickeln würde.

3. Bereits in Cels. $2,30^{237}$ scheint er außerdem vorauszusetzen, dass Kriege zwischen verschiedenen Staaten und Völkern unter gewissen Umständen eine Notwendigkeit darstellen, die erst durch die Vereinigung all dieser politischen Einheiten unter der Herrschaft Roms zu einem Ende gekommen ist. Auch hier wird in einer eher beiläufigen Bemerkung Krieg als - unter gewissen Umständen - nötig und daher wohl auch als gerechtfertigt angesehen, wenn auch die Überwindung dieser Notwendigkeit sicherlich in seinen Augen eine Verbesserung der Lage darstellt.

4. In Cels. 7,26 $6^{238}$ schließlich bietet Origenes eine instruktive Abhandlung zur Frage der Kriege der Israeliten im Alten Testament und ihrem Verständnis im Licht der mit Jesus begonnenen neuen Heilsordnung. Das Kapitel gehört in einen größeren Zusammenhang, in dem Origenes die Kritik

selbst am Herzen liegen, aufs Spiel setzt. Zu diesem Zweck nehme Origenes dessen Beispiel auf, spinne den Gedankengang weiter und unterscheide dabei - anders als in 8,73-74 - nicht zwischen der christlichen Sichtweise und derjenigen aller Menschen.

233 Vgl. ScHöPF, Tötungsrecht, 222; außerdem Cadoux, Christian Attitude, 207; MAZzucco, Origene, 74.

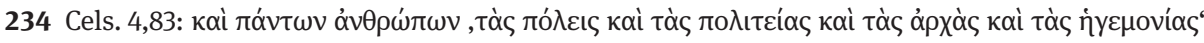

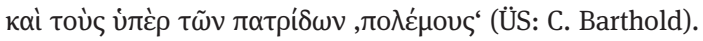

235 Ob Origenes, wie ScHöPF, Tötungsrecht, 222, meint, sogar seine „Glorifizierung“ zu beabsichtigen scheint, ist eher zweifelhaft.

236 Gegen Mazzucco, Origene, 74.

237 „Für die Ausbreitung der Lehre Jesu in alle Welt wäre die Existenz vieler Königreiche ein Hindernis gewesen, nicht nur aus den zuvor genannten (Gründen), sondern auch weil (Menschen) überall gezwungen gewesen wären Krieg zu führen und für die Heimat zu kämpfen. Das war vor der Zeit des Augustus und auch noch früher der Fall, als es zu einem Krieg wie beispielsweise dem der Peloponnesier und der Athener und auch anderer (Völker) untereinander kommen musste." / ${ }^{~} \mathrm{Hv} \delta$ ' àv

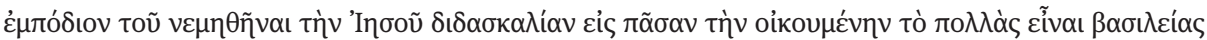

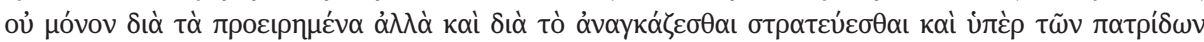

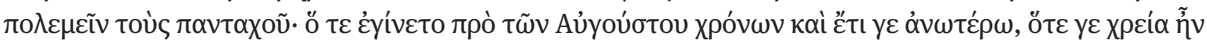

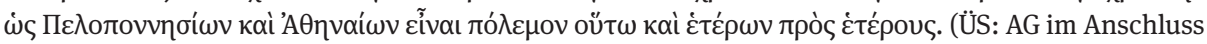
an C. Barthold). Vgl. zu diesem Text Harnack, Militia Christi, 70 und 82-84; Cadoux, Christian Attitude, 137 und 207; SchöPF, Tötungsrecht, 221-222; CASPARY, Politics, 131-132; HelgELAND, Christians (ANRW), 747; SWIFT, War (ANRW), 854, Anm. 81; MAZZUCCo, Origene, 74; BRENNECKE, An fidelis (2007), 218. ReEmTs, Vernunftgemäßer Glaube, 86 und 165-182, hier v. a. 177, stellt den Text in den größeren Zusammenhang der Widerlegung celsischer Einwände gegen die Behauptung, dass in Jesus der Gottessohn selbst gekommen sei.

$238 \mathrm{Zu}$ diesem Text im vorliegenden Zusammenhang vgl. HARnaCK, Militia Christi, 70 - 71; CAdoux, Christian Attitude, 137; BAINTON, Early Church, 212 (= Kirche und Krieg, 215-216); KARPP, Stellung, 507; ScHöPF, Tötungsrecht, 222; HELGELAND, Christians (ANRW), 748-749 und 751; SWIFT, War (ANRW), 
des Celsus an der scheinbaren Widersprüchlichkeit von Altem Testament und Neuem Testament, von Mose und Jesus zurückzuweisen versucht. ${ }^{239}$ Dieser Abschnitt wiederum steht im Zusammenhang mit dem Versuch des Celsus, die christliche Begründung des Hoheitsanspruchs Jesu als Gottessohn auszuhebeln ${ }^{240}$, die sich dazu unter anderem auf die Vorhersagen und Verheißungen alttestamentlicher Texte beruft ${ }^{241}$. Angesichts der Tatsache, dass Celsus hier einen neuralgischen Punkt christlicher Theologie attackiert, wundert es nicht, dass Origenes sich an eine ausführliche und scharfe Erwiderung macht. ${ }^{242}$ Da Celsus selbst großes Gewicht auf den Unterschied zwischen der alttestamentlichen lex talionis, Auge um Auge, Zahn um Zahn ${ }^{243}$, und ähnlichen Gedanken einerseits und dem neutestamentliche Gebot des „die andere Wange Hinhaltens“244 sowie vergleichbarer Inhalte andererseits legt ${ }^{245}$, widmet Origenes am Ende seiner Überlegungen dem

854; MAZzUCCo, Origene, 81-84. Vorbereitet werden die hier vorgetragenen Gedanken u. a. bereits in Cels. 3,7-8.

239 Cels. 7,18-26. Zur Kritik des Celsus in Cels. 7,18 vgl. LonA, Kelsos, 397-399, der diese in drei Punkten zusammenfasst: „1. Zieht man nur die Boten in Betracht, dann hat einer von ihnen die ihm aufgetragene Botschaft verfälscht, aber wer: Mose oder Jesus? 2. Überträgt man das Problem auf Gott, der beide gesandt hat, könnte man mit der Vergesslichkeit Gottes rechnen, der bei der Sendung des Sohnes schon vergessen hatte, was er dem Mose angeordnet hatte. 3. Eine weitere Erklärung auf der gleichen Basis wäre die Annahme, Gott habe seine eigenen Gesetze verworfen [...] und darum sendet er seinen Sohn mit ,entgegengesetzten Bestimmungen.““

240 Ab Cels. 6,69; vgl. dazu Pichler, Streit, 161-163 und 283-284; Lona, Kelsos, 379-399.

241 Ab Cels. 7,2.

242 Cels. 7,19-26. Zur Verhältnisbestimmung von Altem und Neuem Testament bei Origenes vgl. VoGT, Kommentar Bd. 2, 17-19. Ebd., 17 beschreibt er treffend diese Verhältnisbestimmung und ihre Bedeutung für Origenes: „Origenes ist überzeugt, daß im Alten wie im Neuen Testament ein und derselbe Geist wirkt, aber nicht nur inspirierend, sondern lehrend, ja sogar, so müßte man sagen, offenbarend. [...] Als Offenbarungsdokumente stehen Altes und Neues Testament also auf der gleichen Stufe; trotzdem besteht ein großer Unterschied zwischen beiden; [...] Der entscheidende Unterschied besteht darin, daß die Juden ,für Mose keinen Beweis zu bieten haben', während die Christen ,aus dem Gesetz und den Propheten die Nachweise für Jesus‘ erbringen können; daraus aber ergibt sich die gänzlich unerwartete (paradoxe) Folge, daß die Beweise, die sich ,für Jesus aus Gesetz und Propheten entnehmen lassen, dann ihrerseits wieder beweisen, ,das auch Mose und die Propheten 〈tatsächlich〉 Propheten Gottes waren'“ Angesichts dieser wechselseitigen Bestätigung beider Testamente muss Origenes viel daran gelegen sein, den Vorwurf der Widersprüchlichkeit oder sogar Inkompatibilität auszuräumen.

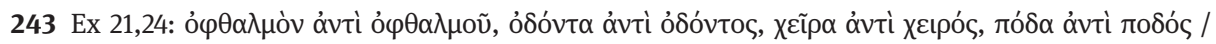
„Auge für Auge, Zahn für Zahn, Hand für Hand, Fuß für Fuß“ (ÜS: LXX Deutsch).

244 Nach Mt 5,38-39; Lk 6,29.

245 Cels. 7,18: „Hierauf sagt Celsus Folgendes: ,Werden sie nicht noch jenen Punkt überdenken? Wenn die Propheten des Gottes der Juden vorhersagten, dass dieser der Sohn jenes (Gottes) sein werde, wie kann dann dieser Gott durch Mose als Gesetz anordnen, man solle reich werden, herrschen, die Erde erfüllen, die Feinde Mann für Mann ermorden und ihren ganzen Volksstamm töten, was ja auch er selbst, wie Mose sagt vor ihren Augen tut? [...] Sein Sohn allerdings, der Mann aus Nazareth, ordnet Gesetze an, die dazu im Gegensatz stehen: Für den Reichen soll es keinen Zutritt zum Vater geben, auch nicht für den Machtliebenden oder für den, der Anspruch auf Weisheit und Ruhm erhebt [...] und dem,

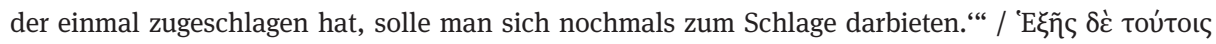

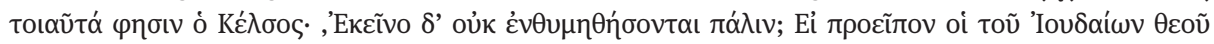

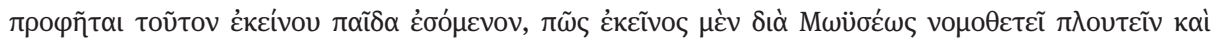

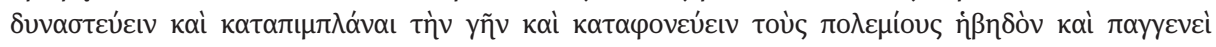


„Unterschied der Lebensform“ zwischen dem Gottesvolk des Alten Testaments, das „früher nach dem mosaischen Gesetz“ lebte, und dem der christlichen Heilszeit, das „nach der Lehre Jesu“ 246 lebt, den hier zu behandelnden längeren Abschnitt. Um diesen Unterschied zu erklären, bedient er sich - ähnlich Tertullian - heilsgeschichtlicher Überlegungen. Im Alten Testament sei das Gottesvolk, nämlich Israel, tatsächlich ein Volk mit einem eigenen Staatswesen und einem dazugehörigen Land gewesen. ${ }^{247}$ Daher sei es unumgänglich gewesen, dass sie damals auch das Recht zur Kriegführung und andere Rechte gehabt hätten, denn hätte man ihnen das Recht wegnehmen wollen,

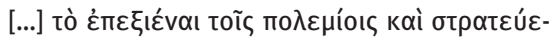

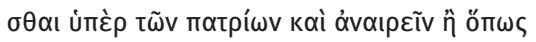
„ihre Feinde zu bekämpfen und für ihre Heimat in den Krieg zu ziehen und die Ehebrecher,

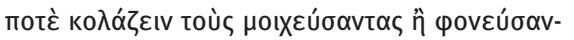

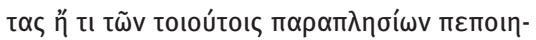
Mörder oder ähnliche Übeltäter zu vernichten oder irgendwie zu bestrafen, so wären sie zu

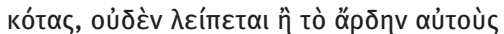
Zeiten feindlicher Übergriffe auf ihr Volk voll-

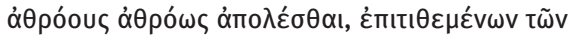

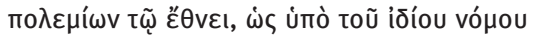

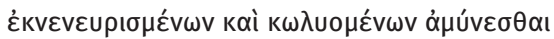
тоن̀ৎ по $\lambda \varepsilon \mu$ Í́оч५. ${ }^{248}$ ständig zugrunde gegangen, da sie vom eigenen Gesetz geschwächt und an der Abwehr der Feinde gehindert worden wären.“

(ÜS: AG nach C. Barthold)

Dann aber hätte die Vorsehung eine Fortführung dieser Ordnung nicht mehr gewollt. Sie habe daher die Stadt Jerusalem samt dem Tempel der Juden zerstört ${ }^{249}$, dagegen das Evangelium gegeben und dem Christentum Wachstum geschenkt, durch das Heiden aus unterschiedlichen Völkern zu einem neuen Gottesvolk berufen wurden. Mit der neuen Heilszeit sei somit aber auch eine neue Heilsordnung angebrochen, in der das Gottesvolk der Christen eben keinen eigenen Staat mehr besitzen sollte und daher auch keine politische Ordnung mit Justiz- und Heerwesen benötigte. Die Christen als Gottesvolk der neuen Heilszeit, das nach dem Evangelium lebt, so lässt sich folgern, strafen also keine Verbrecher mehr und führen auch keine Kriege. Hat man noch die Stelle Cels. 2,30 im Kopf, so wird auch deutlich, warum sie das nicht mehr nötig haben. Denn die göttliche Vorsehung hat doch das Römische Reich zur einigenden Macht für alle Völker der Oikumene gemacht, das diese Funktionen in einer geeinten Völkerwelt ausführt. In dem Schutz dieses Reiches kann das Gottesvolk der Christen darauf verzichten, solche Aufgaben auszuführen. ${ }^{250}$

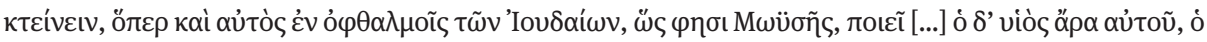

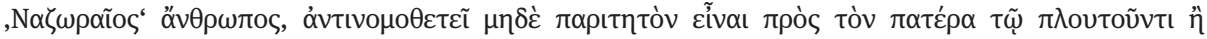

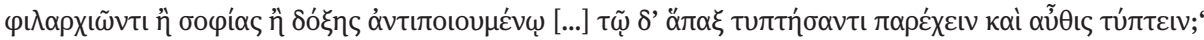
(ÜS: C. Barthold).

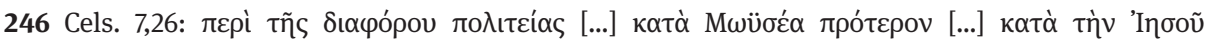
$\delta เ \delta \alpha \sigma \kappa \alpha \lambda i ́ \alpha v$ (ÜS: C. Barthold).

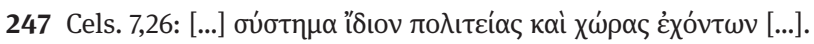

248 Cels. 7,26.

249 Ähnliche Überlegungen finden sich auch in comm. in Mt. 10,21.

250 Ob man dagegen mit BigELMAIR, Beteiligung, 171, aus diesem Text folgern kann: „In dem Staate, der Origenes vor Augen schwebt, wird Kriegsdienst überhaupt nicht mehr nötig sein.“, dürfte zweifelhaft sein. Denn Origenes steht hier ja gerade kein christlicher Staat vor Augen. Und auch in Cels. 7,68, die A. Bigelmaier mit Cels. 7,26 verbindet, formuliert er wahrscheinlich keine realistische Erwartung eines christlichen Reiches (s. oben S. 290 f.). Ähnlich meint auch Mazzucco, Origene, 83-84, Origenes sehe in seiner Gegenwart überhaupt keinen Platz für Kriege mehr. Krieg sei eine Sache der Vergangenheit, eine Sache der alten Israeliten und der alten Heiden, Athener und Peloponnesier, vor Augustus. Er denke deshalb für die Gegenwart und die Zukunft auch überhaupt nicht über die Möglichkeit 
Kriege sind also auch für Origenes eine Notwendigkeit und der Kaiser hat jedes Recht, sie zu führen, wenn sie zum Schutz des Reiches und seiner Bewohner notwendig, gerecht und geordnet sind. Es ist weiter klar, dass Origenes eine Beteiligung der Christen an diesen - gerechten ${ }^{251}$ - Kriegen und dem damit verbundenen Vernichten

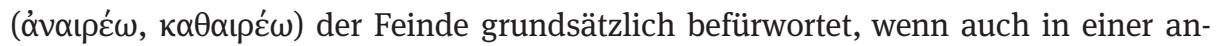
deren Funktion als derjenigen der Soldaten. ${ }^{252}$ Trotz dieser anderen Funktion nehmen sie in ihrer priesterlichen Rolle aber in ,geistlicher 'Art und Weise an den Kämpfen teil und ihre Gebete werden ja sogar als noch effektiver als die Waffen der Soldaten betrachtet. So hält H. von Campenhausen zu Recht fest: „Origenes versteht die Ablehnung des Kriegsdienstes also nicht als eine Weigerung der Kirche, an der Verteidigung des Reiches mitzuarbeiten. [...] Aber es geschieht in einer anderen, mittelbaren und geistlichen Weise. “253 Aus diesem Grund sollte man diesen Text nicht, wie aber bei einem großen Teil der modernen Forschung der Fall, als einen Beleg für den Pazifismus des Origenes lesen. ${ }^{254}$

gerechter Kriege nach, sondern wolle vielmehr die Möglichkeit eines Krieges abschaffen. Auch das scheint über den Aussagegehalt der Texte hinauszugehen.

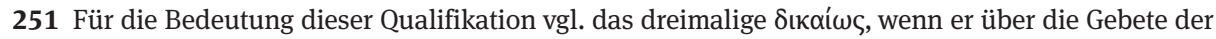

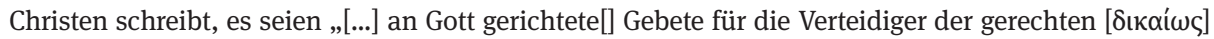

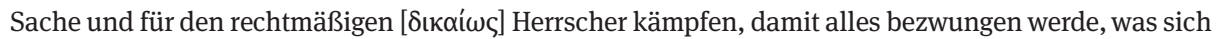

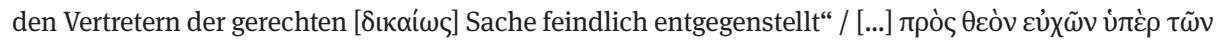

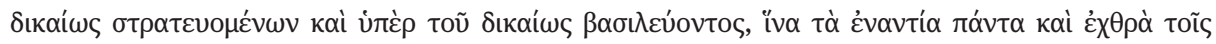

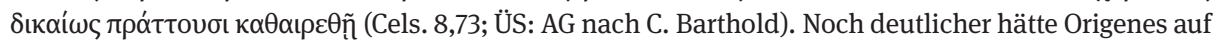
das Gewicht dieses Aspekts kaum hinweisen können. Vgl. KARPP, Stellung, 507: „Origenes erkennt also im Bereich des gegebenen staatlichen Lebens die Tatsache ja die Unvermeidlichkeit der Kriege an. Er zieht sie aber aus der Schicksalhaftigkeit in die sittliche Betrachtung hinein, indem er - vor den zitierten Sätzen - von der ,gerechten Sache‘ und dem ,rechtmäßigen König‘ spricht, für deren Sieg die Christen beten." Leider bietet er nirgends Kriterien, um einen Krieg als gerecht zu erweisen. Vgl. auch Cadoux, Christian Attitude, 137 und 207-208; Borret, Contre Celse 4, 346-347, Anm. 1; Helgeland, Christians (ANRW), 749; Hunter, Church, 174-175. Wenn HoRnus, Politische Entscheidung, 84, Anm. 185, nur fragt, ,Wie ist dieses ,rechtmäßig zu verstehen?“, und dann auf J. Cadoux verweist, ohne eine eigene Antwort zu bieten, so weicht er damit dieser Stelle in unzulässiger Weise aus. MAzzucco, Origene, 69-72, hält dagegen fest, dass Origenes den Verweis auf die gerechten Unternehmungen des Kaisers von Celsus übernehme, um daraufhin zwei Vorstellungen von Gerechtigkeit zu kontrastieren:

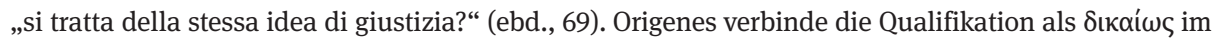
Folgenden so deutlich mit dem gewaltlosen Verhalten der Christen, dass es sich nur auf dieses beziehen könne und nicht auf den Krieg, den der Kaiser und sein Heer führen.

252 GeERLings, vorkonstantinische Kirche, 13, spricht hier treffend von einer „Arbeitsteilung“ bzw. einer ,arbeitsteiligen Kooperation von Heiden und Christen“.

253 CAmpenhausen, Kriegsdienst, 259; vgl. GeERLIngS, vorkonstantinische Kirche, 12-13; außerdem HunTER, Church, 174: „[...] Origen freely admits that there is such a thing as a righteous emperor and such a thing as a righteous or just cause for war. Furthermore, Origen sees the Christian taking an active role in the battle for justice, but only in a nonviolent way. The Christian participates in the defense of political society by prayer, thereby going to the root of the problem."

254 Anders dagegen z. B. CAdoux, Christian Attitude, 137: „All these passages [8,73; 3,7 und 7,26; 2,30; $4,82 \mathrm{AG}$ ] but the last explicitly refer to the warfare of some set of non-Christians: and in the last there is no indication that Origenes has Christians in mind. When the fact is once clearly grasped that his 
Es kann ebenfalls nicht behauptet werden, der Text schließe jeglichen Heeresdienst von Christen kategorisch aus oder belege gar, dass Origenes noch zu seiner Zeit nichts von Christen in den kaiserlichen Armeen gewusst habe. ${ }^{255}$ Denn einerseits weist er ausdrücklich lediglich eine freiwillige Meldung von Christen zum Kriegsdienst zurück, sagt aber kein Wort über Soldatenkonvertiten. Andererseits sind christliche Soldaten in der Mitte des 3. Jhds. n. Chr. bereits zu gut belegt, wie sogleich gezeigt

allusions to justifiable wars are always, either explicitly or implicitly, to wars waged by non-Christians, many of the criticisms levelled at his teaching will be seen to rest on a misapprehension." Darum betrachtet er Origenes trotz der Anerkenntnis gerechter Kriege als christlichen Pazifisten. Er unterschätzt aber das Gewicht dieser Anerkenntnis wie auch das Gewicht, das Origenes der, wenn auch anders gearteten, Beteiligung der Christen an den Kriegen des Kaisers beimisst. Für diesen Text als ein Musterbeispiel des urchristlichen Pazifismus bzw. zumindest des urchristlichen Verbots des Soldatenberufs vgl. HARnACK, Militia Christi, 31 und 70 - 71; CADOux, Christian Attitude, 129, 131, 139 und 141; Ryan, Rejection, 20; CAmPEnhausen, Kriegsdienst, 259-260, der allerdings vorsichtig nur von einem „leise[n], pazifistische[n] Unterton“ spricht, „der als solcher nicht aus der Bibel, sondern aus dem spätplatonischen Spiritualismus stammt."; KARPP, Stellung, 507; HoRnus, Politische Entscheidung, 154; CASPary, Politics, 126-128, der (ebd., 126) zu Contra Celsum sogar meint: „The pacifism of the Christians as a people, he insists in that work, is indeed their most noticeable characteristic."; TRIGG, Bible and Philosophy, 235-236; Swift, Views, 257-258; Mazzucco, Origene; SHEAN, Soldiering, 232; SIDER, Killing, 67. Mit Recht wendet sich Helgeland, Christians (ANRW), 751, dagegen, hier eine pazifistische Haltung erkennen zu wollen: „If Origen had bloodshed in mind when he prohibited enlistment, he would not have said that Christians should pray for the emperor's success in just wars; he was too consistent a thinker to let such a contradiction escape him." Außerdem weist er zu Recht darauf hin, dass Origenes im Fall der städtischen Ämter (Cels. 8,75) analog argumentiert, obwohl es dort nicht um die Frage von Gewaltanwendung und Töten geht. Darauf wird noch zurück zu kommen sein. Ebenso BRENNECKE, An fidelis (2007), 220: man wird die Haltung des Origenes „nicht unbedingt als pazifistisch ansehen können.“ Vgl. auch HunTER, Church, 174-175: „an ambiguous legacy“ (ausführlicher s. oben S. 297, Anm. 225).

255 So aber explizit BaInton, Early Church, 193 (= Kirche und Krieg, 192): „The section most disinclined to military service appears to have been the Hellenistic East. Such may be inferred [...] from the testimony of Celsus [...]. Origen of Alexandria [...] reveals that in the territory of his acquaintance the situation had not altered. [...] Origen through his travels was able to speak not only for Egypt, but also for Palestine, Greece, and Asia Minor.“ Vgl. auch ebd., 196 (= Kirche und Krieg, 195), wo er meint, Celsus und Origenes bezeugten eine „total abstinence for the period up to A.D. 250“ für den Osten. Erst um die Mitte des 3. Jhds. n. Chr. habe es in dieser Frage einen Wendepunkt gegeben, wie er aus einer Grabinschrift zweier christlicher Soldaten aus Phrygien (Ramsay, Cities Bd. 1,2, 717-718, Nr. 651) folgert. Ebenso noch in BaINToN, Attitudes, 69-70. Gegen diese Sicht der Dinge sprechen neben den in Kürze zu besprechenden Aspekten einige grundsätzliche Überlegungen:1.) R. Bainton übersieht völlig die im Folgenden dargestellte Beleglage - soweit sie ihm schon bekannt war - bzw. setzt sie nicht zu den Aussagen des Origenes in Beziehung. Diese Belege zeigen aber, dass die phrygische Inschrift nicht einen Wendepunkt markiert, sondern sich vielmehr in das vorliegende Gesamtbild für diese Zeit einfügt. 2.) Seine Konzentration gerade auf den Osten steht im eklatanten Widerspruch zur Beleglage. Es ist R. Bainton selbst, der (Bainton, Early Church, 194 [= Kirche und Krieg, 193]; vgl. Bainton, Attitudes, 70), festhält: „But the most indisputable and persistent tradition of Christian sanction for participation in warfare comes from the eastern provinces." Als für die Zeit des Origenes relevante Belege führt er die bereits diskutierte Geschichte der Donnerlegion sowie die Bekehrung des syrischen Fürsten Abgar IX. von Edessa zu Christentum an. 
werden wird. Es stellt sich angesichts dieser Beleglage vielmehr die Frage, warum er gegenüber Celsus nicht - wie bereits Tertullian im Apologeticum ${ }^{256}$ - auf die Christen, die es zu seiner Zeit im Heer gibt, hinweist. Damit hätte er doch den Vorwürfen des Celsus schnell und einfach ihre Spitze nehmen können. ${ }^{257}$ Dass er nichts von christlichen Soldaten wusste beziehungsweise dass es in seinem Umfeld keine gab, ist schlicht unvorstellbar. Vielmehr muss Origenes von ihnen gewusst, wenn nicht sogar einige von ihnen gekannt haben. ${ }^{258}$ Dafür sprechen folgende Überlegungen ${ }^{259}$ :

1. Tertullian wusste schon rund 40-50 Jahre früher von einer substantiellen Zahl christlicher Soldaten in Nordafrika und Rom. Außerdem bezeugt er in der Regenwundererzählung die Anwesenheit von Christen in einer Legion aus dem ostanatolischen Raum bereits in den 170er Jahren n.Chr. Dass diese Geschichte auch im Osten des Reiches bekannt war, wird aus zwei schlichten Tatsachen deutlich: Sie handelt von Christen in einer im Osten (Melitene) stationierten Legion. Eusebius hat sie aus einer Schrift des kleinasiatischen Bischofs und Apologeten Apollinaris von Hierapolis in seine Kirchengeschichte übernommen ${ }^{260}$.

2. Auch Cyprian bezeugt für die 30er und 40er Jahre des 3. Jhds. n. Chr. die Anwesenheit von Christen im Heer. ${ }^{261}$

3. Bereits Clemens Alexandrinus kannte - wie im letzten Kapitel festgestellt - sehr wahrscheinlich christliche Soldaten in größerer Zahl in Alexandria und Ägypten in der Zeit um 200 n. Chr. Zugleich bezeugt er, dass deren Existenz auch in der christlichen Gemeinde Alexandrias bekannt und anerkannt war.

4. Es ereigneten sich gerade in Alexandria während der decischen (249-251 n. Chr. $)^{262}$ und valerianischen (257-260 n.Chr. $)^{263}$ Verfolgung Soldatenmartyrien. Von ersterer berichtet Bischof Dionysius von Alexandria in seinem Brief an Fabius, der bei Eusebius überliefert ist. ${ }^{264}$ Letztere ist ebenfalls durch Dionysius

256 Tert. Apol. 37,4-5; 42,1-3; siehe dazu oben S. $56 \mathrm{ff}$. und $61 \mathrm{ff}$.

257 So auch BRENNECKe, An fidelis (2007), 221, Anm. 213.

258 So auch ausdrücklich BRENNECKE, An fidelis (2007), 220-221: „Die ganze Argumentation des Origenes scheint nun im eklatanten Widerspruch zu dem unbezweifelbaren Faktum christlicher Soldaten und vielleicht ganzer christlicher Truppenteile in der Mitte des dritten Jahrhunderts zu stehen.“ Bereits CAdoux, Christian Attitude, 140, war zu dieser Einsicht gekommen.

259 SIDER, Killing, 185-190, gibt ebenfalls einen instruktiven Überblick über die Beleglage. Er unterschätzt allerdings die Bedeutung einiger Texte bei Clemens Alexandrinus.

260 Euseb. hist. eccl. 5,5,4. SHEAN, Soldiering, 191, fragt sogar, ob die Weiterverbreitung der christlichen Version des ,Regenwunders im Quadenland“ nicht durch das Bemühen motiviert war, „to counteract some of the anti-patriotic charges being leveled by pagan critics of the church“, wie er sie bei Celsus findet.

261 Siehe oben S. 77 f., zu der wichtigen Stelle epist. 39,3.

262 Vgl. dazu z. B. Vogt, Christenverfolgung (RAC), 1184-1187; Molthagen, Staat, 61-84; HuttneR, Maximinus, 204 und 208; Pietzner, Christen, 994-999.

263 Vgl. dazu z. B. Vogt, Christenverfolgung (RAC), 1187-1188; Molthagen, Staat, 85-98; HutTnER, Maximinus, 241-242; PietzNER, Christen, 1000-1005.

264 Hist. eccl. 6,41,16.22-23. Vgl. HARnACK, Militia Christi, 75-78, der zu Recht festhält: „[...] gewiss ist, dass die ganze kleine Soldatenschar aus Christen oder aus christlich Gesinnten bestand, die im 
bekannt, da er in seinem gleichermaßen bei Eusebius tradierten Brief an Dometius und Didymus davon erzählt. ${ }^{265}$ Beide Verfolgungen fanden in unmittelbarer zeitlicher Nähe zur Abfassung von Contra Celsum statt, die Existenz christlicher Soldaten wird in diesen Berichten aber unkommentiert als selbstverständlich vorausgesetzt. Daher kann kaum angenommen werden, dass es sich um ein dem Alexandriner Origenes völlig unbekanntes Phänomen gehandelt hat. ${ }^{266}$ Die Martyrien bestätigen vielmehr das aus den Schriften des Clemens gewonnene Bild für die Zeit, in der die Abfassung von Contra Celsum ungefähr anzusetzen ist.

5. Das sogenannte Martyrium des optio ad spem ordinis Marinus ${ }^{267}$ ereignete sich nur ca. 10 Jahre nach dem Tod des Origenes in Cäsarea, gerade an dem Ort also, an dem dieser etwa 13 Jahre vorher Contra Celsum verfasst hatte. Auch in dieser Geschichte wird ein christlicher Soldat, sogar ein optio unkommentiert als normal vorausgesetzt. Das Verhalten des Bischofs von Cäsarea lässt ebenfalls keine grundsätzlich ablehnende Haltung gegenüber christlichen Soldaten erkennen.

6. Sollte sich die 2005 in Megiddo in Israel gefundene Gaianus-Inschrift tatsächlich, wie von den Ausgräbern in ihrem vorläufigen Grabungsbericht vorgeschlagen ${ }^{268}$, in die Zeit um etwa 230 n.Chr. datieren lassen, wäre das ein weiterer wichtiger Beleg. Allerdings ist diese Datierung umstritten und der endgültige Grabungsbericht steht noch aus. ${ }^{269}$

kritischen Fall auf die Seite der Christen traten. Da man zum Schutz einer gegen Christen gerichteten Gerichtsverhandlung doch nicht absichtlich christliche Soldaten ausgewählt haben kann, so zeigt diese Geschichte, wie verbreitet die christliche Religion in dieser alexandrinischen Truppe damals gewesen sein muss und wie entschlossen diese christlichen Soldaten waren, ihre Religion der militärischen Disziplin überzuordnen. Diese kleine Episode spricht Bände [...].“; außerdem BRENNECKE, An fidelis (2007), 201-202 und 221; SHEAN, Soldiering, 193; SIDER, Killing, 159-160.

265 Hist. eccl. 7,11,20. Vgl. Harnack, Militia Christi, 78; Brennecke, An fidelis (2007), 202 und 221. 266 Man darf nicht annehmen, dass Origenes nach seiner Übersiedlung nach Cäsarea den Kontakt zur alexandrinischen Gemeinde völlig abgebrochen hätte. Vielmehr stand er weiterhin mit kirchlichen Kreisen Alexandrias in Verbindung und möglicherweise noch aus den späten 240er Jahren n.Chr. ist ein Brief an ,Seine Freunde in Alexandria bekannt. Vgl. NAUtin, Origène, 161-172, 412 und 437-438, der den Brief in diese Zeit ansetzt. CROUZEL, Origen, 20, dagegen meint, er sei schon von Athen aus in den frühen 230 Jahren n. Chr. geschrieben worden.

267 Euseb. hist. eccl. 7,15. Vgl. HARNACK, Militia Christi, 78-80; Helgeland, Christians (ANRW), 774; KerESZTES, Government II (ANRW), 377-378; BRENNECKE, An fidelis (2007), 202-204 und 221-222; Huttner, Maximinus, 257, Anm. 184; Pietzner, Christen, 1005, Anm. 193; SHEAN, Soldiering, 196 - 198. Siehe außerdem oben S. $156 \mathrm{f}$.

268 Tepper, Yotam; Di Campagnano Segni, Leah, A Christian Prayer Hall of the Third Century CE at Kefar Othnay (Legio) - Excavations at the Megiddo Prison 2005, Jerusalem 2006, v.a. 34-35 und $46-53$.

269 Zur Gaianus-Inschrift vgl. weiter RIESNER, Rainer, What does Archaeology Teach us about Early House Churches? In: TTK 78/3-4, (2007), 159-185, hier 165-170, der diese zeitliche Ansetzung zumindest für möglich hält; ADAms, Edward, The Ancient Church at Megiddo - The Discovery and an Assessment of its Significance. In: ExpT 120/2, (2008), 62-69, v.a. 65-66, zur Datierung, wo er auch kritische Stimmen anführt, die für eine Datierung ins frühe 4. Jhd. n.Chr. votieren; für eine solche spätere Datierung der Inschrift plädiert auch MARKschIEs, Christoph, Was lernen wir über das frühe 
7. Origenes war weit gereist - unter anderem hatte er sich in Alexandria, Rom, Athen, Antiochia, dem römischen Arabien und Ephesus aufgehalten ${ }^{270}$ - und kannte die Welt des Römischen Reiches besser als viele andere Kirchenschriftsteller dieser Zeit. Es ist schlicht nicht vorstellbar, dass er angesichts der angeführten Belege nichts von der Existenz christlicher Soldaten wusste. Gerade für Rom ist mit großer Sicherheit anzunehmen, dass es zur Zeit des Origenes christliche Soldaten gab. So führt R. Bainton ${ }^{271}$ selbst unter Verweis auf J. Cadoux eine römische Inschrift aus dem Jahr 217 n.Chr. ${ }^{272}$ als Beleg an. Ebenso weist er darauf $\operatorname{hin}^{273}$, dass von den acht christlichen Soldateninschriften, die er als vorkonstantinisch anerkennt und von denen immerhin zwei von ihm sogar dem 2. Jhd. n. Chr. zugewiesen werden, ganze sechs aus Rom stammen. ${ }^{274}$ Außerdem hat sich bereits gezeigt, dass die Episode aus Tert. coron. 1 mit ziemlicher Sicherheit im Rom des frühen 3. Jhds. n. Chr. spielt. ${ }^{275}$

8. Eine noch zu besprechende Stelle in comm. ser. in Mt. $102 \mathrm{zu}$ Mt 26,52 scheint die Existenz christlicher Soldaten geradezu vorauszusetzen ${ }^{276}$, ein ebenfalls noch $\mathrm{zu}$

Christentum aus der Archäologie des Heiligen Landes. In: ZAC 11, (2008), 421-447, hier 432-442, v. a. 439.

270 Siehe oben S. $263 \mathrm{f}$.

271 Bainton, Early Church, 192-193 (= Kirche und Krieg, 191); BAInTon, Attitudes, 69

272 CIL VI 8498 (= Rossi, Giovanni B., Inscriptiones Christianae urbis Romae septimo saeculo antiquiores, Bd. 1, Rom 1857-1861, 9-10, Nr. 5 = MARUCCHI, Orazio, Christian Epigraphy, An Elementary Treatise, with a Collection of Ancient Christian Inscriptions mainly of Roman Origin, Cambridge 1912, 225, Nr. 259 und 259a). Es handelt sich um die Grabinschrift des M. Aurelius Prosenes. Zu dieser Inschrift vgl. auch WischMEYER, Wolfgang, Griechische und lateinische Inschriften zur Sozialgeschichte der Alten Kirche, (Texte zur Kirchen- und Theologiegeschichte 28), Gütersloh 1982, 32-33; LAMPE, Christen, 278-282 und 454; LAMPE, Christians at Rome, 330 - 334.

273 BAInTON, Early Church, 192-193 (= Kirche und Krieg, 191-192).

$274 \mathrm{Zu}$ diesen Inschriften vgl. den Überblick bei HELGELAND, Christians (ANRW), 791, der weitere hinzufügt; außerdem SHEAN, Soldiering, 183-188; und die Zusammenstellung in englischer Übersetzung samt knappem Kommentar bei SIDER, Killing, 145-151. Hinzuzufügen wären außerdem CIL VI 2873 = ILCV 398 B und CIL VI 2610 + 32654 = ILCV 2199, in denen jeweils ein Zenturio der cohors X urbana und ein Soldat der cohors VI praetoriana nachgewiesen sind (vgl. GuYot/KLEIN (Hrsg.), Christentum Bd. 2, 66-67, mit Kommentar ebd., 279-280). Es handelt sich dabei um Grabinschriften und BAINTON, Early Church, 193 (= Kirche und Krieg, 191), verweist zu Recht darauf, dass sie ,as such prove that the Christian communities where these men were buried did not prohibit the recording of the military profession upon their tombs. “Wie seine etwas gewundene Formulierung andeutet, handelt es sich um eine Entwicklung, die R. Bainton kritisch sieht (vgl. ebd., 193-194 [= Kirche und Krieg, 192-193]). Positiver drückt es SHEAN, Soldiering, 185, aus: „In fact, the very existence of Christian epitaphs which proudly report the military career of the deceased would also suggest that the Christian communities these men belonged to not only did not exclude military men from their membership but also did not regard military service as objectionable or inconsistent with their understanding of Christian ethics.“ Vgl. bereits SwIFT, War (ANRW), 862.

275 S. oben S. $107 \mathrm{f}$.

276 Vgl. CASPary, Politics, 90 -91; SwIFT, Views, 285. 
behandelnder, in einer Katene zu Mt 26,52 277 überlieferter Kommentar sogar die Legitimität des Heeresdienstes im Frieden. Beide Texte zeigen, was die anderen angeführten Belege schon wahrscheinlich gemacht haben: Origenes wusste von christlichen Soldaten zu seiner Zeit.

Nimmt man all das zusammen, ist es tatsächlich erstaunlich, dass Origenes in seiner Erwiderung nicht, gleich Tertullian, einfach auf solche christlichen Soldaten im römischen Heer hinweist. Eine Erklärung dieser Spannung zwischen der Realität einerseits und der Antwort des Origenes andererseits muss die aufgezeigte Beleglage zwingend berücksichtigen. Zugleich besteht die begründete Hoffnung, dass eine befriedigende Lösung dieser so auffälligen und inhaltlich schwerwiegenden Spannung auch wichtige Hinweise für das Verständnis der gesamten Passage Cels. 8,69-75 bieten kann.

In der bisherigen Forschung wurden einige mehr oder weniger tragfähige Vorschläge für eine solche Lösung - so die Spannung überhaupt als solche empfunden beziehungsweise thematisiert wurde! - gemacht:

1. Auf die These R. Baintons, dass Origenes das völlige Fehlen von Christen in den Heeren des Ostens bezeuge, sowie auf ihre mangelnde Haltbarkeit angesichts der Beleglage wurde bereits hingewiesen. Zumindest ähnlich, wenn auch behutsamer versucht R.J. Sider ${ }^{278}$ diese Spannung zu lösen. Er meint, Origenes habe sicherlich von der Existenz einiger weniger christlicher Soldaten gewusst, es könnte sich aber eben nur um wenige gehandelt haben. Dass Origenes „could simply accept Celsus's generalization about AD 250“279 lasse sich nur erklären, wenn es nicht viele Christen im Heer gegeben habe. Denn „his general response to Celsus makes little sense unless their numbers were relatively small.“280

2. J. Cadoux meint einerseits, dass Origenes die 70 Jahre alte Behauptung des Celsus, „that Christians did as a body refuse to serve in the army and to hold magistracies“, akzeptiere und selbst so spräche „as if he was not aware that Christians ever took any other line“ ${ }^{281}$. Andererseits aber könne man ihn nicht so verstehen, als habe er nicht von christlichen Soldaten gewusst, dem würden die weiteren Belege klar widersprechen. Man könne ihm aber auch keine Unehrlichkeit vorwerfen, als

277 Frg. Mt. 537 Klostermann (Origenes, Werke 12,1, Matthäuserklärung 3 - Fragmente und Indices 1, hrsg. von Erich KlostermanN, (GCS 41,1), Berlin 1941, 219).

278 SIDER, Killing, 67, 186 und 189.

279 Ebd., 189; vgl. auch ebd., 176: „If Origen had thought either that many Christians currently served in the Roman army or that they should, he would obviously have simply corrected Celsus's misinformed views. Instead, Origen simply accepts Celsus's view of Christian behavior and explains why it is for the best."

280 Ebd., 186. R.J. Sider scheint die sich den Belegen für christliche Soldaten spiegelnde Realität im Licht der - hochgradig interpretationsbedürftigen - Aussagen des Celsus und des Origenes deuten zu wollen. Es scheint aber sinnvoller, die Aussagen der beiden Autoren stattdessen im Licht der Belege zu interpretieren.

281 Cadoux, Christian Attitude, 139-140. 
hätte er absichtlich verschwiegen, wovon er wusste, denn „the dishonesty would have been so patent as to serve no purpose“ ${ }^{\text {282 }}$. Stattdessen zeigten seine Ausführungen, dass ,even at this date, the middle of the third century, the predominant opinion among Christians was that their religion forbade them to serve in the legions. “283 Origenes habe also sein eigenes Ideal - und das vieler christlicher Zeitgenossen - wiedergegeben, anstatt auf die Realitäten in den Heerlagern hinzuweisen.

3. J. Helgeland geht nicht auf das hier festgestellte Problem ein, gibt aber zumindest einige Hinweise, wie seine Antwort möglicherweise lauten könnte. ${ }^{284}$ Zum einen sei es das primäre Anliegen des Origenes, dass Christen dem Kaiser keine falsche, weil ihnen religiös verbotene Loyalität schwören. ${ }^{285}$ Es geht also auch in der Frage des Soldatendienstes um die richtige Haltung dem Kaiser gegenüber. Zum anderen sei seiner Ansicht nach der geistliche Heeresdienst der Christen ohnehin effektiver als derjenige der Soldaten auf dem Schlachtfeld. Somit wäre also auch das Argument, Christen würden sich nicht einbringen und wären illoyal Kaiser und Reich gegenüber, mehr als nur widerlegt. Beide Aspekte sieht J. Helgeland völlig richtig und ihm ist an dieser Stelle auch $\mathrm{zu}$ folgen. Er verbindet diese Bruchstücke aber nicht ausreichend zu einem Gesamtbild, um die Antwort des Origenes verstehen zu können. Außerdem entgeht ihm das Problem des Schweigens des Origenes über im Heer dienende Christen und somit kann er darauf keine letztlich befriedigende Antwort geben.

4. J. Shean dagegen sieht die Antwort des Origenes nicht allzu weit von derjenigen des Tertullian entfernt. ${ }^{286}$ Letztlich wiesen beide darauf hin, dass die Christen ihre Pflicht dem Kaiser gegenüber auch im Krieg erfüllten, nur dass Tertullian sie auch konkret im Heer verortet, während Origenes sie einen geistlichen Kriegsdienst leisten lässt. Allerdings sieht er auch einen entscheidenden Unterschied:

„[...] so, in the case of Origen, military service was to be avoided since one could do better service to the state by praying for the active intervention of God in human affairs. Others, such as Tertullian, saw no problem with Christians engaging in all forms of public service, including armed conflict if it served a just cause.“287

282 CAdoux, Christian Attitude, 140.

283 CADoux, Christian Attitude, 140.

284 Helgeland, Christians (ANRW), 750 - 751. Er vergleicht die Antwort des Origenes mit der Tertullians und kommt zu dem Ergebnis (ebd., 746), dass die Antwort des Alexandriners völlig anders sei, wie die im Apologeticum, aber ähnlich der in De corona. Zu einem vergleichbaren Ergebnis kommt auch CAmpenhausen, Kriegsdienst, 259: „Origenes urteilt in dieser Hinsicht durchaus nicht anders als Tertullian. Die Christen haben auf Erden einen anderen Beruf als die Heiden.“

285 Helgeland, Christians (ANRW), 750.

286 SHEAN, Soldiering, 232.

287 SHEAN, Soldiering, 232. Auf die Problematik dieser Art pauschalisierender und teilweise widersprüchlicher Aussagen J. Sheans v.a. zu Tertullian wurde bereits hingewiesen (s. z. B. oben S. 40, Anm. 23 und S. 97, Anm. 315). 
Auch J. Shean weist, soweit das aus seinen wenigen Sätzen ersichtlich ist, in die richtige Richtung. Allerdings ist er noch weiter von einer zufriedenstellenden Gesamtlösung entfernt als J. Helgeland.

5. H. Brennecke stellt, wie bereits festgehalten, sehr deutlich fest, dass es unmöglich ist, dass Origenes nichts von christlichen Soldaten gewusst haben kann. ${ }^{288}$ Auch polemisiere er gar nicht gegen christliche Soldaten, wie beispielsweise Tertullian. Vielmehr gehe es ihm darum, auf der Grundlage „seiner besonderen Lehre vom Priestertum aller Getauften [...] den Vorwurf des Celsus zu entkräften." ${ }^{289}$ Die Frage aber, ob sich das christliche Bekenntnis und der Heeresdienst gegenseitig ausschließen, bleibe „am Ende [...] unbeantwortet““290.

Keine der vier erstgenannten Positionen kann die aufgezeigte Spannung zufriedenstellend erklären. Vor allem diejenige von J. Helgeland bietet aber zumindest einzelne Ansätze, um in die richtige Richtung weiterzudenken. Über dessen Ausführungen hinausgehend bieten die Überlegungen von $\mathrm{H}$. Brennecke eine Grundlage für eine sinnvolle Antwort auf die aufgeworfene Problemstellung, dürften aber noch etwas zu eng gefasst sein, was die Reichweite der Kritik des Celsus angeht.

Es soll daher an dieser Stelle ein Neuansatz versucht werden. Dieser Neuansatz wird die Anregungen von J. Helgeland und vor allem von H. Brennecke aufnehmen und versuchen, sie weiterzuentwickeln sowie in einen größeren kontextuellen Rahmen zu stellen. ${ }^{291}$ Auszugehen ist von dem schon dargelegten Befund, dass die Kap. 69-75 des achten Buches im weiteren Zusammenhang der positiven Darlegung der wahren Lehre seit Cels. 7,62 zu lesen sind. Celsus buchstabiert darin durch, wie man sich im Licht dieser wahren Lehre gegenüber den Göttern, den Dämonen und dem Kaiser zu verhalten hat. J. Cook hat dieses geforderte rechte Verhalten gut zusammengefasst:

„Christians should take part in public festivals [...] and should sacrifice to the demons $(8,24[\ldots])$. They should propitiate demonic powers and the emperors who hold their position by the power of the demons $(8,63[\ldots])$. They should take oaths by the emperor $(8,65[\ldots])$. If all refuse to do this, as the Christians do, then the emperor would be abandoned and anarchy would ensue $(8,68[\ldots])$. [...] Christians should , aid the emperor [...]'“،'“292

288 BRENNECKE, An fidelis (2007), 220 - 221; vgl. auch ebd. 217-218. Siehe dazu oben S. 305, Anm. 256.

289 BRENNECKE, An fidelis (2007), 221.

290 BRENNECKE, An fidelis (2007), 221.

291 Es spricht weitestgehend für sich, wenn HoRnus, Politische Entscheidung, 84-85, den Text von Cels. 8,73-74 in Übersetzung zitiert und ihn dann fast unkommentiert stehen lässt, um zum nächsten Autor weiter zu gehen. Seine einzige Bemerkung dazu ist (ebd., 85): „Denn welcher Art auch immer der Staat sein mag, der Christ ist, ohne daß hier irgendein Zweifel aufkommen könnte, eine Mensch des Friedens.“ Diese fast kommentarlose Anführen von Belegstellen, oftmals ohne jede Diskussion vorhandener Fragen, die vom Text selbst aufgeworfen werden und damit ohne den Versuch eine Einordnung und Interpretation im eigentlichen Sinn, stellt eine der großen Schwächen der Arbeiten von J.M. Hornus dar und begrenzt ihren Wert erheblich.

292 Соок, Interpretation NT, 90 -91. 
Dabei wird die Funktion und Stellung des Kaisers „dämonologisch“293 eingeordnet und begründet. Ziel des Celsus ist die ,Bekehrung“ der Christen, weg vom Christentum, hin zur wahren Lehre und damit auch zum richtigen Verhalten den Göttern, den Dämonen und dem Kaiser gegenüber. Sie sollen den christlichen Pseudo-vó $\mu$ o ̧aufgeben und zum ,König vó $\mu \varsigma^{\text {‘294 }}$ der wahren Lehre umkehren.

In dem Appell des Celsus, dem Kaiser als Soldaten und vor allem als Anführer in den Heeren sowie als Amtsträger in den Städten zu dienen, spitzt sich diese Aufforderung zur ,Bekehrung‘ endgültig zu. Es handelt sich dabei, das muss noch einmal ausdrücklich festgehalten werden, nicht um ein Friedensangebot an das Christentum, sondern um den zugespitzten Aufruf zur Apostasie. ${ }^{295}$ Indem die Leser des Celsus diese ihrem Stand angemessenen Aufgaben erneut übernehmen, erkennen sie den Kaiser wieder als - im homerischen Sinn - ,einen König ${ }^{6296}$ an, der als der Statthalter des einen Gottes und seiner göttlichen und dämonischen Diener auf Erden herrscht. ${ }^{297}$

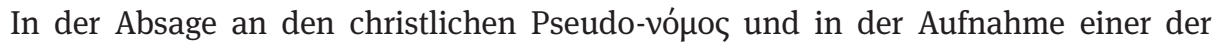
wahren Lehre gemäßen, sich in der Übernahme der standesgemäßen Aufgaben konkretisierenden Lebensweise würden die ,Bekehrten' dann auch wieder zur Stabilität der gesellschaftlichen Ordnung und zur Sicherheit des Reiches vor seinen Feinden beitragen.

Das ist der Erklärungsrahmen, innerhalb dessen die Antwort des Origenes verstanden werden muss. Seine Aussagen sind als eine direkte Antwort auf die konkrete Kritik des Celsus zu lesen. ${ }^{298}$ Hat man diese Zusammenhänge vor Augen, so wird deutlich, warum er nicht einfach auf Christen in den Heerlagern - und in den städtischen Ämtern - hinweisen und die Sache damit auf sich beruhen lassen kann. Denn auf diese Weise würde er ja dem Celsus entweder in seinem Vorwurf Recht geben, dass die Christen, wenn sie ihrer eigenen (radikal zu Ende gedachten) Lebensweise folgen, unter Umständen die Stabilität des Reiches und damit die gottgewollte Ordnung gefährdeten und sich daher von jener abwenden müssten. Oder er würde einräumen, dass viele Christen (wissentlich oder unwissentlich) schon erste Schritte der Umkehr zur wahren Lehre gegangen sind, indem sie in Heer und Verwaltung dienen. Entgegen diesem Dilemma muss Origenes vielmehr daran gelegen sein, am von Celsus vorgegebenen Beispiel (Heeresdienst und Ämterübernahme) exemplarisch zu zeigen, dass die Christen gerade dann, wenn sie ihrem eigenen, christlichen Nomos gemäß leben,

293 PICHLER, Streit, 295.

294 In Anspielung an Cels. 5,34, wo Celsus wiederum auf Hdt. 3,38 Bezug nimmt.

295 Siehe oben S. 272f. EmmenEgGer-Sieber, Pflichten, 77, scheint ebenfalls in diese Richtung zu denken.

296 Nach Cels. 8,68, wo Celsus aus Hom. Il. 2,204f. zitiert.

297 EMmENEGGER-SiEBER, Pflichten, 77, scheint ebenfalls zumindest ansatzweise in diese Richtung zu denken.

298 Vgl. Helgeland, Christians (ANRW), 751; und v. a. BRENnECKE, An fidelis (2007), 217-218. Schon MofFAT, War, 666, könnte zumindest im Ansatz in eine ähnlich Richtung gedacht zu haben, allerdings führt er diesen Gedanken nicht weiter, sondern lässt Origenes doch nur einen idealistischen Träumer sein (ebd., 666-667). 
Kaiser und Reich nicht nur nützlich, sondern sogar von größtem Nutzen sind. ${ }^{299}$ Denn dass sie den Kaiser grundsätzlich als von Gott eingesetzt anerkennen und ihm darum auch in den Grenzen des ihnen Erlaubten dienen, hatte er ja bereits betont herausgestellt. ${ }^{300}$ Nur eben nicht $\mathrm{zu}$ den Bedingungen des Celsus! So betont der Kirchenschriftsteller an dieser Stelle gerade ihre Andersartigkeit mit Blick auf den Heeresdienst und die Ämterübernahme sehr stark, ja sogar übertrieben stark, ebenso aber auch den Wert ihres Dienstes. Christen haben, und zwar gerade als Christen, eine andere, ganz eigene Rolle zu spielen, eine Rolle, die aber gleichwohl von größter Wichtigkeit und höchstem Wert für Kaiser und Reich ist. Seine Antwort auf Celsus lautet also paraphrasiert wie folgt:

Lasst uns Christen doch wirklich Christen sein, zwingt uns nicht, dem - jetzt abwertend gemeint-
alten, nämlich heidnischen Logos zu folgen. Denn gerade so, als Christen, die auch christlich
leben, sind wir für den Kaiser und das Imperium am Wertvollsten. Im Fall des geforderten
Kriegsdienstes helfen wir als priesterliche Gemeinschaft dem Kaiser mit unseren Gebeten besser,
die Barbaren zu besiegen und zu vernichten, als alle seine Soldaten mit ihren Schwertern und
Lanzen (Cels. 8,73-74). Und im Fall der geforderten Übernahme von Amtspflichten in den Städten
gilt Vergleichbares: Wir können durch das Ausfüllen von Ämtern in den christlichen Gemeinden
sehr viel mehr Gutes und Nützliches für das Gemeinwesen tun als durch den Dienst als Magistrate
(Cels. 8,75).

Origenes geht es nicht darum, ein objektives Bild der Wirklichkeit des Verhältnisses von Christentum und Soldatenstand zu seiner Zeit zu zeichnen. ${ }^{301}$ Er leistet vielmehr argumentativen Widerstand gegen die mit dem Aufruf zum Heeresdienst verbundene Aufforderung des Celsus, den christlichen Nomos aufzugeben, sich wieder der alten, wahren Lehre anzuschließen und ihr gemäß zu leben. Anders als Celsus es fordert, sollen sich die Christen nicht

„durch Erfüllung ihrer Pflichten gegenüber Kaiser und Staat vorbehaltlos in die gesellschaftliche Ordnung [...] integrieren, um durch die Akzeptanz des geltenden Nomos einen angemessenen Platz im Gesellschaftsgefüge einnehmen zu können.““302

299 Man beachte nur die betonte Feststellung in Cels. 8,74: „Die Christen aber erweisen ihrer Heimat

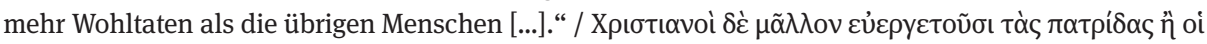

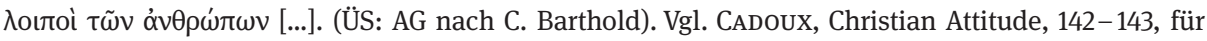
diesen Aspekt des positiven Dienstes der Christen am Staat; außerdem BaInTon, Early Church, 206 (= Kirche und Krieg, 208).

300 Cels. 8,65; vgl. GeERLINGS, vokonstantinische Kirche, 11: „Origenes gibt [...] die prinzipielle Berechtigung der heidnischen Forderung zu. Alle Bürger, auch die Christen, müssen zum Besten des Staates beitragen.“

301 Von daher bietet der Text auch keinerlei Handhabe, um eine Aussage zur Haltung des Origenes zu Soldatenkonvertiten oder allgemein zu bereits im Heer dienenden Christen zu treffen. Diese Problematik kommt hier schlicht nicht vor.

302 Barthold/Fiedrowicz, Contra Celsum Bd. 1, 31. 
Stattdessen sollen sie diesen „,angemessenen Platz im Gesellschaftsgefüge“303 gerade als Christen, die ihrem eigenen Nomos folgen, einnehmen dürfen. Was Origenes hier anhand der Beispiele von Soldatenberuf und Ämterübernahme, in denen Celsus seine Forderung zur ,Bekehrung‘ der Christen zuspitzt, argumentativ durchspielt, muss in gleicher Weise auch für die anderen von Celsus aufgeworfenen Problemfelder gelten. Es muss gerade auch dort gelten, wo Christen - anders als im Heer - tatsächlich im gesellschaftlichen Abseits stehen und eine Partizipation in keiner Weise möglich ist (kultische Verehrung der traditionellen Gottheiten, Eidesleistung beim Kaiser beziehungsweise seiner Tyche, etc.). Auch hier ist in analoger Weise dem Gemeinwesen am besten gedient, wenn die Christen ihrem eigenen Nomos gemäß leben dürfen. Origenes argumentiert nach dem skizzierten Verständnis des Textes a minori ad maiorem. Die geforderte Verehrung der Götter und des Kaisers sind das ungleich gewichtigere Problem, hier darf ein Christ keinesfalls wanken, noch weniger fallen. Demgegenüber wäre der Dienst im Heer und in städtischen Ämtern ein ungleich geringeres Problem, sind Christen dort doch schon zu finden - wie zahlreich oder auch nicht, sei hier dahingestellt. Erst durch die Funktion im Argumentationsgang des Celsus gewinnt der Aufruf zum Dienst sein Gewicht, hier soll die Umkehr beziehungsweise der Abfall des Christen praktisch vollzogen werden. Indem Origenes diesem ,Umkehrruf‘ des Celsus die argumentative Spitze nimmt, eröffnet er sich (und anderen Christen) die Möglichkeit, im Gespräch mit heidnischen Kritikern das Diskussionsfeld von hinten aufzurollen.

Hat man diese sehr konkrete, damit aber auch begrenzte Zielsetzung erkannt, lassen sich auch einige andere Eigenheiten des Textes erklären. Dazu gehört der religionsgeschichtlich interessante Vergleich der Christen mit heidnischen Priestern. Geht es Origenes vor allem darum, den Vorwurf der Nutzlosigkeit und den damit verbundenen Aufruf zur ,Bekehrung، durch den Platoniker Celsus zu widerlegen, gewinnt dieser Gedanke einige Plausibilität. Im Hintergrund steht neben der letztlich auf dem Neuen Testament beruhenden Überzeugung vom priesterlichen Charakter des Christentums ${ }^{304}$ die auf Plato zurückgehende Vorstellung, dass es in einem Staatswesen unterschiedliche Stände mit ihren je eigenen Aufgaben ${ }^{305}$ gibt. So un-

\section{Ebd.}

304 Für die neutestamentliche Grundlage siehe v.a. 1. Petr 2,9: „Ihr aber seid das auserwählte Ge-

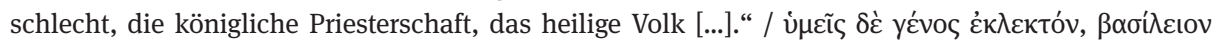

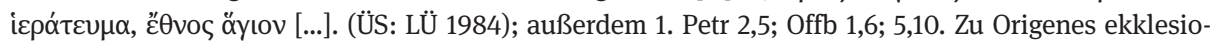
logisch begründeter Theologie des „Priestertum[s] aller Getauften“ (BREnNECKE, An fidelis (2007), 221) vgl. kurz Williams, s.v. Origenes/Origenismus (TRE), 411-412, mit Belegen.

305 Auf diesen Hintergrund im Platonismus hat bereits CAMPEnHaUSEn, Kriegsdienst, 260, aufmerksam gemacht: „Ein leiser, ,pazifistischer‘ Unterton klingt auf, der als solcher nicht aus der Bibel, sondern aus dem spätplatonischen Spiritualismus stammt. Von hier her stammt auch die eigentümliche Vorstellung der Stufung und Stellvertretung, der den vollkommenen Geistmenschen und Asketen [...] von der Masse scheidet und aus den alltäglichen Sorgen und Geschäften des Lebens heraushebt. Gerade so erscheint die christliche Zurückhaltung in der Frage des Kriegsdienstes nicht mehr so störend, sondern durchaus ,vernünftig،. Sie bezeichnet keine radikale Ausnahme, sondern sie hat die 
terscheidet Plato einen Wirtschafts- oder Erwerbsstand (Handwerker, Bauern), einen Wächterstand (Soldaten) und einen aus Philosophen bestehenden Herrscherstand. ${ }^{306}$ Indem jeder dieser Stände seine ihm zugewiesenen Aufgaben erfüllt, dient er dem Ganzen und garantiert die Aufrechterhaltung der staatlichen Ordnung. So lässt er Sokrates resümierend festhalten: „Nun, eine Stadt erschien uns doch als gerecht, wenn sich in ihr drei Arten von Naturen finden und jede das Ihre tut; [...].“307 Auf Grundlage einer solchen Konzeption kann Origenes dem Platoniker Celsus und seinen auch damit vertrauten Lesern ${ }^{308}$ das Christentum ebenfalls als einen im platonischen Sinne besonderen Stand präsentieren, der seine ganz eigenen Aufgaben wahrnimmt

Bedeutung einer sinnvollen Arbeitsteilung.“ Auch KARPP, Stellung, 507, weist darauf hin, dass sowohl das Drängen auf einen gerechten Krieg als auch die Forderung nach einer Ausnahmestellung für die Christen ,ihr Vorbild im antiken Denken“ haben.

306 Plat. rep. 2,371a-373d (Erwerbsstand); rep. 2,373d-4,427c (Wächterstand); 3,412b-414b; 5,473b6,504a (Herrscherstand). Vgl. dazu CANTo-Sperber, Monique, Brisson, Luc, Zur sozialen Gliederung der Polis (Buch II 372d-IV 427c). In: Höffe, Otfried (Hrsg.), Platon Politeia, (Klassiker Auslegen 7), Berlin 2005, 95-117. Plato setzt dieses Modell der Gesellschaft bzw. des Staates ausdrücklich in Verbindung zu seiner Lehre von der dreigeteilten menschlichen Seele; siehe rep. 4,435a-436a. Vgl. dazu kurz SzLezÁK, Thomas A., s.v. Platon [1]. In: DNP 9, (2000), 1095-1109, hier 1104-1105; ausführlicher, HöFfe, Otfried, Zur Analogie von Individuum und Polis (Buch II 367a-374d). In: Höffe (Hrsg.), Platon Politeia, 69-93, hier v. a. 84-93.

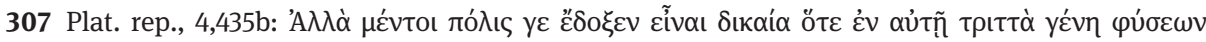

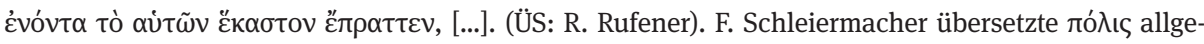
meiner als Staat, was der Zeit des Celsus und des Origenes eher entspricht als Stadt. Der dazu gehörende Gedankengang setzt bereits in rep. 4,433a ein. Vgl. zu dieser Stelle ZEHNPFEnNIG, Barbara, Platon, Politeia. In: Brocker, Manfred (Hrsg.), Geschichte des politischen Denkens - Ein Handbuch, Frankfurt a. M. 2007, 14-30, hier 24: „Das Glück dieser Polis liegt darin, das jeder eine Aufgabe erfüllt, die seiner Anlage entspricht - die Zuteilung zu den Ständen erfolgt gemäß der Begabung -, und dass jeder seinen Teil zum Gelingen des Ganzen beiträgt, welches so zu einer harmonischen Einheit zusammenwächst. [...] Da der gesamte Staat auf die Tugend ausgerichtet ist - also auf die Überwindung des Eigennutzes, der das Übel der besten Staaten darstellt -, lässt sich auch die gesuchte Gerechtigkeit unter den anderen Tugenden dingfest machen. [...] Die Gerechtigkeit aber sorgt dafür, dass der Staat so, wie er ist, bestehen kann, und das liegt an dessen für jeden geltendem Grundprinzip, ,das Seinige zu tun“ (433a).“ Zum Gedankengang als Ganzem vgl. Schubert, Andreas, Platon ,Der Staat“ - Ein einführender Kommentar, Paderborn 1995, 59 - 66; WEBER, Simon, s.v. Gerechtigkeit. In: Horn, Christoph, Müller, Jörn, Söder, Joachim (Hrsg.), Platon Handbuch - Leben, Werk, Wirkung, Stuttgart, Weimar 2009, 275-284, hier v. a. 278-280.

308 Zur umfangreichen Rezeption von Platos Politeia vgl. den Überblick bei RADKE-UHLMANN, Gyburg, s.v. Platon. C. Republic. In: Brill's New Pauly Supplements 5 - The Reception of Classical Literature, hrsg. von Christine Walde, Leiden 2012, 318-327, hier v. a. 318-321, zu Antike und Spätantike. Außerdem ausführlich mit zahlreichen Belegen DöRRIE, Heinrich, BALTES, Matthias, Der Platonismus in der Antike Bd. 3, Bausteine 73-100, Stuttgart, Bad Cannstatt 1993, 44-47 (Belege) und 201-208 (Kommentar). Sie können resümierend festhalten: „Denn von allen Schriften Platons - den Timaios ausgenommen - hat keine in der Antike ein solches Echo gefunden wie der Platonische Staat, der wohl auch aus diesem Grund häufiger als andere Schriften kommentiert worden ist.“ Unter den Kommentatoren finden sich so bedeutende Platoniker wie Numenios und Porphyrios; vgl. ebd., 205-207. Wie intensiv Origenes seine Kenntnisse Platons und des platonischen Denkens gerade in die Auseinandersetzung mit Celsus einfließen lässt, zeigt jetzt VillaNi, Andrea, Platon und der Platonismus. 
und damit dem Ganzen dient. Sollte Origenes dieser Text oder ein ähnlicher Gedanke aus der platonischen Tradition tatsächlich vor Augen gestanden haben, kann man

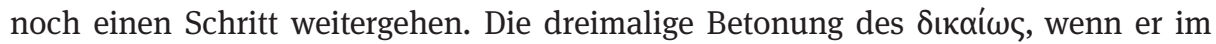
unmittelbaren Zusammenhang mit der Diskussion der priesterlichen Rolle der Christen über ihre Gebete schreibt, es seien

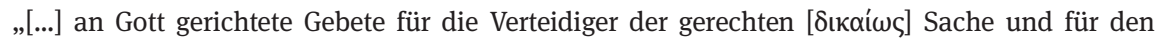

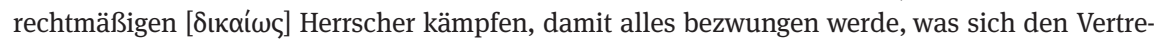

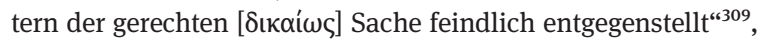

ließe sich dann möglicherwiese direkt mit dem von Plato geäußerten Gedanken verbinden, dass gerade der Staat gerecht ist, der die unterschiedlichen Stände ihre je eigenen Aufgaben wahrnehmen lässt. Origenes würde dann für den, der Ohren hat zu hören, festhalten: Gerade, indem der Kaiser die Christen ihre priesterliche Rolle ausfüllen lässt, erweist er sich und seine Sache als gerecht.

Voraussetzung dafür ist allerdings, dass die Christen zu dieser Zeit noch immer eine gesellschaftliche Minderheit sind und es eine heidnische Mehrheit gibt, die tatsächlich mit dem Schwert in der Hand in den Heeren kämpft und Ämter in den Städten übernimmt. ${ }^{310}$ Darin zeigt sich, dass auch an dieser Stelle wieder die heilsgeschichtliche Konzeption von der providentiellen Rolle des römischen Kaisertums und dem unpolitischen Charakter des christlichen Gottesvolkes eine große Rolle spielt. Es ist für Origenes eine schlichte Tatsache, dass gemäß der gottgewollten Ordnung der heidnische Kaiser und sein Reich den äußeren Rahmen für die Entfaltung des Christentums als einem Gottesvolk ohne staatliche Ordnung bilden. Man muss zumindest fragen, ob Origenes bei seiner Argumentation bleiben würde oder gar könnte, wenn tatsächlich die Mehrheit der Bewohner des Reiches oder gar die Kaiser Christen wären, wie es dann ab dem 4. Jhd. n. Chr. der Fall sein sollte. Würde dann wieder ein Modell vergleichbar dem eines Gottesvolkes mit Staatswesen aus Cels. 7,26 greifen? ${ }^{311}$ Letztlich ist eine Antwort auf diese Frage nicht möglich, da ein solcher Gedanke für Origenes noch nicht denkbar gewesen sein dürfte. Aber sie zu stellen hilft, sich der

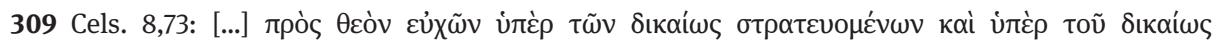

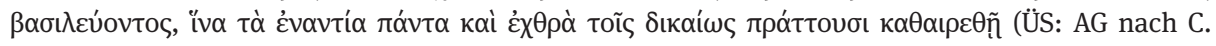
Barthold).

310 So richtig CAmpenhausen, Kriegsdienst, 260; GeERLings, vorkonstantinische Kirche, 13; vgl. auch SCHÖPF, Tötungsrecht, 224-225.

311 Vgl. KARPP, Stellung, 507-508, der meint, sollten die Christen wieder zur Mehrheit werden, würde „auch das alttestamentliche Vorbild der gottgewollten nationalen Verteidigung wieder ein neues Gewicht erhalten“. Origenes aber sei der Ansicht, würde es soweit kommen, würde alle Kriege aufhören, da die Feinde entweder durch Gebet besiegt würden oder, ebenfalls bekehrt, aufhören würden, Feinde zu sein. „Das ist aber nicht mehr eine konkrete Stellungnahme zu einem gegenwärtigen Problem, sondern eine eschatologische Hoffnung.“ 
Grenzen seines argumentativen Ansatzes ${ }^{312}$ auch in dieser Richtung bewusst zu werden.

Auch die Frage, ob Origenes im pazifistischen Sinn das Vergießen von Menschenblut in den Vordergrund seiner Ablehnung rückt oder ob nicht auch hier das Problem der Idolatrie eine wichtige(re) Rolle spielt, kann mit dieser Einordnung des Textes noch einmal neu überdacht werden. Oftmals wird Cels. 8,73-74, darauf wurde bereits hingewiesen ${ }^{313}$, als ein Ausdruck des frühchristlichen Pazifismus verstanden. So meint J. Cadoux: „Note further that fear of idolatrous contamination had nothing to do with Origenes' disapproval of military service. His view was based [...] on the Christians' determination to keep their hands free from the stain of blood“314 Und G. Caspary schreibt zugespitzt:

\begin{abstract}
„The ambivalence of Origen's attitude to warfare is apparent. Celsus' accusation cannot be gainsaid. Christians are indeed a sect of radical pacifists: they do not fight for the Empire, even if 'pressed' to do so. In the words of 1 Peter 2:9, they form 'a chosen generation, a royal priesthood, an holy nation, a peculiar people': they are priestly worshippers of the one True God, who must keep their hands undefiled and may not therefore 'go out into the lines to kill all the troops they can.' [...] There is not a word about the points so dear to anti-pacifist historians; nothing about the military oath, nothing about the pagan sacrifices soldiers supposedly had to perform.““315
\end{abstract}

Im Gegensatz dazu muss erstens auf die begrenzte Zielsetzung des Textes hingewiesen werden. Cels. 8,73-74 für sich genommen genügt allein aus diesem Grund nicht, eine pazifistische Haltung des Origenes zu belegen. Denn der Alexandriner gibt an dieser Stelle ja gerade keine allgemeine Positionsbestimmung, sondern eine äußerst präzise Antwort auf eine sehr konkrete Frage.

Zweitens zeigt seine Haltung zur Rechtmäßigkeit eines vom Kaiser geführten gerechten Krieges, an dem sich die Christen in ihrer priesterlichen Rolle ja auch beteiligen, dass der Begriff Pazifismus für die Beschreibung der Position des Origenes nicht hilfreich ist. ${ }^{316}$ Vielmehr handelt es sich, wie noch anhand weiterer Texte zu zeigen

312 Campenhausen, Kriegsdienst, 260, hält fest, dass seine Lösung der Soldatenfrage letztlich scheitern musste, da sie einzig unter Voraussetzung der Minderheitsposition der Christen funktionieren konnte. Dieser Punkt behält seine grundsätzliche Richtigkeit auch dann, wenn es sich hier weniger um eine Lösung der Soldatenfragen als vielmehr um ein Argument gegen den ,Umkehrruf‘ des Celsus handelt. Auch dieses Argument wird scheitern, sobald die Christen keine kleine Minderheit mehr sind.

313 Siehe oben S. 303, Anm. 254.

314 Cadoux, Christian Attitude, 141.

315 CASPARy, Politics, 127-128. Ähnlich Hunter, Church, 273-275, der Origenes ausschließlich im Licht des Verbotes, Gewalt anzuwenden und Blut zu vergießen, liest. Auch SidER, Killing, 68, gesteht der Idolatrieproblematik ein bestenfalls geringes Gewicht zu und betont das Verbot, Blut zu vergießen, als eigentliche Grundlage der Haltung des Origenes.

316 Das haben v. a. HELgeland, Christians (ANRW), 751; und BRENNECKE, An fidelis (2007), 220 richtig erkannt; siehe ebenfalls oben S. 303, Anm. 254. 
sein wird ${ }^{317}$, um Fragen der Heilsgeschichte und der Eschatologie. Angesichts des Kommens Christi hat für Origenes eine neue Phase der Heilsgeschichte begonnen, in welcher die Christen als das eschatologische Gottesvolk eine ganz eigene Rolle zu spielen haben. ${ }^{318}$ Diese Rolle einer priesterlichen Minderheit wiederum ist auf das Engste verbunden mit der providentiellen Rolle des Römischen Reiches als Ordnungsund Schutzmacht. Dass diese Überlegungen zutreffend sind, zeigt sich auch darin, dass Origenes nicht nur mit Blick auf die Soldatenfrage in dieser Weise argumentiert, sondern auch mit Blick auf die Übernahme städtischer Ämter, bei denen das Töten von Menschen kein schwerwiegendes Hindernis darstellen würde. ${ }^{319}$ Der Ansatz des Origenes ist in seiner inhaltlichen Bestimmung viel zu speziell und in seinen Voraussetzungen viel zu zeitgebunden, um einfach unter dem modernen Schlagwort ,Pazifismus' subsummiert werden zu können.

Drittens ist es zwar richtig, dass bestimmte auf heidnische Kulte hinweisende Schlagworte in Cels. 8,73-74 fehlen. Durch die Lektüre der Passage im weiteren literarischen Zusammenhang wurde allerdings deutlich, dass die ganze Diskussion eingebettet ist in das Werben des Celsus für die wahre Lehre und die daraus folgende angemessene Verehrung des Kaisers, der Dämonen, der Götter und auf diese Weise des höchsten Gottes. Diese Einbettung ist, wie gezeigt wurde, von entscheidender Bedeutung für das Verständnis des Textes und belegt, dass die Diskussion um die Frage des Heeresdienstes von Christen auch bei Origenes nicht losgelöst von dem Problem des heidnischen Kultus und vor allem eines heidnischen Weltbildes geführt wird. ${ }^{320}$ Es darf ebenfalls nicht übersehen werden, dass Christen im Heer genau den Kaisereid würden schwören müssen, den Origenes so vehement als unvereinbar mit dem christlichen Bekenntnis abgelehnt hat. ${ }^{321}$ Auch wenn all diese Dinge nicht explizit in den Kapiteln 73 und 74 genannt werden, so sind sie doch aufgrund ihrer Diskussion in den vorhergehenden Passagen noch immer präsent ${ }^{322}$ und dürften den Lesern des Origenes außerdem vertraut genug gewesen sein, um von ihrer engen Verbindung mit dem Heeresdienst zu wissen. Dass Origenes selbst diesen Zusammenhang zwischen

317 Siehe unten S. $319 \mathrm{ff}$.

318 Etwas zu unpräzise ist hier CASPARY, Politics, 126-127: „Indeed, it is essentially because of this eschatological role that Christians, Origen insists, are forbidden to fight the Emperor's wars. “ Denn die Christen kämpfen ja durchaus in den Kriegen des Kaisers mit und haben - sogar großen - Anteil an dessen Siegen, nur eben nicht in der Rolle als Soldaten, sondern als Priester. Richtig ist aber die Feststellung: „The ambivalence of the early Christian attitude towards war is thus merely a part of the dialectical relation between Old and New Dispensation.“

319 So mit vollem Recht Helgeland, Christians (ANRW), 751.

320 Vgl. Helgeland, Christians (ANRW), 750: „Origen's objection to Christian enlistment was religious, not ethical; he was primarily opposed to Christians pledging loyalty to the emperor.“

321 Cels. 8,65-67.

322 Von daher greift z.B. CADoux, Christian Attitude, 141, schlicht zu kurz: „He does indeed once mention ,impiety towards God‘ as a means of currying favour with kings, but never as a bar to service in the army.“ 
Heeresdienst und Idolatriegefahr auch über Contra Celsum hinaus als gegeben ansieht, wird eine Stelle aus seiner Auslegung zum 1. Korintherbrief des Paulus zeigen. ${ }^{323}$

Allerdings muss auch festgehalten werden, dass das Töten von Menschen in Cels. 8,73-74 ein Gewicht erhält, welches das bei Tertullian und umso mehr bei Clemens bei weitem übersteigt. Denn die Forderung nach Händen, die rein sind von Menschenblut, hat im Argumentationsgang sicherlich große Bedeutung. ${ }^{324}$ Im Weiteren wird neben den bereits angeführten Passagen aus Cels. 2,30 und 7,26 auch noch auf andere Texte aus dem Werk des Origenes hinzuweisen sein, die zeigen, dass es sich hier nicht um eine zufällige Gewichtung handelt. Vielmehr fügt sie sich in ein häufig auftretendes Motiv ein, das der ,zwei Schwerter‘, des geistlichen und des fleischlichen, von denen die Christen nur das erstere zu führen haben. ${ }^{325}$ Zugleich ist dieser Aspekt damit aber wiederum eindeutig in die heilsgeschichtlich-eschatologische Gesamtschau des Origenes eingeordnet und gewinnt erst von daher seinen Sinn. Also ist es auch hier zumindest problematisch von ,Pazifismus' zu sprechen.

Viertens hat die betonte Herausstellung der Friedfertigkeit der Christen zumindest auch die Aufgabe, die Ungefährlichkeit der Christen angesichts des immer wiederkehrenden Vorwurfs der Rebellion und der Aufsässigkeit aufzuzeigen.

\section{Fazit}

Zuletzt bleibt festzuhalten, dass dieser so zentrale und viel diskutierte Text des Origenes zur Frage des Heeresdienstes von Christen für sich allein gelesen letztendlich weit weniger aussagekräftig ist als vielmals angenommen. ${ }^{326}$ Andererseits gewinnt er erst in der Beschränkung auf seine eigentliche Zielsetzung seine inhaltliche Prägnanz zurück: Christen sind und leben anders als der Rest der Gesellschaft, so erklärt der Kirchenschriftsteller, und das ist auch gut so. Nur so können sie nämlich auch ihrer

323 Siehe unten S. $324 \mathrm{ff}$.

324 Vgl. SснӧPF, Tötungsrecht, 223: „Origenes ist überzeugt, ein Christ dürfe um keinen Preis Menschen töten. Aber in seiner Auseinandersetzung mit Celsus beschränkt er sich darauf, jene irrationalen Elemente, nämlich die instinkthafte Scheu, Menschenblut zu vergießen, und die Angst vor der Befleckung, anzuführen. Eben diese Faktoren waren auch im zeitgenössischen Heidentum noch wirksam [...].“

325 Siehe unten S. $332 \mathrm{ff}$. und S. $336 \mathrm{ff}$. Zur Frage der ,zwei Schwerter v vgl. die ausführliche Studie von CASPARY, Politics, auf die sich die Ausführungen zu diesem Thema weitgehend stützen.

326 Vgl. HaRnaCK, Militia Christi, 31, der zu Cels. 8,73 meint: „Aber vom weltlichen Kriegsdienst will Origenes nichts wissen; er hält ihn für unerlaubt.“ Oder GEERLINGS, vorkonstantinische Kirche, 11: „[...] betont er, daß die Christen niemals als Soldaten zu Felde ziehen werden [...]“. HunTeR, Church, 173-174, leitet seinen knappen Überlegungen zu Cels. 8,73 mit ausführlichen Zitaten aus Cels. 3,7-8 ein, wo Origenes sich zur Gewaltlosigkeit der Christen äußert und dazu, dass diese als Christen, als neues Gottesvolk keinen Krieg führen dürfen. Diese Bemerkungen stehen aber in einem völlig anderen Kontext und dienen v. a. der Abgrenzung gegenüber dem Judentum und der Widerlegung des Vorwurfs,

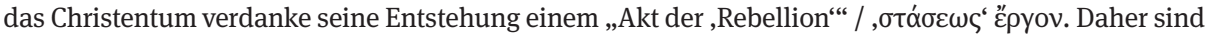
sie nur sehr bedingt für die Interpretation von Cels. 8,73 brauchbar. 
ganz anderen Rolle gerecht werden, die sie von Gott her in dieser Welt zu spielen haben.

Die Feststellung, dass Origenes dabei aber auch insgesamt eine reservierte Haltung zumindest gegenüber der Meldung von Christen zum Dienst im Heer einnimmt, scheint sich dennoch treffen $\mathrm{zu}$ lassen. $\mathrm{Zu}$ anders ist der Ton seiner Ausführungen beispielsweise im Vergleich zu Clemens Alexandrinus, selbst wenn man die argumentative Zielsetzung und die polemische Lage in vollem Umfang mit einberechnet. Allerdings muss sich diese Feststellung bei der Interpretation der weiteren Texte erst noch bewähren.

Eine Frage bleibt angesichts der hier vorgetragenen Interpretation dann aber offen. Wie H. Brennecke mit Blick auf Cels. 8,73-74 zu Recht feststellt: „Es bleibt allerdings bei Origenes am Ende die Frage unbeantwortet, ob Militärdienst und christlicher Glaube sich grundsätzlich ausschließen. “327 Denn eine grundsätzliche Antwort darauf wollte Origenes in den Schlusskapiteln von Contra Celsum nicht geben und er hat es auch nicht getan. ${ }^{328}$ Und selbst eine reservierte Haltung bedeutet noch nicht die Annahme einer prinzipiellen Unvereinbarkeit. Darum gilt es jetzt, diese weiteren Texte zu untersuchen und in Zusammenhang mit Contra Celsum zu setzen.

\subsubsection{Weitere Texte in Auswahl}

\subsubsection{Hom. in Lc. 23 Einführung}

Die Predigten des Origenes über das Lukasevangelium ${ }^{329}$ entstammen ebenfalls seiner Zeit in Cäsarea, wo es zu seinen alltäglichen Pflichten als Presbyter gehörte ${ }^{330}$, die

327 BRENNECKE, An fidelis (2007), 221. Ihm widerspricht ausdrücklich Sider, Killing, 68, da Origenes ja „clearly says ,we do not fight under him [the emperor]“ (Against Celsus 8.73).“ Leider entgeht im der hier dargelegte weitere Kontext der Stelle, was zu diesem Fehlurteil führt.

328 Aus diesem Grund kann man aus Contra Celsum auch nur schwerlich ein vollständiges ,Programm des Origenes mit Blick auf die Soldaten- und Ämterfrage herausarbeiten wie das z. B. CADoux, Christian Attitude, 144-147, versucht, wenn er schreibt (ebd., 145): „His programme thus consists of two gradual processes going on side by side as the result of the spread of Christianity: firstly, the gradual diminution of crime and the risk of foreign aggression, and secondly, the gradual substitution of spiritual influence for physical coercion, i.e. of a more for a less effective remedy for crime and aggression.“ Vgl. auch SwIFT, War (ANRW), 856: „What Origen had in mind was a gradual transformation involving not only the Roman world but that beyond the frontiers. What he was arguing for was the freedom necessary for this gradual change and union of all men under the law of Christ.“ Die besagte Einheit aller Menschen unter dem Gesetz Christi war für Origenes außerdem eine eschatologische Hoffnung, aber keine Erwartung, die sich innerweltlich in näherer oder weiterer Zukunft erfüllen würde.

$329 \mathrm{Zu}$ den Lukashomilien des Origenes vgl. HARNACK, Geschichte, 35 und 45; Origenes, Werke Bd. 9 , Die Homilien zu Lukas in der Übersetzung des Hieronymus und die griechischen Reste der Homilien und des Lukas-Kommentars, hrsg. von Max RaUER, (GCS 49), 2., neu bearb. Aufl., Berlin 1959, VII-XVIII; Nautin, Origène, 253, 398-399 und 411; SiebEN, In Lucam 1, 25-53; WiLliams, s.v. Origenes/Orige- 
Bibel in den Gottesdiensten der Gemeinde auszulegen. ${ }^{331}$ Im Unterschied $\mathrm{zu}$ den meisten anderen überlieferten Homilien handelt es sich dabei aber nicht um Texte des gereiften, über sechzigjährigen Origenes ${ }^{332}$, sondern sie dürften eher aus seiner frühen Zeit an seiner neuen Wirkungsstätte stammen. H.-J. Sieben datiert sie in sehr plausibler Weise in die Jahre um 234-235 n.Chr. ${ }^{333}$, eine Datierung, die auch diesem Kapitel zu Grunde liegt.

Die lateinische Übersetzung, in der die Lukashomilien überliefert wurden, ist aus der Feder des Hieronymus. ${ }^{334}$ Dieser fertigte sie wohl als polemische Replik auf die sehr stark auf die Origenes zurückgreifende ${ }^{335}$ Lukasauslegung des Ambrosius an, die

nismus (TRE), 406; CROUZEL, Origen, 30 und 43; Vogt, s.v. Origenes (LACL), 530; Als Textausgabe wurde auf die überarbeitete Ausgabe der Edition von M. Rauer zurückgegriffen (RAUER, Origenes Bd. 9 [2.A],) sowie auf die zweisprachige Ausgabe Origenes, In Lucam homiliae - Homilien zum Lukasevangelium, lat./griech./dt., übers. und eingel. von Hermann-Josef Sieben, 2 Bde., (Fontes Christiani 4), Freiburg i. Br. 1991-1992.

330 Vgl. Euseb. hist. eccl. 6,19,16, wo deutlich nahegelegt wird, dass Origenes seine (regelmäßige) Predigttätigkeit erst in Cäsarea aufnahm.

$331 \mathrm{Zu}$ Origenes als Prediger vgl. Trigg, Bible and Philosophy, 176-188; SieBen, In Lucam 1, 13-24; CRouzel, Origen, 24 und 29-30, Heine, Origen, 171-187. Der Kommentar zum Lukasevangelium, den Origenes ebenfalls verfasste, ist leider nur noch fragmentarisch erhalten, ohne die für diese Untersuchung relevanten Stellen.

332 Nach Euseb. hist. eccl. 6,36,1 hätte Origenes erst als über Sechzigjähriger erlaubt, dass Schnellschreiber seine Predigten aufzeichneten. Vgl. CROuzEL, Origen, 29-30, zu dem Ausdruck $\delta ı \lambda \varepsilon_{\varepsilon} \xi \varepsilon$; siehe bereits HaRnack, Geschichte, 35; und z. B. SiEBEN, In Lucam 1, 31. Eine Erklärung der früheren Abfassung der Lukashomilien angesichts dieses Sachverhalts bietet bereits HARNACK, Geschichte, 45, Anm. 3: comm. in Joh. 32,2 und comm. in Mt. 13,29 (Beleg nach HARNACK, Geschichte, 35; Sieben, In Lucam 1, 31) legen nahe, dass Origenes die Homilien selbst herausgegeben hat. So auch RAUER, Origenes Bd. 9 (2.A), VII-VIII; SIEBEN, In Lucam 1, 31, hält sie für „Notizen des Predigers selber“. Bei der Erlaubnis, die der über Sechzigjährige gegeben hat, handelt es sich um die Erlaubnis, dass Dritte seine Predigten zur Veröffentlichung mitstenographieren. Außerdem zählt auch Hieronymus die Lukashomilien in seinem einleitenden Brief an Paula und Eustochium zu den virilia, den Werken des noch jüngeren Origenes, der quasi puerum talis ludere / „gleichwie ein Junge mit Würfeln spielt“ (ÜS: AG). 333 SiEBEN, In Lucam 1, 28 - 31. Zur Datierung der Homilien vgl. HARNACK, Geschichte, 45 mit Anm. 3; RAUER, Origenes Bd. 9 (2.A), VIII-IX; NAUTIN, Origène, 411, der sie gemäß Theorie zu den Homilien des Origenes (ebd., 389-409) in die Jahre 239-242 datiert; ihm folgt TRIGG, Bible and Philosophy, 177; anders Sieben, In Lucam 1, 28-31, mit einer Kritik der Datierung P. Nautins; CRouzEL, Origen, 30. 334 Zur Übersetzung des Hieronymus vgl. RAUER, Origenes Bd. 9 (2.A), X-XVII; und SiEBEN, In Lucam 1, 33 - 46, denen die nachstehende Diskussion im Wesentlichen folgt. Siehe außerdem CrouzEL, Origen, 42 und 48-49; und FÜRST, Origenes, 231-233, für einen knappen, allgemeinen Überblick über die Problematik der lateinischen Übersetzungen der Schriften des Origenes. Zu Hieronymus vgl. kurz NAUTIN, Pierre, s.v. Hieronymus. In: TRE 15, (1986), 304-315; FÜrST, Alfons, s.v. Hieronymus. In: DöPP/ GEERLings (Hrsg.), LACL, 323-330; EIGLER, Ulrich, s.v. Hieronymus. In: DNP 5, (1998), 548-551; außerdem ausführlicher CAMPENHAusen, Lateinische Kirchenväter, 109-150; FüRst, Origenes, 25 - 42. 335 Vgl. RAuER, Origenes Bd. 9 (2.A), XI-XII; SiEBEN, In Lucam 1, 35-36. Hieronymus dürfte beabsichtigt haben, „den Plagiator bloßzustellen, freilich ohne seinen Namen zu nennen.“ (SIEBEN, In Lucam 1, 35). 
jener wohl 390 oder 391 n.Chr. veröffentlichte. ${ }^{336}$ Da die Übersetzungsarbeit des Hieronymus relativ zeitnah nach der Veröffentlichung des Ambrosius erfolgt sein wird, kann man sie mit H.-J. Sieben in etwa in das Jahr 392 n. Chr. ansetzen. ${ }^{337}$

Die Qualität der Übersetzung ist im Anschluss an M. Rauer und H.-J. Sieben als im Großen und Ganzen zuverlässig zu beurteilen. ${ }^{338} \mathrm{Zu}$ fragen ist allerdings, ob Hieronymus alle ihm vorliegenden Homilien des Origenes zum Lukasevangelium ins Lateinische übertrug oder ob er nur eine Auswahl wiedergab. Diese Frage, die auch für die Interpretation noch von Relevanz sein wird, ergibt sich aus der Tatsache, dass die Homilien in ihrer lateinischen Form signifikante Lücken in der Auslegung des Lukastextes aufweisen, darunter auch Auslassungen zu Texten, bei denen es sich nur schwer vorstellen lässt, dass Origenes sie nicht ausgelegt hätte. ${ }^{339}$ Außerdem erwähnt Origenes selbst zwei Homilien zum Lukasevangelium, die sich nicht bei den Übersetzungen des Hieronymus finden. ${ }^{340}$ Ob diese Auslassungen, sollten sie überhaupt auf Hieronymus zurückzuführen sein, zumindest teilweise einer Unzufriedenheit des Hieronymus mit theologischen Positionen des Origenes geschuldet sind oder andere Gründe haben, kann nicht mit letzter Sicherheit geklärt werden. ${ }^{341}$ Andererseits, und das spricht dagegen, die Reduzierung der Anzahl dem Hieronymus anzulasten, beschreibt dieser in dem einleitenden Brief an Paula und Eustochium die an ihn herangetragene Bitte, „wenigstens die 39 auf Griechisch vorliegenden Homilien unseres Adamantius [= Origenes; AG] über das Lukasevangelium zu übersetzen“342. In der Liste aus epist. 33 nennt er ebenfalls 39 Homilien. Wie H.-J. Sieben festhält,

„[w]ir verfügen über keinerlei positiven Beweis, daß Hieronymus nur einen Teil der ihm vorliegenden Homilien übersetzt hat. Wir haben deswegen davon auszugehen, daß er dem an ihn

336 Vgl. die kurze Diskussion bei Sieben, In Lucam 1, 36, der sich für das Jahr 391 n. Chr. ausspricht; MARKSCHIES, Christoph, s.v. Ambrosius von Mailand. In: DöPP/GeERLINGS (Hrsg.), LACL, 19-28, hier 23, datiert sie auf das Jahr 390 n. Chr.

337 Sieben, In Lucam 1, 36 - 37. So auch NAUTIN, s.v. Hieronymus (TRE), 306; FÜRST, s.v. Hieronymus (LACL), 325; FÜRST, Origenes, 267, 490 und 493. Da Hieronymus im Jahr 393 n.Chr. auf die Seite der Gegner des Origenes überwechselte, muss die - wertschätzende - Übersetzung der Lukashomilien vorher erfolgt sein.

338 RAUER, Origenes Bd. 9 (2.A), XIII-XV; Sieben, In Lucam 1, 37- 43.

339 Vgl. NAutin, Origène, 253, 398-399; SieBen, In Lucam 1, 40: „Fortlaufend erklärt werden in den Homilien 1-33 nur die Kapitel 1-4,27, und auch dort gibt es noch Lücken. Es fehlt die Auslegung von Lk 1,32-38; 2,3-7 und 2,17-20. Die Homilien 34-39 behandeln dann nur noch ausgewählte Textstücke, nämlich Lk 10,25 - 37; 12,58f.; 17,33.20 - 21; 19,29 - 40; 19,41-45; 20,21-40.“ Als Beispiel für eine solche, schwer verständliche Lücke nennt z. B. SIEBEN, In Lucam 1, 40 -41, die Perikope Lk 1,32-38.

340 Comm. in Mt. 13,29 und comm. in Joh. 32,2 (Beleg nach Sieben, In Lucam 1, 42, mit Anm. 59). Es handelt sich um Homilien zu Lk 15,3-7 und 14,12-14. Vgl. auch RAUER, Origenes Bd. 9 (2.A), VII-VIII. 341 Vgl. dazu Sieben, In Lucam 1, 41.

342 Hom. in Luc. praef.: saltem triginta et novem Adamanti nostri in Lucam omelias, sicut in graeco habentur, interpreter (ÜS: AG nach H.-J. Sieben). 
herangetragenen Wunsch, die 39 Homilien seiner Vorlage zu übersetzen, tatsächlich auch entsprochen hat. “343

Es ist daher durchaus möglich, wenn nicht sogar wahrscheinlich, dass es sich bei den genannten 39 Predigten bereits um eine schon früher zusammengestellte Auswahlsammlung gehandelt hat. ${ }^{344}$ Außerdem ist wohl davon auszugehen, dass Hieronymus an einigen Stellen Kürzungen und unter Umständen leichte Änderungen vorgenommen hat. ${ }^{345}$ Diese Gesichtspunkte werden bei der Textinterpretation zu berücksichtigen sein.

\section{Interpretation}

An dieser Stelle ist kein Text $\mathrm{zu}$ interpretieren, sondern auf eine Leerstelle hinzuweisen. Es handelt sich dabei um die sogenannte Standespredigt Johannes des Täufers aus Lk 3,10 - 14. ${ }^{346}$ In Vers 14 werden bekanntlich konkret Soldaten angesprochen, ein Vers, der bereits bei Tertullian und Clemens Alexandrinus Erwähnung fand. ${ }^{347}$ Dieser Text scheint in der Diskussion um die Soldatenfrage innerhalb der vorkonstantinischen Kirche eine wichtige Rolle gespielt zu haben und seine jeweilige Behandlung zeigt bei den genannten Autoren sehr deutlich ihre Einstellung zu dieser Problematik. ${ }^{348}$

Umso erstaunlicher ist es, dass genau dieser Vers in den Homilien des Origenes zum Lukasevangelium fehlt. ${ }^{349}$ In hom. 23 zu Lk 3,9-12 behandelt er sehr ausführlich die Antwort des Johannes an die Volksmenge (populi) und an die Zöllner (publicani), bricht dann aber vor der Behandlung des Wortes an die Soldaten in Vers 14 ab. Hom. 24 setzt daraufhin mit Lk 3,15 ein. Dieser Sachverhalt ist umso merkwürdiger, als er zu Beginn der 23. Homilie noch festgehalten hatte:

„Dann ist die Rede von drei Gruppen von Menschen, die Johannes nach dem Seelenheil fragen, einer ersten, die die Heilige Schrift ,Scharen, die zur Taufe herausgehen' nennt, einer zweiten, die sie als ,Zöllner‘ bezeichnet, und einer dritten, die den Namen ,Soldaten` trägt.“ ${ }^{\text {‘30 }}$

343 Sieben, In Lucam 1, 41.Vgl. auch RAuER, Origenes Bd. 9 (2.A), X-XII, der festhält (ebd., XII): „Die 39 Homilien scheinen also zur Zeit des Kirchenvaters [Hieronymus; AG] ein Corpus gebildet zu haben. Wer die Auswahl getroffen hat und unter welchen Gesichtspunkten, ist unbekannt. Kaum ist es Hieronymus selbst gewesen, sonst hätte er sich in seinem Briefe anders ausgedrückt“.

344 So Rauer, Origenes Bd. 9 (2.A), XII; und im Anschluss an diesen Sieben, In Lucam 1, 42.

345 Vgl. Rauer, Origenes Bd. 9 (2.A), XIV und XVI-XVII; Sieben, In Lucam 1, $42-43$.

346 Für den Text s. oben, S. 131, Anm. 480.

347 Siehe Tert. idol. 19,3; coron. 11,4; Clem. Al. paed. 3,12,91,2.

348 Bei Tertullian gibt die Verwendung dieses Textes in idol. 19 darüber hinaus auch Einblick in die Argumentation seiner Gegner.

349 Aus der Literatur zu Origenes vermerkt einzig SchöPF, Tötungsrecht, 225, diese Lücke.

350 Hom. in Lc. 23,2: deinde tres ordines inducuntur sciscitantium Ioannem super salute sua: unus, quem scriptura appellavit 'populos exeuntes ad baptisma', alius, quem ,publicanos' nominat. tertius, qui ,militum' appelatione censetur. (ÜS: H.-J. Sieben). Auch das bei RAUER, Origenes Bd. 9 (2.A), 151, an- 
Man würde angesichts dessen erwarten, dass er nach dieser Übersicht auch alle drei Gruppen behandeln würde. Sein Schweigen über die Soldaten ist umso erstaunlicher, als er am Ende seiner Predigt noch einmal auf sie zurückkommt, wenn seine Behandlung der Zöllner abschließt: „Ebenso war es auch mit den Soldaten, die zur Bußtaufe ,herausgingen' [...].“351. Damit rahmen Bezugnahmen auf die Soldaten die eigentliche Auslegung des Bibeltextes ein, die Mahnung an sie selbst wird aber nicht erläutert. In hom. 27,1 folgt dann noch einmal ein Rückverweis auf den ausgelassenen Vers 14: „Johannes verkündigte Christus [...] er lehrte die Zöllner das Heil, die Soldaten Zucht [...].“352 Warum findet sich dann kein einziges Wort über diesen Textabschnitt in seiner Predigt?

Da wie bereits in der Einführung festgehalten, die überlieferte lateinische Sammlung der Lukashomilien des Origenes unvollständig ist, dem Hieronymus aber wohl bereits in seiner griechischen Vorlage in dieser (Auswahl-)Fassung vorgelegen hat, wäre es möglich, dass eine Predigt aus der ursprünglichen Sammlung herausgestrichen worden war. Dafür könnte ein späterer Herausgeber einer griechischen Sammlung seiner Lukashomilien verantwortlich sein. Zwischen Homilie $23 \mathrm{zu}$ Lk 3,9-12 und Homilie $24 \mathrm{zu}$ Lk 3,15-16 hätte also noch eine weitere Auslegung zu Vers 14 stehen können. Sollte das der Fall sein, wäre das Fehlen ausgesprochen bedauerlich, da es sich dann um eine Auslegung gehandelt hätte, die allein der Soldatenparänese gewidmet gewesen wäre und die daher für diese Studie von größtem Interesse gewesen wäre. Allerdings ist diese Lösung nicht ohne schwerwiegende Probleme. Das ist nicht nur wegen der Kürze des Evangelientextes der Fall - diese Kürze wäre kein unausräumbares Hindernis ${ }^{353}$ - sondern vor allem, da die einleitenden Worte aus hom. 23,2 erwarten lassen, dass alle drei angesprochenen Gruppen in dieser Predigt thematisiert werden. Diese Erwartung wird durch die Bemerkung in hom. 23,9 und vor allem den kurzen Verweis in hom. 27,1 bestärkt.

Eine weitere Möglichkeit besteht darin, dass Origenes, der die Herausgabe der Predigten vermutlich verantwortete ${ }^{354}$, selbst für die Auslassung verantwortlich ist. Entweder hat er sie im Nachhinein bei der Edition aus der Sammlung gestrichen - sei es, dass er eine entsprechende Passage aus Homilie 23 entfernte, sei es, dass er eine vollständige Predigt nicht in die Sammlung aufnahm - oder er hat diesen Vers von Anfang an überhaupt nicht ausgelegt. So fragt B. Schöpf:

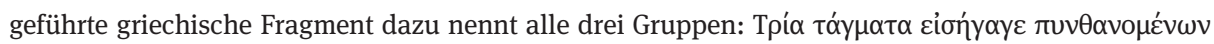

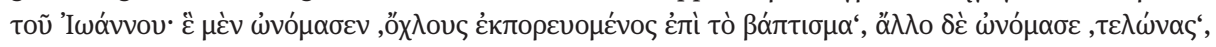

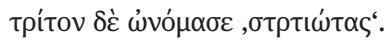

351 Hom. in Lc. 23,9: sicut et alii milites, qui egrediebantur ad baptismum paenitentiae (ÜS: H.-J. Sieben).

352 Hom. in Lc. 27,1: Ioannes [...] annuntiavit Christum [...] publicanos salutem docuit, milites disciplinam [...]. (ÜS: H.-J. Sieben).

353 So behandelt beispielsweise die unmittelbar folgende hom. 24 auch nur zwei Verse (Verse 15-16), ja eigentlich sogar nur einen Vers, nämlich Vers 16, da Vers 15 nur als Einleitung dient.

354 Siehe oben S. 320, Anm. 332. 
„War das Wort dem Gegner des Kriegsdienstes [sc. Origenes; AG] ungelegen? Fast möchte man das vermuten; denn jeder Zuhörer hätte wohl eine Exegese auch der letzten Täuferweisung erwartet, nachdem zuvor die drei Gruppen ausdrücklich genannt worden waren.“355

Aber auch in diesem Fall bleiben Fragen offen. Zum einen hätte, falls B. Schöpf die Haltung des Origenes zum Kriegsdienst richtig einschätzt, eine entsprechende Auslegung des Textes in seinem Sinne seiner Position sehr nützlich sein können. Auch Tertullian packte ja bekanntlich in idol. 19 den metaphorischen Stier bei den Hörnern. Dass der Text allerdings ein Eigengewicht hat, das einem gegenüber dem Heeresdienst von Christen skeptisch eingestellten Kirchenmann durchaus Probleme bereiten konnte, musste bereits besagter Tertullian feststellen. Auch für Origenes spricht, ähnlich wie bereits für Clemens, der Heilige Geist selbst durch den Mund des Johannes eine Mahnung aus ${ }^{356}$, die auch zu seiner, des Origenes eigener Zeit höchste ethische Relevanz hat. Das könnte für die These von B. Schöpf sprechen, sollte dem Origenes die Soldatenfrage tatsächlich so große Not bereitet haben, wie jener annimmt. Zum anderen, das ist die zweite ungelöste Frage, würde auch dann noch offen bleiben, ob der Alexandriner rund 15 Jahre später bei der Abfassung von Contra Celsum immer noch dieselben Bedenken hatte.

Auch wenn einiges für die Erklärung der Auslassung von B. Schöpf spricht, ist Sicherheit leider nicht zu gewinnen, so wünschenswert das auch wäre. Die Gefahr an dieser Stelle ist, den Text erst von der Voraussetzung einer sehr kritischen Haltung des Origenes dem Soldatenberuf gegenüber zu lesen und ihn dann als weiteren Beleg für diese Haltung herzuziehen, sich also in einem argumentativen Zirkel zu verfangen.

\subsubsection{Die Auslegung des 1. Korintherbriefes Einführung}

Hier ist kurz auf zwei Stücke aus dem insgesamt nur in Katenenform fragmentarisch erhaltenen Kommentar (oder aus Homilien?) des Origenes zum 1. Korintherbrief des Paulus einzugehen. ${ }^{357}$ P. Nautin datiert diese Auslegung in die Jahre 239-242 n. Chr.

355 ScнöpF, Tötungsrecht, 225.

356 Siehe hom. in Lc. 23,5 zur Weisung an die Zöllner: qui enim plus exegerint, non Ioannes mandatum praevaricantur, sed Spiritus sancti, qui locutus est in Ioanne. / „Wer aber mehr verlangt, der vergeht sich nicht gegen das Gebot des Johannes, sondern des Heiligen Geistes, der in Johannes gesprochen hat.“ (ÜS: H.-J. Sieben). Darauf weist auch SchöpF, Tötungsrecht, 225, hin. Auch in anderen Texten wie z. B. hom. in Lc. 4,6; 21,3 äußert sich Origenes zur bleibenden Bedeutung der Verkündigung des Johannes. Bei Clemens (paed. 3,12,2) war es der präexistente Logos, der durch Johannes sprach (und noch immer gültig spricht); s. oben S. $215 \mathrm{ff}$.

357 Vgl. Crouzel, Origen, 39, Anm. 17, der meint, dass sich die elf Bücher Homilien zum 2. Korintherbrief, die Hieronymus in epist. 33 erwähnt, evtl. darauf beziehen könnten und daher bei Hieronymus ,erster Brief‘ zu lesen sei; außerdem NAUTin, Origène, 254 und 411, der dieser bereits älteren Sicht, wie sie auch H. Crouzel vertritt, widerspricht (ebd., 254); und VoGT, s.v. Origenes (LACL), 530. Zum Text der Fragmente siehe Jenkins, Claude, The Origin-Citations in Cranmer's Catena on I Corinthians. In: JThS O.S. 6, (1904), 113-116; JENkINS, Claude, Origen on I Corinthians I-III. In: JThS O.S. 9, 
Da diese Datierung aber auf seiner, teilweise sehr hypothetischen Sicht zu den Homilien des Origenes beruht, ist es an dieser Stelle angebracht, eine gewisse Vorsicht walten zu lassen. Das ist umso mehr der Fall, als nicht ganz klar ist, ob die Fragmente aus Homilien oder aus einem Kommentar stammen. In Anbetracht der Tatsache, dass Contra Celsum aber zusammen mit dem Matthäuskommentar das Alterswerk des Origenes darstellt, dürfte es nicht falsch sein anzunehmen, dass die Auslegung zum 1. Korintherbrief aus einer (etwas?) früheren Zeit stammt.

\section{Text}

In $§ 26 \mathrm{zu}$ 1. Kor 5,9-11358, hier genauer zu V. 11, schreibt Origenes:

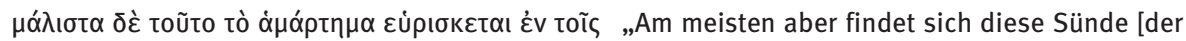

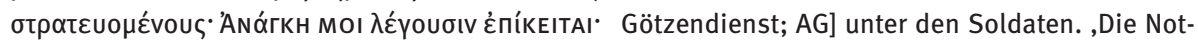

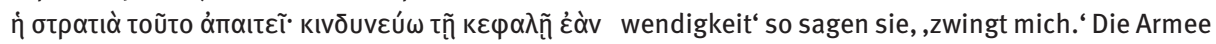

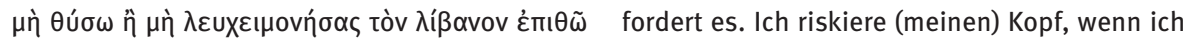

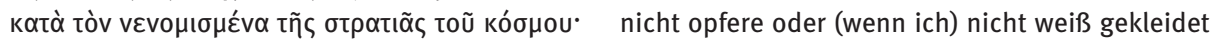

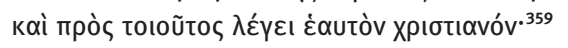
den Weihrauch nach der Sitte der Armee der Welt darbringe. Und doch nennt sich so einer selbst Christ.“

(ÜS: AG)

Und in $\S 27 \mathrm{zu} 1$. Kor 6,9-10360 hält er fest:

(1908), 231-247, 353-372, 500 -514; JENkins, Claude, Origen on I Corinthians IV. In: JThS O.S. 10, (1909), 29-50. Vgl. weiterhin die Anmerkungen dazu bei TuRner, Cuthbert H., Notes on the Text of Origen's Commentary on I Corinthians. In: JThS O.S. 10, (1909), 270-276.

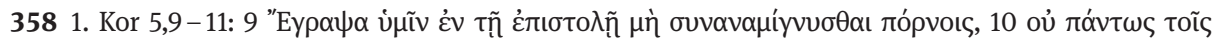

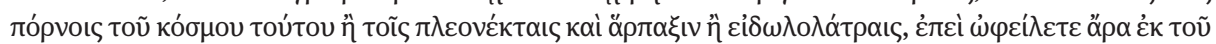

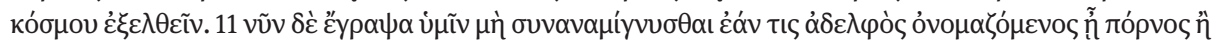

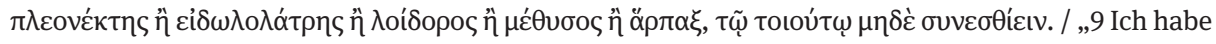
euch in dem Brief geschrieben, dass ihr nichts zu schaffen haben sollt mit den Unzüchtigen. 10 Damit meine ich nicht allgemein die Unzüchtigen in dieser Welt oder die Geizigen oder Räuber oder Götzendiener; sonst müsstet ihr ja die Welt räumen. 11 Vielmehr habe ich euch geschrieben: Ihr sollt nichts mit einem zu schaffen haben, der sich Bruder nennen lässt und ist ein Unzüchtiger oder ein Geiziger oder ein Götzendiener oder ein Lästerer oder ein Trunkenbold oder ein Räuber; mit so einem sollt ihr auch nicht essen.“ (ÜS: LÜ 1984).

359 JENKIns, Origen I-III, 366 - 369. In Kapitälchen gesetzte Worte geben die von C. Jenkins in „unical type“ (JENKINS, Origen I-III, 231) gesetzten biblischen Zitate oder Anspielungen wider. TURNER, Notes, 270, schreibt zur Bedeutung der Katenen der Korintherauslegung, hier mit besonderem Augenmerk auf die behandelte Stelle: „A reference to the inconsistencies between the duty of a Christian and the duty of a soldier (on 1 Cor. V 11) has escaped even Harnack's encyclopaedic knowledge of early Christian literature.“

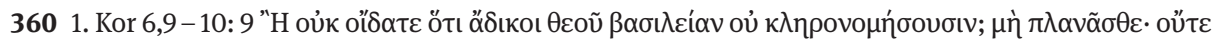

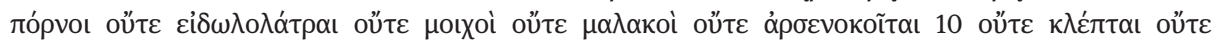

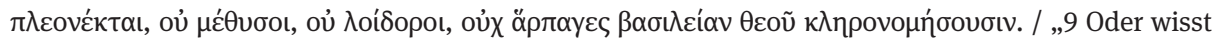
ihr nicht, dass die Ungerechten das Reich Gottes nicht ererben werden? Lasst euch nicht irreführen! 


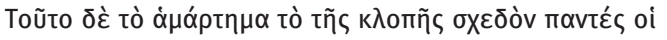

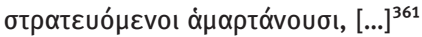

„Diese Sünde aber, die des Diebstahls, fast alle Soldaten begehen sie.“

(ÜS: AG)

\section{Interpretation}

Besonders die erste Stelle ist von Bedeutung, zeigt sie doch, dass Origenes die Verbindung von Soldatentum und Götzendienst durchaus präsent war. Nimmt man hinzu, dass er hier einen Text kommentiert, in dem Soldaten an sich gar nicht vorkommen, sondern der nur vom Götzendienst und anderen Vergehen handelt, Origenes aber nur aufgrund dieses Stichwortes sofort Soldaten in Spiel bringt, lässt sich mit gutem Grund vermuten, dass der Zusammenhang zwischen beiden in seinem Denken sehr eng gewesen sein muss. Da nicht anzunehmen ist, dass er diesen Zusammenhang bis zur Abfassung von Contra Celsum bereits wieder vergessen hatte, unterstützt dieser Text die hier vorgelegte Interpretation, nach der auch in Cels. 8,73-74 das Problem der Idolatrie - wenn auch in einer weniger direkten Form - mit hineinspielt.

Beide Stellen zeigen zudem eine sehr kritische Haltung gegenüber dem Heer und dem Dienst von Christen in jenem. Diese kritische Haltung entspringt aber - zumindest in den kurzen Sätzen der Korintherauslegung - nicht einem wie auch immer gearteten frühchristlichen Pazifismus, sondern handfesten Missständen, die aus christlicher Sicht dort vorherrschten. ${ }^{362}$ Dennoch wird damit die Annahme unterstützt, dass die Skepsis gegenüber dem Soldatendienst von Christen, die in Contra Celsum zu finden ist, nicht allein durch die polemische Situation der Schrift bedingt ist. Hinter dieser konkreten Ausformulierung seiner Skepsis könnten tatsächlich tiefere Überzeugungen stehen. Der fragmentarische Zustand der Textüberlieferung verbietet weitere, über das Dargelegte hinausgehende Folgerungen.

\subsubsection{Zum Umgang mit den Kriegstexten des Alten Testaments}

Der Umgang mit diesen Texten ist von nicht geringem Interesse für die Analyse der Haltung eines Kirchenschriftstellers zu Krieg und Soldatendienst. So viel wurde bereits im Kapitel zu Clemens Alexandrinus deutlich. ${ }^{363}$ Vergleicht man in dieser Hinsicht Origenes mit Clemens, dann zeigt sich, wie anders jener diese Texte behandelt. Hatte Clemens sie ohne erkennbares Problembewusstsein zur gegenwärtigen ethischen Ermahnung genutzt, so sieht Origenes hier erhebliche Probleme und thematisiert sie ausdrücklich. Da die entsprechenden Stellen in der Literatur zum Thema

Weder Unzüchtige noch Götzendiener, Ehebrecher, Lustknaben, Knabenschänder, 10 Diebe, Geizige, Trunkenbolde, Lästerer oder Räuber werden das Reich Gottes ererben.“ (ÜS: LÜ 1984).

361 JENKINS, Origen I-III, 369.

362 Aus der Literatur zu Origenes weisen lediglich RYAN, Rejection, 20; BAINTON, Early Church, 201 (= Kirche und Krieg, 201); und SIDER, Killing, 68 und 70 -71, kurz auf diese Texte hin.

363 Siehe oben S. $238 \mathrm{ff}$. 
ausreichend behandelt wurden, genügt es hier, auf einige zentrale Passagen kurz einzugehen. ${ }^{364}$

\section{Cels. 7,26}

Diese Stelle wurde bereits oben erörtert ${ }^{365}$, so dass an dieser Stelle der Verweis darauf und eine kurze Bemerkung genügen. Origenes erklärt den kriegerischen Charakter des alttestamentlichen Gottesvolkes Israel für heilsgeschichtlich überholt und die entsprechenden Texte damit für Christen nicht mehr im wörtlichen Sinn gültig.

\section{Homiliae in Jesu Nave \\ Einführung}

Diese Predigten zum alttestamentlichen Buch Josua wurden in den 240er Jahren in Cäsarea gehalten. ${ }^{366}$ Rufinus, dem wir auch diese Übersetzung verdanken, vermerkt in seiner Einleitung, dass sie von Origenes als senex ${ }^{367}$ gehalten worden seien, was bei aller Ungenauigkeit vielleicht an das Ende dieses Zeitraums denken lassen könnte.

Das Buch Josua bietet sich allein schon wegen der Namensgleichheit seiner Hauptperson Josua mit der Gestalt des Jesus von Nazareth hervorragend für eine allegorische Interpretation an. Denn beide werden auf Griechisch ('Inбoũc) wie auch auf Lateinisch (Iesus) gleich geschrieben. Außerdem agieren beide in der Rolle eines gottgesandten Retters und Heilsmittlers. Für Origenes ist Josua ein Typos, ein (Vor-) Bild Jesu. ${ }^{368}$

364 Für eine noch immer gute Übersicht über zahlreiche einschlägige Passagen vgl. HARNACK, Militia Christi, 99-103. Zu den Texten allgemein vgl. HarnaCK, Militia Christi, 26-31; Cadoux, Christian Attitude, 175-176; SCHÖPF, Tötungsrecht, 226-227; BAINTON, Early Church, 211-212 (= Kirche und Krieg, 215-216); HeLgeland, Christians (ANRW), 747-749; SwIFT, War (ANRW), 854-855; SWIFT, Views, 285-286; SHEAN, Soldiering, 89-90.

365 Siehe oben, S. $300 \mathrm{ff}$.

$366 \mathrm{Zu}$ diesen Homilien vgl. NAUTin, Origène, 401-405, 411; Williams, s.v. Origenes/Origenismus (TRE), 404; Crouzel, Origen, 43; Vogt, s.v. Origenes (LACL), 530; und jetzt ElsSnER, Thomas R., Josua und seine Kriege in jüdischer und christlicher Rezeptionsgeschichte, (Theologie und Frieden 37), Stuttgart 2008, 226-254. Der lateinische Text folgt der Ausgabe von W.A. Baehrens (Origenes, Werke Bd. 7, Homilien zum Hexateuch in Rufins Übersetzung - Zweiter Teil: Die Homilien zu Numeri, Josua und Judices, hrsg. von Wilhelm A. BaEhrens, (GCS 30), Leipzig 1921, 286-463). Eine hilfreiche deutsche Übersetzung bieten ElSSNER, Thomas R.; HeITHER, Theresia, Die Homilien des Origenes zum Buch Josua - Die Kriege Josuas als Heilswirken Jesu, (Beiträge zur Friedensethik 38), Stuttgart 2006, die (ebd., 8-17) auch eine gute Einleitung vorgelegt haben.

367 Hom. in Jos. praef.

368 Hom. in Jos. 1,1-4, hier v. a. 1,3: quo igitur nobis haec cuncta prospiciunt? nempe eo, quod liber hic non tamgesta nobis filii Nave indicet quam Iesu Domini nobis sacramenta depingat. / „Woraufhin weist dies alles für uns voraus? Natürlich dahin, dass dieses Buch uns nicht so sehr die Taten des Sohnes Nuns verkündet, als und vielmehr die Sakramente Jesu, meines Herrn, abbildet.“ (ÜS: T. Elßner). Vgl. dazu ELSSNER/HeIther, Homilien, 11; ELSSNER, Josua, 237-340. 
Zugleich bietet das Buch aber auch durch seine vielen Kriegsgeschichten und die Tatsache, dass diese Kriege einschließlich der physischen Vernichtung der Feinde im Auftrag Gottes geführt werden, zahlreiche Anstößigkeiten. Es waren ja nicht nur heidnische Kritiker des Christentums wie Celsus ${ }^{369}$, welche die Spannung zwischen dem zum Teil recht harten und sogar kriegerischen Gott des Alten Testaments mit seinem Gesetz und dem scheinbar ganz anderen Gott, den Jesus nach dem Neuen Testament verkündigt haben soll, und seinem bis hin zur Feindesliebe gesteigerten Liebesgebot $^{370}$ empfunden haben. ${ }^{371}$ Ein christlicher ,Erzhäretiker ${ }^{\star}$ wie Markion empfand im 2. Jhd. n.Chr. diese Spannung so stark, dass er am Ende zwei Götter postulierte, den gerechten und harten Gott des Alten Testaments und den davon eindeutig zu unterscheidenden liebenden Gott des Neuen Testaments und Vater Jesu Christi. $^{372}$

Auch einen betont kirchlichen Theologen wie Origenes beschäftigte dieses Problem, wie sich vor allem in seinen Homilien zum Buch Numeri und zum Buch Josua zeigt. In letzteren äußert er sich an mehreren Stellen dazu, von denen hier drei der wichtigsten (hom. in Jos. 11,6; 12,1; 15,1) kurz betrachtet werden sollen.

\section{Hom. in Jos. 11,6 -12,1 \\ Text}

In hom. in Jos. 11,6 schreibt Origenes:

sed interim lesus interfecit inimicos, non crudelitatem docens per hoc, sicut haeretici putant, sed futura in his, quae geruntur, sacramenta designans, ut, cum interemerit eos reges, qui regnum
„Aber wenn Jesus [sc. Josua; AG] die Feinde getötet hat, dann nicht, um damit Grausamkeit zu lehren, wie die Häretiker glauben, sondern um mit diesen Taten die zukünftigen Sakramente zu be-

369 Siehe oben, S. $301 \mathrm{f}$.

370 Es mag bedeuten, die sprichwörtlichen Eulen nach Athen zu tragen, dennoch soll zumindest darauf hingewiesen werden, dass das Gebot der Nächstenliebe aus der neutestamentlichen Jesusüberlieferung (Mt 22,39 par. Mk 12,31 par. Lk 10,27) eine direkte und bewusste Übernahme aus dem Alten Testament (Lev 19,18) darstellt. Zur Feindesliebe siehe Mt 5,44 und die in Anm. 371 genannte Literatur.

371 Vgl. ElsSNer/Heither, Homilien, 10-11. Diese Spannung wird beispielsweise in den sogenannten Antithesen der Bergpredigt Mt 5,21- 48 mit Händen greifbar. Siehe dazu ScHWEIzER, Eduard, Das Evangelium nach Matthäus, (NTD 2), 16. Aufl., 1. Aufl. d. neuen Fass., Göttingen 1973, 66-68 und 77-85; Luz, Ulrich, Das Evangelium nach Matthäus, Teilbd. 1: Mt 1-7, (EKK), 5., völlig neu bearb. Aufl., Düsseldorf/Neukirchen-Vluyn 2002, 324-416; HAGNER, Matthew 1-13 (WBC), 126-136; FrANCE, R.T., The Gospel of Matthew, (NICNT), Grand Rapids 2007, 191-229.

372 Zu Markion und den Markioniten vgl. kurz CHADwick, Kirche, 38-40; McKechnie, First Christian Centuries, 167-169 und 180-183. Außerdem Aland, Barbara, s.v. Marcion/Marcioniten. In: TRE 22, (1992), 89-101, mit einer ausführlichen Bibliographie; GRESCHAT, Katharina, s.v. Markion. In: DNP 7, (1999), 918-919. Etwas ausführlicher ist der Überblick bei Foster, Paul, Marcion - His Life, Works, Beliefs, and Impact. In: ExpT 121/6 (2010), 269-280.

373 Die Anspielung an den Apostel bezieht sich auf Röm. 6,19. 
peccati tenent in nobis, possimus illud implere, quod dixit Apostolus: ,sicut exhibimus membra nostra servire iniquitati ad iniquitatem, ita nunc exhibeamus membra nostra servire iustitiae in sanctificationem. ${ }^{6373}$ zeichnen. Wenn er nämlich die Könige, die in uns ein Königreich der Sünde besitzen, vernichtet hat, dann können wir das Wort des Apostels erfüllen: ,Wie wir unsere Glieder in den Dienst der Ungerechtigkeit zu (immer mehr) Ungerechtigkeit gestellt haben, so stellen wir jetzt unsere Glieder in den Dienst der Gerechtigkeit, so dass wir heilig werden.““

(ÜS: AG nach T. Heither)

Und in hom. in Jos. 12,1 fährt er fort:

si ea, quae per Moysen de tabernaculo vel sacrificiis et omni illo cultu adumbrabantur, ,typus et umbra' dicuntur ess, coelestium; sine dubio et bella, quae per lesum geruntur, et regnum atque hostium strages ,coelstium rerum umbra et typus" esse dicenda sunt, eorum dumtaxat bellorum, quae noster Dominus lesus cum suo exercitu et magistratibus, id est credentium populis atque eorum ducibus, contra diabolum et eius angelos proeliatur. ${ }^{374}$
„Wenn die Dinge, die durch Mose über das Bundeszelt, die Opfer oder den ganzen Kult schattenhaft angedeutet werden, als ,Abbild und Schatten der himmlischen Dinge' bezeichnet werden, dann müssen wir ohne Zweifel auch die Kriege, die durch Jesus [sc. Josua; AG] geführt werden, die Niederlagen der Könige und der Feinde als ,Schatten und Abbild himmlischer Dinge“ bezeichnen. Genau genommen sind es Kriege, die unser Herr Jesus mit seinem Heer und seinen Offizieren - gemeint ist das Volk der Glaubenden und ihre Anführer - gegen den Teufel und seine Engel führen.“

(ÜS: AG im Anschluss an T. Heither)

\section{Kontext}

In der elften Homilie legt Origenes Jos. 10 aus $^{375}$, wo Josua den mit den Israeliten verbündeten Gibeonitern zu Hilfe kommt und deren Feinde, eine Koalition kanaanäischer Könige, vernichtet. Am Ende wendet er sich in der angeführten Stelle auch dem Problem der Tötung der Feinde durch Josua, dem Typus Jesu, zu.

Und in der unmittelbar folgenden zwölften Homilie thematisiert er, wie es in der Einführung heißt, „dass die Kriege, die Jesus [sc. Josua; AG] geführt hat, geistig verstanden werden müssen“376. Gleich zu Beginn trifft er die zitierte, für sein Verständnis dieser Texte wichtige Feststellung.

374 Das Wort über „Abbild und Schatten“ nimmt auf Hebr 8,5 Bezug (vgl. ElsSNER, Josua, 233), eine Schlüsselstelle für das neutestamentliche Verständnis von Typologie (siehe auch Hebr 10,1). Vgl. dazu Michel, Otto, Der Brief an die Hebräer, (KEK 13), 14., durchges. Aufl., 8. Aufl. d. Ausl., Göttingen 1984, 286-293; Jeremias, Joachim; Strobel, August, Die Briefe an Timotheus und Titus, Der Brief an die Hebräer, (NTD 9), 12. Aufl., 2. Aufl. d. neuen Fass., Göttingen 1981, 162-164.

375 Vgl. zu diesen Stellen besonders HARNACK, Militia Christi, 26-27.

376 Hom. in Jos. 12 praef. : quod spiritualiter intelligi debeant bella, quae gessit Iesus (ÜS: T. Heither). 


\section{Interpretation}

Dass es Kriege im Alten Testament gegeben hat und dass diese Kriege im Auftrag Gottes von dessen Volk geführt wurden, kann Origenes nicht bestreiten. Wie A. von Harnack treffend formuliert: Origenes hätte „am liebsten [...] gewiss das Kriegerische in jedem Sinn über Bord geworfen; aber der Buchstabe der heiligen Schrift - und Origenes ist überzeugter Schrifttheologe - duldete das nicht.“

Darum wählt er einen anderen Ausweg, der auch seiner sonstigen Schriftauslegung $^{377}$ entspricht, er allegorisiert diese Texte und verortet sie heilsgeschichtlich als Schatten und Bilder der mit Christus beginnenden Heilszeit. Nur die Häretiker meinen, so stellt er fest, dass es darin wirklich um Gewalt und Krieg im Wortsinn gehe, und nehmen deshalb daran Anstoß. Dieser Seitenhieb dürfte unter anderem den auch im 3. Jhd. n. Chr. noch immer aktiven Markioniten gelten, für die im Anschluss an Markion der harte Gott des Alten Testaments nicht der Vater Jesu Christi gewesen sein kann. Für Origenes sind diese Texte dagegen als schattenhafte Vorausdeutungen des geistlichen Kampfes der Christen gegen den Teufel und seine Dämonen zu lesen und auch nur in dieser Weise von der christlichen Kirche auf das gegenwärtige Leben anzuwenden. ${ }^{378}$

Hier scheinen zwei Motive auf, die in Contra Celsum entscheidendes Gewicht erhalten werden, zum einen das des geistlichen Kampfes des neutestamentlichen Gottesvolkes und zum anderen das der heilsgeschichtlichen Einordnung alttestamentlicher Eigenheiten. Wenn auch der Aspekt der Nützlichkeit dieses Kampfes für die Gesellschaft und den Staat an dieser Stelle nicht im Blick ist, so wird doch deutlich, dass auch dieser Aspekt von Cels. 8,73-74 nicht nur einer Ad-hoc-Argumentation geschuldet ist, sondern allem Anschein nach einer tiefer liegenden Überzeugung des Origenes entspricht. Dasselbe gilt auch für sein heilsgeschichtliches Denken, wie es in Cels. 7,26 zu Tage tritt.

377 Vgl. kurz WiLliams, s.v. Origenes/Origenismus (TRE), 412-413, mit weiterer Literatur (ebd., 420); VoGT, s.v. Origenes (LACL), 532-533, mit ausführlicher Bibliographie (ebd., 533); VoGt, Origenes, 54; sowie etwas umfassender VogT, Kommentar Bd. 1, 10-38; außerdem Crouzel, Origen, 61-84. Mit konkretem Bezug zu den Josuahomilien diskutiert ElssNER, Josua, 227-236, die Hermeneutik des Origenes.

378 Zur Bedeutung der gegenwärtigen Relevanz für die homiletische Bibelauslegung des Origenes vgl. ELSSNER/HeIther, Homilien, 10: „Leitende Frage dieser Auslegung ist daher nicht wie in vielen modernen Kommentaren: ,Was meinte das Buch Josua im Kontext seiner Entstehungszeit?‘, sondern: ,Was bedeutet das Buch Josua hier und heute für uns?' Es geht Origenes darum, seiner gottesdienstlichen Gemeinde das Buch Josua als aktuelles Wort Gottes zuzusprechen und ihnen eine Auslegung zu bieten, die ihnen hilft, durch die Lesung dieses Buches etwas für ihren Glauben und für ihr Leben als Christen zu gewinnen." Sie verweisen in einer Anmerkung auf die instruktive Stelle hom. in Jos. 8,2: his auditis versimile est auditores dicere: quo mihi haec? quid mihi confert, si cognoscam quod victi sunt hi, qui habitabant Gai, quasi non simila aut etiam potentiora bella vel gesta sint vel gerantur?/,Wenn sie dies hören, werden die Zuhörer wahrscheinlich sagen: Was bedeutet das für mich? Was nützt es mir, wenn ich weiß, dass die Bewohner von Ai besiegt sind, als ob es nicht gleiche oder noch heftigere Kriege gäbe, die geschehen sind oder geschehen könnten.“ (ÜS: T. Heither). Vgl. außerdem ELSSNER, Josua, $227-228$. 


\section{Hom. in Jos. 15,1 \\ Text}

nisi bella ista carnalia figuram bellorum spiritalium gererent, numquam, opinor, Iudaicarum historiarum libri discipulis Christi, qui venit pacem docere, legendi in ecclesiis fuissent $a b$ Apostolis traditi. [...] unde denique sciens Apostolus nulla nobis iam ultra bella esse carnaliter peragenda, sed animae certamina contra spiritales adversarios desudanda, velut magister militiae praeceptum dat militibus Christi dicens: induite vos arma Dei, ut possitis stare adversus astutias diaboli: et ut horum spiritalium bellorum ex veterum gestis habere possimus exempla, istas nobis rerum gestarum narrationes in ecclesia voluit recitari, [.... ${ }^{379}$
„Wenn diese fleischlichen Kriege nicht das Vorbild geistlicher Kriege in sich tragen würden, so meine ich, wären die Bücher über die jüdische Geschichte niemals von den Aposteln den Jüngern Christi - (des Christus,) der kam, den Frieden zu lehren - zur Lesung in den Kirchen übergeben worden. [...] Daher schließlich, weil er weiß, dass von uns keine fleischlichen Kriege mehr zu führen sind, sondern dass wir uns in seelischen Kämpfen gegen geistliche Feinde abzumühen haben, gibt der Apostel den Soldaten Christi einem Feldherrn gleich den Befehl und spricht: ,Legt die Waffen Gottes an, damit ihr gegen die Verschlagenheit des Teufels bestehen könnt.' Und damit wir für diese geistlichen Kriege aus den Taten der Alten Vorbilder haben können, wollte er, dass die Erzählungen dieser Taten uns in der Kirche vorgetragen werden. [...." (ÜS: AG)

\section{Kontext}

In dieser Predigt legt Origenes vor allem Jos. 11,8-20 aus ${ }^{380}$, wo erst ausführlich vom Sieg der Israeliten über den kanaanäischen König Jabin von Hazor und dann summarisch von den darauf folgenden Kämpfen erzählt wird. Gleich zu Beginn hält er in der angeführten Passage - fast schon programmatisch - seinen Standpunkt fest.

\section{Interpretation}

An dieser Stelle zeigt sich, wie sehr Origenes an den alttestamentlichen Kriegstexten Anstoß nimmt - zumindest ihrem wörtlichen Sinn nach verstanden. Der Graben, der sich hier zwischen ihm und Clemens Alexandrinus aufzutun scheint, ist von großer Tiefe. Während dieser auch im Wortsinn von Kriegstexten des Alten Testaments wertvolle ethische Wegweisung entdecken kann, wendet sich jener erschrocken von ihnen ab und kann ihnen überhaupt keinen Wert beimessen. Allein allegorisch auf Christus und den geistlichen Kampf der Christen mit dämonischen Mächten hin

379 Hom. in Jos. 15,1. Der Hinweis auf den Apostel meint Eph 6,11, einen Vers aus dem Text über die sogenannte geistliche bzw. göttliche Waffenrüstung, der auch bei Tertullian (coron. 1,4; s. oben S. 112, Anm. 390) und Clemens (prot. 11,116,3-4; s. oben S. 231, Anm. 210 mit dem Wortlaut der Stelle) sowie in Cels. 8,73 (siehe oben S. 295, Anm. 211) bereits in Erscheinung trat.

380 Vgl. besonders dazu Harnack, Militia Christi, 27; BaInton, Early Church, 212 (= Kirche und Krieg, 215-216); ScHöPf, Tötungsrecht, 226 - 227; SwIFT, Views, 286; ELSSNER, Josua, 240 - 242. 
ausgelegt, ist es möglich, diese Texte überhaupt in der Kirche zu rezipieren und als Anweisung für die christliche Lebensführung zu nutzen. Auch wenn Origenes den historischen Gehalt der Texte, das vergangene Geschehen an sich, nicht in Frage stellt ${ }^{381}$, so „,verlieren diese Ereignisse ganz und gar an geschichtlicher Bedeutung und werden durch und durch spiritualisiert. “" ${ }^{382}$ Erneut bricht das Thema des geistlichen Kampfes der Christen mit aller Gewalt durch und bestimmt die Diskussion. Das wird auch in dem letzten Text der Fall sein, den es noch zu betrachten gilt.

\section{Homiliae in Numeri \\ Einführung}

Diese Predigten wurden ebenfalls in Cäsarea gehalten, wahrscheinlich zu einer ähnlichen Zeit wie die zum Buch Josua. ${ }^{383}$ Und auch sie wurden von Rufinus übersetzt; sie bieten sehr wahrscheinlich sogar seine letzte erhaltene Übersetzung. ${ }^{384}$ In ihnen ist vor allem eine Stelle von Interesse, in der das Konzept der ,zwei Schwerter', wie es G. Caspary $^{385}$ in großer Gründlichkeit analysiert hat, auftritt. Die Diskussion dieses Konzepts folgt im Wesentlichen G. Caspary.

\section{Hom. in Num. 20,5 \\ Text}

Haec aedificaverint priorem populum; tibi autem, „Diese Dinge mögen das vorherige Volk (Gottes) qui a Christo redemptus es et cui de manibus gladius corporalis ablatus est et datus est, gladius spiritus', arripe hunc gladium; et si videris Istraheliticum sensum cum Madianiticis scortantem meretricibus, id est cum diabolicis se cogitationibus volutantem, nolo parcas, nolo dissimules, sed statim percute, statim perime. [...] Hoc enim si facias, continuo sedabis iracundiam Domini; [...]. [...] Et ideo surgentes oremus, ut inveniamus paratum semper istum, gladium spiritus', per quem exterminentur et semina ipsa et erbaut haben. Du aber, der du von Christus erlöst wurdest, dem ein körperliches Schwert aus den Händen genommen wurde und dem ein ,geistliches Schwert' gegeben wurde, ergreife dieses Schwert. Und wenn du einen israelitischen Gedanken siehst, der mit einer midianitischen Dirne Unzucht treibt, das bedeutet, der sich mit teuflischen Vorstellungen beschäftigt, dann will ich, dass du inn nicht schonst, ihn nicht verheimlichst, sondern ihn sofort durchbohrst, ihn sofort tötest. [...] Denn wenn du das tust, wirst du sogleich den

381 Vgl. ElSSNER, Josua, 228 und 242.

382 ELSSNER, Josua, 242.

383 Zu den Homilien zum Buch Numeri vgl. NAUtin, Origène, 401-405 und 411; WiLliams, s.v. Origenes/Origenismus (TRE), 404; Crouzel, Origen, 43; Vogt, s.v. Origenes (LACL), 530. Der lateinische Text folgt der Ausgabe von BAEHREns, Origenes Bd. 7, 286-463. Eine gute Einleitung bietet die englische Übersetzung von Scheck, Thomas P.; Hall, Christopher A., Origen: Homilies on Numbers, (Ancient Christian Texts), Downers Grove 2009, xix-xxxii.

384 Siehe seine Bemerkungen zu seiner Lebenslage im Vorwort der Übersetzung (hom. in Num. praef.).

385 CASPARY, Politics.

$386 \mathrm{Zu}$ diesem Text vgl. v. a. CASPary, Politics, 32-39. 
conceptacula peccatorum ac propitius nobis fiat Deus per verum Fineem ipsum Dominum nostrum lesum Christum [...]. ${ }^{386}$
Zorneseifer Gottes besänftigen. [...] Und deshalb, lasst uns aufstehen und beten, dass wir dieses ,geistliche Schwert' immer bereit vorfinden, durch das sowohl die Samen der Übertretungen selbst als auch ihre Gefäße ausgelöscht werden. Und Gott wird uns gnädig werden durch den wahren Phineas, unseren Herrn Jesus Christus selbst [...].“ (ÜS: AG)

\section{Kontext}

Diese Predigt behandelt die Phineas-Episode in Num. 25,1-18 $8^{387}$, in der erzählt wird, wie einige Israeliten im Verlauf der Wüstenwanderung nach dem Exodus mit moabitischen Frauen ,Unzucht' begingen und daraufhin begannen, den moabitischen Göttern zu opfern. Nachdem bereits der Zorn Gottes über diese Untat verkündet worden war, brachte ein gewisser Zimri eine Midianiterin mitten in das Lager und sogar zum Heiligtum, der Stiftshütte. Ein Priester namens Phineas tötete beide, Zimri und die Midianiterin, indem er sie mit einer Lanze durchbohrte, und sühnte auf diese Weise die Schuld des Volkes. Daraufhin wurde eine Plage, die Gott zur Strafe über das Volk gebracht hatte, abgewendet und Gott verlieh Phineas und seinen Nachkommen für seinen Eifer ein ewiges Priestertum. Soweit der Text aus dem Buch Numeri.

Auch wenn dieser Text weder konkret von Kriegführung noch vom Soldatendienst handelt, ist er dennoch von großem Interesse. Zum einen, weil er noch einmal sehr deutlich zeigt, wie Origenes mit Gewalt im Alten Testament umgeht. Zum anderen, weil hier, wie schon gesagt, das Thema der ,zwei Schwerter auftritt, das in der Verbindung mit Mt 26,52 für das Verständnis seiner Haltung zu Krieg und Gewalt von Bedeutung ist. Dieses Thema wird bei der Diskussion aller Texte aus dem Matthäuskommentar noch eine wichtige Rolle spielen.

\section{Interpretation}

Origenes deutet nun diesen Text erneut allegorisch auf den Kampf des Christen mit der Sünde und dem Bösen. Phineas wird dabei zu einem weiteren typos für Christus, da er durch seine Handlung ebenfalls die Schuld des Volkes sühnt und Vergebung erwirkt. Zur Tat des Phineas äußert er sich in der angeführten Textstelle.

In dieser Auslegung zeigt sich sehr schön die dialektische Verhältnisbestimmung ${ }^{388}$, die Origenes zwischen den heilsgeschichtlichen Epochen, der Zeit des Alten Testaments einerseits und der Zeit des Neuen Testaments andererseits, vornimmt.

387 Vgl. dazu Wenham, Gordon J., Numbers - An Introduction and Commentary, (TOTC 4), Leicester 1981, 184-189; Schmidt, Ludwig, Das 4. Buch Mose Numeri - Bd. 2: Kap. 10,11-36,13, (ATD 7,2), Göttingen 2004, 144-152.

388 Nach CASPARY, Politics, 37. 
Christen empfangen einerseits selbst aus einem so grausamen Text wie dem über die Gewalttat des Phineas wertvolle geistlich-ethische Unterweisung und haben dessen Handlung selbstverständlich nachzuahmen. Diese Nachahmung darf aber andererseits auf keinen Fall buchstäblich erfolgen, es darf also unter keinen Umständen zu einer tatsächlichen Ausübung von körperlicher Gewalt kommen. Das mag dem „Vorherigen Volk (Gottes)“389 so gegolten haben, aber nicht mehr den Christen, dem Volk des neuen Bundes. Für diese gilt vielmehr, wie G. Caspary vermerkt:

„Christians [...] realize that 'types and shadows have had their ending' and they must not push their imitation of Old Testament types to the point of resisting the Advent of Truth. Phineas example should be imitated, yet it should also be rejected: in other words, there must be a transfiguration, or a conversion (metanoia) from the carnal to the spiritual level.“"390

Annahme und Zurückweisung, Nachahmung und Widerspruch sind hier ganz eng miteinander verbunden und ineinander verschlungen. Der Hinweis darauf, dass dem Christen das gladius corporalis aus den Händen genommen wurde, dürfte wie schon bei Tertullian ${ }^{391}$ eine Bezugnahme auf die Entwaffnung des Petrus im Garten Gethsemane sein. ${ }^{392}$ Hier aber gewinnt sie tatsächlich in programmatischer Weise und nicht nur als Ad-hoc-Argument wie bei Tertullian Bedeutung für die Haltung des Christen zur Gewaltanwendung. Der Christ steht in einem anderen Kampf als der Israelit im Alten Testament, in einem geistlichen Kampf gegen die Sünde und den Teufel, nicht mehr in einem fleischlichen Kampf gegen Menschen. Hier deutet sich etwas von der Andersartigkeit der christlichen Lebensweise an, wie sie Origenes dann einige Jahre später in Cels. 8,73-74 - allerdings nicht mehr gegenüber dem Judentum, sondern gegenüber der heidnischen Welt - hervorheben wird.

\section{Fazit}

Nach diesem kurzen Überblick über einige zentrale Stellen zum Verständnis der Kriegstexte des Alten Testaments bei Origenes kann man zusammenfassend festhalten: Origenes steht diesen biblischen Texten im unverkennbaren Gegensatz zu Clemens mit einer deutlichen inneren Reserve gegenüber. ${ }^{393}$ So sehr sie für ihn Heilige

389 Hom. in Num. 20,5: priorem populum. (ÜS: AG).

390 CASPary, Politics, 37.

391 Tert. idol. 19,3: quomodo autem bellabit, immo quomodo etiam in pace militabit sine gladio, quem dominus abstulit? Diese Stelle wird gemäß der Konjektur Petrus statt populus in idol. 19,2, die in 19,3 fortgesetzt wird, auf Petrus bezogen. Siehe oben S. $89 \mathrm{f}$.

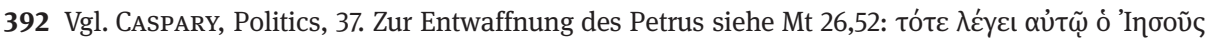

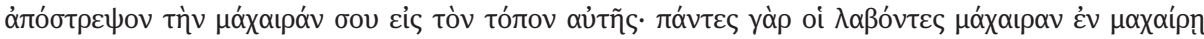

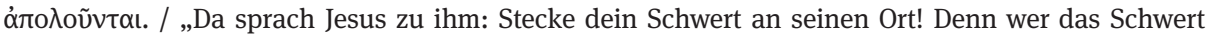
nimmt, der soll durchs Schwert umkommen.“ (ÜS: LÜ 1984).

393 Die hier festgestellten Unterschiede unterstützen auch die im Kapitel zu Clemens Alexandrinus vorgelegte Interpretation der Texte älteren Alexandriners. 
Schrift sind und daher höchste Autorität haben, so sehr ringt er doch mit der inhaltlichen Spannung zwischen diesen Texten und zentralen Texten des Neuen Testaments. Die Auflösung dieser Spannung gelingt ihm nur, indem er die alttestamentlichen Texte einerseits einer allegorischen Auslegung unterzieht und sie andererseits heilsgeschichtlich verortet. Damit kann er sie inhaltlich - das heißt in ihrem Literalsinn im engeren literarischen Kontext - begrenzen. Auf diese Weise lässt sich dann auch zeigen, wie A. Harnack zu hom. in Jos. 11-12 festgehalten hat: „Einen kriegerischen Gott gibt es also auch im Alten Testament nicht [...].“394

Am Beispiel dieser Texte werden außerdem inhaltliche Linien deutlich, die in Contra Celsum ebenfalls sichtbar waren, wenn sie auch dort auf eine ganz bestimmte Problemstellung hin angewendet und daher teilweise anders akzentuiert wurden. Diese Beobachtungen unterstützen die Annahme, dass diese Aspekte in Contra Celsum bei aller konkreten Zuspitzung doch auf prinzipiellen Erwägungen beruhen. Durch diese Texte zeigt sich außerdem weiter, was schon die vorher untersuchten Stellen nahelegten, nämlich dass die Haltung des Origenes zum Heeresdienst von Christen eher reserviert und die gegenüber der Beteiligung an Kriegen wohl sehr skeptisch sein dürfte.

\subsubsection{Der Matthäuskommentar Einführung}

Von den 25 Büchern des Matthäuskommentars ${ }^{395}$, den Origenes wahrscheinlich um 249 n. Chr. in Cäsarea verfasste und der daher zu seinen spätesten Werken gehört ${ }^{396}$, sind immerhin acht Bücher in Griechisch erhalten. ${ }^{397}$ Dabei handelt es sich um die Bücher 10 -17, die Mt 13,36-22,33 kommentieren. Dazu kommt eine paraphrasierende lateinische Übersetzung des Kommentars zu Mt 16,13-27,66, für die sich zu den Teilen, die dem griechischen Text entsprechen, die Bezeichnung vetus interpretatio einge-

394 HARNACK, Militia Christi, 26.

395 Zum Matthäuskommentar des Origenes vgl. HARNACK, Geschichte, 35 und 41; NAUTIN, Origène, 375- 376 und 412; Trigg, Bible and Philosophy, 211-214; VogT, Kommentar Bd. 1, 1-59; Origenes, Der Kommentar zum Evangelium nach Matthäus, Bd. 2, eingel. und übers. von Hermann J. Vogt, (BGL 30), Stuttgart 1990, 1-31; Origenes, Der Kommentar zum Evangelium nach Matthäus, Bd. 3, eingel. und übers. von Hermann J.VogT, (BGL 38), Stuttgart 1993, 1-22; WiLliams, s.v. Origenes/Origenismus (TRE), 405; Crouzel, Origen, 41-43; Vogt, s.v. Origenes (LACL), 530; Vogt, Origenes, 56-57. Als Textausgabe wurde auf die Edition von E. Klostermann zurückgegriffen (Origenes, Matthäuserklärung, 3 Bde., hrsg. von Erich KlostermanN, (GCS), Leipzig 1933-1955) sowie auf die deutsche Übersetzung von H.J. Vogt (Origenes, Der Kommentar zum Evangelium nach Matthäus, 3 Bde., eingel. und übers. von Hermann J. VoGT, (BGL), Stuttgart 1983-1993).

396 Euseb. hist. eccl. 6,36,1-2 ordnet auch den Matthäuskommentar dem Alterswerk des Origenes zu. Zur Datierung vgl. Nautin, Origène, 375 - 376 und 412; Vogt, Kommentar Bd. 2, 1-4; Heine, Origen, 219-221. Wie VoGT, Kommentar Bd. 1, 49-50, festhält, kann man den Matthäuskommentar daher wohl „[z]u vielen Fragen [...] als sein letztes Wort nehmen, das frühere Aussagen bestätigt oder korrigiert.“ Vgl. auch HeINE, Origen, 219-256.

397 Leider sind die von Hieronymus erwähnten Homilien zum Matthäusevangelium nicht erhalten. 
bürgert hat und für den Teil, zu dem es keine griechische Entsprechung gibt, die Bezeichnung commentariorum series. ${ }^{398}$

Beide Teile sind, obwohl unmittelbar fortlaufend, wie eigenständige Werke mit jeweils eigenen Kapitelangaben versehen. Die Übersetzung stammt nicht wie die meisten anderen lateinischen Wiedergaben aus der Feder des Rufinus oder des Hieronymus, sondern von einem anonymen Übersetzer, der wohl in der Zeit um die Wende vom 5. zum 6. Jhd. n.Chr. seine lateinische Fassung anfertigte. ${ }^{399}$ Außerdem sind einzelne griechische Stücke zu dem Kommentar fragmentarisch überliefert, von denen eines, ein Katenenfragment, im weiteren Verlauf der Interpretation noch wichtig werden wird.

\section{Die Auslegung des Origenes zu Mt 19,2 \\ Comm. in Mt. 15,1-2}

An dieser Stelle seines Matthäuskommentars ${ }^{400}$ legt Origenes den Text Mt 19,12 ${ }^{401}$ aus. Es handelt sich dabei um die erste Stelle in diesem Werk, in dem er auf den Unterschied der ,zwei Schwerter‘ zu sprechen kommt. Doch zunächst geht es ihm darum aufzuzeigen, dass es sich bei der dritten im Bibeltext genannten Gruppe, das sind diejenigen, die sich selbst zur Ehe unfähig gemacht haben, anders als bei den ersten beiden Gruppen nicht um eine körperliche Angelegenheit handelt. Manche hätten das so verstanden und sich daher selbst in schrecklicher Weise verstümmelt. ${ }^{402}$ Andere

398 Für das Verhältnis der beiden lateinischen Textfassungen zum griechischen Text des Matthäuskommentars siehe Vogt, Kommentar Bd. 3, 3-6; Vogt, Hermann J., Bemerkungen zur lateinischen Übersetzung des Matthäus-Kommentares von Origenes. In: Vogt, Origenes als Exeget, 91-104; außerdem Vogt, Hermann J., Das Verhältnis der alten lateinischen Übersetzung (L) zum griechischen Text des Matthäus-Kommentares (Gr). In: Vogt, Origenes als Exeget, 121-134. Für die commentariorum series vgl. besonders die Einleitung bei Vogt, Kommentar Bd. 3, 1-22

399 CROUZEL, Origen, 42.

400 Siehe dazu die ausführliche Diskussion bei CASPARY, Politics, 56-82, dem dieses Kapitel viel verdankt.

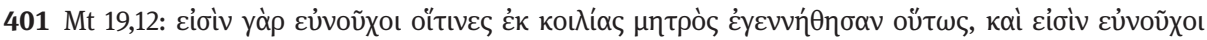

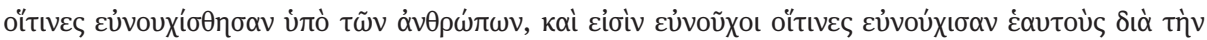

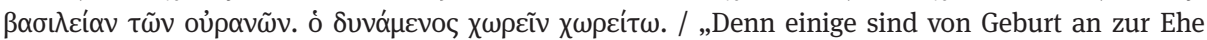
unfähig; andere sind von Menschen zur Ehe unfähig gemacht; und wieder andere haben sich selbst zur Ehe unfähig gemacht um des Himmelreichs willen. Wer es fassen kann, der fasse es!“ (ÜS: LÜ 1984). 402 Origenes selbst soll sich in jungen Jahren ebenfalls einer solchen Selbstverstümmelung unterzogen haben, so z. B. Euseb. hist. eccl. 6,8,2. In der Forschung ist umstritten, ob es sich dabei um eine zuverlässige Nachricht handelt, oder um Polemik seitens seiner alexandrinischen Gegner, der selbst ein Eusebius zum Opfer gefallen ist. Für nicht authentisch halten diese Nachricht z. B. VoGT, Kommentar Bd. 2, 141-142, Anm. 7; WilliAMs, s.v. Origenes/Origenismus (TRE), 398; FüRsT, Origenes, 5. Dagegen meinen andere, dass es sich um eine zutreffende Überlieferung handeln dürfte, so beispielsweise CAmpenhausen, Griechische Kirchenväter, 45; Crouzel, Origen, 8-10, mit Anm. 32. Eine umstrittene Frage ist dabei, ob es sich bei seiner Kritik an einer solchen Handlung in comm. in Mt. 15,1 um eine Korrektur einer in jungen Jahren von ihm selbst vertretenen Ansicht handelt, oder ob diese Stelle eine solche Handlung gerade ausschließt. 
dagegen hätten nur die ersten beiden Fälle (ausschließlich) buchstäblich verstanden, den dritten Fall aber sinnbildlich. Dagegen hätten auch die beiden ersten Fälle neben der buchstäblichen noch eine übertragene Bedeutung, welche auch hier die wichtigere sei. Beide Gruppen hätten daher in der Auslegung der Passage methodische Fehler begangen, die Origenes auch entsprechend bespricht. ${ }^{403}$ Gegen beide, aber vor allem gegen die erste Gruppe, gelte es festzuhalten, dass auch für diese Stelle aus dem Matthäusevangelium der Grundsatz aus 2. Kor 3,6 Gültigkeit behalte, dass der Buchstabe tötet, der Geist aber lebendig macht. ${ }^{404}$ Die tötende Wirkung der buchstäblichen Interpretation, so versteht Origenes hier $ү \rho \alpha ́ \mu \mu \alpha$, zeige sich daran, dass sie sich aufgrund ihres buchstäblichen Textverständnisses selbst verstümmelten. ${ }^{405}$ Für die Gültigkeit dieses paulinischen Prinzips führt Origenes dann noch weitere Beispiele an.

Sein erstes Beispiel ist Lk 22,35-36. Dort fordert Jesus an entscheidender Stelle seine Jünger auf: „[...] und wer's nicht hat, verkaufe seinen Mantel und kaufe ein Schwert. “406 Origenes kommentiert diesen Vers wie folgt:

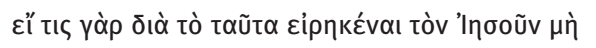

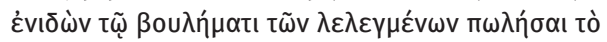

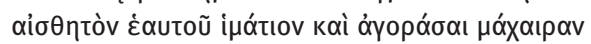

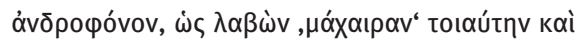

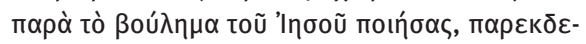

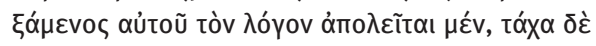

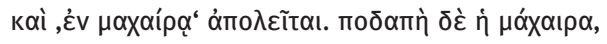

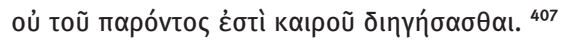

„Wenn einer nämlich, weil Jesus das gesagt hat, nicht auf die Absicht des Gesagten schaut und etwa sein sichtbares Kleid verkauft und ein männertötendes Schwert kauft, wird er, weil er ein solches Schwert genommen und gegen den Willen Jesu gehandelt hat, umkommen, weil er sein Wort falsch aufgefasst hat; vielleicht wird er sogar ,durch das Schwert umkommen'. Welcher Art aber das Schwert ist, das auszulegen, ist jetzt nicht die Zeit".

(ÜS: H. Vogt)

Als weitere Beispiele nennt er in 15,2 die beiden Stellen Lk 10,4 (,[...] und grüßt niemanden unterwegs. “408), und Mt 5,29-30 (,Wenn dich aber dein rechtes Auge zum Abfall verführt, so reiß es aus und wirf's von dir. [...]Wenn dich deine rechte Hand zum

\footnotetext{
403 Seine eigene Lösung ist, wie er in comm. in Mt. 15,4 erklärt, alle drei Abschnitte sinnbildlich zu deuten.

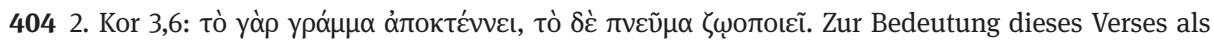
„hermeneutische[r] Leitlinie“ (Vogt, Origenes, 53) des Origenes vgl. CaSPaRY, Politics, hier v. a. 42-63; Vogt, Kommentar Bd. 2, 12-13; Crouzel, Origen, 64-69; Vogt, Origenes, 53-54.

405 Soweit alles nach comm. in Mt. 15,1, was folgt steht in 15,2.

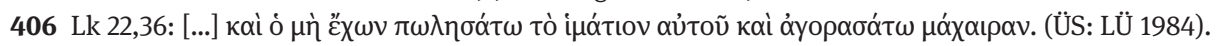
407 Comm. in Mt. 15,2. Bereits in hom. in Lev. 7,5 zu Lev 11 hatte er diesen Text - dieses Mal zusammen mit Joh 6,53 - in derselben Weise benutzt. Siehe dazu CASPARY, Politics, 44-56. Durch den Hinweis, dass der, der das Schwert aufnimmt, auch durch das Schwert umkommt, verbindet er den Lukastext mit Mt 26,52, woher diese Mahnung entnommen ist.
}

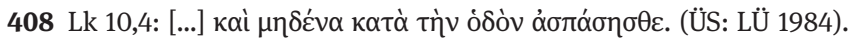


Abfall verführt, so hau sie ab und wirf sie von dir.“409), wo eine buchstäbliche Umsetzung in unterschiedlicher Weise ebenfalls großen Schaden anrichten würde.

In comm. in Mt 15,5 spricht er dann dementsprechend auch von einem ,vernunftgemäßen [bzw. geistigen] Schwert“410, das dazu gebraucht werden kann, in sinnbildlich-geistiger Weise den dritten Teil des Jesuswortes aus Mt 19,12 umzusetzen. Gemeint ist damit im Anschluss an comm. in Mt 15,4 das Wort Gottes, das dort nach Hebr 4,12 und Eph 6,17 als „das lebendige und wirksame und schärfer ,als jedes zweischneidige Schwert“ schneidende Wort“ und als „das Schwert des Geistes“ bezeichnet wird. Mit diesem könne man „die Leidenschaftlichkeit der Seele herausschneide[n], ohne aber Hand an den Körper zu legen“"411.

Insgesamt geht es ihm hier, wie G. Caspary festgehalten hat, um die „misconstruction of a metaphor “412, die zu einem gravierenden Fehlverhalten führt. Dagegen will Origenes, wie auch schon in seinen Auslegungen alttestamentlicher Kriegstexte, auf den richtigen, das heißt den sinnbildlichen Gebrauch solcher Texte hinweisen. Nur in dieser Weise gelesen lassen sich aus ihnen ethische Maximen ableiten. G. Caspary hat den Sachverhalt sehr gut getroffen, wenn er schreibt:

„In all four cases [Mt 5,29; 19,12; Lk 10,4; 22,36; AG], Origen is worried about aggressiveness in the name of Christ, whether against others or against the self. He is worried about misconstruction of ,the sword of the spirit" of Ephesians and ,the word of God, sharper than any two edged sword" of Hebrews. “413

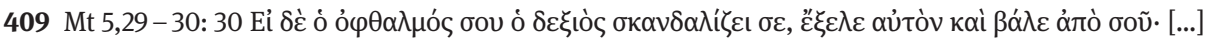

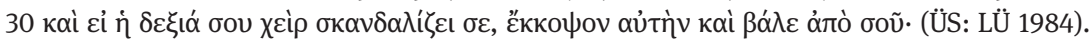

410 Comm. in Mt. 15,5: „Es ist aber eine große Kraft der Seele durch das Wort zu fassen, welche nicht alles fassen, sondern nur die, denen es gegeben ist. Es wird aber all denen gegeben, die von Gott das vernunftgemäße [bzw. geistige; AG] Schwert erbitten und es gebrauchen, wie es sich gehört, um sich

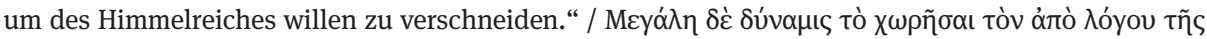

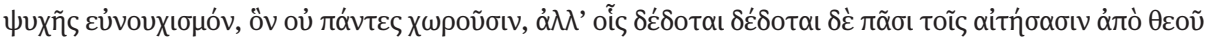

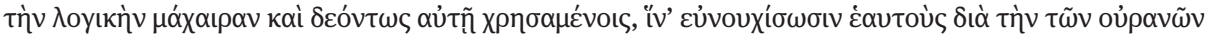

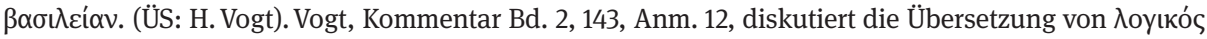

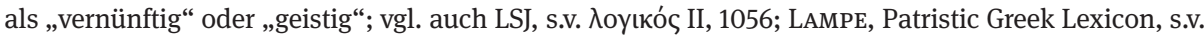
入оуıко́ৎ, 805.

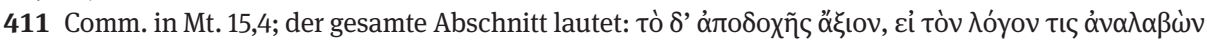

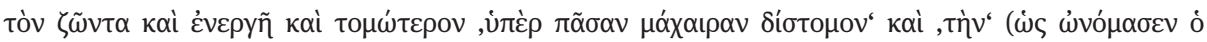

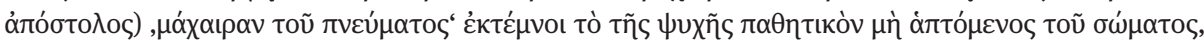
[...] / „Das aber verdient Zustimmung, wenn jemand das lebendige und wirksame und schärfer ,als jedes zweischneidige Schwert' schneidende Wort ergreift und ,das Schwert des Geistes' (wie der Apostel es nennt) und die Leidenschaftlichkeit der Seele herausschneidet, ohne aber Hand an den Körper zu legen [...].“ (ÜS: H. Vogt).

412 CASPARY, Politics, 77.

413 CASPARY, Politics, 77; ebd., 78 fügt er hinzu: „Origens meaning is reasonably clear. An overly literal interpretation of the first moment of the sword pericope will have the same results as the misconstruction of the three other sayings in the list of the Commentary on Matthew. To castrate oneself, practice self-mutilation, or indeed simply refuse to salute anyone on the way will only result in subjecting oneself to shame and obloquy, ,make men hate the very words of Jesus ', and ,in the end pe- 
Es findet sich also an dieser Stelle, wo man es angesichts des Themas von Mt 19,12 vielleicht gar nicht erwarten würde, erneut die Unterscheidung der ,zwei Schwerter', von denen der Christ selbstverständlich nur das geistige/geistliche zu führen hat. Vor dem Hintergrund dieser Unterscheidung ist auch der Hinweis auf das Schwert aus Lk 22,36 $\mathrm{zu}$ verstehen. Es ist bedauerlich, dass sein positives Verständnis dieser Stelle nicht ermittelt werden kann, da der Lukaskommentar des Origenes verloren ist und er diesen Text weder in den erhaltenen Homilien noch in den Fragmenten behandelt.

Sein Kommentar zu dieser Stelle in der hier behandelten Matthäusauslegung führt allerdings zu der Frage, ob Origenes in seiner Sorge um eine mögliche Aggressivität im Namen Christi dort vielleicht (auch) christliche Soldaten gemeint haben kann. Dann würde es sich nämlich um eine sehr scharfe Verurteilung der Ausübung einer solchen Tätigkeit handeln. Und diese Verurteilung würde sich zudem noch ausdrücklich auf

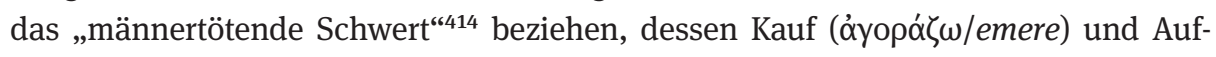
nahme $(\lambda \alpha \mu \beta \alpha ́ v \omega /\langle$ accipere $)$ Handlungen gegen den Willen Jesu darstellen. Der Text würde also einen starken Anhalt bieten, dass Origenes den Soldatenberuf wegen des damit verbundenen Tötens von Menschen ablehnt. Außerdem könnte man dann folgern, dass der behandelte Lukastext unter Umständen von christlichen Soldaten zur Begründung der Ausübung ihrer Tätigkeit genutzt wurde und Origenes ihnen an dieser Stelle widerspricht. ${ }^{415}$ Allerdings lässt sich eine solche Deutung angesichts des knappen Textbefunds in keiner Weise positiv belegen.

Weiterhin hat G. Caspary wohl zu Recht darauf hingewiesen, dass Origenes sich hier wahrscheinlicher um die Möglichkeit eines christlichen Zelotismus im Angesicht drohender Verfolgungen sorgt. ${ }^{416}$ Die angespannte Lage der Kirche zur Zeit der Abfassung des Kommentars kurz vor der sogenannten decischen Verfolgung gibt dieser Annahme durchaus Plausibilität. Eine noch zu besprechende Katene zu Mt 26,52417 lässt eine so scharfe Wendung gegen christliche Soldaten außerdem unwahrscheinlich erscheinen.

rhaps' bring about a ,fruitless death“ having, incurred the hatred of all. 'Similarly, those who take up the sword will surely perish, perhaps even perish by means of the sword.“"

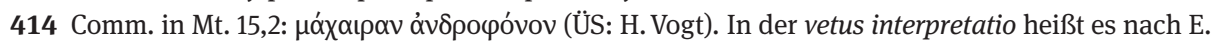
Klostermann (Origenes, Werke Bd. 10, Matthäuserklärung 1 - Die griechisch erhaltenen Tomoi, hrsg. von Erich KLOSTERMANN, (GCS 40), Leipzig 1935, 352) gladius 〈homicidalem [...]), wobei es sich bei dem Text in \langle\rangle um eine Ergänzung gemäß der griechischen Fassung handelt.

415 Vgl. Caspary, Politics, 77.

416 CASPARY, Politics, 77-78: „In the specific case of the first moment of the sword pericope, he may be worried about Christian soldiers in the Roman armies (such as those attacked by Tertullian) who might use Luke 22,36 as an excuse for killing in wartime. More likely, he is troubled by the possibility that Christian Zealots might offer armed resistance in the face of persecution, as will be the case here and there within a few decades after Origen's death; [...]. [...] The fact that the 'Book of the wars of Jahweh' operates under two radically distinct Dispensations may be forgotten, the sword of the spirit may once more be confused with the sword of Phineas.“

417 Siehe unten S. $345 \mathrm{ff}$. 
Somit bietet der Text keinen direkten Anhalt, was die Stellung des Origenes zum Soldatenberuf von Christen angeht. Er zeigt aber, dass die Behauptung, dass Christen anstelle des buchstäblichen Schwertes ein geistliches Schwert führen beziehungsweise zu führen haben, ein durchgehendes Motiv in seinem Werk ist. Von daher bietet er eine wichtige Hilfe, um den Hintergrund der Texte mit expliziten Bezugnahmen auf die Soldatenfrage besser auszuleuchten.

\section{Die Auslegung des Origenes zu Mt 26,51-52}

Comm. ser. in Mt. 101-102

In dieser Stelle, die ausschließlich in der lateinischen Übersetzung erhalten ist, kommentiert Origenes den Text von Mt 26,51-54. Dabei handelt es sich um die Begebenheit, auf die Origenes selbst und zuvor auch Tertullian mehrfach angespielt haben, nämlich die Entwaffnung des Petrus im Garten Gethsemane. Der Text des Matthäusevangeliums lautet:

„[51] Und siehe, einer von denen, die bei Jesus waren, streckte die Hand aus und zog sein Schwert und schlug nach dem Knecht des Hohenpriesters und hieb ihm ein Ohr ab. [52] Da sprach Jesus zu ihm: Stecke dein Schwert an seinen Ort! Denn wer das Schwert nimmt, der soll durchs Schwert umkommen."“418

Origenes schreibt dazu:

[101] [...] , unus' autem eorum, qui erant cum lesu', nondum manifeste concipiens apud se evangelicam patientiam illam traditam sibi a Christo nec pacem, quam dedit discipulis suis, sed secundum poptestatem datam ludaeis per legem de inimicis ,extendens manum 'accepit, gladium et" percussit ,servum principis sacerdotum' et , amputavit auriculam eius'. [...]

„[101] [...] ,Einer‘ aber von denen, ,die bei Jesus waren', hatte bei sich noch nicht offenkundig jene evangeliumsgemäße Geduld aufgenommen, die ihm von Christus übergeben worden war, noch den Frieden, den er seinen Jüngern gegebene hatte, sondern ,streckte“ im Sinne der Macht, die den Juden durch das Gesetz über die Feinde gegeben war, ,seine Hand aus', nahm ,das Schwert', schlug ,auf den Knecht des Hohenpriesters ein und, hieb sein Ohr' ab. [...]

[102] Mox lesus ad eum, qui fuerat gladio usus et [102] [...] Sogleich sagt Jesus zu dem, der das abstulerat , auriculam' servi illius dextram, non Schwert benutzt und das rechte ,Ohr jenes

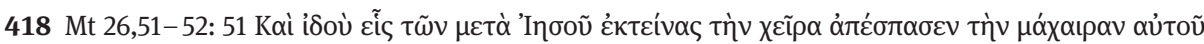

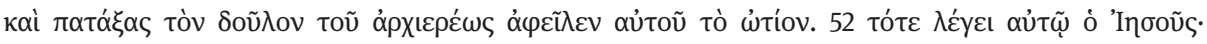

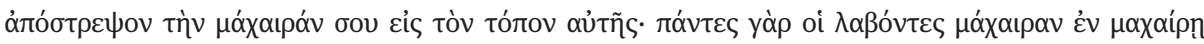

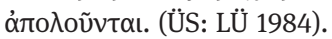

419 Comm. ser. in Mt. 101. Im Anschluss an den zitierten Text von comm. ser. in Mt. 101 deutet Origenes es allegorische aus, dass Petrus dem Diener laut Joh 18,10 gerade das rechte Ohr abgeschlagen hat.

420 Vogt, Kommentar Bd. 3, 276, übersetzt: „ein geheimnis(voller Hinweis auf) Krieg und Streit“. Zur Übersetzung von mysterium als „Symbol“ vgl. GEORGES, s.v. mysterium, Bd. 2, 1083. 
dicit: exime gladium, sed: ,converte gladium in locum suum: est ergo gladii aliquis locus, ex quo non licet accipere eum, qui non vult perire, maxime in gladio. pacificos enim vult esse lesus discipulos suos, ut bellicum hunc, gladium 'deponentes alterum pacificum accipiant,gladium;, quem dicit scriptura, gladium spiritus'. simile autem mihi videtur quod dicit: 'omnes qui accipiunt gladium, gladio et peribunt', id est, omnes qui non sunt pacifici sed belli concitatores, in eo bello peribunt quod concitant, ut sit in eis gladius mysterium belli et litis. et puto quod omnes tumultuosi et concitatores bellorum et conturbantes animas hominum, maxime ecclesiarum, accipiunt gladium in quo et ipsi peribunt; quoniam, qui fodit foveam, ipse incidet in eam', quoniam, convertetur dolor' eorum ,in caput' ipsorum, et ,iniquitas“ eorum ,in cerebrum 'eorum, descendet'. sed et simpliciter audientes quod dicit: ,qui accipiunt gladium, gladio peribunt' cavere nos convenit, ut ne occasione militiae aut vindictae propriarum iniuriarum eximamus, gladium ‘ aut ob aliquam occasionem, quam omnem abominatur evangelica haec Christi doctrina, praecipiens ut impleamus quod scriptum est: ,cum his qui oderunt pacem eram pacificus'. si ergo, cum odientibus pacem debemus esse pacifici, adversus neminem gladio uti debemus. ${ }^{419}$
Knechtes abgeschlagen hatte, nicht: Zieh dein Schwert heraus, sondern: ,Steck das Schwert an seinen Platz zurück!' Es gibt also einen Platz für das Schwert, von dem man es nicht nehmen darf, wenn man nicht gerade durch das Schwert umkommen will. Jesus will nämlich, dass seine Jünger friedfertig sind, damit sie dieses kriegerische ,Schwert' ablegen und das andere friedfertige ,Schwert' nehmen, welches die Schrift ,Schwert des Geistes“ nennt. Von ähnlicher Bedeutung scheint mir aber sein Wort zu sein: ,Alle, die zum Schwert greifen, werden auch durch das Schwert umkommen', d.h. alle, die nicht friedfertig sind, sondern Krieg schüren, werden in dem Krieg umkommen, den sie schüren, so dass bei ihnen das Schwert ein Symbol für Krieg und Streit ${ }^{[420]}$ ist. Und ich meine, dass alle Unruhestifter, Kriegstreiber und solche, welche die Seelen der Menschen in Aufruhr versetzen, besonders die der Kirchen $^{[421]}$, zu dem Schwert greifen, durch das sie auch selber umkommen werden, denn, ,wer eine Grube gräbt, wird selbst hineinfallen', denn ihr ,Schmerz kehrt auf ihr eigenes Haupt zurück, und ihre Bosheit steigt herab auf ihr eigenes Hirn'. Aber auch wenn wir sein Wort: ,Die zum Schwert greifen, kommen durch das Schwert um', nur einfach hören, müssen wir uns hüten, damit wir nicht bei Gelegenheit des Militärdienstes oder zur Vergeltung des von uns selbst erlittenen Unrechts ,das Schwert' herausziehen oder aus irgendeinem Anlass; dies alles verabscheut die Lehre Christi gemäß dem Evangelium, die uns das Schriftwort zu erfüllen befiehlt: , Mit denen, die den Frieden hassen, war ich friedfertig،. Wenn wir also mit denen, die den Frieden hassen, friedfertig sein müssen, dürfen wir gegen niemand das Schwert gebrauchen."

(ÜS: AG nach H. Vogt)

Diese Stelle bietet die schärfste Verurteilung des Soldatendienstes aufgrund des Umgangs mit Waffen und der Verwicklung in Krieg und Gewalt in allen bisher untersuchten Texten der drei Kirchenschriftsteller. Zugleich ist diese Verurteilung auch hier wieder eng in ein heilsgeschichtliches Verständnis des Verhältnisses zwischen Altem und Neuem Testament, zwischen Israel und der christlichen Kirche einge-

421 Vogt, Kommentar Bd. 3, 276, übersetzt: „alle Aufrührer und Kriegshetzer und Menschenseelenverwirrer, besonders die in den Kirchen [...]“. Zur Diskussion siehe unten S. 344. 
bunden. Erneut stehen die ,zwei Schwerter‘, das körperliche, buchstäbliche und das geistig-geistliche Schwert, im Mittelpunkt dieser heilsgeschichtlichen Schau.

Indem der bei Matthäus namentlich nicht genannte Jünger ${ }^{422}$ ein buchstäbliches Schwert zieht, um Jesus zu verteidigen, fällt er wieder in Verhaltensmuster zurück, die belegen, ,that the Prince of the Apostles was still entangled in the meshes of the Old Testament“, wie G. Caspary festhält. Der Jünger führt gewissermaßen noch das Schwert des Phineas und eifert für seinen Gott durch die Ausübung von Gewalt, ohne zu begreifen, dass mit dem Kommen Jesu ein neues Heilszeitalter begonnen hatte, durch das ein solches Verhalten obsolet wurde. ${ }^{423}$ Wie Origenes erklärt, wäre dieses Verhalten im alten Heilszeitalter durchaus angemessen und vor allem durch das Gesetz Gottes abgedeckt gewesen. ${ }^{424}$

Hier stellt seine Erklärung dieses Sachverhalts eine Kurzfassung dessen dar, was er kurz vorher oder ungefähr zeitgleich in Cels. 7,26 ausführlich dargelegt hatte ${ }^{425}$ : Das alttestamentliche Gottesvolk hatte das Recht, Kriege zu führen und Verbrecher abzuurteilen, da es sich zugleich um ein Staatswesen handelte, das neutestamentliche Gottesvolk aber hat all das nicht mehr, besitzt es doch auch kein eigenes Staatswesen mehr, sondern lebt eingebettet und geschützt innerhalb des Imperium Romanum. $\mathrm{Zu}$ diesen heilsgeschichtlichen Überlegungen kommt ergänzend noch eine quasi psychologische Erklärung dieses Verhaltens hinzu, das Fehlen der dem Evangelium gemäßen Geduld und des von Christus verliehenen Friedens.

Dazu beinahe im Gegensatz steht die in comm. ser. in Mt. 101 folgende, allegorische Ausdeutung der Tatsache, dass der Jünger, jetzt mit Petrus identifiziert, dem Tempeldiener, Malchus, ausgerechnet das rechte Ohr abgeschlagen hat. Es handle sich um einen ,,sacramental` act full of hidden allegorical meaning“4226, wie G. Ca-

422 Erst Joh 18,10 identifiziert diesen namenlosen Jünger mit Petrus, eine Identifizierung, die Origenes im weiteren Verlauf von comm. ser. in Mt. 101 voraussetzt. Das gilt ebenso für die Nennung des Namens des Tempeldieners, Malchus, im Johannestext.

423 Vgl. CASPARy, Politics, 85, in Anlehnung an Formulierungen aus hom. in Num. 20,5: „What they did not as yet understand was that with the passover from the Old to the New Dispensation, the corporeal sword (which might have edified God's former people) had been taken away and replaced with the sword of the spirit." In Cels. 2,2 bietet Origenes in Verbindung mit Joh 16,12-13 eine ähnliche Erklärung für gewisse Erkenntnisdefizite der Jünger Jesu vor dessen Auferstehung. Solche Erkenntnisdefizite zeigten sich aus dieser Perspektive - Origenes würde sicher zustimmen (vgl. CASPARY, Politics, 82) - bereits in der Reaktion der Jünger auf das Schwertwort aus Lk 22,36, wo es in V. 38 zu

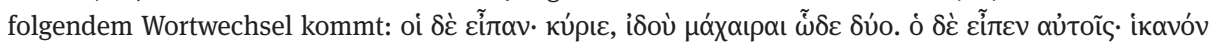

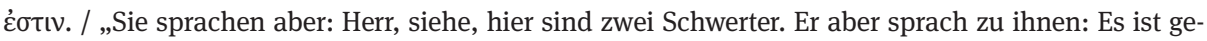
nug.“ (ÜS: LÜ 1984). Auch G. Caspary weist (ebd., 85) auf diese beiden Texte hin.

424 Vogt, Kommentar Bd. 3, 275, lässt ihn hier an Texte wie Dtn 7,2; 20,17 denken, an erstere Stelle denkt auch E. Klostermann (Origenes, Werke Bd. 11, Matthäuserklärung 2 - Die lateinische Übersetzung der Commentariorum series, hrsg. von Erich Klostermann, (GCS 38), Leipzig 1933, 221, Anm. zu Z. 4). Man könnte auch Dtn 2,17-24 und andere Texte hinzufügen.

425 Siehe oben S. $300 \mathrm{ff}$.

426 CASPARY, Politics, 85-86. Origenes beschreibt die Handlung des Petrus als ein mysterium (comm. ser. in Mt. 101: et forsitan quod agebat Petrus mysterium erat, [...] / „Und vielleicht war das ein Ge- 
spary meint. Origenes entdeckt darin nämlich ein sinnbildliches Gericht über das durch Malchus personifizierte Judentum, das fortan, wegen seines bösen Verhaltens Jesus gegenüber, das Gesetz des Mose nicht mehr richtig hören und verstehen könne. ${ }^{427}$ Hier erhält die Tat des Petrus eine beinah positiv zu nennende zeichenhafte Bedeutung.

Grundsätzlich aber beurteilt er die Handlung des Petrus negativ und löst sie zugleich aus ihrem konkreten historischen Kontext. Er sieht in der Zurechtweisung durch Jesus eine prinzipielle Aussage über die Stellung Jesu und damit der Christen zum Schwert, das heißt an dieser Stelle: zur Gewaltanwendung im Namen Gottes beziehungsweise im Namen des Glaubens. Wie er in comm. ser. in Mt. 102 noch einmal ausführlich darlegt: Im Gottesvolk der neuen Heilszeit hat das buchstäbliche ,Schwert“ und damit die Anwendung von Gewalt im Namen des Glaubens keinen Platz mehr. Das Schwert hat vielmehr an seinem Ort (locus) ${ }^{428}$ zu bleiben, von dem es auch nicht aufgenommen (accipere) werden darf, will man nicht durch eben dieses Schwert umkommen. Da Jesus die Friedfertigkeit (pacificus esse) seiner Jünger wollte, dürfen diese nicht mehr das kriegerische Schwert (bellicus gladius) führen, sondern nur noch das Schwert des Friedens (pacificus gladius), das auch das in der Heiligen Schrift erwähnte gladius spiritus ist.

Origenes identifiziert außerdem das buchstäbliche Schwert als ein mysterium belli et litis, sieht darin also ein - sakramental verstandenes? ${ }^{429}$ - Sinnbild für Krieg und Streit. Er stellt daher alle diejenigen, die Krieg und Streit schüren unter das Ver-

heimnis, was Petrus tat, [...]“ [ÜS: H. Vogt]) und benutzt, sollte dahinter das griechische $\mu v \sigma \tau$ tŕpıv stehen, was wahrscheinlich ist, damit sakramentale Sprache.

427 Origenes bezieht sich am Ende seiner Ausführung ausdrücklich auf die Gerichtsprophetie aus Jes 6,10, wo dem Volk Israel die Ohren schwer gemacht und die Augen verschlossen werden sollen, damit sie weder hören noch sehen können. Als Grund dafür nennt er außerdem, dass durch die Verschlossenheit der Juden den Heiden der Weg zu Christus eröffnet worden sei. Es handelt sich hierbei um eine Anlehnung an die und zugleich Missdeutung der Diskussion des Paulus zum Verhältnis von Juden und Heiden in Röm 9-11. Vgl. zu diesem Teil aus comm. ser. in Mt. 101 ausführlicher CASPARY, Politics, 85-89, der auch festhält, dass Origenes die Tatsache, dass Jesus den laut Lk 22,51 unmittelbar nach dem Angriff seines Jüngers heilte und sein Ohr wieder herstellte, für seine Allegorese ignoriert. Erst am Ende der Auslegung der ganzen Perikope in comm. ser. in Mt. 103 nimmt er auf die Heilung Bezug, dann aber in ganz buchstäblicher Weise und ohne allegorischen Bezug auf das Judentum. In seinem eindeutig vor dem Matthäuskommentar anzusetzenden Kommentar zum Römerbrief (comm. in epist. ad Rom. 8,12; zur Datierung vgl. NAuTin, Origène, 385-386, der auf die Bezugnahmen in comm. in Mt. 17,32 und Cels. 5,47; 8,65 hinweist) kommt dagegen auch die endzeitliche Errettung Israels in einer „rather touching exegesis“ (CASPARY, Politics, 89) in sein Blickfeld. Dieses Beispiel zeigt sehr gut, was auch in der bisherigen Diskussion der Texte deutliche geworden ist: Man darf von Origenes an einzelnen Stellen keine unbedingte inhaltliche Vollständigkeit erwarten, vielmehr spitzt er von bestimmten inhaltlichen Grundlinien ausgehend Inhalte immer wieder gemäß seiner konkreten Zielsetzung zu. Das gilt auch für seine jeweilige Diskussion der Soldatenfrage.

428 Leider bietet Origenes keine weitere (allegorische) Erklärung dieses Ortes! Erst in comm. ser. in Mt. 103 erwähnt er am Ende der Auslegung der Perikope dann die Schwertscheide, quod est patientia.

429 Vgl. CaSPary, Politics, 90. 
dammungsurteil von Mt 26,52, dass sie nämlich auch durch das Schwert, das sie aufgenommen haben, selbst umkommen werden. Das gelte nicht nur für alle Unruhestifter, Kriegstreiber und solche, welche die Seelen der Menschen in Aufruhr versetzen (omnes tumultuosi et concitatores bellorum et conturbantes animas hominum), sondern maxime ecclesiarum. H. Vogt übersetzt hier: „,alle Aufrührer und Kriegshetzer und Menschenseelenverwirrer, besonders die in den Kirchen [...] “430. Das lässt daran denken, dass seines Erachtens Origenes solche kriegerischen, aufrührerischen Menschen auch in den Kirchen vermutet. Der Genitiveinschub maxime ecclesiarum sollte aber besser in Parallele zu hominum verstanden werden. Es gibt also Leute, welche die Seelen der Menschen, besonders die der - hier personifiziert gedachten - Kirchen in Aufruhr versetzen und daher unter diesem Urteil stehen. ${ }^{431}$ Das Gericht wird hier also nicht Christen angedroht, die sich mit Blick auf das buchstäbliche Schwert als Aufrührer etc. erweisen, sondern solchen Menschen, die durch ihre aufrührerischen Handlungen die Kirchen von außen bedrängen und in Unruhe versetzen.

Anschließend folgen dann die stärksten Worte über den Gebrauch des (buchstäblichen) Schwertes: Dieses dürfe selbst bei einem einfachen (simpliciter), das heißt wohl buchstäblichen, nicht allegorischen ${ }^{432}$ Verständnis des Textes von keinem Christen jemals bei irgendeiner Gelegenheit (aus der Schwertscheide) herausgenommen (eximere) werden. Dieses Verbot gilt sowohl für die persönliche Vergeltung (vindictae propriarum iniuriarum) als auch für den Gebrauch der Schwertes „aus Gelegenheit des Heeresdienstes“ (occasione militiae) oder „aus irgendeinem Anlass“ (ob aliquam occasionem). Denn das alles verabscheut (abominari) diese Lehre Christi gemäß dem Evangelium (evangelica haec Christi doctrina). Als Begründung dazu führt er Ps 119,7 an: „Mit denen, die den Frieden hassen, war ich friedfertig.“433

Nimmt man diesen Text des Origenes, wie er sich auf den ersten Eindruck darbietet, so ist damit jegliche Möglichkeit christlichen Heeresdienstes kategorisch ausgeschlossen. G. Caspary fasst diesen Eindruck wie folgt zusammen:

„Nothing could be clearer. [...] Christians are absolutely forbidden to make use of the sword under
any pretext whatsoever (ob aliquam occasionem): for the teaching of Christ considers all such uses
to be abominations (quam omnem abominatur Christi doctrina). [...] Despite all his allegorism, he
beliefs, with the remainder of the pre-Constantinian Church, that the decree of the Apostolic
Council is literally binding. For Origen, as for all his contemporaries, to shed blood is for Chris-
tians ,a sacrilege and an abomination.' This prohibition, moreover, includes both killings un-
dertaken ,by reason of self-defense“ (occasio vindictae propriarum iniuriarum) and killings un-
dertaken ,by reason of being in the army“ (occasio militiae). Like Tertullian in De Corona and

430 Vogt, Kommentar Bd. 3, 276.

431 So versteht auch CASPARY, Politics, 90, diesen Text: ,that all who create uproar, incite war, and stir up the souls of men (though especially those who stir up the churches of Christ) [...]“.

432 So Caspary, Politics, 90.

433 Comm. ser. in Mt. 102: cum his qui oderunt pacem eram pacificus (ÜS: H. Vogt). 
Hippolytus in Traditio Apostolica, Origen obviously believes that Matthew 26:52 forbids Christians to kill even when they are soldiers and are ordered to do so by their commanding officer." ${ }^{\star 434}$

Die gesamte Auslegung des Origenes klingt wie eine vollständige Ablehnung jeglicher Möglichkeit des Heeresdienstes für Christen, denn man darf das Schwert ja nicht einmal aufnehmen. Noch mehr als das: Hat man die harten, verurteilenden Worte über diejenigen Menschen vor Augen, die das Schwert führen, Worte, die ja so allgemein gehalten sind, dass sie gerade auch Heiden einschließen, kann man sich kaum vorstellen, dass es für Origenes überhaupt eine Rechtfertigung für den Einsatz des Schwertes gibt. Auch der Gedanke an einen legitimen Verteidigungskrieg oder an einen - in welchem Sinne auch immer - gerechten Krieg scheint hier keinerlei Platz zu finden. Damit würde dieser Text aber in einem radikalen Widerspruch zu den Aussagen der nur kurze Zeit vorher oder vielleicht sogar zeitgleich abgefassten Schrift Contra Celsum stehen. Bereits dieser Widerspruch führt zumindest zu der Frage, wie strikt seine weiteren Aussagen gemeint sind und wie sehr hier ,die eigentliche Position' des Origenes zur Frage des Heeresdienstes von Christen $\mathrm{zu}$ finden ist. ${ }^{435} \mathrm{Um}$ darauf eine Antwort zu finden, muss zunächst noch ein weiterer Text, ein Katenenfragment zu Mt 26,52, betrachtet werden.

\section{Comm. in Mt. Frg. 537 (Klostermann)}

In diesem Fragment findet sich folgende Aussage zu Mt 26,52 ${ }^{436}$ :

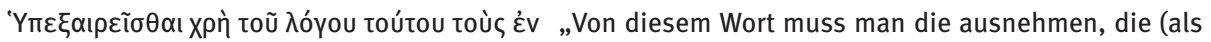

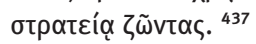

Soldaten) im Heer leben.“

(ÜS: AG)

Zunächst klingt das wie ein Widerspruch zu dem in comm. ser. in Mt. 102 festgestellten Befund.

434 CASPARY, Politics, 91. Mit Blick auf Tertullian wurde bereits darauf hingewiesen, dass dessen Haltung weniger eindeutig und rigoristisch ist, als G. Caspary hier und anderswo in seiner Studie (z. B. S. 37-38, Anm. 86; S. 92) annimmt.

435 Das gilt umso mehr angesichts der schon aufgezeigten Tatsache (s. oben S. $305 \mathrm{ff}$.), dass es zur Zeit des Origenes bereits christliche Soldaten in größerer Zahl gegeben haben muss und eine grundsätzliche kirchliche Verdammung dieser Tatsache nirgends greifbar ist. Hätte sich ein bewusst ,kirchlicher‘ Autor wie Origenes hier so deutlich im Widerspruch zur allgemeinen Haltung der Kirche(n) positioniert?

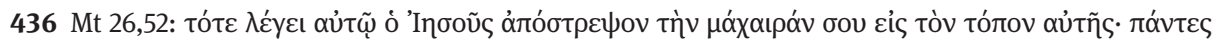

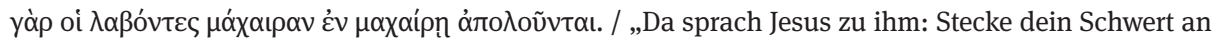
seinen Ort! Denn wer das Schwert nimmt, der soll durchs Schwert umkommen.“ (ÜS: LÜ 1984).

437 Klostermann, Origenes 12,1, 219. 
Ein Problem dabei ist, dass eine Übersetzung aus unbekannter Hand einerseits gegen ein kontextfreies Textfragment aus einer Katene andererseits steht. ${ }^{438}$ Grundsätzlich besteht an beiden Stellen die Möglichkeit einer fehlerhaften Wiedergabe des Origenes. Andererseits gelten sowohl die Übersetzung der commentariorum series wie auch die in den kritischen Ausgaben gesammelten Katenenfragmente als in aller Regel zuverlässige Interpretation zumindest des Sinngehalts der Texte des Origenes. Eine Entscheidung ist nur schwer zu treffen. Da sich für einen Irrtum beider Texte Gründe anführen ließen, könnte dieser Widerspruch unter Umständen dazu führen, dass beide Zeugnisse bis zur Klärung der Frage zurückgestellt werden müssten.

G. Caspary hat allerdings eine Möglichkeit vorgeschlagen, beide Texte als kompatible Zeugnisse für die Haltung des Origenes zu lesen, die in ihren Grundzügen durchaus Plausibilität beanspruchen kann. ${ }^{439}$ So meint er, der Text würde die Interpretation der Haltung des Origenes, wie sie sich in comm. ser. in Mt. 102 findet, klären, aber nicht modifizieren. Die längere Passage sage, der Heeresdienst sei keine Entschuldigung dafür, das Schwert zu ziehen (eximere), die Katene besage, dass der Fluch Jesu über diejenigen, welche das Schwert nehmen (accipere), nicht Soldaten treffe, die im Frieden dienen. Er schreibt zusammenfassend:

„The purpose of the fragment is simply to prevent the sort of rigorist exegesis exemplified in $D e$ Idololatria: there [...] Tertullian had argued in so many words that Matthew 26:52 puts a curse even on the military costume. For Origen, those ,surprised by faith" while serving in the ranks need choose between martyrdom and desertion only when faced by a command to kill. To be a soldier is for a Christian a highly dangerous but no an absolutely illicit profession." ${ }^{440}$

Treffen diese zugegebenermaßen teilweise hypothetischen ${ }^{441}$ Überlegungen zumindest im Grundsatz zu, dann muss der Text von comm. ser. in Mt. 102 tatsächlich behutsamer interpretiert werden, als der erste Eindruck nahelegt. Es sollte zwar gegen G. Caspary gefragt werden, ob es sich angesichts der Schärfe der Aussagen in der längeren Textstelle tatsächlich ,nur' um eine Klärung handelt, oder nicht vielmehr eine leichte (klärende?) Modifizierung des Befundes der lateinischen Übersetzung nötig ist, die einen solchen Hinweis an irgendeiner Stelle - sollte er authentisch sein ausgelassen haben muss. Aber jenseits solcher semantischer Feinheiten ist sein An-

438 Auch die Überlieferungslage bietet keine große Hilfe: Der Text der commentariorum series von E. Klostermann beruht im Wesentlichen auf drei Handschriften aus dem 9.-12. Jhd. n. Chr. (siehe KlosTERMANN, Origenes 11, VII-VIII und XI), der Text der Katene aus einer Handschrift je des 11. und des 14. Jhds. n. Chr. (KlostermanN, Origenes 12,1, 12 und 219). In einer anderen Handschrift aus dem 12. Jhd.

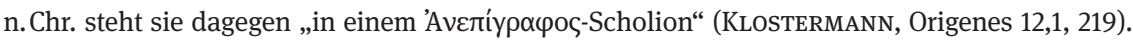

439 CASPARY, Politics, 92-94. Er weist außerdem darauf hin, dass sich so „some puzzling features“ (ebd., 93) der längeren Passage klären ließen.

440 So auch CASPARY, Politics, 92.

441 So steht in dem Fragment weder etwas vom Dienst nur in Friedenszeiten bzw. nur unter Absehung vom Einsatz der Waffe, noch etwas von Soldaten, die erst im Verlauf ihres Dienstes Christen wurden. 
satz tatsächlich hilfreich. Das ist umso mehr der Fall, als sich ja bereits aus dem Text selbst Anhaltspunkte für Anfragen ergeben.

Folgt man dieser Lösung, dann ist zumindest die Akzeptanz von Heereskonvertiten durch Origenes gegeben, vielleicht sogar, über G. Caspary hinausgehend, die Akzeptanz des Eintritts von Christen in das Heer, vorausgesetzt sie halten gewisse Vorgaben ein.

\section{Fazit}

Fasst man den Befund beider Stellen der Auslegung zu Mt 26 zusammen, kann man folgende Punkte festhalten:

Origenes kontrastiert erneut den Gebrauch der ,zwei Schwerter‘ und lässt für den Christen nur das geistliche Schwert zu, ohne dass dessen Gebrauch an dieser Stelle näher erläutert wird. Der Grund dafür ist wieder in seinem heilsgeschichtlichen Denken zu finden. Ein Jünger Jesu, der das buchstäbliche Schwert führt, handelt „im Sinne der Macht, die den Juden durch das Gesetz über die Feinde gegeben war“442. Er führt also erneut das Schwert des Phineas anstatt des dem Christen übergebenen Schwertes des Geistes. Gewalt im Namen Jesu beziehungswiese im Namen des Glaubens schließt Origenes somit kategorisch aus.

Daraus entwickelt Origenes dann eine allgemeine Abhandlung über das Verhältnis des Christen zum Schwert, das hier als ein Symbol für Krieg und Streit verstanden wird. Von Krieg und Streit sollen Christen sich fernhalten, stattdessen sollen sie sich - wie man unter Rückgriff auf vorher Gesagtes festhalten kann - in Geduld und Frieden üben. Es gibt, so stellt er fest, keine Rechtfertigung für die Ausübung von Gewalt. Selbst der Heeresdienst bietet eine solche nicht, noch persönliche Vergeltung oder irgendein anderer Grund. Dieses Gewaltverbot gilt in erster Linie für Christen, wie der Verweis auf die evangelica [...] Christi doctrina ${ }^{443}$ deutlich macht.

Hier verschwimmen zugleich die Grenzen zwischen dem Verbot der Gewaltanwendung im Namen des Glaubens einerseits und einem allgemeinen Verbot jeglicher Gewaltanwendung andererseits. Die ersten Aussagen, vor allem in comm. ser. in Mt. 101, hätten sich noch so verstehen lassen, dass sich die Ablehnung von Gewalt allein auf erstere bezieht. In diesem Fall wäre die Frage christlichen Heeresdienstes nicht per se von seinen Ausführungen betroffen, würde ein Christ im Heer ja nicht aus Glaubensgründen beziehungsweise im Namen seines Gottes Gewalt ausüben. Am Ende von comm ser. in Mt. 102 ist ein solches begrenztes Verständnis allerdings nicht mehr ohne weiteres möglich. Hier scheint tatsächlich die Anwendung von Gewalt an sich Thema zu sein.

Der Hinweis auf die doctrina Christi zeigt außerdem, dass sich aus diesem Text keine Ablehnung gerechter Kriege, wenn sie denn von Heiden geführt werden, ableiten

442 Comm. ser. in Mt. 101: secundum poptestatem datam Iudaeis per legem de inimicis (ÜS: H. Vogt). 443 Comm. ser. in Mt. 102: „die Lehre Christi gemäß dem Evangelium“ (ÜS: AG). 
lässt, auch wenn es im Verlauf der Erörterungen des Origenes mitunter so aussehen mag.

Zugleich lässt sich aber aus diesem Text auch keine kategorische Ablehnung jeglichen christlichen Heeresdienstes entnehmen, vor allem dann nicht, wenn das Katenenfragment authentisch und G. Casparys Interpretation dieses Fragments zutreffend sein sollte. Ist dem so, dann scheint es Origenes unter gewissen Umständen zumindest hingenommen, vielleicht sogar akzeptiert zu haben, wenn Christen unter Einhaltung bestimmter Vorgaben im Heer dienten. $\mathrm{Zu}$ diesen Vorgaben gehört nach comm. ser. in Mt. 102 in hohem Maße die Bereitschaft zur Friedfertigkeit und die Ablehnung von Gewalt und Streit. Die Frage der Gewaltanwendung spielte also für ihn in diesem Text tatsächlich eine große Rolle bei der Beantwortung der Soldatenfrage. Ein freudiger Befürworter christlichen Dienstes im römischen Heer war er, so der Eindruck, der sich an dieser Stelle ergibt, sicherlich nicht.

Man muss weiterhin bedenken, dass Origenes auch in der Matthäusauslegung wieder mit dem aus Contra Celsum wie auch aus den Homilien zu den alttestamentlichen Kriegstexten bekannten heilsgeschichtlichen Schema arbeitet, demzufolge Krieg und Gewaltanwendung in der alten Heilszeit dem Volk Israel erlaubt waren, aber jetzt in der neuen Heilszeit den Christen verboten sind. Dahinter steht angesichts der engen Parallele mit Sicherheit auch die aus Cels. 2,30 und 7,26 abzuleitende Sicht vom unpolitischen Charakter der Kirche als einer gesellschaftlichen Minderheit und von der providentiellen Rolle des Imperium Romanum als Schutz- und Ordnungsmacht. Damit stellt sich dann aber an dieser Stelle dieselbe Frage wie schon bei Contra Celsum: Was passiert, wenn die Mehrheit der Gesellschaft sich dem Christentum zuwendet oder gar der Kaiser Christ wird? Bleibt dann die neue Ordnung bestehen oder müsste man sich in diesem Fall wieder eher in Richtung der alttestamentlichen Vorgaben orientieren? Dass Origenes auf diese Fragen keine Antwort gibt, zeigt wie weit der Gedanke an ein christliches Römerreich oder auch nur an eine christliche Gesellschaftsmehrheit von seinen Realitäten entfernt ist.

Allerdings ist auch seine Stellungnahme in der Matthäusauslegung auf keinen Fall eine erschöpfende Abhandlung zum Thema Christentum und Soldatenstand. Es handelt sich vielmehr auch hier wieder um eine inhaltlich zugespitzte Variation einiger grundlegender Positionen des Origenes. Das ist bei der Frage nach der Reichweite seiner Gedanken im Blick zu behalten.

\subsection{Zusammenfassende Überlegungen zur Haltung des Origenes}

Versucht man die bei der Interpretation der einzelnen Texte erhobenen Befunde zusammenzufassen, so ergibt sich folgendes Gesamtbild: 


\subsection{1 Überzeugungen und ihre konkrete Anwendung}

In Cels. 8,73-74 propagiert Origenes im Angesicht der celsischen Kritik und seiner Aufforderung zur Abwendung vom gesellschaftsschädigenden Christentum den Gedanken, dass die Christen gerade in ihrer besonderen Rolle als priesterliche Gruppe einen geistlichen Kampf für Kaiser und Reich führen. In diesem geistlichen Kampf würden sie dem Kaiser besser dienen und ihn effektiver gegen äußere Feinde unterstützen als seine Soldaten in den Heeren. Gleichzeitig wird das Recht des Kaisers, gerechte Kriege $\mathrm{zu}$ führen, vollauf anerkannt und er wird der (geistlichen) Unterstützung der Christen versichert.

Alles in allem handelt es sich bei diesen Aussagen um die praktische Anwendung einiger, wie sich gezeigt hat, grundsätzlicher Überzeugungen des Origenes auf die konkrete argumentative Situation, in der er sich befindet. Daher lassen sich seine Aussagen keinesfalls nur auf den polemischen Kontext seiner Auseinandersetzung mit der Streitschrift des Celsus begrenzen. Sie sind aber vor dem Hintergrund dieses Kontexts in ihren Details zu verstehen und in ihrer Aussagekraft einzuordnen.

Im Ergebnis kann man festhalten, dass Christen sich, anders als von Celsus gefordert, nicht von ihrem Glauben abwenden werden, indem sie in die Heere des Kaisers eintreten und die Magistraturen in den Städten übernehmen werden. Stattdessen kämpfen sie für ihn und dienen ihm auf ihre eigene Weise. Diese Weise des Kampfes und des Dienstes ist die des geistlichen Kampfes mit dem geistlichen Schwert, wie es der heilsgeschichtlichen Stellung der christlichen Kirche als Volk Gottes des neuen Bundes entspricht. Bedingt ist die Schärfe der Ablehnung, das wurde bereits festgehalten, durch die argumentative Situation des Origenes: Dem ,Umkehrruf‘ des Celsus soll die argumentative Spitze genommen werden.

\subsubsection{Die gundlegende Haltung des Origenes}

Bei dieser skizzierten Position handelt es sich allerdings zumindest in der Substanz um grundlegende Überzeugungen des Origenes, wenn auch zugespitzt auf die argumentativen Notwendigkeiten der jeweiligen Schrift. Das zeigen die bereits früher abgefassten Auslegungen zu den Kriegstexten des Alten Testaments. In ihnen werden die gleichen großen heilsgeschichtlichen Linien sichtbar, wie auch in der etwa zeitgleich mit Contra Celsum verfassten Matthäusauslegung. Dort werden diese Überzeugungen ebenfalls aufgegriffen. ${ }^{444}$

Fragt man nach der letztendlichen Haltung des Origenes zum Heeresdienst von Christen, so wird sich diese in ihren Grundzügen nicht zu sehr von der Tertullians unterschieden haben. Die Zahl der Christen im römischen Heer dürfte allerdings zur Zeit des Origenes um einiges größer gewesen sein, was er in seine Überlegungen si-

444 Vgl. Helgeland, Christians (ANRW), 751. 
cherlich einzubeziehen hatte. Angesichts der Tatsache der Existenz christlicher Soldaten einerseits und des völligen Fehlens eines expliziten und unmissverständlichen Verbots des Heeresdienstes für Christen andererseits - selbst comm. ser. in Mt. 102, was dem am nächsten kommt, scheint sich nicht so verstehen zu lassen -, kann nicht davon ausgegangen werden, dass Origenes die Ausübung dieses Berufs kategorisch ausgeschlossen hat. Er muss von christlichen Soldaten gewusst und ihre Profession in gewissen Grenzen akzeptiert beziehungsweise zumindest hingenommen haben.

Zugleich zeigen seine Aussagen auch in ihrer jeweiligen argumentativen Zuspitzung sehr wohl eine große Distanz zu diesem Beruf. Er dürfte es ähnlich Tertullian sicherlich begrüßt haben, wenn Christen ihn nicht ausübten, denn die Probleme, mit denen sie in der Armee konfrontiert wurden, waren ja unübersehbar.

Zwei davon sind besonders hervorgehoben: Da ist zum einen die Gefahr des Götzendienstes, insbesondere in Gestalt der Heeresreligion, wie anhand der Korintherbrief-Auslegung deutlich wird, und in der des Kaisereides, wie sich in Contra Celsum zeigt. Zum anderen aber auch die Gefahr der Gewaltanwendung, die bei ihm eine wesentlich größere und offensichtlichere Rolle spielt als bei Tertullian - von Clemens Alexandrinus ganz zu schweigen. ${ }^{445}$

Bei Origenes ist deutlich erkennbar, dass seines Erachtens die Anwendung von Gewalt und das Töten von Menschen nur schwer mit dem christlichen Bekenntnis vereinbar sind. Dabei thematisiert er vor allem Gewalt aus Glaubensgründen, aber es scheint ihm auch um Gewaltanwendung ganz allgemein zu gehen.

Wie genau sich ein christlicher Soldat, mit dessen Existenz er ja rechnen musste, gegebenenfalls allerdings in der Praxis zu verhalten hat, sagt er nicht. Einerseits kann trotz der scharf klingenden Texte in Cels. 8,73-74 und comm. ser. in Mt. 102 wohl nicht einmal gänzlich ausgeschlossen werden, dass Origenes im schlimmsten Fall sogar die Beteiligung an einem gerechten Verteidigungskrieg (zumindest durch Heereskonvertiten?) hätte gutheißen können. Dafür ist er von der grundsätzlichen Legitimität eines solchen gerechten Krieges und von der großen, providentiellen Bedeutung des Imperium Romanum zu tief überzeugt. ${ }^{446}$ Aber damit begibt man sich wahrscheinlich schon zu weit in den Bereich der Spekulation. Eine auch nur einigermaßen sichere

445 Während die Mehrheit der Forschung vor allem im Verbot des Blutvergießens den eigentlichen Grund der ablehnenden Haltung des Origenes zu erkennen meint, räumen nur einige Autoren auch der Idolatrie das ihr zustehende Gewicht ein. So z.B. RYAN, Rejection, 20, der als einer der wenigen auch die Fragmente der Korintherauslegung ausdrücklich mit in die Überlegungen einbezieht. Außerdem CAMpenhausen, Kriegsdienst, 259-260, der neben der Idolatrie und der Gefahr des Unrechttuns auch dem Blutvergießen einen entsprechenden Platz eingeräumt wissen möchte; weiterhin BRENNECKE, An fidelis (2007), 220. HELGELAND, Christians (ANRW), 751, übersieht die Korintherauslegung leider völlig und kann daher nur sagen: „Origen displays no knowledge of the Roman army and its unique religious observances, but if he had known such things it is clear that he would have been opposed to them." 446 Einer solchen Einschätzung widerspricht ausdrücklich CADoux, Christian Attitude, 139: „It is abundantly clear that he regarded the acceptance of Christianity as incompatible with the use of arms; and his relative justification of the wars of non-Christians cannot be made a ground either for doubting that his rigorism was seriously meant, or for accusing him of inconsistency in maintaining it.“ 
Aussage dürfte nicht möglich sein. Andererseits scheint er doch sehr grundsätzlich der Ansicht zu sein, dass Kriegführung und alles, was damit verbunden ist, seinem heilsgeschichtlich-eschatologischen Schema entsprechend nicht die eigentliche Aufgabe des Christen in der Welt ist. Der (heidnische) Kaiser und das (heidnische) Reich sind die von Gott eingesetzten Ordnungsmächte, also ist es auch deren Aufgabe, diese Ordnung aufrechtzuerhalten und zur Not auch Kriege zu führen. Dieses heilsgeschichtlich-eschatologische Denken steht letztlich auch hinter seiner Ablehnung der Gewaltanwendung durch Christen. Origenes lehnt Gewalt nicht an und für sich ab, der Kaiser und die heidnischen Autoritäten des Reiches dürfen sie selbstverständlich als Teil ihrer gottgegebenen Ordnungsfunktion ausüben. ${ }^{447}$ Aber Christen haben in dieser Welt eine andere Aufgabe zu erfüllen, ihr Kampf ist ein geistlicher. Darum, und nicht wegen einer grundsätzlichen Verurteilung jeder Form der Gewaltanwendung, sollen Christen sich der Ausübung von Gewalt enthalten.

\subsubsection{Origenes und die Haltung(en) der christlichen Gemeinden}

Weiterhin ist in keiner Weise deutlich, in welchem Verhältnis seine Haltung in all diesen Fragen zur Position der Gemeinden stand, in denen er lebte und denen er diente. Bedenkt man aber seine bewusste Kirchlichkeit sowie die Wertschätzung, die er in vielen Kirchen vor allem der östlichen Reichshälfte auch nach seinem Bruch mit Demetrius von Alexandria erfuhr, wird man eine zumindest relative Nähe der jeweiligen Positionen auch bei dieser Thematik annehmen können. ${ }^{448}$ Allerdings könnten viele Gemeinden eher ein gutes Stück offener in dieser Frage gewesen sein als ihr großer Theologe. Zumindest legen die unbestreitbaren Belege für eine substantielle Zahl christlicher Soldaten zu dieser Zeit das nahe. Es ist das Privileg des ,akademischen Theologen' Origenes, dass er seine Positionen nicht im gleichen Maß auf Praxistauglichkeit abstimmen musste, wie das bei Bischöfen und Kirchenleitern der Fall war. $^{449}$

447 Vgl. auch seine Haltung zur Todesstrafe, die ScHöPF, Tötungsrecht, 158-165, herausgearbeitet hat.

448 Keinesfalls kann man Origenes zu einem „extremist“ abstempeln und ihn in der Weise der Mehrheit der „Catholics“ seiner Zeit gegenüberstellen, wie das bei RYAN, Rejection, 14-15, der Fall ist. Er dürfte allerdings insoweit Recht haben, als die Kirchen eine zumindest tendenziell (deutlich?) offenere Haltung eingenommen haben dürften.

449 Vgl. die allerdings allgemein gehaltenen und vielleicht etwas zu scharfen Bemerkungen bei Campenhausen, Griechische Kirchenväter, 59. 


\subsubsection{Grenzen der Texte des Origenes}

Es zeigt sich, dass alle seine Texte zu diesen Fragen letztlich nur bestimmte Aspekte davon behandeln. Keiner davon bietet eine systematische Abhandlung über das Problem von Christentum und Soldatenstand. Alle behandeln es unter einer konkreten argumentativen Zielsetzung und sprechen nur die dafür nützlichen Punkte in zugespitzter Weise an. Daher sind der Bestimmung der Position des großen Alexandriners zur Soldatenfrage auch engere Grenzen gezogen, als Teile der Forschung wahrhaben wollen. Außerdem lässt die starke heilsgeschichtlich-eschatologische und auf die damalige Situation der Christen als Minderheit bezogene Verortung zahlreicher grundsätzlicher Linien im Denken des Origenes eine Erfassung seiner Haltung - soweit sie sich rekonstruieren lässt - mittels einer modernen Kategorie wie beispielsweise ,Pazifismus‘ nur schwer als möglich erscheinen. 